\title{
The Behavior, Quantity, and Location of Undissolved Gas in Tank 241-SY-101
}

M. E. Brewster

N. B. Gallagher

J. D. Hudson

C. W. Stewart

October 1995

Prepared for the U.S. Department of Energy under Contract DE-ACO6-76RLO 1830.

Pacific Northwest National Laboratory Operated for the U.S. Department of Energy by Battelle Memorial Institute 


\section{DISCLAIMER}

This report was prepared as an account of work sponsored by an agency of the United States Government. Neither the United States Government nor any agency thereof, nor Battelle Memorial Institute, nor any of their employees, makes any warranty, express or implied, or assumes any legal liability or responsibility for the accuracy, completeness; or usefúlness of any information, apparatus, product, or process disclosed, or represents that its use would not infringe privately owned rights. Reference herein to any specific commercial product, process; or service by trade name, trademark, manufacturer, or otherwise does not necessarily constitute or imply its endorsement, recommendation, or favoring by the United States Government or any agency thereof, or Battelle Memorial Institute. The views and opinions of authors expressed herein do not necessarily state or reflect those of the United States Government or any agency thereof.

\section{PACIFIC NORTHWEST NATIONAL LABORATORY}

operated by

BATTELLE

for the

UNITED STATES DEPARTMENT OF ENERGY under Contract DE-AC06-76RLO 1830

\section{Printed in the United States of America}

Available to DOE and DOE contractors from the

Office of Scientific and Technical Information, P.O. Box 62, Oak Ridge, TN 37831; prices available from (615) 576-8401.

Available to the public fram the National Tectnical Information Service, U.S. Department of Commerce, 5285 Port Royal Rd., Springfield, VA 22161 


\title{
THE BEHAVIOR, QUANTITY, AND LOCATION OF UNDISSOLVED GAS IN TANK 241-SY-101
}

\author{
M. E. Brewster . \\ N. B. Gallagher \\ J. D. Hudson \\ C. W. Stewart
}

October 1995

Prepared for the U.S. Department of Energy

under Contract DE-AC06-76RLO 1830

Pacific Northwest National Laboratory

Richland, WA 99352

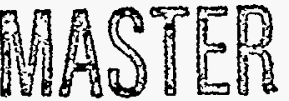





\section{Abstract}

Mitigation of episodic flammable gas releases from Hanford Waste Tank 241-SY-101 was accomplished in July 1993 with the installation of a mixer pump that prevents gas retention. But it has not been possible until recently to measure the effects of mixing on the waste or how much gas remains and where it is located. Direct measurements of the void fraction and rheology of the mixed waste by the void fraction instrument (VFI) and ball rheometer along with previous data provide estimates of the location, quantity, and behavior of undissolved gas in the tank. This report documents the compilation and integration of the information that enables this understanding. 


\section{Summary}

Mitigation of large, episodic gas releases from Hanford waste Tank 241-SY-101 has been a top priority since 1990. This objective was accomplished in July 1993 with installation of the mixer pump that still operates to mix the waste and prevent flammable gas accumulation. Although mitigation persists as long as mixing continues, until recently we had not been able to determine any details about the effects of mixing on the waste or, more importantly, how much gas remains in the waste and where it is located. Since late 1994 direct measurements of the void fraction and rheology of the mixed waste have become available from deployments of the void fraction instrument (VFI) and ball rheometer. This new information helped interpret previous data to yield a fairly clear picture of the waste in 241-SY-101 as well as the location, quantity, and behavior of undissolved gas in the tank. This report documents the compilation and integration of the information that forms this understanding.

Information regarding undissolved gas was obtained from a variety of data and analyses, including analyses of the hydrogen release data and thermal data following pump activity, analysis of gas release relating the observed waste surface level changes, inferences from the waste temperature profiles, correlations that relate the variations in waste surface level and atmospheric pressure to the retained gas inventory, and direct measurements from the in situ void fraction and rheology instruments.

The hydrogen release following pump activity was analyzed to determine the time distribution of the release and how this distribution has changed. The release signatures for pump operations prior to September 8, 1994, are different from those after that date. This is probably due to the change in pump operation procedure that occurred at that time. Other notable changes in the data are evident; after September 8, 1994, pump-induced hydrogen releases decreased, the baseline hydrogen release decreased, and the shape of the release signature shifted. Differences in signatures as a function of pump orientation were also noted and could be attributed to the pump being off-center and/or to a non-uniform, angular distribution of the waste.

The waste surface level is used as the main indicator of retained gas volume and potential prompt release in the mixer pump Safety Assessment (Sullivan 1995). Waste level measurements are available from a variety of instruments that report different values and respond differently to gas releases. The differences are due largely to waste surface irregularities and operational peculiarities of the individual instruments. The data from the level instruments have been evaluated by correlating each gauge with the others and each gauge with gas release using a linear model. These analyses indicate that the Enraf ${ }^{\circledR}$ buoyancy gauge is potentially the most precise and accurate level instrument. The Food Instrument Corporation (FIC) contact probe responses correspond closely with the Enraf gauge and correlate with gas release reasonably well.

Temperature profiles and transients from the two multifunction instrument trees (MITs), the results of the VFI tests in December 1994 and January 1995, and the ball rheometer deployment in March and April 1995 were analyzed to determine the configuration of the waste and gas content in Tank 241-SY-101. The temperature profiles and transients provide an indication of 1) the penetration of the mixer pump jets into the waste and 2) thermal mixing. Recently, it has also become possible to measure properties in situ at specific points by using the ball rheometer and the VFI. 
possible to measure properties in situ at specific points by using the ball rheometer and the VFI. When integrated, this information provides a framework from which the quantity and distribution of retained (undissolved) gas in Tank 241-SY-101 can be estimated. The results of this analysis, summarized in Table 4.4 of the report, indicate that the tank currently contains approximately $5,700 \mathrm{ft}^{3}$ of gas in situ ( $3.8 \%$ average void), or about $7,800 \mathrm{ft}^{3}$ when expanded to atmospheric pressure.

In addition to the "best" estimate derived from in-tank temperature and property measurements, two other estimation methods were considered in this report. The first of these correlates atmospheric pressure and waste surface level to determine the waste compressibility. This compressibility, along with an assumed gas elevation, yields an estimate of the gas volume that is consistent with the best estimate described above, provided that the gas elevation is defined properly. The second method, developed in support of the current mixer pump safety assessment, uses an extrapolation of retained gas estimates from historical data prior to pump installation to determine a gas-free waste level. The current gas inventory is inferpolated between the gas-free state and that just prior to a large gas release event using waste surface level measurements. As proposed, this method gives significantly larger volumes than the best estimate, but it can be made consistent by correcting some of its assumptions.

Direct measurements, similar to those of the VFI, are difficult, expensive, and available from only a few locations in the tank. But indirect measurements, such as the response of the tank waste level to barometric pressure changes, provide little information about the distribution of the gas and, in fact, require some knowledge of the distribution of the gas in order to provide an estimate of retained gas quantity. To help address this problem, a set of dynamic bubble/particle models has been developed that provide insight into the state, amount, and distribution of retained gas in Tank 241-SY-101 as it responds to the mixer pump and barometric pressure variations. The models predict average amounts of retained gas in various layers of the tank-crust, convective layer, and loosely-settled layer that are compared with the VFI measurements to calibrate the model. While the models have not been fully tested, they provide valuable insight into observed tank behavior and measured distributions of retained gas.

In addition to the estimates of retained gas volume, some interesting aspects of gas release behavior that occurred in the past are discussed, such as diurnal variation in gas composition and interruption of gas release following pump bumps. While not directly related to safety issues, understanding this kind of behavior may provide important insight into the chemical and physical processes in tarik waste. Also described are some analyses that were not successful for various reasons. The purpose of including these negative results is two-fold: first, to avoid future duplication of failed efforts; second, to document attempts that might have been successful if additional information had been available so that, if desired, the methods can be more easily revisited. 


\section{Contents}

Abstract $\ldots \ldots \ldots \ldots \ldots \ldots \ldots \ldots \ldots \ldots \ldots \ldots \ldots \ldots \ldots \ldots \ldots \ldots$

Summary $\ldots \ldots \ldots \ldots \ldots \ldots \ldots \ldots \ldots \ldots \ldots \ldots \ldots \ldots \ldots \ldots \ldots$

1.0 Introduction $\ldots \ldots \ldots \ldots \ldots \ldots \ldots \ldots \ldots \ldots \ldots \ldots \ldots \ldots \ldots \ldots \ldots$

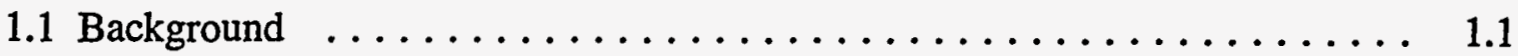

1.2 Tank Instrumentation $\ldots \ldots \ldots \ldots \ldots \ldots \ldots \ldots \ldots \ldots \ldots$

1.2.1 Ventilation Header Flow Rate $\ldots \ldots \ldots \ldots \ldots \ldots \ldots \ldots$

1.2.2 Gas Composition Measurements $\ldots \ldots \ldots \ldots \ldots \ldots \ldots$

1.2.3 Total Gas Release Calculation . . . . . . . . . . . . . . . 1.5

1.2.4 Waste Temperatures $\ldots \ldots \ldots \ldots \ldots \ldots \ldots \ldots \ldots$

1.2.5 Waste Surface Level $\ldots \ldots \ldots \ldots \ldots \ldots \ldots$

1.2.6 Summary of Instrument Uncertainty $\ldots \ldots \ldots \ldots \ldots \ldots \ldots$

1.3 Overview of Tank Data $\ldots \ldots \ldots \ldots \ldots \ldots \ldots \ldots$

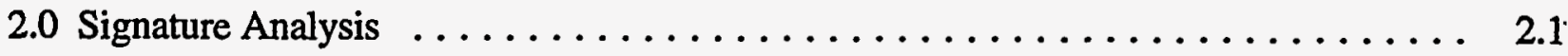

2.1 Overview of the Signature Analysis Method $\ldots \ldots \ldots \ldots \ldots \ldots \ldots \ldots$

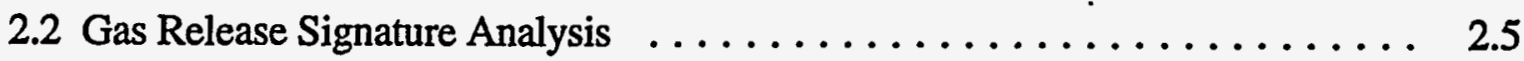

2.3 MTT 17B Temperature Signature Analysis $\ldots \ldots \ldots \ldots \ldots \ldots \ldots \ldots \ldots$

2.3.1 Principal Components Analysis of Baseline Temperatures . . . . 2.11

2.3.2 Principal Components Analysis of MIT 17B Response Signatures .. $\quad 2.14$

3.0 Waste Level $\ldots \ldots \ldots \ldots \ldots \ldots \ldots \ldots \ldots \ldots \ldots \ldots \ldots \ldots \ldots \ldots$

3.1 Correlation of Level with Gas Release $\ldots \ldots \ldots \ldots \ldots \ldots \ldots$

3.2 Intercorrelation of Level Instruments $\ldots \ldots \ldots \ldots \ldots \ldots \ldots \ldots$

3.3 Long-term Changes in the Waste Surface $\ldots \ldots \ldots \ldots \ldots \ldots$ 
3.4 Crust Buoyancy Effects $\ldots \ldots \ldots \ldots \ldots \ldots \ldots \ldots \ldots \ldots \ldots .10 \ldots \ldots$ 4.0 Undissolved Gas Stored in the Waste $\ldots \ldots \ldots \ldots \ldots \ldots \ldots \ldots \ldots \ldots .1$

4.1 Temperature Profiles and Transient Temperature Response $\ldots \ldots \ldots \ldots . .2$

4.2 Void Fraction Instrument (VFI) $\ldots \ldots \ldots \ldots \ldots \ldots \ldots \ldots \ldots \ldots$

4.3 Results of the Ball Rheometer Tests $\ldots \ldots \ldots \ldots \ldots \ldots \ldots \ldots \ldots .8$

4.4 Gas Volume Estimate $\ldots \ldots \ldots \ldots \ldots \ldots \ldots \ldots \ldots \ldots \ldots$

4.4.1 Dimensions Of The Nonconvecting Layers $\ldots \ldots \ldots \ldots \ldots .4 .9$

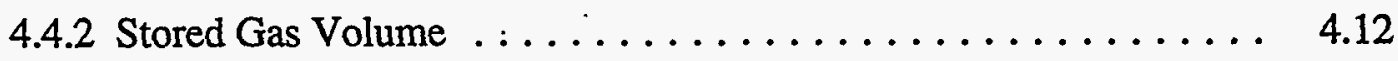

4.5 Estimated Gas Release Fraction $\ldots \ldots \ldots \ldots \ldots \ldots \ldots \ldots . .16$

5.0 Other Stored Gas Estimates $\ldots \ldots \ldots \ldots \ldots \ldots \ldots \ldots \ldots \ldots \ldots \ldots \ldots \ldots \ldots \ldots \ldots$

5.1 Computing Retained Gas Volume from Barometric Pressure-Induced

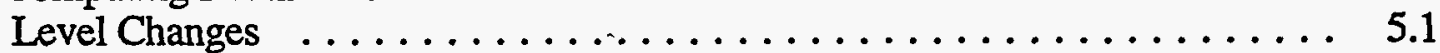

5.1 .1 Technical Basis $\ldots \ldots \ldots \ldots \ldots \ldots \ldots \ldots \ldots \ldots \ldots .1$

5.1.2 Prediction of Level Response from Stored Gas Estimates ....... 5.3

5.1.3 Estimates of Response from Enraf Level Measurements ....... 5.4

5.1.4 Estimates of Response from Radar Measurements $\ldots \ldots \ldots \ldots \quad 5.5$

5.1.5 Historical Estimates of Response $\ldots \ldots \ldots \ldots \ldots \ldots \ldots \ldots .6$

5.1 .6 Soluble Gas Effects $\ldots \ldots \ldots \ldots \ldots \ldots \ldots \ldots \ldots \ldots \ldots$

5.2 Extrapolation from Past GRE Behavior $\ldots \ldots \ldots \ldots \ldots \ldots \ldots \ldots .8$

6.0 Bubble Dynamics Analysis $\ldots \ldots \ldots \ldots \ldots \ldots \ldots \ldots \ldots \ldots \ldots . . \ldots \ldots$

6.1 Bubble Dynamics Model $\ldots \ldots \ldots \ldots \ldots \ldots \ldots \ldots \ldots \ldots \ldots \ldots .1$

6.1.1 Model Assumptions $\ldots \ldots \ldots \ldots \ldots \ldots \ldots \ldots \ldots \ldots .6 .1$

6.1 .2 Governing Equations $\ldots \ldots \ldots \ldots \ldots \ldots \ldots \ldots \ldots .6 .4$

6.1 .3 Calculations $\ldots \ldots \ldots \ldots \ldots \ldots \ldots \ldots \ldots \ldots \ldots .6 \ldots \ldots \ldots \ldots$ 
6.2 Results from Bubble Dynamics Model $\ldots \ldots \ldots \ldots \ldots \ldots \ldots \ldots .6$

6.2 .1 Representative Model Solution $\ldots \ldots \ldots \ldots \ldots \ldots \ldots \ldots .6 .8$

6.2.2 Parameter Study for a Fixed Bubble Size $\ldots \ldots \ldots \ldots \ldots \ldots .6$

6.3 Bubble Size Distribution from Gas Release Signatures $\ldots \ldots \ldots \ldots \ldots .6 .10$

6.3.1 Model Derivation $\ldots \ldots \ldots \ldots \ldots \ldots \ldots \ldots \ldots \ldots .6 .10$

6.3.2 Application To Tank SY-101 $\ldots \ldots \ldots \ldots \ldots \ldots \ldots \ldots .6 .13$

7.0 Unusual Gas Release Observations $\ldots \ldots \ldots \ldots \ldots \ldots \ldots \ldots \ldots \ldots \ldots \ldots \ldots$

7.1 Hydrogen Suppression $\ldots \ldots \ldots \ldots \ldots \ldots \ldots \ldots \ldots \ldots \ldots \ldots \ldots \ldots$

7.2 Variation in Ratio of $\mathrm{N}_{2} \mathrm{O}$ to $\mathrm{H}_{2} \quad \ldots \ldots \ldots \ldots \ldots \ldots \ldots \ldots \ldots \ldots \ldots \ldots \ldots \ldots$

8.0 Unsuccessful Attempts at Correlating Gas Releases $\ldots \ldots \ldots \ldots \ldots \ldots \ldots . . \ldots$

8.1 State-Space Models $\ldots \ldots \ldots \ldots \ldots \ldots \ldots \ldots \ldots \ldots \ldots .1$

8.2 Correlation Calculations $\ldots \ldots \ldots \ldots \ldots \ldots \ldots \ldots \ldots \ldots .3$

8.3 Empirical Model of Gas Release $\ldots \ldots \ldots \ldots \ldots \ldots \ldots \ldots \ldots . \ldots \ldots$

8.4 Correlation of Hydraulic Energy Input to Gas Release $\ldots \ldots \ldots \ldots \ldots .8$

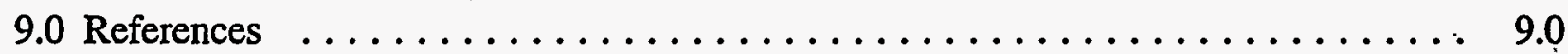




\section{Figures}

1.1 Tank $241-S Y-101$ Instrumentation $\ldots \ldots \ldots \ldots \ldots \ldots \ldots \ldots \ldots \ldots$

1.2. Pump Operation and Gas Release $5 / 15 / 94-5 / 14 / 95 \ldots \ldots \ldots \ldots \ldots$

1.3 Gas Release and Waste Level $\ldots \ldots \ldots \ldots \ldots \ldots \ldots \ldots$

1.4 Waste Temperature History $\ldots \ldots \ldots \ldots \ldots \ldots \ldots \ldots \ldots \ldots$

2.1 Example of GC3 Hydrogen Measurements as a Function of Date $\ldots \ldots \ldots$. . . . 2.2

2.2 Process Dynamic Response Signatures $\ldots \ldots \ldots \ldots \ldots \ldots \ldots \ldots \ldots \ldots$

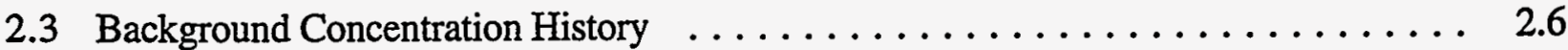

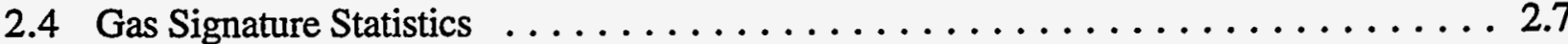

2.5 Loadings for the First Three PCs . . . . . . . . . . . . . . . . . 2.9

2.6 Scores on First Three PCs $\ldots \ldots \ldots \ldots \ldots \ldots \ldots \ldots \ldots \ldots \ldots \ldots \ldots$

2.7 Scores on PC 1 Versus Nozzle Azimuth $\ldots \ldots \ldots \ldots \ldots \ldots \ldots \ldots \ldots$

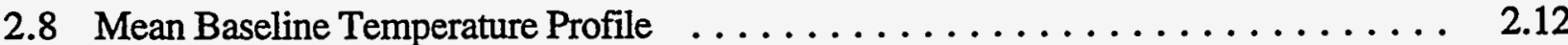

2.9 Q Residuals and $\mathrm{T} 2$ Statistics for Baseline Temperatures $\ldots \ldots \ldots \ldots \ldots \ldots$

2.10 Loadings for PC 1 and 2 for Baseline Temperature Profiles $\ldots \ldots \ldots \ldots$

2.11 Scores on PC 1 and 2 for Baseline Temperature Profiles $\ldots \ldots \ldots \ldots \ldots$

2.12 Mean MIT-17B Temperature Signature $\ldots \ldots \ldots \ldots \ldots \ldots \ldots \ldots$

$2.13 \mathrm{Q}$ and $\mathrm{T} 2$ with $95 \%$ Confidence Limits for MIT-17B Signatures $\ldots \ldots \ldots . \ldots 2.17$

2.14 Scores on PC 1 for MIT-17B Signatures as a Function of Pump Orientation $\ldots \ldots$. . 2.18

3.1 Waste Level History in Tank $241-S Y-101 \ldots \ldots \ldots \ldots \ldots \ldots \ldots \ldots$

3.2 Comparison of Linear Model and FIC Data $\ldots \ldots \ldots \ldots \ldots \ldots$

3.3 Level Change Versus Gas Release $\ldots \ldots \ldots \ldots \ldots \ldots \ldots \ldots \ldots$

3.4 History of Difference in Enraf and FIC Levels $\ldots \ldots \ldots \ldots \ldots \ldots \ldots$ 
3.5 Pump Vicinity on December $9,1993 \ldots \ldots \ldots \ldots \ldots \ldots \ldots \ldots \ldots \ldots . \ldots \ldots$

3.6 Pump Vicinity on October $12,1994 \ldots \ldots \ldots \ldots \ldots \ldots \ldots \ldots \ldots \ldots \ldots \ldots \ldots$

3.7 Area Around the FIC Probe on December 9, $1993 \ldots \ldots \ldots \ldots \ldots \ldots \ldots$

3.8 Area Around the FIC Probe on October 12, $1994 \ldots \ldots \ldots \ldots \ldots \ldots \ldots .$.

3.9 Closeup of FIC Probe on December 9, $1993 \ldots \ldots \ldots \ldots \ldots \ldots \ldots \ldots$

3.10 Closeup of FIC Probe on October 12, $1994 \ldots \ldots \ldots \ldots \ldots \ldots \ldots \ldots . . . \ldots$

3.11 Floating Crust Model $\ldots \ldots \ldots \ldots \ldots \ldots \ldots \ldots \ldots \ldots \ldots \ldots \ldots \ldots \ldots \ldots \ldots$

4.1 Location of Instruments in Tank $241-S Y-101 \ldots \ldots \ldots \ldots \ldots \ldots \ldots .1$

4.2 Temperature Profiles - 17B MIT Validation Probe $\ldots \ldots \ldots \ldots \ldots \ldots \ldots .4 .3$

4.3 Temperature Profiles - 17C MIT Validation Probe $\ldots \ldots \ldots \ldots \ldots \ldots . \ldots .3$

4.4 Transient Temperature Response at 17B June $28,1995 \ldots \ldots \ldots \ldots \ldots \ldots$

4.5 Transient Temperature Response at $17 \mathrm{C}$ June $23,1995 \ldots \ldots \ldots \ldots \ldots \ldots$

4.6 Void Fraction Measurements in Tank $241-S Y-101 \ldots \ldots \ldots \ldots \ldots \ldots \ldots .7$

4.7 Yield Stress of the Loosely Settled Layer in Tank 241-SY-101 . . . . . . . . . . 4.9

4.8 Sludge Geometry Model A $\ldots \ldots \ldots \ldots \ldots \ldots \ldots \ldots \ldots \ldots \ldots .11$

4.9 Sludge Geometry Model B $\ldots \ldots \ldots \ldots \ldots \ldots \ldots \ldots \ldots \ldots \ldots \ldots .12$

6.1 Total Level Due to Gas as a Function of Time $\ldots \ldots \ldots \ldots \ldots \ldots . \ldots . \ldots$

6.2 Normalized $\mathrm{Nd}(\mathrm{Db})$ as a Function of $\mathrm{Db} \ldots \ldots \ldots \ldots \ldots \ldots \ldots \ldots \ldots \ldots$

6.3 Probability Density Versus $\mathrm{Nm}(\mathrm{m} / \mu) \ldots \ldots \ldots \ldots \ldots \ldots \ldots \ldots \ldots \ldots \ldots$

7.1 Hydrogen Suppression Event Induced by the Pump Bump . . . . . . . . . 7.2

7.2 Well-Mixed Model for Hydrogen Suppression $\ldots \ldots \ldots \ldots \ldots \ldots \ldots \ldots \ldots \ldots$

7.3 Integrated Ratios of Gas Concentrations in Pump-Induced Gas Releases ～. . . . . 7.5

8.1 Cross-Correlation Function for Pump rpm and Hydrogen Concentration $\ldots \ldots \ldots 8.3$ 
8.2 Auto-Correlation Function for Pump rpm $\ldots \ldots \ldots \ldots \ldots \ldots \ldots \ldots .4$

8.3 Auto-Correlation Function for Hydrogen Concentration $\ldots \ldots \ldots \ldots \ldots \ldots .8$

8.4a FFT of Hydrogen Concentration: Power Versus Frequency $\ldots \ldots \ldots \ldots \ldots .6$

$8.4 \mathrm{~b}$ FFT of Hydrogen Concentration: Power Versus Period $\ldots \ldots \ldots \ldots \ldots \ldots .6$

8.5 Hydrogen Concentration History Compared with Empirical Model $\ldots \ldots \ldots \ldots 8.8$

8.6 Weekly Gas Release Versus Hydraulic Energy Input $\ldots \ldots \ldots \ldots \ldots \ldots \ldots .9$

8.7 Actual and Predicted Hydraulic Energy Input $\ldots \ldots \ldots \ldots \ldots \ldots \ldots . .10$

\section{Tables}

1.1 Gas Composition Sensor Calibrated Ranges and Overall Accuracy $\ldots \ldots \ldots \ldots 1.5$

1.2 Released Gas Compositions $\ldots \ldots \ldots \ldots \ldots \ldots \ldots \ldots \ldots \ldots \ldots \ldots \ldots \ldots \ldots$

1.3 Summary of Likely Minimum Uncertainties $\ldots \ldots \ldots \ldots \ldots \ldots \ldots \ldots \ldots$

2.1 Variance Information for Principal Components $\ldots \ldots \ldots \ldots \ldots \ldots \ldots . .5$

2.2 Variance Captured By First Five PCs $\ldots \ldots \ldots \ldots \ldots \ldots \ldots \ldots \ldots \ldots \ldots \ldots \ldots \ldots .12$

2.3 Variance Captured by First Five PCs $\ldots \ldots \ldots \ldots \ldots \ldots \ldots \ldots \ldots \ldots \ldots$

3.1 Correlation of Level Change and Gas Release $\ldots \ldots \ldots \ldots \ldots \ldots \ldots \ldots$

3.2 Correlation of Level Measuring Instruments $\ldots \ldots \ldots \ldots \ldots \ldots \ldots \ldots .5$

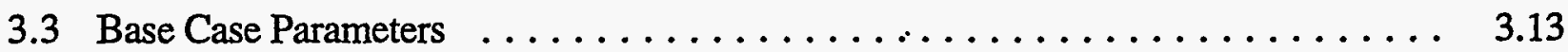

3.4 Summary of Waste Level Changes $\ldots \ldots \ldots \ldots \ldots \ldots \ldots \ldots \ldots \ldots \ldots \ldots \ldots$

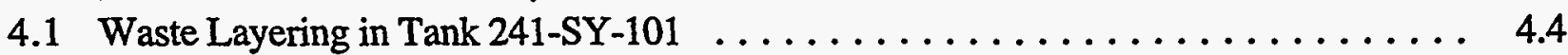

4.2 Sludge Depth Data from MITs, VFI, and Ball Rheometer $\ldots \ldots \ldots \ldots \ldots \ldots .10$

4.3 Sludge Volume Calculation Summary $\ldots \ldots \ldots \ldots \ldots \ldots \ldots \ldots \ldots . \ldots \ldots$ 
4.4 Volume of Gas Stored in Waste Layers $\ldots \ldots \ldots \ldots \ldots \ldots \ldots \ldots$

4.5 A Summary of GREs in Tank $241-S Y-101 \ldots \ldots \ldots \ldots \ldots \ldots$

5.1 Stored Gas Parameters Calculated from Level Response to Barometric Pressure $\quad \ldots \quad 5.7$

5.2 Estimates of Gas Volume from Past Pre-GRE State $\ldots \ldots \ldots \ldots \ldots \ldots$

6.1 Definitions of Model Parameters, Variables, Symbols, Values, and Units $\ldots \ldots .5$

6.2 Parameter Study Results $\ldots \ldots \ldots \ldots \ldots \ldots \ldots \ldots \ldots \ldots \ldots$

6.3 Parameters for Variable Bubble Size $\ldots \ldots \ldots \ldots \ldots \ldots \ldots \ldots \ldots \ldots \ldots$

6.4 Model Parameters $\ldots \ldots \ldots \ldots \ldots \ldots \ldots \ldots \ldots \ldots \ldots \ldots \ldots \ldots$

7.1 Released Gas Compositions $\ldots \ldots \ldots \ldots \ldots \ldots \ldots \ldots \ldots \ldots$ 



\subsection{Introduction}

Mitigation of large, episodic gas releases from Hanford waste Tank 241-SY-101 has been a priority since 1990 and was effectively accomplished in July 1993 with installation of the mixer pump that still operates to mix the waste and prevent flammable gas accumulation. Although mitigation persists as long as mixing continues, until recently we had not been able to determine any details about the effects of mixing on the waste or, perhaps more importantly, how much gas remains in the waste and where it is located.

In late 1994 and early 1995 new analysis methods were developed, and direct measurements of the void fraction and rheology of the mixed waste became available from deployments of the void fraction instrument (VFI) and ball rheometer. This new information helped interpret previous data to yield a fairly clear picture of the waste in 241-SY-101 as well as the location, quantity, and behavior of undissolved gas in the tank.

This section contains the background on mitigation of Tank 241-SY-101, the instruments available, and some of the historical data trends. Section 2 describes a study of gas release signatures by the method of principal components analysis. Section 3 is devoted to the measurement and analysis of waste surface level changes, which is an important indicator of gas content. The actual estimates of gas volume from direct measurements are given in Section 4, and Section 5 discusses gas volume estimates obtained by indirect means. Section 6 describes the dynamics of buoyant bubble-particle systems in response to periodic mixing and changes in barometric pressure. Finally, Sections 7 and 8 discuss some unusual gas release observations and some unsuccessful attempts at correlating gas release.

\subsection{Background}

Since 1943, large underground concrete storage tanks (currently numbering 177) have been used at Hanford to store the byproducts of plutonium production. The tanks are steel-lined, up to $22.8 \mathrm{~m}$ ( 75 feet) in diameter, up to $9.8 \mathrm{~m}$ (32 feet) high, and are capable of holding up to $3.8 \mathrm{mil}-$ lion liters (one million gallons) of waste. The waste in these tanks is chemically complex and ranges from mostly liquid to thick sludge to a crystalline salt cake. Several of these tanks have been placed on the flammable gas watch list (FGWL), because the waste in them is either known or suspected to be generating, storing, and periodically releasing flammable gases.

While awaiting retrieval and ultimate disposition, the waste in each FGWL tank must be maintained in a safe condition. The accumulation of flammable gases in the waste must be controlled so that episodic releases of large volumes of gas that could cause potentially hazardous concentrations of flammable gas in the tank dome space are prevented. The actions to accomplish this (if any are required) constitute mitigation as it pertains to the flammable gas safety issue.

Flammable gas mitigation efforts were first focused on Tank 241-SY-101, because that tank was releasing large volumes of hydrogen, nitrous oxide, ammonia, and other gases during and after gas release events (GREs) that had been occurring every 100 to 150 days since about 1981 (Antoniak 1993). Video recordings in Tank 241-SY-101 showed that the episodic GREs 
were accompanied by extensive and violent disruption of the waste surface. This suggested that these gas releases involved large-scale movement of waste from the lower layers, or "rollovers."

The GRE sequence in Tank 241-SY-101 and other similar waste tanks arises from the retention of gas in a layer of cohesive sludge (Babad et al. 1992). The local density decreases as gas is generated, and the sludge eventually becomes more buoyant than the liquid above it. When the buoyancy of the gas-retaining mass exceeds the cohesive forces, a portion of the sludge breaks loose, rises quickly through the convective layer, and breaks through the crust to the waste surface, where the bulk of the gas is released immediately. The remaining gas continues to evolve at a relatively slow rate until the gas content is insufficient for buoyancy. The sludge then begins to sink, and the remaining gas is recompressed as the hydrostatic head increases.

Without intervention, the cycle of gas retention and release would continue indefinitely. The basic aim of all the mitigation concepts is to destroy the ability of the waste to retain gas, so that it is released at nearly the same rate as it is generated, and large GREs are eliminated.

A spare 150-hp mixing pump from the Hanford Grout Program was installed just west of the centerline in Tank 241-SY-101 on July 3, 1993, and it is still operating. It pulls liquid in from the $660 \mathrm{~cm}(260$-in.) level and injects it as a high-speed jet through two opposing, $6.6 \mathrm{~cm}$ (2.6-in.) nozzles about $60 \mathrm{~cm}(2 \mathrm{ft})$ from the tank bottom. Mixing has homogenized the waste in the original convective and nonconvective layers to a great extent, as evidenced by a nearly isothermal temperature profile extending through much of the waste's depth and by the recent results from the VFI and ball rheometer (Stewart et al. 1995). Also, since December 1993, the waste surface level has remained essentially constant, indicating that gas is no longer being retained in the sludge.

The results of mixer pump operation in Tank 241-SY-101 since July 1993 have been extensively documented (Allemann et al. 1994; Stewart et al. 1994). High-speed mixer pump testing began October 21,1993, with the objective of proving that mixing would mitigate the tank. Initial mixing of the sludge layer released a large volume of retained gas over the first few weeks of testing and reduced the waste level to a historic low of $1016 \mathrm{~cm}$ ( $400 \mathrm{in}$.). By early December, the pump jets had apparently mixed most of the gas-bearing sludge, and there were no large gas releases for the rest of the test period that ended December 17, 1993. The uniform vertical temperature profiles at two in-tank thermocouple trees showed that the waste was mixed well except for approximately $125 \mathrm{~cm}$ (50 in.) of sludge at the bottom and $100 \mathrm{~cm}$ (40 in.) of crust on top.

The Full-Scale test program was run from February 4 to April 13, 1994, to confirm the long-term operational strategy for mitigation and to show that the mixer pump could control the gas release and waste level. Four test periods were conducted. From February 4-25 the pump was run one hour at $750 \mathrm{rpm}$ three days per week, indexing the nozzles 30 degrees before each run, to represent nominal long-term operation. From February 28-March 25 minimal operations were run to investigate how rapidly the waste level would grow if the pump were not run. On March 28 and March 30, full tank sweeps were run at $750 \mathrm{rpm}$ to release gas and reduce the waste level as quickly as possible. Finally, on April 4,6,12, and 13, the jet penetration test series explored the ability of the pump to cause flow near the tank wall. The pump was run for 40 minutes at $920 \mathrm{rpm}$ or 25 minutes at $1000 \mathrm{rpm}$ with the nozzles in line with a thermocouple tree to assess the effects of the jet. The thermocouple response clearly indicated that these four runs reduced the sludge depth to less than $40 \mathrm{~cm}$ (16 in.) in the regions excavated by the jet. 
Even though the tank was considered mitigated after high-speed testing (Allemann et al. 1994), an average depth of about $125 \mathrm{~cm}$ (50 in.) of undisturbed sludge remained on the bottom after Full Scale testing (Stewart et al. 1994). It was thought that this layer might hold a large volume of gas that could be released suddenly. The potential consequences of a conservatively large release were included in the mixer pump Safety Assessment (LANL 1994), and, as a result, the operating limits for the mixer pump became much more restrictive. Because of the success of the jet penetration test at reducing sludge depth in a single direction, a campaign of aggressive mixing was begun to 'excavate' the sludge more uniformly over the entire tank. Twenty excavation runs were performed from June through August 1994, mainly in three azimuths, with as many as six sequential runs in a single direction.

In September 1994, the Test Review Group (TRG) became concerned that excavating in a single direction was not mixing the other regions of the tank sufficiently. Accordingly, the TRG decided that the 'nominal' pump operation should be a 25-minute, 1,000-rpm excavation, and three excavations should be run each week with the nozzles indexed 30 degrees each time. As of April 1995, there have been over 100 of these excavation runs about evenly divided among the six nominal azimuths.

This excavation campaign has been the longest period of consistent, uniform mixer pump operation since installation. It has allowed us to observe minor seasonal variations in temperatures and gas release behavior that had been obscured by changing waste conditions. It has also allowed us to examine the behavior of the tank in some detail as it responds to continued mixing. The following two subsections describe the instrumentation in the tank used to monitor the waste and a sampling of historic trends in the data.

\subsection{Tank Instrumentation}

To monitor the gas releases in response to mixer pump operation and the condition of the waste, it is necessary to measure the vent header flow rate, the concentration of hydrogen, nitrous oxide, and ammonia at the vent header, temperature profiles at two locations, and waste surface level. This section briefly describes the main instruments installed in the tank and their uncertainty as well as the calculations required for the total gas release.(a) The location of the instruments in the tank is given in the plan view shown in Figure 1.1.

\subsubsection{Ventilation Header Flow Rate}

The ventilation flow rate of gas exiting the tank is measured in the ventilation header at riser 7A. Flow enters the tank from the atmosphere at riser 7B. Combined with gas composition information, the ventilation volume flow rate yields actual hydrogen, ammonia, and nitrous oxide release rates. Also, the total gas release is obtained from the hydrogen release rates using an estimate of the hydrogen fraction of total released gas.

(a) The information in Section 1.2 was excerpted from a 1995 letter report by M. E. Brewster, E. J. Eschbach, and Z. I. Antoniak, entitled Uncertainty Status of Selected Instruments in Tank 241-SY-101, letter report PNL-MIT-013095. Pacific Northwest Laboratory, Richland, Washington. 


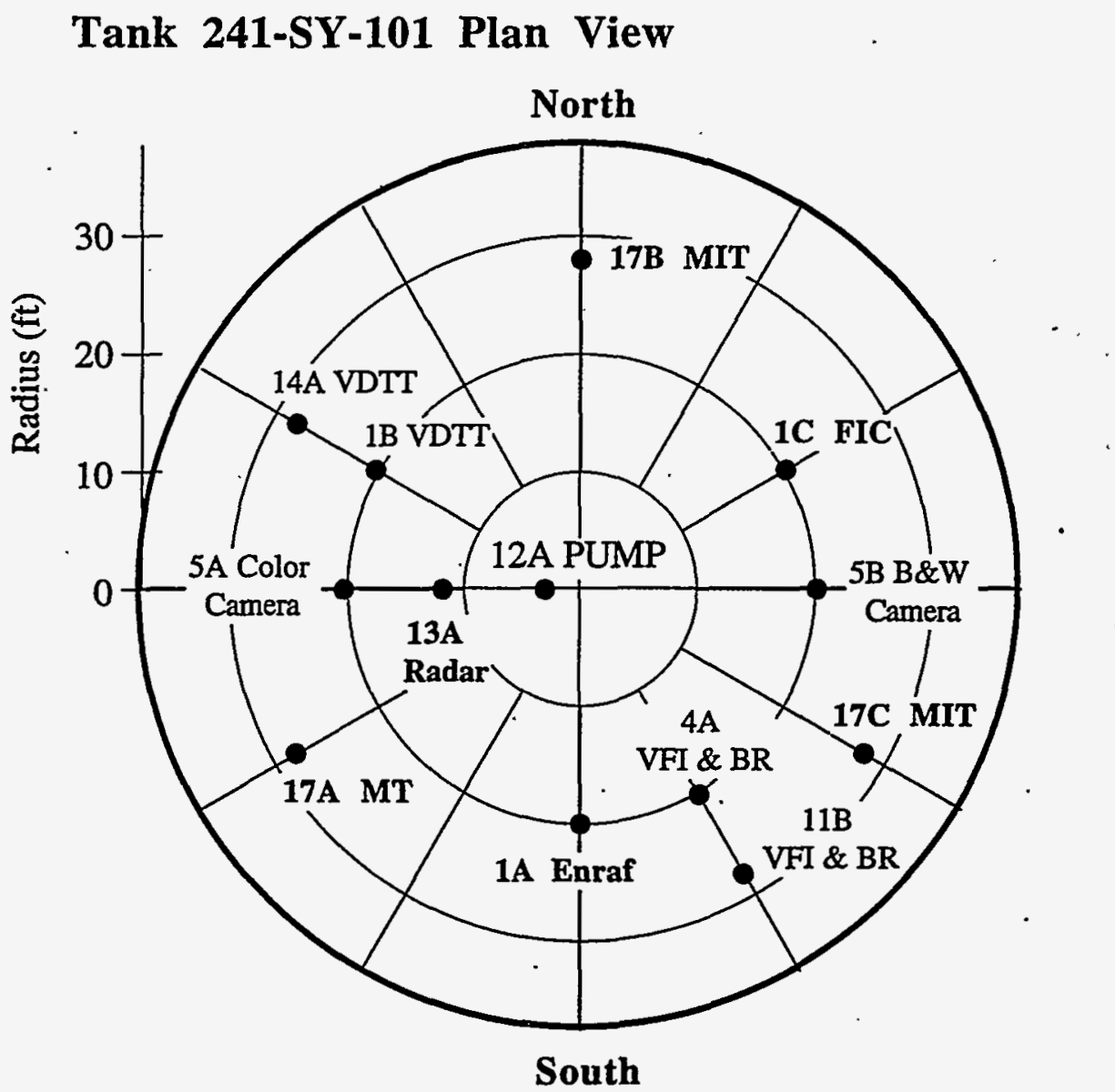

Figure 1.1. Tank 241-SY-101 Instrumentation

All flow rate computations assume that the gas stream is a single component, air. An averaging pitot probe measures a flow velocity in the exhaust header. Volume flow rate is then computed as the product of velocity and cross-sectional area. Calibration relates the measured velocity to the average velocity over the duct. Errors are introduced in the measurement of velocity, gas temperature and pressure, and in calculating the duct area. The dominant error is the contribution of the cross-sectional area. The error of the pipe cross-sectional area is nominally $4 \%$. Given the limitations of this analysis, the ventilation flow rate measurement uncertainty is at least $\pm 4.3 \%$ of the reading. At a nominal flow rate of $14 \mathrm{~m} 3 / \mathrm{min}(500 \mathrm{scfm})$, the minimum error estimate is $\pm 0.6 \mathrm{~m}^{3} / \mathrm{min}$ ( $\left.\pm 22 \mathrm{scfm}\right)$. 


\subsubsection{Gas Composition Measurements}

The RGA-3 and RGA-5 gas chromatograph (GC) instruments and the Fourier Transform Infrared Spectrometer (FTIR) are some of the best-characterized instruments taking measurements in Tank 241-SY-101. All instruments are calibrated regularly in the field by injecting standard gas samples, whose concentrations are known to $2 \%$, five times in succession. RGA-5 is calibrated every 12 hours. The response factors-proportionality constants that relate peak area to concentration-are not changed unless the instrument is reading out of specifications, which are $10 \%$ of reading. This happens very seldom once the instrument has "settled down." Table 1.1 summarizes the gas composition sensor information.

A measurement of interest is the ratio of nitrous oxide to hydrogen. When this is calculated using $\mathrm{GC}$ data for the hydrogen fraction, small variations are observed in the ratio at the onset of a pump run. This is probably attributable to the slower response time of the FTIR, which gives an averaged reading over the previous nine minutes, while the $\mathrm{GC}$ has a response time less than three minutes.

\subsubsection{Total Gas Release Calculation}

Around $2.8 \mathrm{~m} 3 / \mathrm{day}$ ( $100 \mathrm{SCF}$ per day or $0.07 \mathrm{scfm}$ ) of gas at $1 \mathrm{~atm}$ is released from the waste; the total exhaust flow is about $14.2 \pm 0.6 \mathrm{~m}^{3}$ per minute $(500 \pm 22 \mathrm{scfm})$. Since it is much smaller than the uncertainty in the flow rate measurement, the total gas released from the waste cannot be measured directly. Instead it is calculated as the product of the hydrogen concentration and the exhaust flow.

Given the ventilation flow rate, the first step in the estimation of the total gas release is estimating the hydrogen gas release rate. This is obtained by multiplying the gas flow rate by the concentration (mole fraction) of hydrogen in the outflow gas stream. The second step is calculating total gas released from the amount of hydrogen released by dividing the hydrogen release by the assumed concentration (mole fraction) of hydrogen in the released gas.

Table 1.1. Gas Composition Sensor Calibrated Ranges and Overall Accuracy

\begin{tabular}{||c|c|l||}
\hline Sensor & Range & \multicolumn{1}{|c|}{ Sensor error } \\
\hline \hline $\begin{array}{c}\text { GC-1 } \\
\text { (Low-range RGA-5) }\end{array}$ & $5-800 \mathrm{ppm}$ & $\begin{array}{l} \pm 2 \% \text { of reading } \\
(5-20 \mathrm{ppm}) ; \pm 10 \% \text { of } \\
\text { reading }(20-800 \mathrm{ppm})\end{array}$ \\
\hline GC-2 & $\begin{array}{c}700-30,400 \mathrm{ppm} \\
(3.04 \%)\end{array}$ & $\pm 10 \%$ of reading \\
(High-range RGA-5) & & $\begin{array}{l} \pm 2 \% \text { of reading } \\
(5-20 \mathrm{ppm}) ; \pm 10 \% \text { of } \\
\text { reading }(20-100 \mathrm{ppm})\end{array}$ \\
\hline GC-3 & $5-100 \mathrm{ppm}$ & $\pm 10 \%$ of reading \\
\hline (Low-range RGA-3) & $5-50,000 \mathrm{ppm}$ & \pm 12 \\
\hline FTIR &
\end{tabular}


Measurements of release gas composition were made from gas samples obtained from the exhaust header during the GREs prior to pump installation. The best-estimate compositions given in the Mixer Pump Safety Assessment, Appendix B (Sullivan 1995), are shown in Table 1.2. Note that the term "total released gas" applies only to gas released as bubbles. Current calculations do not include the actual contribution of ammonia in the total since about $75 \%$ of the ammonia release now comes from evaporation of dissolved gas.

Combining the uncertainties in each step of the calculation yields an overall uncertainty of $\pm 25 \%$ in the total gas release. An improved method is being developed using the actual nitrous oxide concentration, measured by the FTIR, along with the measured hydrogen concentration. This will potentially reduce the uncertainty to $\pm 13 \%$.

\subsubsection{Waste Temperatures}

Vertical temperature profiles in the waste have proved invaluable in determining the probable waste configuration (Allemann et al. 1994; Stewart et al. 1994). These profiles are measured by two multifunction instrument trees (MITs). The MITs provide 22 thermocouple readings spaced from 30 to $61 \mathrm{~cm}$ (12 to 24 in.) apart. Additional information about waste temperatures can also be inferred from thermocouples attached to the tank bottom and sides.

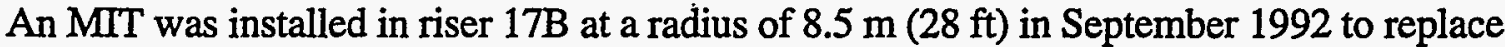
an old, bent thermocouple tree. A second, very similar MIT was installed in riser 17C in July 1993. The new trees (hereafter identified as MIT 17B and MIT 17C) use type $\mathrm{K}$ thermocouples mounted inside an 8.9-cm (3.5-in.) outer diameter (OD) by 7.9-cm (3.125-in.) inner diameter (ID) tube. Since installation of the mixer pump in July 1993, thermocouple readings are taken every 12 seconds by an automated data acquisition system (DACS). Manual readings continue to be taken one per shift.

Approximately quarterly, independent temperature measurements are made by inserting a validation probe into the thermocouple trees. This probe consists of a resistance temperature detector (RTD) and readout instrument that were carefully calibrated as a system at LANL;(a) the system

Table 1.2. Released Gas Compositions (LANL 1995)

\begin{tabular}{|c|c|}
\hline Gas Component & Reported Composition \\
\hline \hline Hydrogen & $28.8 \% \pm 3.7 \%$ \\
\hline Nitrous oxide & $24.5 \% \pm 3.2 \%$ \\
\hline Nitrogen & $32.8 \% \pm 13.1 \%$ \\
\hline Ammonia & $11.0 \pm 5.6 \%$ \\
\hline
\end{tabular}

(a) Los Alamos National Laboratory. 1994. Hanford Multifunction Instrument Tree, Test Data Report, Validation Probe. TDR-NIS4-VAL94-354, Los Alamos, New Mexico. 
error was measured to be approximately $\pm 0.17^{\circ} \mathrm{C}\left( \pm 0.3^{\circ} \mathrm{F}\right)$. This system has not been recalibrated since arriving at Hanford. However, it is checked prior to use against an accurate digital thermometer that reads ambient temperature, and it always has read within $0.6^{\circ} \mathrm{C}\left(1^{\circ} \mathrm{F}\right)$ of this instrument. Its use demands care, both in ensuring that the RTD probe is in firm contact with the validation tube inside the MIT and in allowing it to equilibrate in temperature as it is progressively lowered within the MIT. The latter error was analyzed extensively with the TEMPEST code and found to be typically on the order of $0.1^{\circ} \mathrm{C}\left(0.2^{\circ} \mathrm{F}\right)$ if temperature stabilization is not achieved.(a)

When the tank was constructed, 24 type J thermocouples were attached to the tank bottom about equally spaced on 2.1-, 6.4-, and 11.1-m (7-, 21-, and 36.5-ft) radii to monitor heat treatment during construction. In addition, two thermocouples are attached to the tank side wall about $38 \mathrm{~cm}$ (15 in.) above the tank bottom. However, except for showing the approximate radial temperature variation of the waste, bottom thermocouple data are not very useful indicators of waste behavior. Loop resistance measurements were made recently that indicated several thermocouples and associated extension wires were in poor condition (Bussell 1992). Thermocouples 6, 9, 10, 11,24 , and 26 are inoperative or give anomalous readings that are higher than the readings of the lowest thermocouples on the MITs and typically vary with time, while other bottom thermocouples remain relatively constant.(b) For about a month in the fall of 1994, the bottom thermocouples were connected to Hewlett-Packard dataloggers that provide $0.02^{\circ} \mathrm{C}\left(0.01^{\circ} \mathrm{F}\right)$ precision. No response was observed in bottom thermocouple readings during and after pump runs.(c)

\subsubsection{Waste Surface Level}

The height of the waste surface is the only direct indication of the total amount of gas in the tank. As gas accumulates the surface level rises. The level also varies with changing barometric pressure in proportion to the amount of gas contained and its depth (see Section 5.0). However, measurement of the surface level is difficult because it is very irregular-changes in level due to gas releases and pressure changes are smaller than the height of the surface features.

Four different instruments are employed to measure waste level: a manual tape, a Food Instrument Corporation (FIC) contact probe, a radar gauge, and an Enraf ${ }^{\circledR}$ buoyancy gauge. The uncertainties and correlation of these instruments with each other and with estimates of the gas release and their response to barometric pressure changes are described in detail in Section 3.0.

(a) Antoniak, Z. I., and K. P. Recknagle. 1994. Study of Validation Probe Error Using the TEMPEST Code. Letter report PNL-MIT-121994, Pacific Northwest Laboratory, Richland, Washington.

(b) Stewart, C. W. 1995. Analysis of Tank 241-SY-101 Bottom Thermocouple Data During November 1994. PNL-MIT:011195, Pacific Northwest Laboratory, Richland, Washington.

(c) Antoniak, Z. I., et al. 1995. Quarterly Review of 241-SY-101 Mixer Pump Data. PNLMIT:952644, Pacific Northwest Laboratory, Richland, Washington. 


\subsubsection{Summary of Instrument Uncertainty}

The uncertainties of the ventilation header flow rate, gas composition measurements, calculation of total released gas, waste temperatures, and tank level have been examined. In general, there is not sufficient information to formally derive measurement uncertainties at $95 \%$ confidence intervals. But it is possible to estimate measurement uncertainty that represent likely minimums; these are presented in Table 1.3.

The majority of instruments reviewed were deployed as process instruments and not intended to provide highly accurate scientific measurements. The detailed information regarding the original specifications, calibration history, deployment conditions and limitations, signal conditioning, and data acquisition and manipulation that are required for a thorough uncertainty analysis are not available. Finally, the details of the actual sensor installation and its operating environment are not well known.

\subsection{Overview of Tank Data}

Data from prior testing of the mixer pump through May 1994 have been documented extensively (Allemann et al. 1994; Stewart et al. 1994). This subsection describes the trends and tank behavior over the one-year period ending mid-May 1995. Two different mixer pump operating strategies were employed during this period, as shown in Figure 1.2. Before September 1994, the nozzles were fixed at a selected azimuth for up to several weeks to excavate the sludge in that area. After that date the nozzles were stepped $30^{\circ}$ each run to ensure that all areas of the tank were mixed periodically.

Table 1.3. Summary of Likely Minimum Uncertainties

\begin{tabular}{||l|l||}
\hline \multicolumn{1}{|c|}{ Measurement } & \multicolumn{1}{c|}{ Estimated Uncertainty } \\
\hline \hline Ventilation flow rate & $\pm 4.3 \%$ of reading (in scfm) \\
\hline Gas composition & $\pm 10 \%$ \\
\hline Calculation of total released gas & $\pm 25 \%$ \\
& \\
\hline Temperature, & $\pm 1.8^{\circ} \mathrm{C}\left( \pm 3.2^{\circ} \mathrm{F}\right)$ \\
17B/DACS & $\pm 1.8^{\circ} \mathrm{C}\left( \pm 3.2^{\circ} \mathrm{F}\right)$ \\
17C/DACS & $\pm 0.2^{\circ} \mathrm{C}\left( \pm 0.3^{\circ} \mathrm{F}\right)$ \\
Validation probe & \\
\hline Level (excluding effect of & $\mathrm{NA}$ \\
surface irregularities) & $\pm 5 \mathrm{~cm}( \pm 2$ in.) \\
Radar gauge & $\pm 0.25 \mathrm{~cm}( \pm 0.1$ in.) \\
Manual tape & $\pm 5 \mathrm{~cm}( \pm 2$ in.) \\
Enraf series 854 & \\
FIC & \\
\hline \hline
\end{tabular}




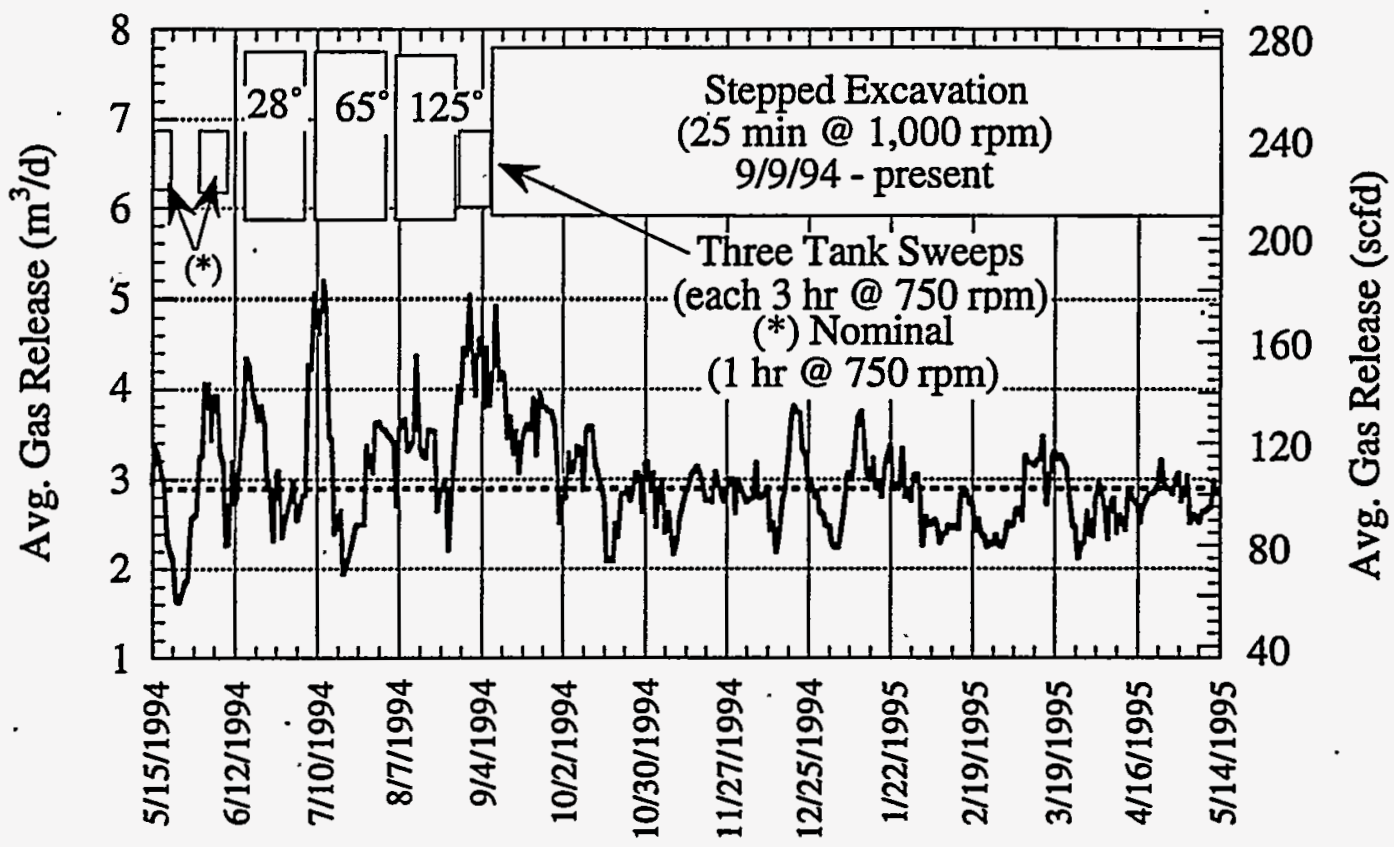

Figure 1.2. Pump Operation and Gas Release 5/15/94 - 5/14/95

. Figure 1.2 also shows a 15-day running average gas release along with the estimated gas generation rate. In each of the excavation campaigns at $28^{\circ}, 65^{\circ}$, and $125^{\circ}$, gas release was initially high but then fell off as decreasing amounts of new sludge were excavated. The same trend is evident after the stepped excavation campaign began, though with a more gradual decrease. However, after about January 1, 1995, gas release seldom exceeded the generation rate.

The relationship of gas release to waste level is shown in Figure 1.3. Level is indicated both by FIC data and by the value predicted solely on the basis of gas release and generation (abrupt departures between these two plots typically correspond to flushes of the FIC probe). The waste level decreased steadily from the generally high gas releases during the focused excavation period and held approximately steady for the first four months of the stepped excavation campaign. However, the reduced gas releases in the first quarter of 1995 allowed gas to accumulate, causing the waste level to grow about $2.5 \mathrm{~cm}$ ( $1 \mathrm{in}$.). To keep this in perspective, $2.5 \mathrm{~cm}$ ( $1 \mathrm{in}$.) of level represents less than $11 \mathrm{~m}^{3}\left(400 \mathrm{ft}^{3}\right)$ of gas accumulation at one atmosphere.

The reduction in gas release rate may be more of a seasonal effect that is not affected by pump operation strategy. Figure 1.4 shows the temperature history of the waste near the top of the crust and four inches of the tank bottom as measured by the MTT at 17B. The seasonal effect on the crust is clear, but there is very little effect on the waste near the bottom. Since about half the total gas accumulation might be held in the crust (see Sections 3.3 and 4.3), and the solubility of 


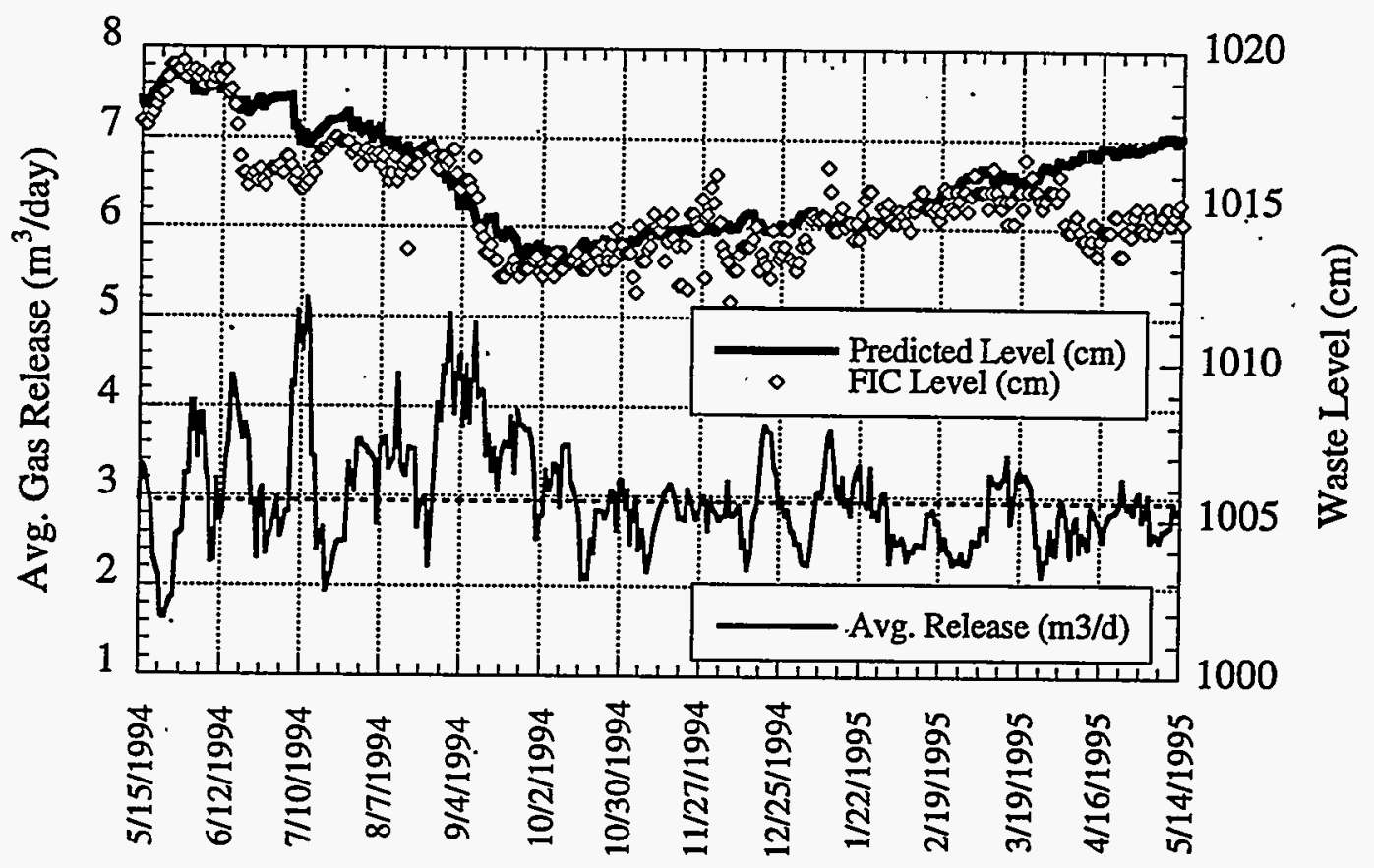

Figure 1.3. Gas Release and Waste Level

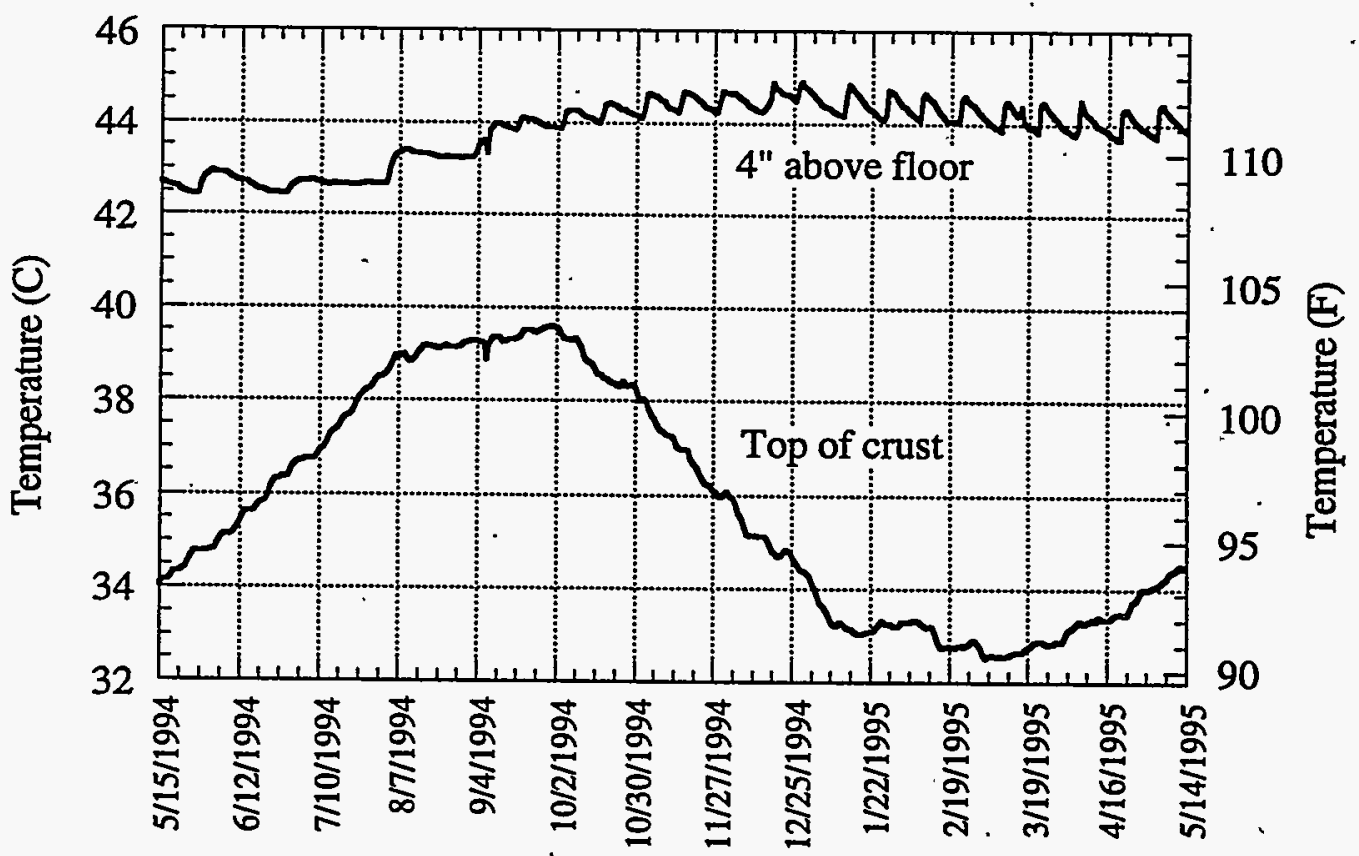

Figure 1.4. Waste Temperature History 
the crust material varies with temperature, it is very likely that the gas volume in the crust also varies with temperature. Comparing Figures 1.3 and 1.4, it appears that the period of highest gas release corresponds to a period of high crust temperature and vice versa.

The jaggedness of the upper curve in Figure 1.4 shows the effect of the pump jet when the nozzles are aimed directly at the 17B MIT. The jet removes loosely settled material, moving hotter slurry from the middle of the tank down to within a few inches of the lower thermocouple. As the jet moves to other angles on succeeding days, the solids settle back, insulating the lower layers and allowing them to cool until the next time the area is disturbed by the jet. The increasing amplitude and abruptness of the sawtooth pattern show the gradual progress of sludge excavation. The closer the jet is to the lower thermocouple, the greater and more rapid the temperature increase.

There is much more information available from the vertical temperature profiles and shortterm transient response to individual pump runs. Likewise, the gas releases and transient composition of the released gas during and immediately following pump runs helps characterize the behavior of the waste. These will be discussed in detail in Sections 2, 4, and 7. 



\subsection{Signature Analysis}

Gas releases from the waste during and for about a day after each mixer pump run produce a characteristic instrument response or signature. The gas concentrations in the exhaust header rise sharply to a peak then decrease slowly to background levels. Waste temperatures as measured by the MIT thermocouples also vary in response to fluid motion caused by the pump jet. These signatures contain a wealth of information about the waste. In Section 6 we use the gas release signature to estimate the size distribution of bubbles liberated by the pump; in Section 7 the integrated concentration signatures are used to evaluate potential changes in gas ratios. In this chapter, a multivariate statistical technique is used to develop a procedure to monitor the mitigation process. The procedure is referred to as Signature Analysis.

Signatures are defined as measurements made from just before pump operation to a time following pump operation where the quantities have nearly returned to background levels. A principal components analysis (PCA) was performed on instrument response signatures of gas chromatograph 3 (GC3) hydrogen concentration measurements, FTIR ammonia and nitrous oxide measurements, and thermocouple tree MIT 17B temperature measurements. This analysis procedure can be used to monitor mitigation, identify off-standard pump induced gas releases and temperature responses, and identify changes in behavior.

Signatures were found to be different between June 10 and August 31, 1994, than during the period following, probably due to initiation of the stepped excavation schedule on September 8 and consequent redistribution of waste. In general, from September 8, 1994, to May 11, 1995, pump-induced gas releases decreased, background hydrogen and nitrous oxide concentrations decreased slightly, and the shape of release signatures also changed. Differences in signatures as a function of pump orientation were also noted and may be attributed to the pump being off-center and/or to a nonuniform waste distribution.

\subsection{Overview of the Signature Analysis Method}

The response of the waste to pump operation can be characterized by analyzing instrument responses. For example, the pump agitates the waste and liberates gas bubbles adhering to waste particles. Liberated bubbles rise to the surface, where they are released to the dome space. Forced ventilation of the dome space carries the low-concentration gases out of the tank through a vent header where gas concentrations are measured. Figure 2.1 shows an example of GC3 hydrogen measurements in the vent header. This figure shows that there is a rise in hydrogen concentration following a pump run. The hydrogen concentration then decays as the release drops to background levels. For this case, a signature is the gas concentration in the vent header measured from just prior to pump start to a time when the gas concentration has decayed to background levels.

The pump is installed just west of the tank center and has two opposed jets about $60 \mathrm{~cm}$ $(2 \mathrm{ft})$ off the bottom. The shape of the signatures is a function of pump operation (speed, duration, and nozzle orientation), the history of pump operation, vent header flow, and the state of the waste in the tank. It is difficult to identify systematic changes in the signatures by inspecting plots such 


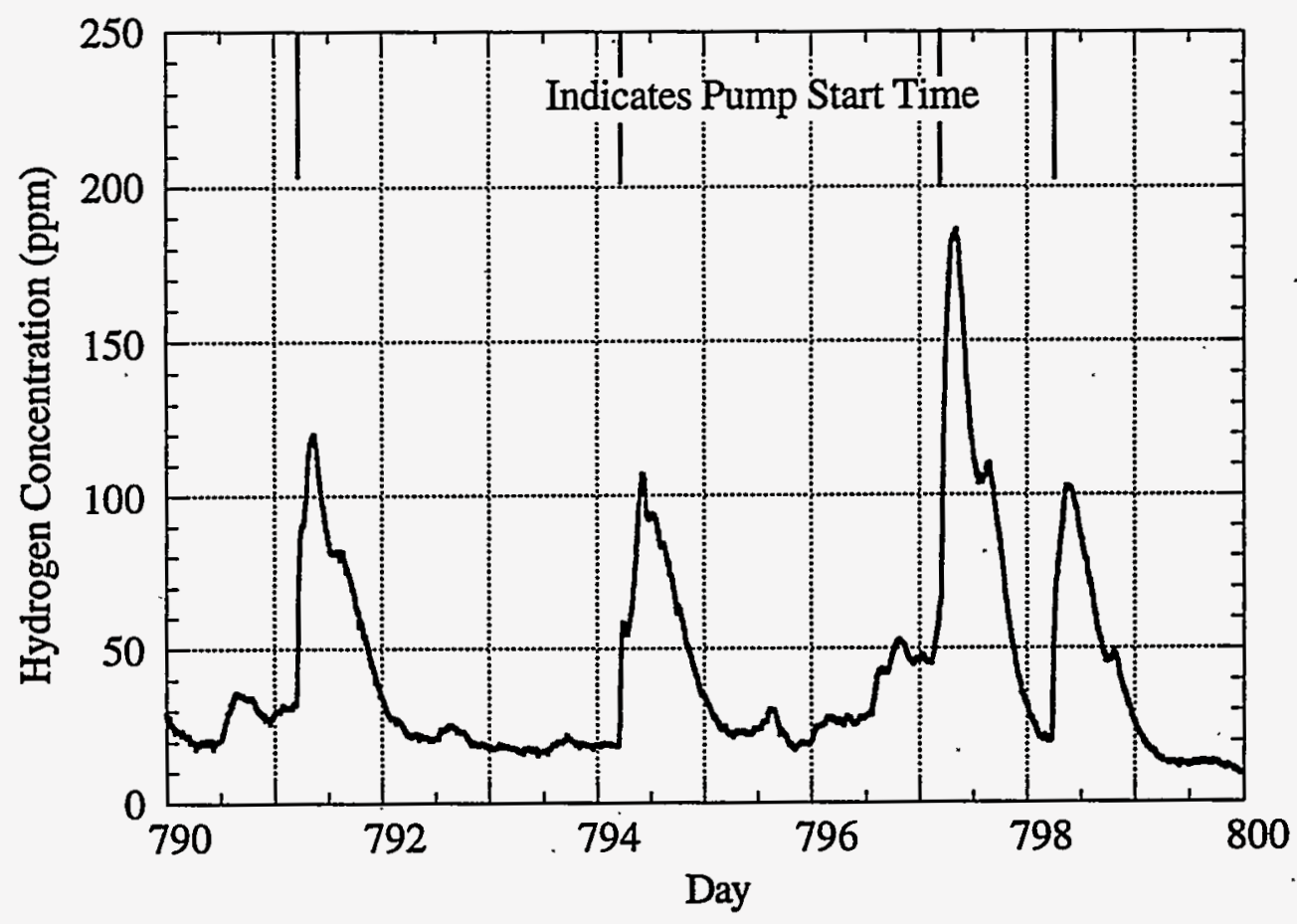

Figure 2.1. Example of GC3 Hydrogen Measurements as a Function of Date

as Figure 2.1 due to noise, changes in background.releases, and subtle slow variations in the signature itself. For this reason a multivariate statistical analysis PCA (Jackson 1991) was used to analyze the signatures and identify systematic changes. The methodology used here is referred to as multi-way principal components analysis (MPCA) and is analogous to that used by Nomikos and MacGregor $(1994,1995)$ to monitor batch operations.

Signatures can be measured for a variety of instruments used to monitor Tank 241-SY-101. In this analysis signatures were measured for three instruments, GC3, FTIR, and the non-crust thermocouples on MIT 17B. GC3 measures hydrogen concentration, and the FTIR measures ammonia and nitrous oxide concentration in the vent header as the gases exit the tank overhead dome space. If the gas in the dome space can be considered well-mixed, and waste is distributed radially and angularly isotropic about the tank, these signatures are not expected to depend on pump jet orientation. However, MTT 17B is located off-center, 95 degrees from the pump jet orientation, and its signatures are expected to depend on pump orientation.

Signatures were measured from about 45 minutes prior to pump start to about 22 hours after pump start, when the responses decay nearly to background levels. .All measurements were interpolated to five-minute increments to allow direct comparisons among instruments. Measured responses suggest that this time scale is adequate to provide a description of the dynamic response of the waste to the pump. Thus individual signatures contain 280 time increments. For each pump run, individual gas signatures were combined into a 3-by-280 matrix, and 17B signatures were combined into a 22-by-280 matrix prior to analysis using MPCA. 
In the nomenclature of MPCA, vectors are represented by bold lower-case characters. Column vectors are represented by $\mathbf{a}$, and $\mathbf{a}$ row vectors are represented by its transpose $\mathbf{a}$. Bold roman capitals (A) refer to second-order tensors, and underlined bold roman capitals $(\underline{\mathbf{A}})$ refer to third-order tensors. The capitals $\mathrm{I}, \mathrm{J}$, and $\mathrm{K}$ are the number of levels in the different modes, and $i$, $j$, and $k$ are running indexes. For example, $\mathrm{I}$ is the number of samples (pump runs), $\mathrm{J}$ is the number of measured responses (e.g., three gas measurements or 22 temperature measurements), and $\mathrm{K}$ is the number of time increments (i.e., 280).

The MPCA procedure is useful because each individual signature is highly autocorrelated, and there is a high degree of correlation between signatures, which allows the multivariate data to be described in far fewer components than the original data. A good discussion of MPCA is given by Wold et al. (1987). The MPCA procedure can be described as follows: for a system with $j=1,2, \ldots, \mathrm{J}$-measured variables measured for $k=1,2, \ldots, \mathrm{K}$ time steps referenced to pump start, each pump run $i$ will result in a J x K matrix $\underline{X}_{i}$ of signatures. The upper left of Figure 2.2 shows an example of the three gas measurements $(\mathrm{J}=3)$. For a set of similar pump runs, each of the $\mathrm{J} \times \mathrm{K}$ matrixes can be considered a sample. Therefore, $i=1,2, \ldots$, I samples (sets of $\mathrm{J} \times \mathrm{K}$ matrixes) can be arranged in a cube $\underline{\mathbf{X}}$, which is $\mathrm{I} \times \mathrm{J} \times \mathrm{K}$. The I samples form the cube $\underline{\mathbf{X}}$, shown in the bottom left corner of Figure 2.2. Samples are arranged along the vertical axis of $\underline{X}$; sample $i$ is one slice in the stack, variables are arranged on the left face, and time is receding into the figure on the right face of $\underline{\mathbf{X}}$. The three-way data matrix $\underline{\mathbf{X}}$ can be unfolded into a two-way matrix $\mathbf{X}$. This unfolding is shown in the top of the figure for sample $i$ and for the entire cube in the bottom of Figure 2.2. The two-way matrix $\mathbf{X}$ is decomposed into scores vectors $\mathbf{t}$ and loads vectors $\mathbf{p}$ using traditional PCA (Jackson and Mudholkar 1979; Wold 1987). The unfolding shown in Figure 2.2 is one of two ways that guarantee that the scores will correspond to samples. Samples in the unfolded data matrix $\mathbf{X}$ are mean-centered and scaled, if appropriate, prior to the decomposition.

The goal of PCA is to decompose a matrix $\mathbf{X}$ into two parts, as shown in Equation 2.1. The first part is the product of the orthogonal matrix $\mathbf{T}$ and the orthonormal matrix $\mathbf{P}$, which contain the scores vectors $t$ and loadings vectors $p$, respectively. This portion contains primarily deterministic information contained in $\mathbf{X}$. The second part, $\mathbf{E}$, is a matrix that can be considered an 'error' term and includes primarily non-deterministic information contained in $\mathbf{X}$.

$$
\mathbf{X}=\sum_{\mathrm{r}=1}^{\mathrm{R}} \mathbf{t}_{\mathbf{r}} \mathbf{p}_{\mathbf{r}}^{\mathrm{T}}+\mathbf{E}=\mathbf{T} \mathbf{P}^{\mathrm{T}}+\mathbf{E}
$$

The scores can be considered linear combinations of the original variables, and the loadings describe how each original variable loads into the new linear combination. Since the signatures were mean-centered, TPT describes the major deviations from the mean.

Over 100 signatures have been measured since June 10, 1994. These signatures correspond to the pump operating at a speed of $1,000 \mathrm{rpm}$ for about 24 minutes. Other pump speeds and durations were not included in this analysis. A calibration set of 57 samples of 25 signatures each was arranged in a cube. These 57 samples corresponded to pump runs from September 13, 1994, through March 31, 1995. Pump operation procedures can be considered consistent throughout this period. Samples that corresponded to pump operations on consecutive days were not included to 


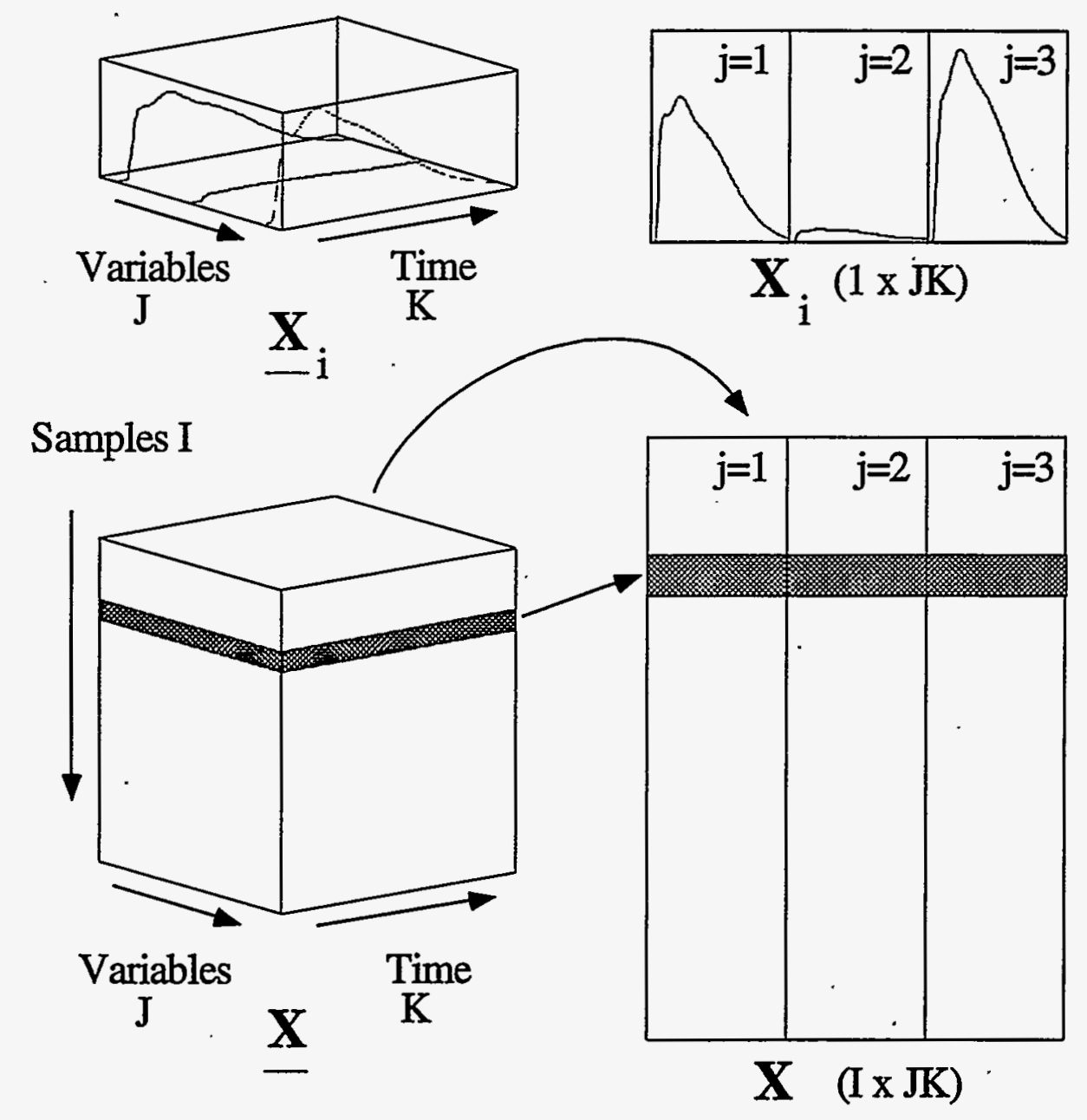

Figure 2.2. Process Dynamic Response Signatures for Sample $i$ (top) and for I Samples (bottom) (the unfolding of $\underline{\mathbf{X}}$ to $\mathbf{X}$ is shown from left to right)

avoid signature overlaps in the calibration set. Each signature was 280 time increments long, including nine increments just prior to pump operation that correspond to the baseline. Therefore the data cube $\underline{X}$ for gas signatures was 57 × 3 × 280, and for MIT 17B it was $57 \times 22 \times 280$.

PCA was performed on each unfolded matrix $\mathbf{X}$, and a principal components (PC) model of the calibration set was created for comparisons to future samples. Two sets of data were projected into the PC models of signatures created for the calibration data. The first set, Set 1 , covered the period prior to calibration, from June 10,1994 , to August 31, 1994. This represents a 'startup' period when pump operation procedures were variable. The second set, Set 2, covered the period after the calibration period, from April 1, 1995, through June 16, 1995. This set represents data from procedures similar to the calibration set and some data from procedures that were different from the calibration set. Set 2 contained 25 samples; the first 12 were obtained from pump operations similar to those performed during the period corresponding to the PC model calibration data. 
Pump operation procedures from April 1 through June 16, 1995, included incrementing the pump orientation $30^{\circ}$ after each run for six orientations of about $35^{\circ}, 65^{\circ}, 95^{\circ}, 125^{\circ}, 155^{\circ}$, and $185^{\circ}$. Starting on May 12,1995, pump runs were performed in additional orientations of about $15^{\circ}, 45^{\circ}, 75^{\circ}, 105^{\circ}, 145^{\circ}$, and $165^{\circ}$. This marks a change in operational procedures. The last 13 samples of Set 2 include 11 with operations in these 'off' orientations and one sample with an operation in a 'standard' orientation.

\subsection{Gas Release Signature Analysis}

Gas release signatures were referenced to their baseline, or background, values. Figure 2.3 shows the background concentration histories. Hydrogen and nitrous oxide background gas concentrations are highly variable and decreased slightly from June 1994 through June 1995. The ammonia baseline is less variable and appears to show a seasonal trend. Variation in background concentrations may be the result of spontaneous releases or diurnal trends raising the concentrations just prior to pump start.

PCA was performed on the 57 calibration samples of gas signatures. Three outliers were identified; one was an outlier for PCA of both the baseline and response signatures. For this sample there was a spontaneous gas release just prior to pump operation that resulted in a nonstandard signature. A five-PC model was created using the remaining 54 samples (i.e., $R=5$ in Equation 2.1). Table 2.1 lists variance information for analysis of the calibration set of samples. The table shows that the first two PCs describe the major portion of the variance in the gas signatures, and PCs 3 through 5 describe finer structure. Remaining PCs capture primarily random non-deterministic behavior in the data set.

Table 2.1. Variance Information for Principal Components

\begin{tabular}{|c|c|c|c||}
\hline $\begin{array}{c}\text { Principal } \\
\text { Component } \\
\text { Number }\end{array}$ & $\begin{array}{c}\text { Eigenvalue } \\
\text { of } \\
\text { Cov }(\mathbf{X})\end{array}$ & $\begin{array}{c}\text { \% Variance } \\
\text { Captured } \\
\text { this PC }\end{array}$ & $\begin{array}{c}\text { \% Variance } \\
\text { Captured } \\
\text { Total }\end{array}$ \\
\hline \hline 1 & 125,500 & 59.57 & 59.57 \\
\hline 2 & 48,432 & 22.99 & 82.56 \\
\hline 3 & 13,942 & 6.62 & 89.18 \\
\hline 4 & 8,982 & 4.26 & 93.44 \\
\hline 5 & 5,253 & 2.49 & 95.94 \\
\hline 6 & 2,422 & 1.15 & 97.09 \\
\hline 7 & 1,827 & 0.87 & 97.95 \\
\hline
\end{tabular}



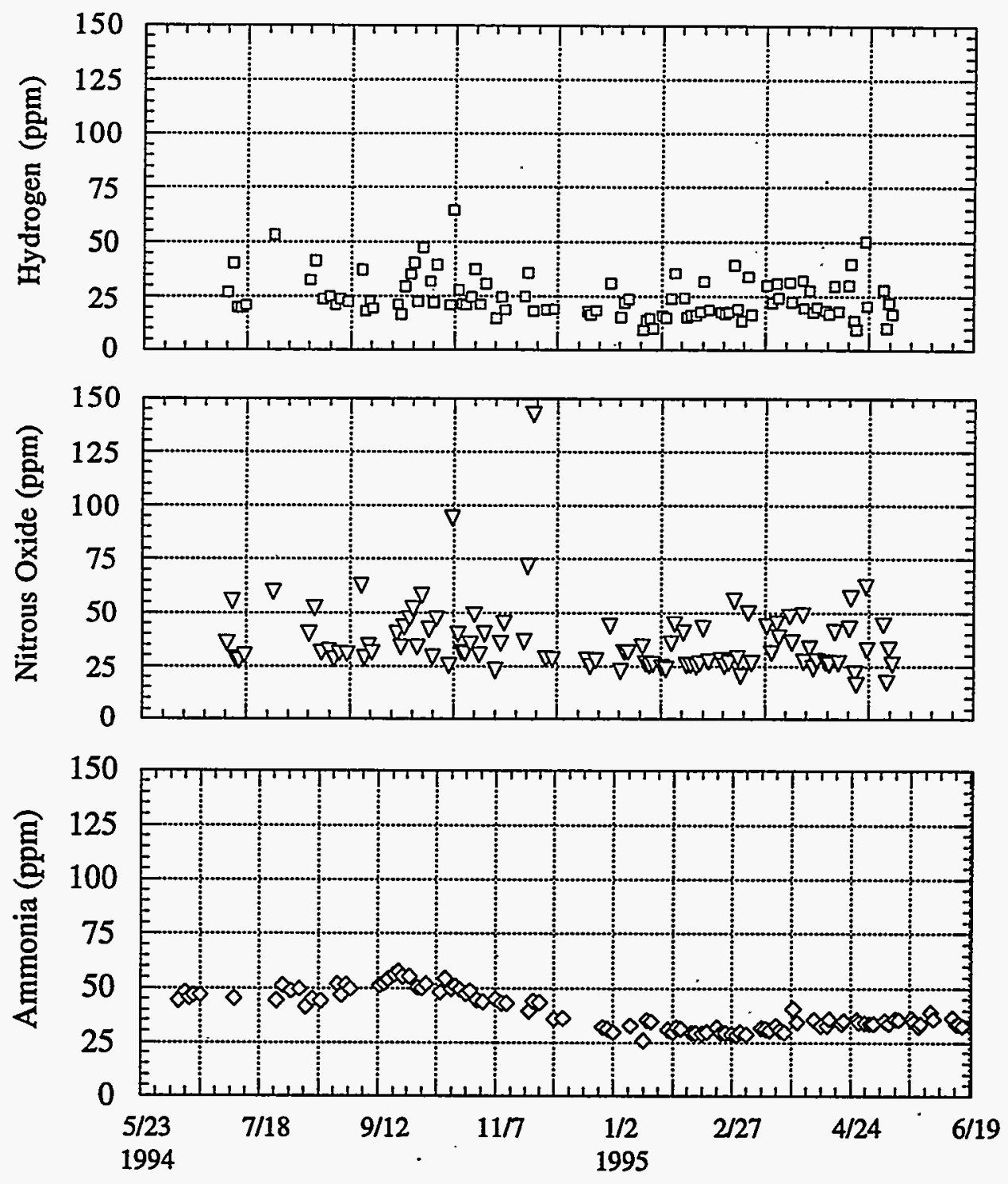

Figure 2.3. Background Concentration History

Two measures of how well samples (a sample is a set of three gas signatures) fit into the five-PC model are the $\mathrm{Q}$ residuals and $\mathrm{T}^{2}$ statistics. $\mathrm{Q}$ is a sum of squares of residuals and is a measure of variance not captured by the PC model. $T^{2}$ is a measure of variability within the PC model; it indicates the distance from the centroid of the data and is directly related to the F-distribution. These statistics are plotted in Figure 2.4. The horizontal dashed line is the 95\% confidence limit assuming normally distributed data. Filled symbols represent the calibration data, and open circles represent data projected into the model. 


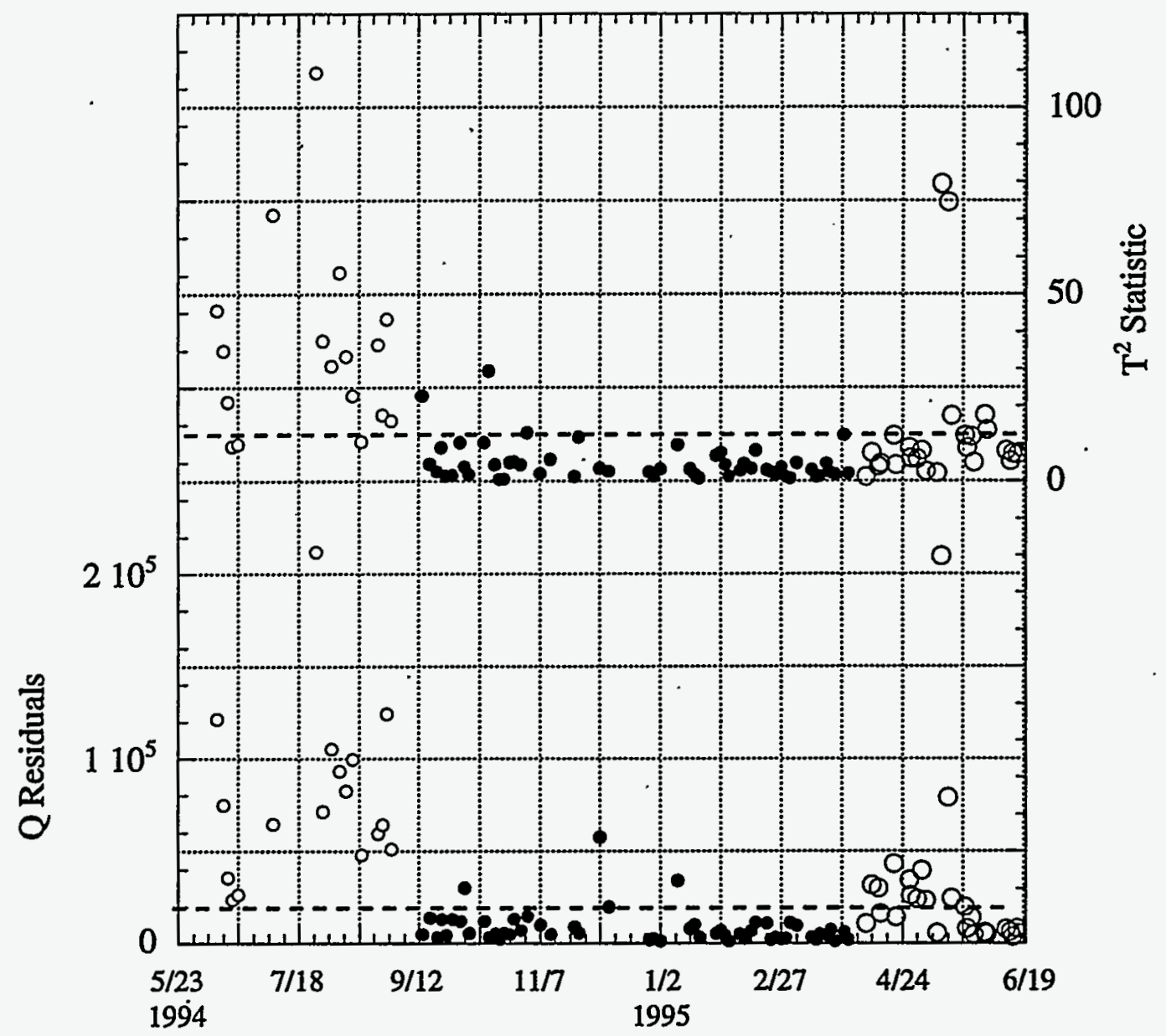

Figure 2.4. Gas Signature Statistics

The $Q$ residuals and $\mathrm{T}^{2}$ for the startup period in Figure 2.4 are generally outside the $95 \%$ confidence limit, indicating that samples from this period are statistically different from the calibration set. Inspection of gas signatures and temperature profiles measured by MIT 17B indicates the waste distribution or the state of the system was different during this early period. Pump operations in the startup period were significantly different from those used in the calibration period. Figure 2.4 gives a clear indication that the pump-induced gas signatures in the startup set are different from the calibration set and gives a statistical basis to identify changes in signatures for future samples, such as those in Set 2.

The first samples from Set 2 projected into the PC model in Figure 2.4 are generally consistent with the calibration data, although they have slightly higher $Q$ residuals and $T^{2}$. This suggests that signature shapes were drifting from that described by the PC model. The first two 
pump operations at 'off' orientations on May 12 and 15, 1995, yield very high residuals and T2, indicating that these two samples are significantly different from the calibration data. Samples taken after this point have generally low residuals and $T^{2}$, suggesting that these gas release signatures are similar to those in the calibration set.

Figure 2.5 shows the loadings (p) for the first three PCs. The first PC, which captures nearly $60 \%$ of the variance in the calibration data set, is representative of major deviations from the average gas signature. Positive scores ( $t$ ) on PC 1 indicate more gas release than the mean. PCs 2 and 3 describe major variations in peak shape from the mean. Signatures with a positive score on PC 2 have gas releases occurring at earlier times, and a high score on PC 3 indicates gas release at the ends of the peak at the expense of middle times.

The scores for the first three PCs are shown in Figure 2.6. Filled symbols are for the calibration data, and open circles are for data projected into the model. Scores on PC 1 generally decrease with time. This trend suggests that the gas release has decreased with time and appears to have leveled off at a lower level. The exceptions are the first two pump operations at off-angles May 12 and 15, 1995, which have high scores and high gas releases. Scores on PC 2 generally decreased until early May, 1995 . This indicates that gas release signatures were gradually shifting to later times. After the first pump operation at an 'off' orientation scores on PC 2 are generally high, suggesting that the change in pump operation shifted the gas release peak shape to earlier times. A possible explanation is a change in the released bubble size distribution (see Section 6.3). Scores on PC 3 generally show normal variation about zero; however, the first two samples at 'off' orientations are slightly higher than the majority of the samples.

If the scores on the first PC are sorted by pump orientation, they can provide information about the azimuthal uniformity of the waste. Figure 2.7 shows scores on PC 1 for the calibration data set as a function of pump orientation. Also included are the first 12 samples of Set 2 that correspond to samples prior to pump operations at 'off' orientations. Open circles represent the calibration data, and filled symbols are for data projected into the model. Samples from Set 1 are significantly different from the calibration set and were not included. There were too few samples after 'off' orientations were pumped to draw meaningful conclusions. There is quite a bit of variability, but scores on $\mathrm{PC} 1$ at pump orientations of $95^{\circ}$ are generally highest, and scores at $125^{\circ}$ are generally lowest, suggesting that there is slightly more gas release at $95^{\circ}$ than at $125^{\circ}$. There is also a definite sinusoidal pattern, as shown by the curve fit (dashed line). This may indicate that the slight differences in scores are due to the pump being installed off-center, creating different circulation patterns at the various angles.

The foregoing analysis of gas release signatures identified that gas signatures have changed over time and with the pump operation schedule. Signatures are clearly different for pump operations in the startup period than for the calibration data. Pump-induced gas releases have decreased, and the shapes of the gas release signatures have been shifting to later times until 'off' orientations began, at which time the signatures shifted back to earlier times. Gas release signatures are also a function of nozzle orientation. This could be attributed to the pump being installed off-center. 

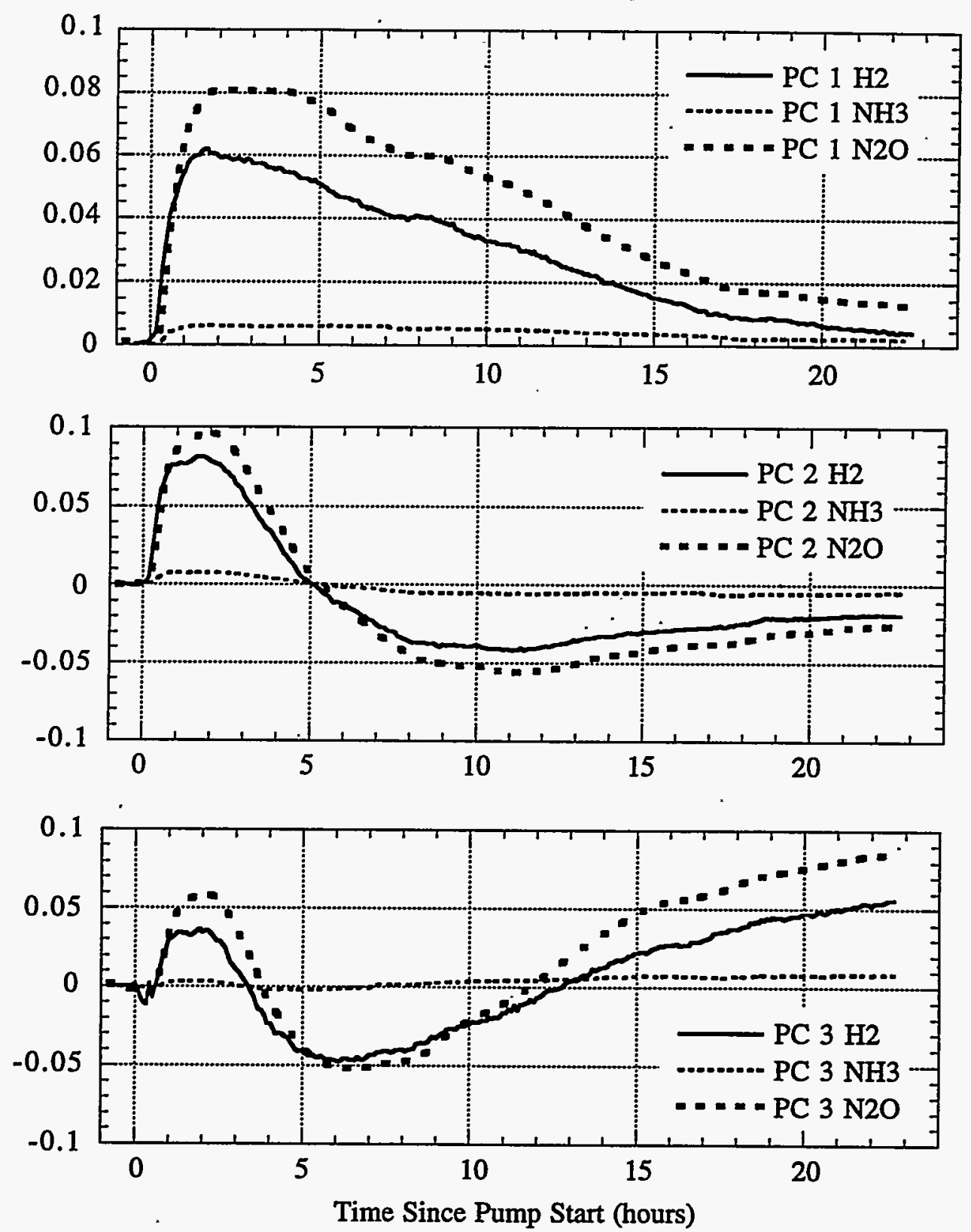

Figure 2.5. Loadings for the First Three PCs 

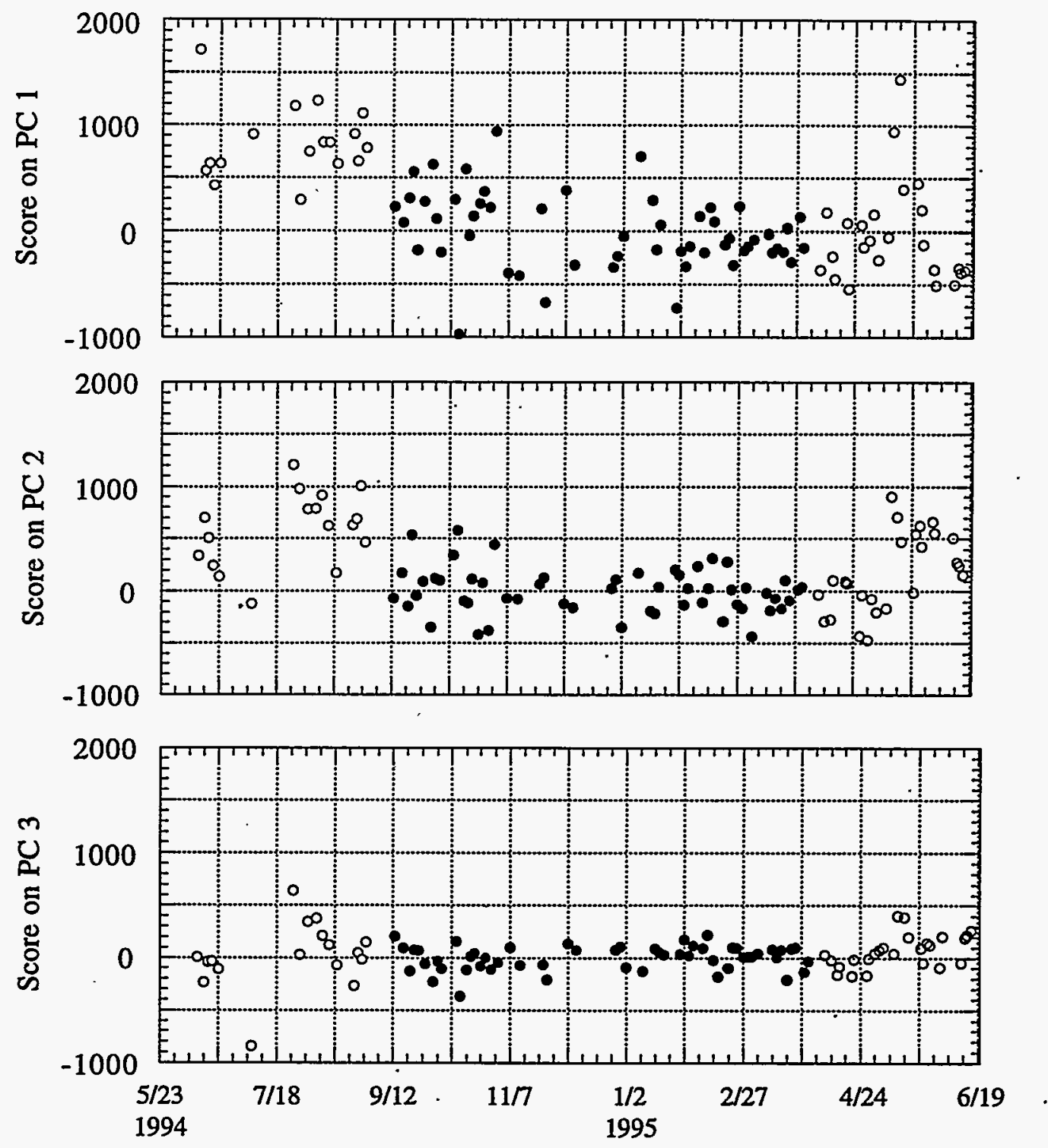

Figure 2.6. Scores on First Three PCs 


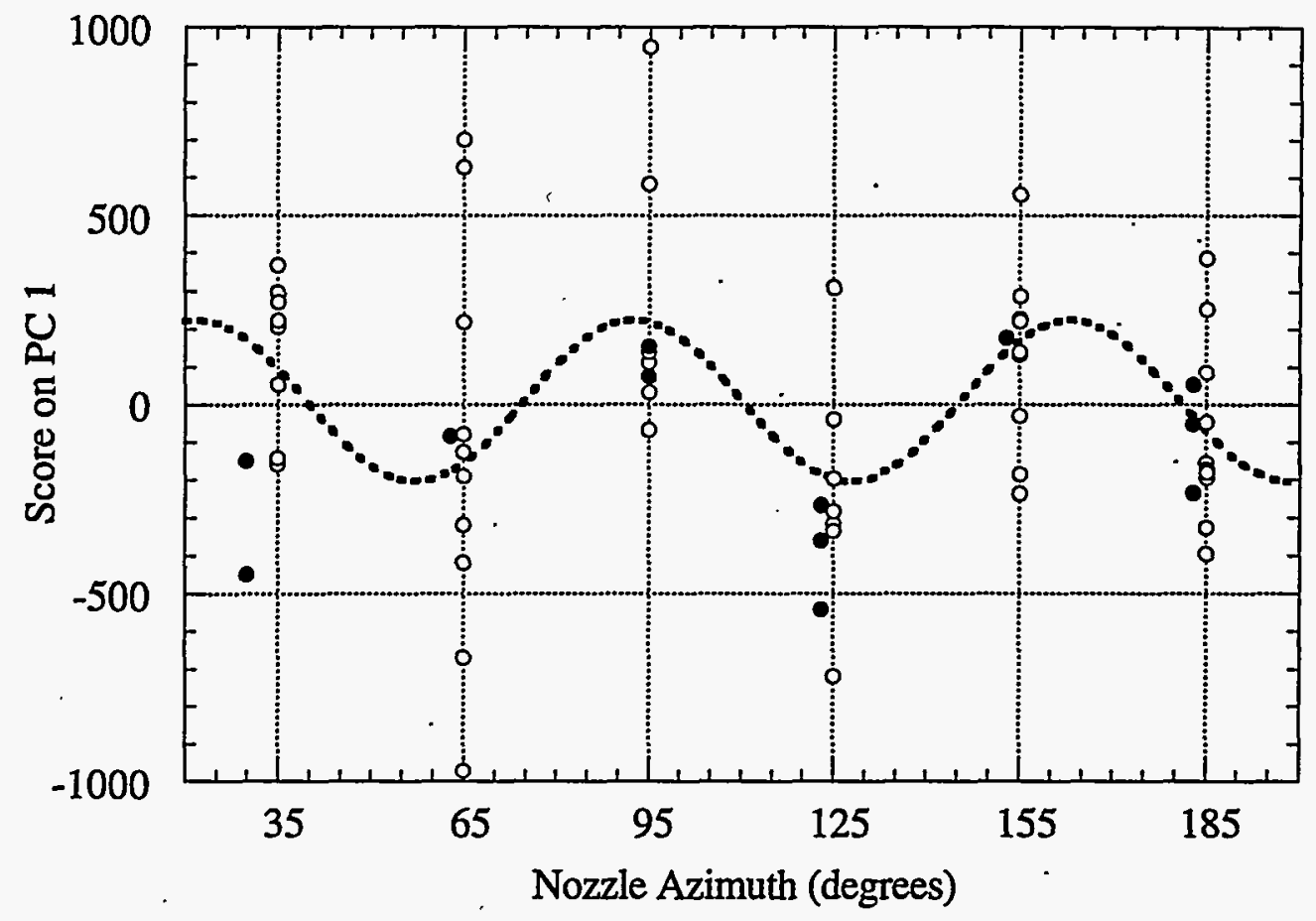

Figure 2.7. Scores on PC 1 Versus Nozzle Azimuth

\subsection{MIT 17B Temperature Signature Analysis}

For each pump operation an MIT 17B signature consists of 22 measured dynamic temperature responses corresponding to thermocouples at different vertical locations and 280 time increments. These temperature signatures were referenced to their baseline profiles to focus the analysis on small changes in temperature as a result of pump operation. PCA was performed for baseline temperature profiles to identify systematic changes in baseline temperature measurements, and MPCA was performed for baseline-referenced signatures to identify systematic changes in dynamic thermocouple responses.

\subsubsection{Principal Components Analysis of Baseline Temperatures}

Baseline thermocouple temperatures are the average of measurements just prior to pump initiation. Figure 2.8 shows the mean baseline profile for the calibration data set. Thermocouples 1 through 3 are thought to be located in a loosely settled nonconvective solids layer near the bottom of the tank. Thermocouples 4 through 19 are located in the convective slurry, and thermocouples 20 through 22 are in the floating crust layer. 


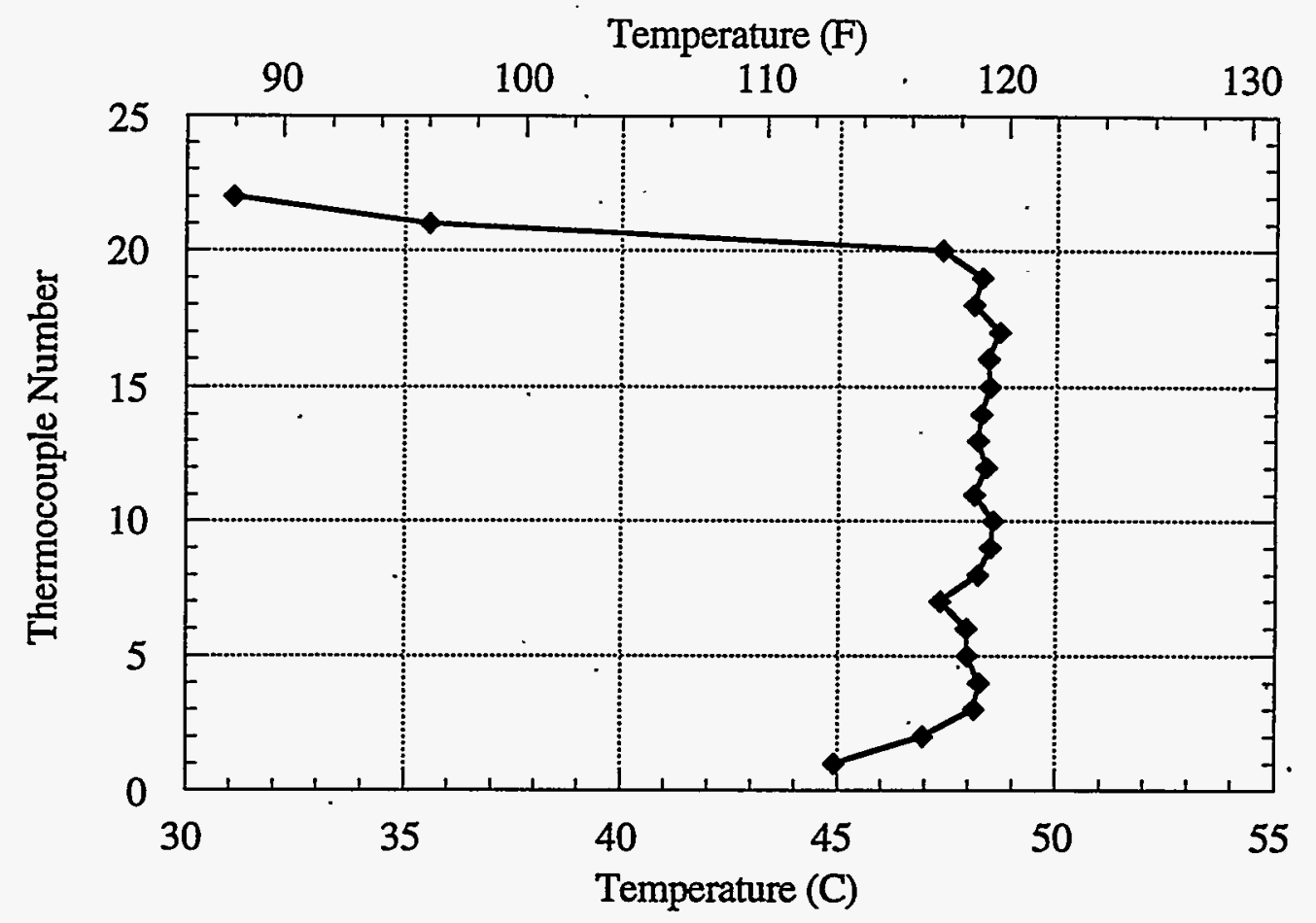

Figure 2.8. Mean Baseline Temperature Profile

PCA identified one sample as an outlier, and a PC model was created from the remaining 56 baseline profiles in the calibration data set. Table 2.2 lists the variance information for the. analysis. Only two PCs were kept to model the calibration data, since these describe the major portion of the variance of the baseline profiles. Figure 2.9 plots residuals and variability statistics, $\mathrm{Q}$ and $\mathrm{T}^{2}$, with $95 \%$ confidence limits. Horizontal dashed lines are the $95 \%$ confidence limits.

Filled symbols are for the calibration data, and open symbols are for data projected into the model.

Table 2.2. Variance Captured By First Five PCs

\begin{tabular}{||c|c|c|c||}
\hline $\begin{array}{c}\text { Principal } \\
\text { Component } \\
\text { Number }\end{array}$ & $\begin{array}{c}\text { Eigenvalue } \\
\text { of } \\
\text { Cov }(\mathbf{X})\end{array}$ & $\begin{array}{c}\text { \% Variance } \\
\text { Captured } \\
\text { this PC }\end{array}$ & $\begin{array}{c}\text { \% Variance } \\
\text { Captured } \\
\text { Total }\end{array}$ \\
\hline \hline 1 & 77.9 & 79.97 & 79.97 \\
\hline 2 & 18.9 & 13.34 & 99.31 \\
\hline 3 & 0.25 & 0.26 & 99.56 \\
\hline 4 & 0.19 & 0.20 & 99.76 \\
\hline 5 & 0.08 & 0.08 & 99.84 \\
\hline
\end{tabular}




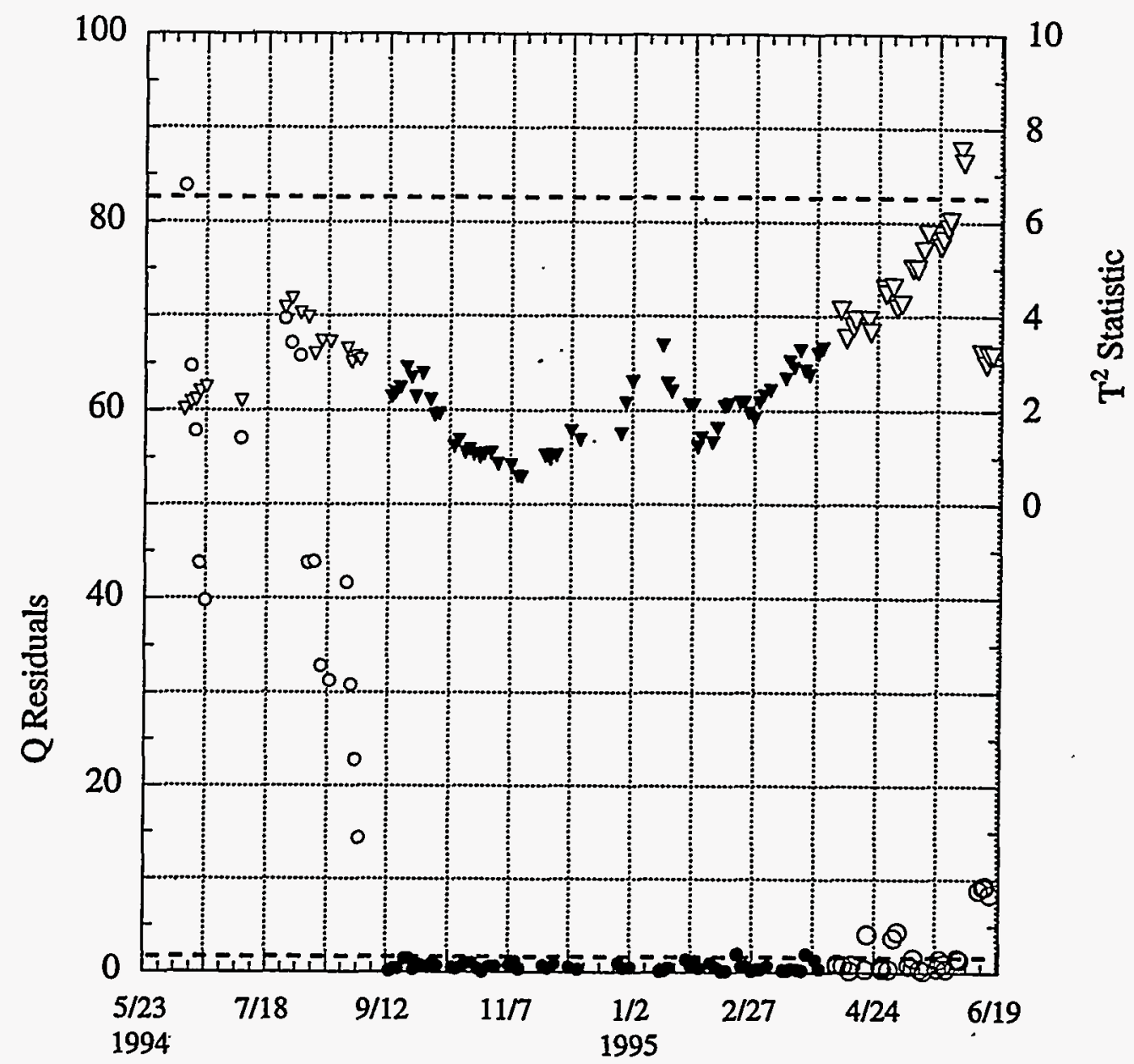

Figure 2.9. $Q$ Residuals and $T^{2}$ Statistics for Baseline Temperatures

The $Q$ residuals indicate that the data from Set 1 are significantly different from the calibration set. In fact, this difference has been identified as a change in the overall profile (Section 4.1). The trend in $\mathrm{T}^{2}$ might be a result of a seasonal variation. The last four samples show a high residual and significant change in the trend in $\mathrm{T}^{2}$. Modifications were made to data acquisition software just prior to these samples, and a door to a cabinet was left ajar allowing cooling air to affect the thermocouple reference junction. This caused very noisy temperature readings for these four samples that can be identified relatively easily by inspecting Figure 2.9 .

Figure 2.10 shows loadings for PCs 1 and 2. PC 1 , which captures nearly $80 \%$ of the variance in the calibration data set, is representative of major deviations from the mean temperature profile. Positive scores on PC 1 indicate a general heating of the tank with respect to the mean profile with a relatively high influence at the surface of the waste. Positive scores on PC 2 describe heating in the dome space relative to the bulk of the waste. 


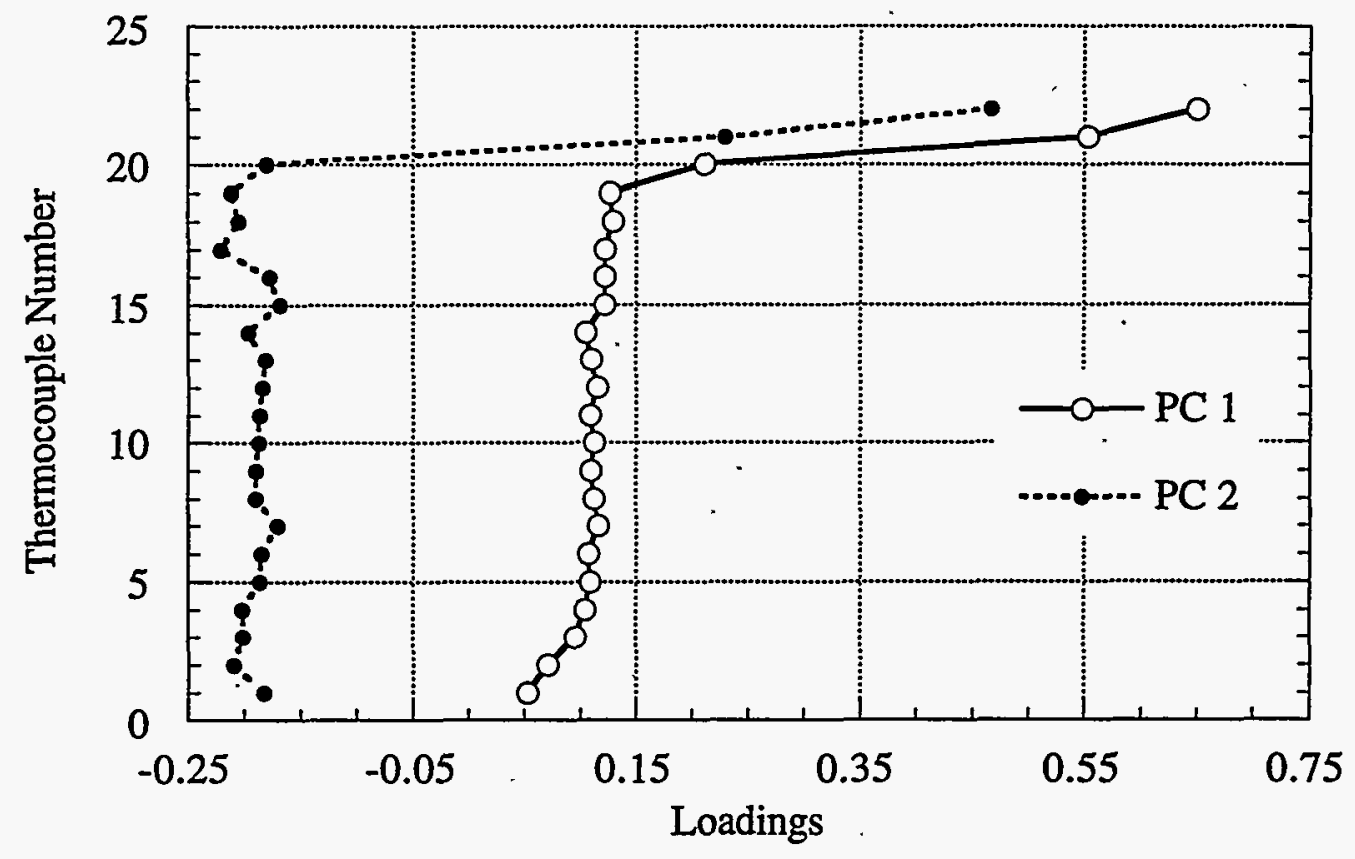

Figure 2.10. Loadings for PCs 1 and 2 for Baseline Temperature Profiles

Figure 2.11 shows the scores on PCs 1 and 2. Filled symbols represent the calibration data, and open symbols represent data projected into the model. Both PCs are apparently capturing primarily seasonal temperature variations. Scores on PC 1 have a maximum at the end of summer (September), decrease through the winter, and have a minimum some time in March. Scores on PC 2 indicate that the behavior described by PC 2 leads that described by PC 1 . This makes sense because PC 2 describes a relative heating of the dome space compared to the bulk of the waste, and the dome space temperature responds faster to ambient conditions. Including seasonal variation as a part of the model of normal variation allows a reasonable method for monitoring and identifying non-standard temperature profiles. The abrupt change on February 17, 1995, is due to an unexplained calibration shift of about $2^{\circ} \mathrm{F}$ that occurred following a power outage.

\subsubsection{Principal Components Analysis of MIT 17B Response Signatures}

The previous section described the behavior of the baseline, or background, temperatures that are measured immediately prior to a pump run. Temperature signatures are the departure of each thermocouple reading from the baseline for the 24-hour period following pump start. This subsection describes PCA of MIT 17B signatures. 


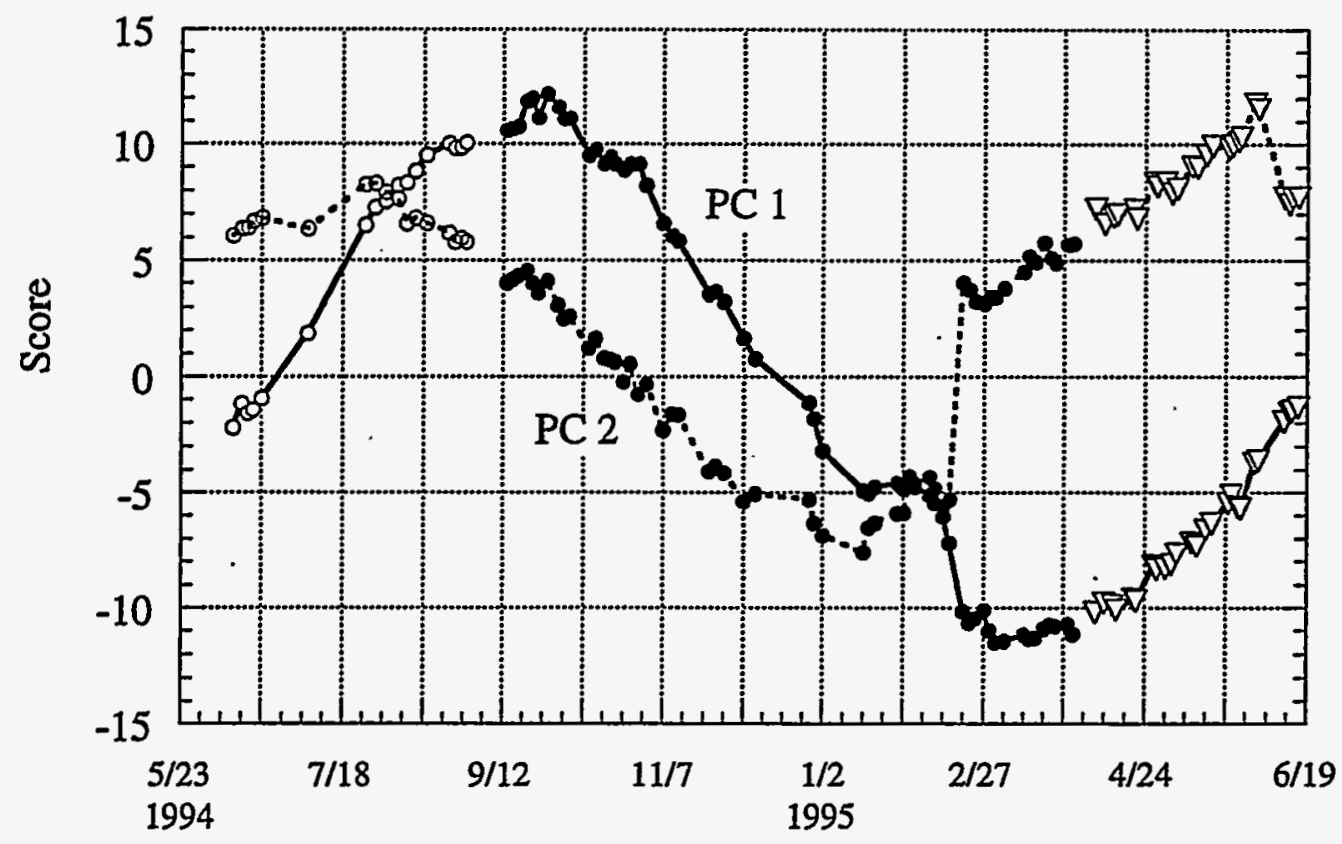

Figure 2.11. Scores on PC 1 and 2 for Baseline Temperature Profiles

The analysis identified two outliers. These samples were removed, and a model was created for the remaining 55 samples in the calibration set. In the analysis of the baseline profiles discussed previously, Figure 2.8 showed the mean temperature profile. Analogously, Figure 2.12 shows the mean MIT 17B signature (dynamic response) resulting from pump operation. The PC model describes variance from this mean signature. If the calibration shift noted on February 17, 1995, in Figure 2.11 was the same for all the thermocouples, referencing to the baseline effectively removes the calibration shifts from the signatures and focuses the analysis on effects due primarily to pump operation.

The mean signature in Figure 2.12 shows that thermocouples 2, 3, and 4, near the bottom of the tank, and 18,19, and 20 , just below the crust, heat up due to pump operation more than thermocouples 5 through 17 , which are in the mixed slurry. This suggests that warmer slurry in the middle of the tank is drawn into the pump inlet and transferred to the bottom of the tank. The waste surface also warms, probably due to forced convection of warmer slurry to the surface. Table 2.3 lists the variance information for the first five PCs. The first three PCs, which capture over $76 \%$ of the variance, were retained in the model. 


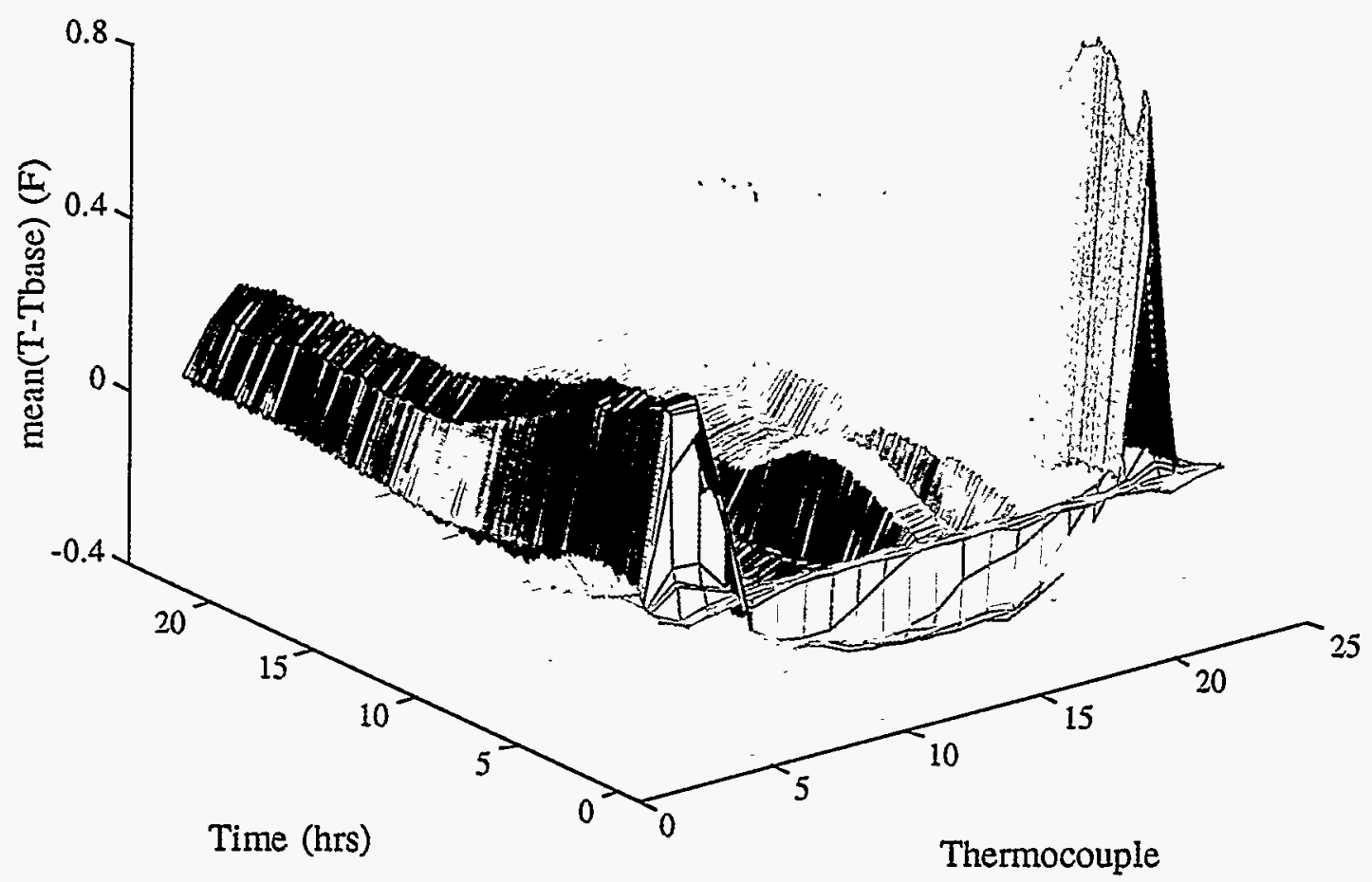

Figure 2.12. Mean MIT-17B Temperature Signature

Table 2.3. Variance Captured by First Five PCs

\begin{tabular}{|c|c|c|c||}
\hline $\begin{array}{c}\text { Principal } \\
\text { Component } \\
\text { Number }\end{array}$ & $\begin{array}{c}\text { Eigenvalue } \\
\text { of } \\
\text { Cov (X) }\end{array}$ & $\begin{array}{c}\text { \% Variance } \\
\text { Captured } \\
\text { this PC }\end{array}$ & $\begin{array}{c}\text { \% Variance } \\
\text { Captured } \\
\text { Total }\end{array}$ \\
\hline \hline 1 & 211.2 & 52.73 & 52.73 \\
\hline 2 & 62.4 & 15.78 & 68.31 \\
\hline 3 & 32.7 & 8.17 & 76.48 \\
\hline 4 & 18.4 & 4.58 & 81.07 \\
\hline 5 & 16.48 & 4.12 & 85.18 \\
\hline
\end{tabular}


Figure 2.13 shows trends of the residuals and variability statistic, $Q$ and $T^{2}$, with $95 \%$ confidence limits for MIT-17B signatures. The $Q$ residuals are high for Set 1 (the startup period) suggesting that these samples are statistically different from the calibration set. This is probably because of the difference in the waste configuration. The last 10 samples of Set 2 projected into the model are showing a trend toward higher $Q$. The three samples prior to these last 10 corresponded to the first three pump operations at 'off' orientations. The changing dynamic response of MIT 17B (changing signatures) may be a result of a redistribution of the waste.

Since the PCs are matrixes it is difficult to show (even in three dimensions) the behavior captured by each. As a result ,Table 2.4 gives general descriptions for loadings of the first three PCs. For example, the first PC, which captures over 52\% of the variance in the data set, is representative of major deviations from the mean temperature signature shown in Figure 2.13. In general, positive scores on PC 1 indicate heating of thermocouples $1,2,3$, and 20 relative to all others.

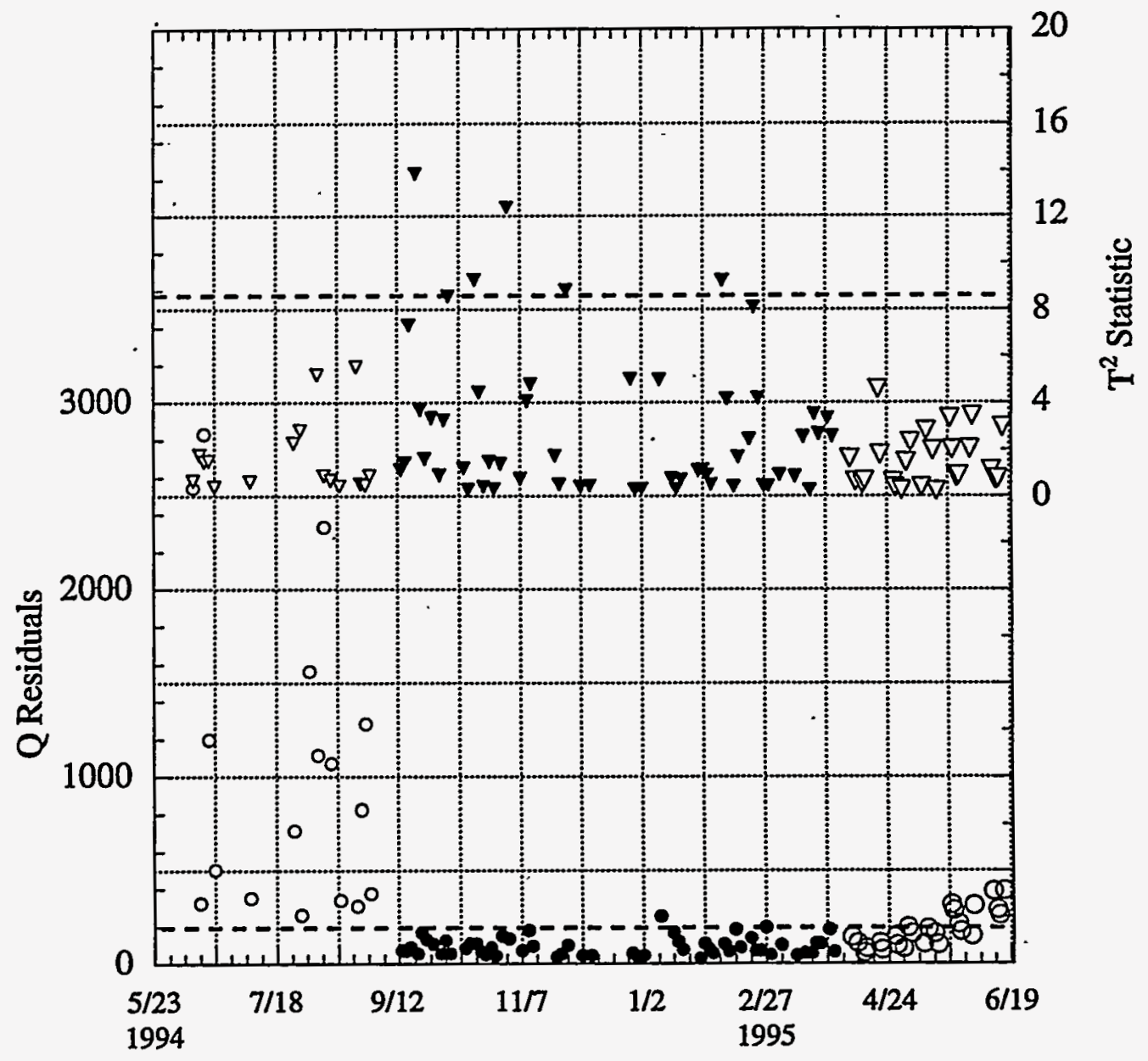

Figure 2.13. $\mathrm{Q}$ and $\mathrm{T}^{2}$ with $95 \%$ Confidence Limits for MIT-17B Signatures 
No significant trends were noted in the scores; however, scores on PC 1 did show a significant trend with pump orientation. Figure 2.14 shows scores on PC 1 as a function of pump orientation. The calibration set is plotted with open symbols, and samples from 'off angle' runs are plotted with closed symbols. Samples from Set 1 are significantly different from the calibration set and were not included in Figure 2.14. Scores on PC 1 are generally higher for operations in the 95-degree orientation since one of two opposed nozzles is aimed directly at MIT 17B in this orientation.

Pump runs in directions in which the nozzle is not aimed directly at MIT 17B affect the thermocouple responses to an increasingly lesser extent. There is a negligible effect beyond $155^{\circ}$ $\left(60^{\circ}\right.$ difference), even when the nozzle approaches within $15^{\circ}$ on the opposite side. This is probably the result of solids settling out during the two-week period required for a tank sweep. The jet is more able to move the waste in the region is was aimed at only one or two days before than in the region that has had two weeks to settle.

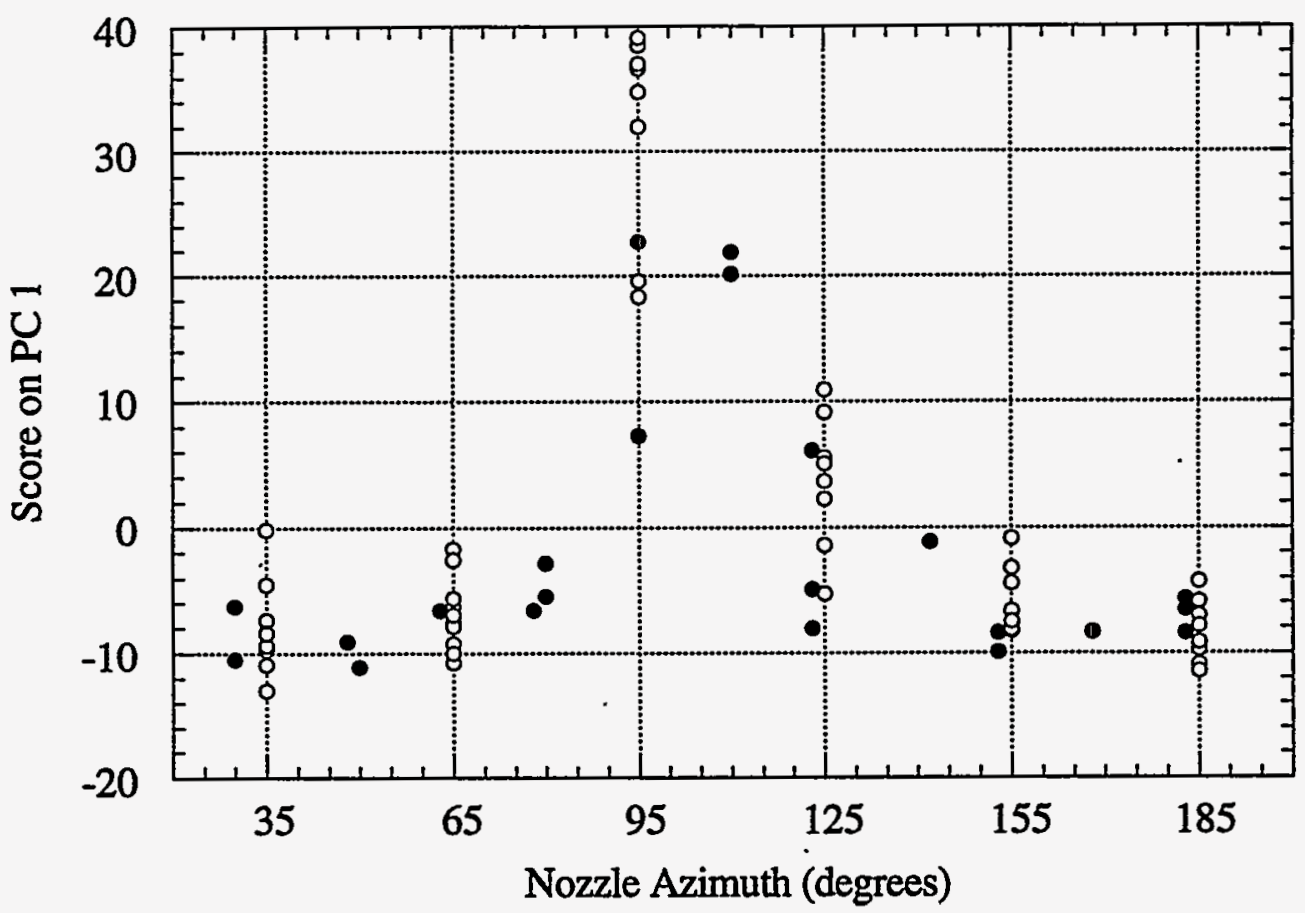

Figure 2.14. Scores on PC 1 for MIT 17B Signatures as a Function of Pump Orientation 


\subsection{Waste Level}

The measurement of waste surface level in Tank $241-S Y-101$ is accomplished by the Food Instrument Corporation (FIC) contact probe in riser $1 \mathrm{C}$, the Enraf-Nonius ${ }^{\otimes}$ radar gauge in 13A, the manual tape in $17 \mathrm{~A}$, and the Enraf buoyancy gauge in $1 \mathrm{~A}$. These instruments report different values and respond differently to gas releases. The readings of each gauge from January 1, 1994, to July 17, 1995, are shown in Figure 3.1. The differences are mainly due to the irregularity of the crust surface. The in-tank video indicates surface features several inches high.

Measurement differences also arise from the method of measurement. The FIC and manual tape must be flushed occasionally to remove accumulated deposits. In-tank video shows that flushing has dissolved or eroded the crust in the vicinity of the FIC, and repeated contact with the waste has excavated a distinct cavity that appears to be several centimeters deep. The manual tape also reads low for the same reasons. The radar gauge tends to be very erratic, and it is unclear whether it is indicating the height of the waste surface or some related quantity sensitive to surface moisture. The Enraf buoyancy gauge does not depend on electrical contact and merely sits stationary on the waste surface. Thus it is potentially the most accurate and reliable surface level indicator.

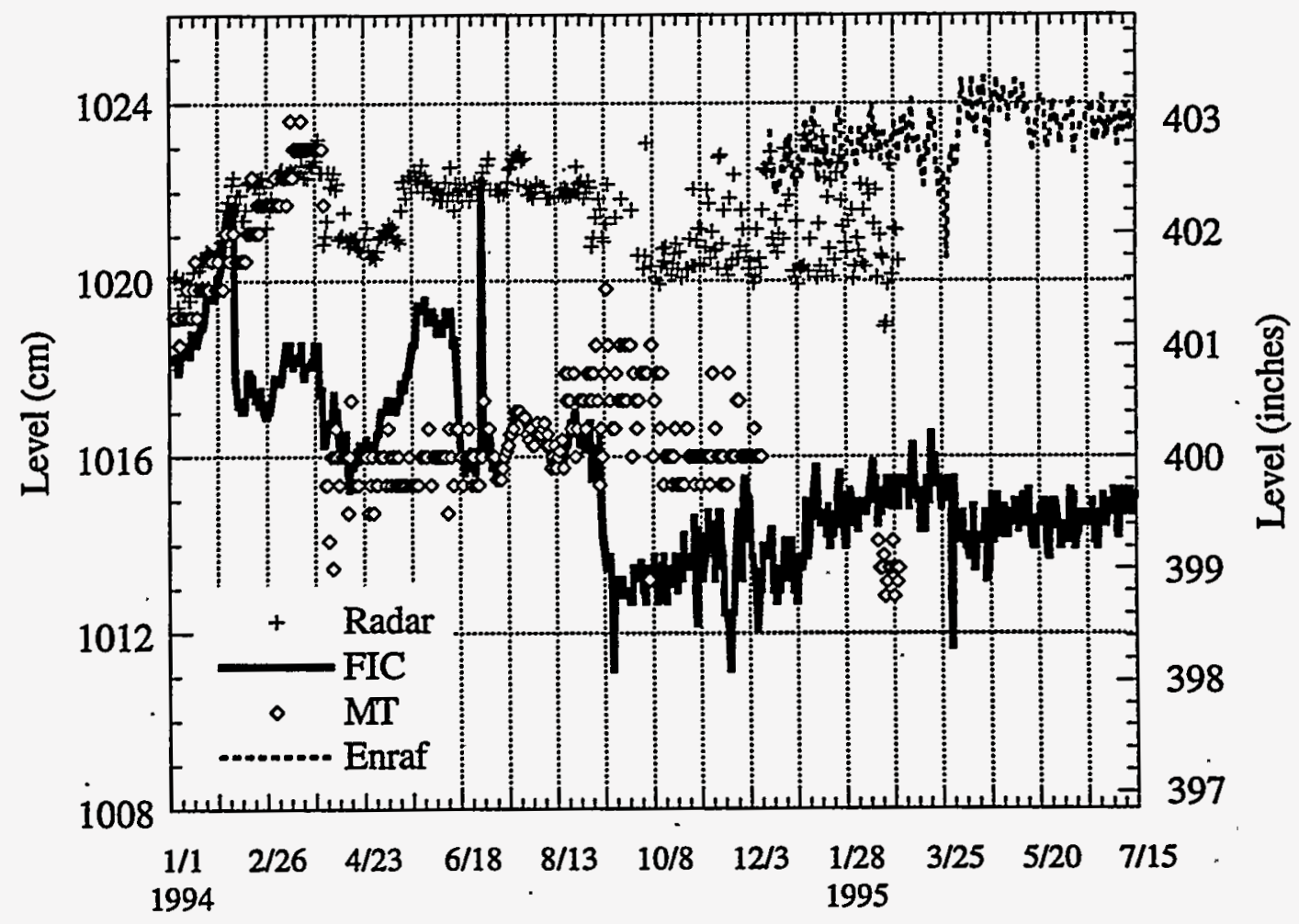

Figure 3.1. Waste Level History in Tank 241-SY-101 
Since waste level is used as the main indicator of retained gas volume and potential prompt release volume in the mixer pump safety assessment, resolving the different readings is critical to mitigation operations and potential pump replacement. Specifically, the FIC has been made the basis for evaluating controls in the mixer pump safety assessment (Sullivan 1995). In this report we have evaluated the instruments.by two methods: .1) correlating each gauge with the others and 2) correlating each gauge with gas release using a linear model.

The results of this study show that the Enraf is potenitially the most precise and accurate level instrument. The FIC responds closely with the Enraf and correlates with gas release reasonably well. There is no clear evidence that it is indicating liquid level instead of surface level. The radar gauge was reasonably accurate but highly erratic and is no longer providing useful level data. The manual tape appears to be uncorrelated with any of the other instruments or with gas release, and its readings should not be used to evaluate controls.

\subsection{Correlation of Level with Gas Release}

As a first-order approximation, the change in surface level over a specific time period is related to the volume of gas generated and released in that period by the linear function

$$
\Delta \mathrm{L}=\frac{\mathrm{G}-\mathrm{R}}{\mathrm{AP}_{\mathrm{i}}}
$$

where $P_{i}$ is the hydrostatic pressure, in atmospheres, at the average elevation from which the gas is released; $G$ is the volume of gas generated; $R$ is the volume of gas released; and $A$ is the waste surface area.

This model considers only the effect of net gas release. It ignores level changes in response to atmospheric pressure variation, which can exceed $1 \mathrm{~cm}(1 / 2 \mathrm{in}$.). However, since gas release is not correlated with pressure changes, this will only affect the standard deviation, not the accuracy. Figure 3.2 compares the model of Equation (3.1) to FIC data. Adjusting the parameters for a good visual fit to the FIC history has placed the generation rate at $2.9 \mathrm{~m}^{3 / 2} \mathrm{day}(102.5 \mathrm{SCF} / \mathrm{d})$ and the pressure at $2.4 \mathrm{~atm}$. This indicates that, although most of the gas is stored at closer to $1 \mathrm{~atm}$ (see Sections 4 and 5), that which is released as a result of pump operation and the background gas release comes from the bottom of the mixed slurry layer.

The actual correlation of the model and FIC and Enraf data for the second quarter of 1995 is shown in Figure 3.3, and the statistical parameters of correlation for each instrument during the first two quarters of 1995 are given in Table 3.1. The daily level change is taken as the difference between first shift readings (the actual time of reading is not recorded but is assigned a time of 2:00 a.m.). The corresponding daily gas release is calculated from midnight by integrating the product of hydrogen concentration and vent flow rate, assuming the waste gas is $29 \%$ hydrogen (see Section 1).

It is clear from the figure that the FIC and Enraf both correlate reasonably well with gas release. The calculated gas generation rates match the visual fit from Figure 3.2 within the 


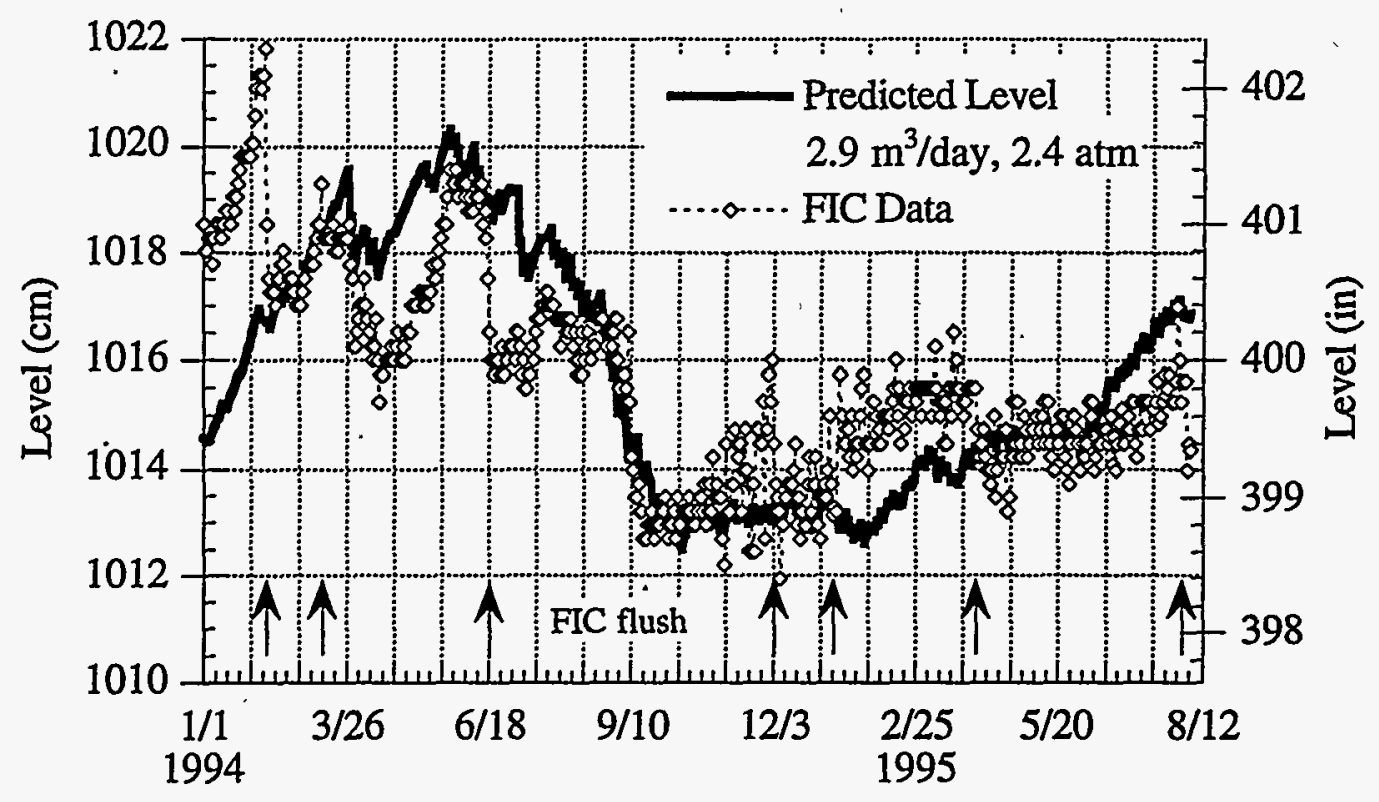

Figure 3.2. Comparison of Linear Model and FIC Data

uncertainty of the calculation, but the average gas retention pressure from the correlation is much lower. There is currently no physical explanation for the low gas retention pressure except that it is likely an artifact of the simple linear fit rather than waste behavior. The manual tape does not correlate with gas release.

Table 3.1. Correlation of Level Change and Gas Release

\begin{tabular}{|c|c|c|c|c|c|c|c|c|}
\hline & \multicolumn{2}{|c|}{$\begin{array}{l}\text { Correlation } \\
\text { Coefficient. }\end{array}$} & \multicolumn{2}{|c|}{$\begin{array}{l}\text { Standard Deviation } \\
\mathrm{cm} \text { (in.) }\end{array}$} & \multicolumn{2}{|c|}{$\begin{array}{c}\text { Gas Generation Rate } \\
\mathrm{m}^{3} \text { (SCF/day) }\end{array}$} & \multicolumn{2}{|c|}{$\begin{array}{c}\text { Average Gas } \\
\text { Pressure (atm) }\end{array}$} \\
\hline & $\begin{array}{c}\text { First } \\
\text { Quarter }\end{array}$ & $\begin{array}{l}\text { Second } \\
\text { Quarter }\end{array}$ & $\begin{array}{c}\text { First } \\
\text { Quarter }\end{array}$ & $\begin{array}{l}\text { Second } \\
\text { Quarter }\end{array}$ & $\begin{array}{l}\text { First } \\
\text { Quarter }\end{array}$ & $\begin{array}{l}\text { Second } \\
\text { Quarter }\end{array}$ & $\begin{array}{l}\text { First } \\
\text { Quarter }\end{array}$ & $\begin{array}{l}\text { Second } \\
\text { Quarter }\end{array}$ \\
\hline FIC & 0.45 & 0.61 & $\begin{array}{c}0.51 \\
(0.20)\end{array}$ & $\begin{array}{c}0.66 \\
(0.26)\end{array}$ & $\begin{array}{l}2.63 \\
(93)\end{array}$ & $\begin{array}{c}2.79 \\
(98.5)\end{array}$ & 1.3 & 1.0 \\
\hline Enraf & 0.53 & 0.75 & $\begin{array}{c}0.43 \\
(0.17)\end{array}$ & $\begin{array}{c}0.61 \\
(0.24)\end{array}$ & $\begin{array}{l}2.78 \\
(98)\end{array}$ & $\begin{array}{c}2.81 \\
(99.2)\end{array}$ & 1.3 & 1.0 \\
\hline
\end{tabular}




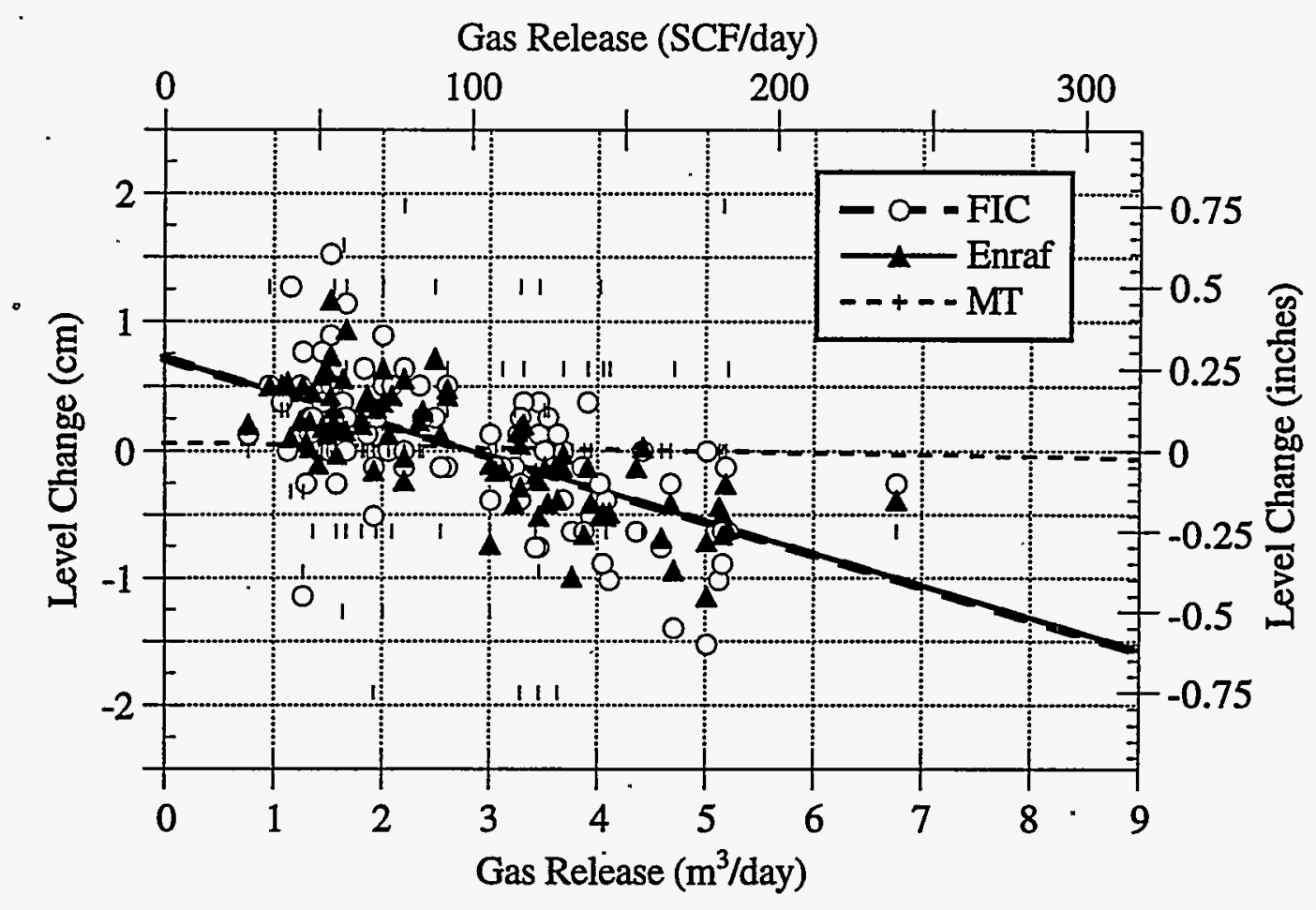

Figure 3.3. Level Change Versus Gas Release, 3/16/95-6/14/95

\subsection{Intercorrelation of Level Instruments}

The correlations of the three available instruments with one another are given in Table 3.2. Values are given for the second quarter and the first half of 1995. In making the correlation from available data recorded manually each shift, outliers were identified graphically and removed. A common source of error was in transcribing the Enraf measurement (i.e., a "402" reading is transcribed as "412"). The average and standard deviations of the difference of a pair of measurements between two instruments were obtained. Then the standard deviation was compared with the probable error if the instruments were independent. The probable error is calculated as the rms value of the standard deviations of the pair of level instruments (i.e., FIC and Enraf), calculated separately.

The Enraf-FIC pair are by far the best correlated, while the manual tape does not correlate well with either. Data from the second quarter of 1995 indicated that the FIC reading in centimeters can be predicted at the $95 \%$ confidence level from the Enraf measurement with this equation: FIC $=$ Enraf $-8.84 \pm 1.63 \mathrm{~cm}$ (FIC = Enraf $-3.48 \pm 0.64 \mathrm{in}$.). 
Table 3.2. Correlation of Level Measuring Instruments - 1995

\begin{tabular}{|c|c|c|c|c|c|c|}
\hline \multirow[b]{2}{*}{ Parameter } & \multicolumn{2}{|c|}{ Enraf-FIC, $\mathrm{cm}$ (in.) } & \multicolumn{2}{|c|}{ Enraf-MT, cm (in.) } & \multicolumn{2}{|c|}{ FIC-MT, cm (in.) } \\
\hline & $\begin{array}{l}\text { Second } \\
\text { quarter }\end{array}$ & First half & $\begin{array}{l}\text { Second } \\
\text { quarter }\end{array}$ & First half. & $\begin{array}{l}\text { Second } \\
\text { quarter }\end{array}$ & First half \\
\hline $\begin{array}{l}\text { Average } \\
\text { difference }\end{array}$ & $\begin{array}{c}8.84 \\
(3.48)\end{array}$ & $\begin{array}{c}8.66 \\
(3.41)\end{array}$ & $\begin{array}{c}8.71 \\
(3.43)\end{array}$ & $\begin{array}{c}8.89 \\
(3.50)\end{array}$ & $\begin{array}{c}-0.13 \\
(-0.05)\end{array}$ & $\begin{array}{c}0.28 \\
(0.11)\end{array}$ \\
\hline $\begin{array}{l}\text { Standard } \\
\text { deviation of } \\
\text { difference }\end{array}$ & $\begin{array}{c}0.81 \\
(0.32)\end{array}$ & $\begin{array}{c}0.79 \\
(0.31)\end{array}$ & $\begin{array}{c}0.71 \\
(0.28)\end{array}$ & $\begin{array}{c}0.81 \\
(0.32)\end{array}$ & $\begin{array}{l}1.01 \\
(0.40)\end{array}$ & $\begin{array}{c}1.22 \\
(0.48)\end{array}$ \\
\hline $\begin{array}{l}\text { Correlation } \\
\text { coefficient }\end{array}$ & 1.50 & 1.37 & 0.76 & 0.27 & 0.14 & 0.11 \\
\hline
\end{tabular}

A significant source of difference between FIC and Enraf readings is the steady growth of a 'wastecicle' on the FIC that is removed periodically by flushing. The accumulated error can exceed one inch. Figure 3.4 shows the history of the difference between FIC and Enraf readings since the Enraf was installed. The downward slope between flushes indicates a constant 'wastecicle' growth rate of $0.013 \mathrm{~cm} /$ day $(0.0051 \mathrm{in} . /$ day). Note that the effect of flushing is not predictable. The January flush did not change the FIC level appreciably, but the March flush did.

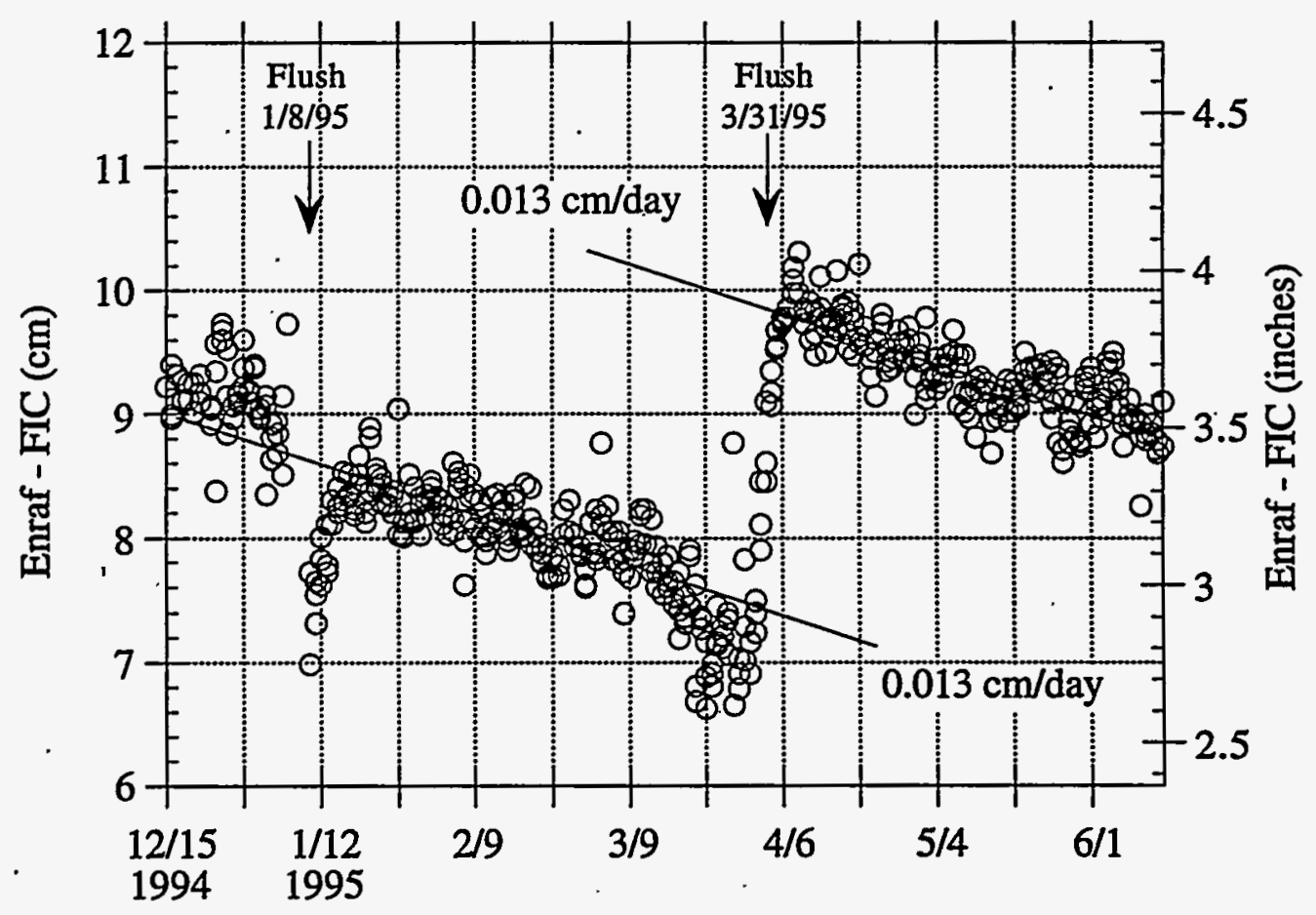

Figure 3.4. History of Difference in Enraf and FiC Levels 


\subsection{Long-term Changes in the Waste Surface}

The changes in the crust surface over approximately a 10-month period were studied by comparing in-tank videos recorded on December 9,1993, and October 12, 1994. It was difficult to compare the condition of the waste because the video quality has deteriorated over the period, and much detail was lost in the later video. Also, the views (as affected by lighting, zoom, tilt angle) were not the same. The new color video camera could not be used for this comparison because it looks at the waste from a completely different location. Complete and detailed archival scans of the crust are now being run and documented regularly so that future changes in crust condition can be monitored in more detail.

Nevertheless, it was possible to compare overall changes in the general character of the waste. The two main conclusions were that 1) there has been absolutely no motion of the crust in the 10-month period, and 2) the surface appears generally to have gradually 'dried out' slightly. There was no evidence that the crust layer had become significantly more or less of a barrier to gas release.

Figures 3.5 and 3.6 are similar views of the mixer pump on December 9, 1993, and October 12,1994 , respectively. The pump is in the central foreground, and the two velocity-densitytemperature trees (VDTTs) are in the upper right of both figures. Note that there is almost perfect correspondence of the perimeter features of the 'lake'(a) to the right of the pump and the two smaller 'ponds' on the left edge of the frame. The positions of these features relative to the pump also correspond exactly. This indicates that there has been no movement of the crust since December 9. By referencing the exposed pump hardware, the surface level is approximately the same, to within $\pm 2.5 \mathrm{~cm}$ ( \pm 1 in.), consistent with the FIC level data. However, consider the regions immediately on the left side and in front of the pump. More surface features are clearly visible in the later frame, and they are generally lighter in color. The 'mud hole' in front appears to have dried up.

Figures 3.7 and 3.8 show the overall vicinity of the FIC probe for December 9, 1993, and October 12,1994, respectively. Similar changes are apparent in the two frames as in the previous figures. However, the region immediately around the FIC probe contact has some different features, apparently due to dissolution of the crust by water dripping down from several FIC flushes that were performed during the period.

Figures 3.9 and 3.10 are closeups of the area where the FIC probe contacts the waste. Besides the FIC probe and the cavity beneath it, corresponding landmarks for orientation are the short diagonal shape on the right edge of the frame, about two-thirds of the way up, and some boulder-like objects near the left edge about three-quarters of the way up. In between, considerable erosion or dissolution is evident, especially of the crusty feature to the right of the probe in Figure 3.10.

(a) The terms 'lake,' 'pond,' etc., describe an appearance of liquid on the surface. The new video camera indicates that these may be regions of darker material and not liquid at all. 


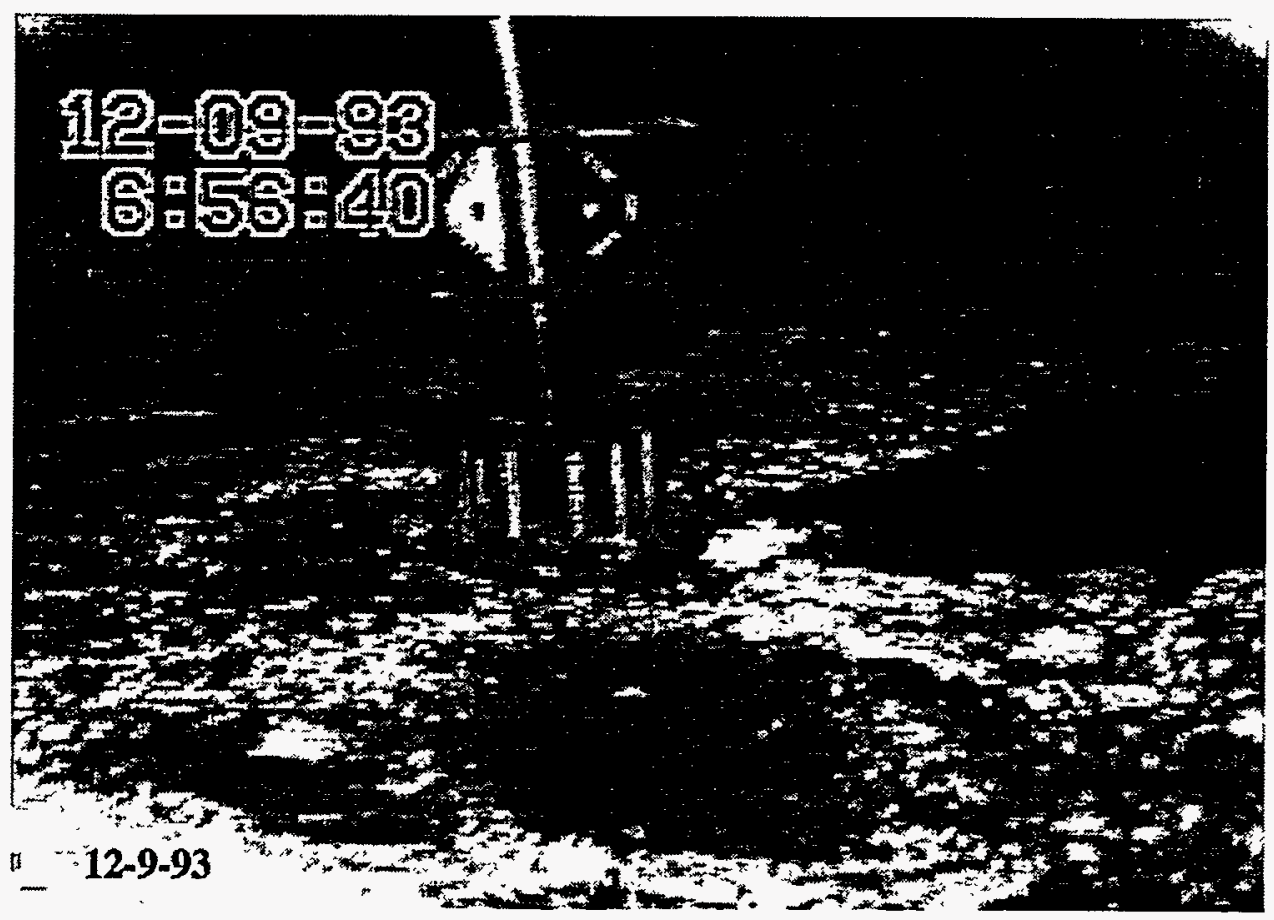

Figure 3.5. Pump Vicinity on December 9, 1993

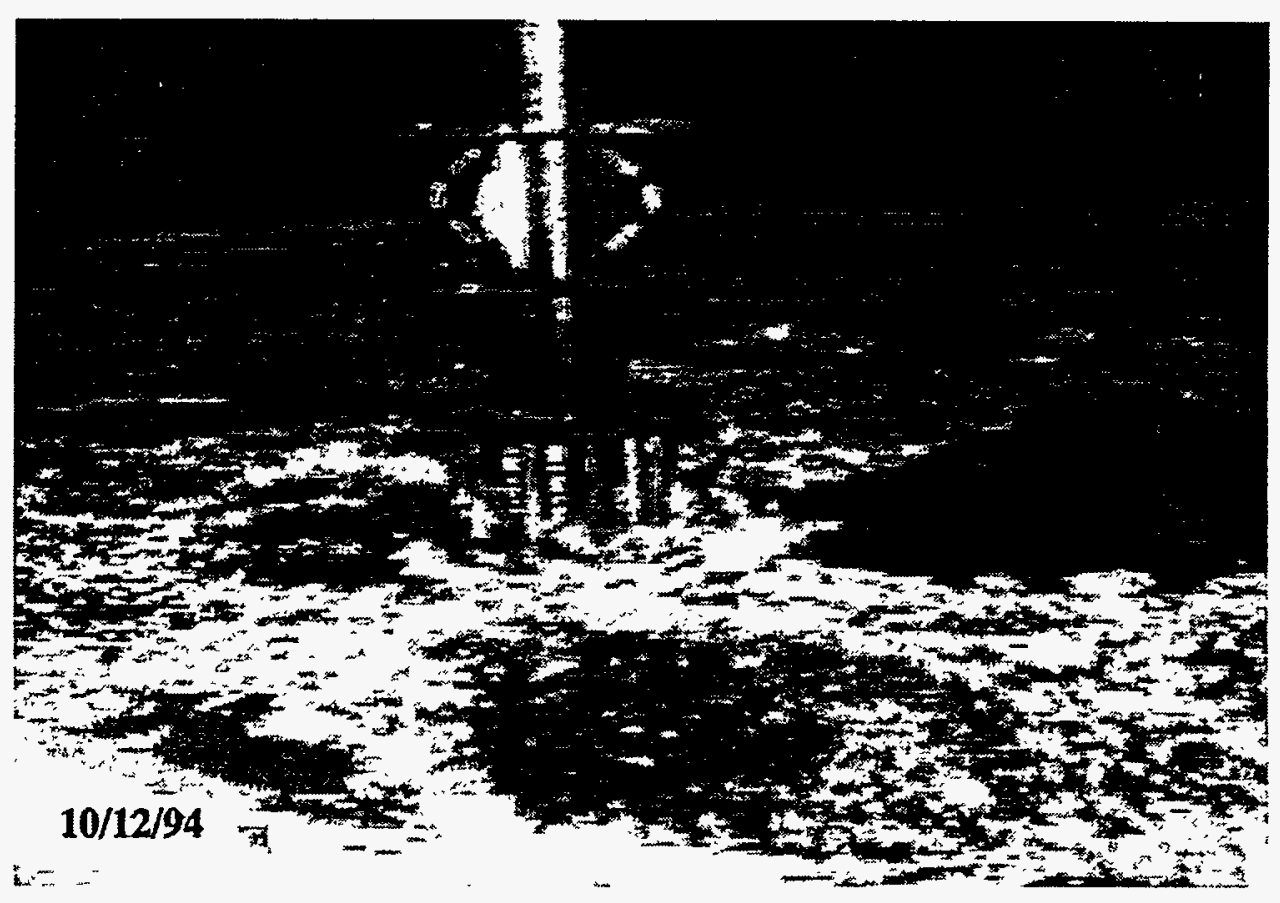

Figure 3.6. Pump Vicinity on October 12, 1994 


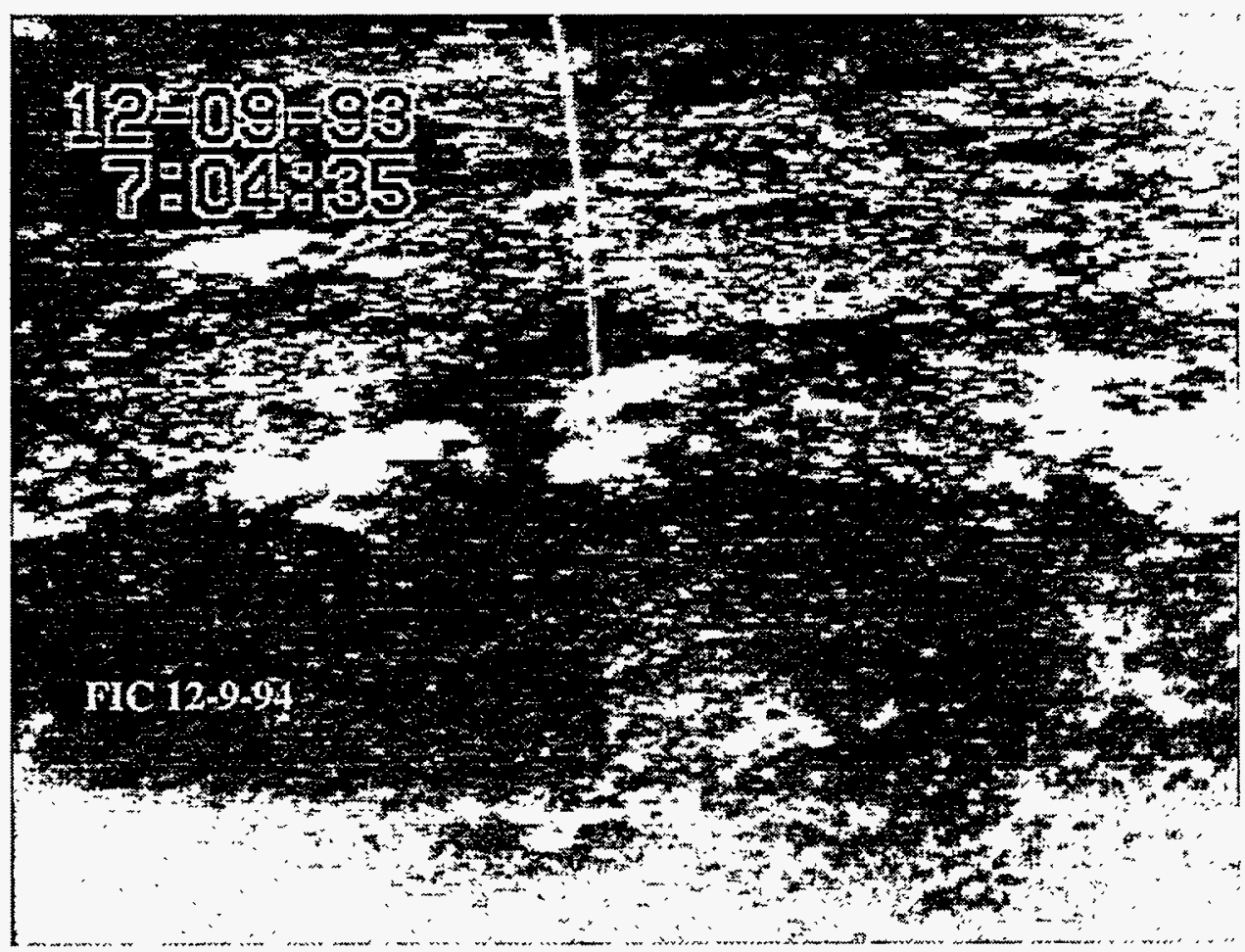

Figure 3.7. Area Around the FIC Probe on December 9, 1993

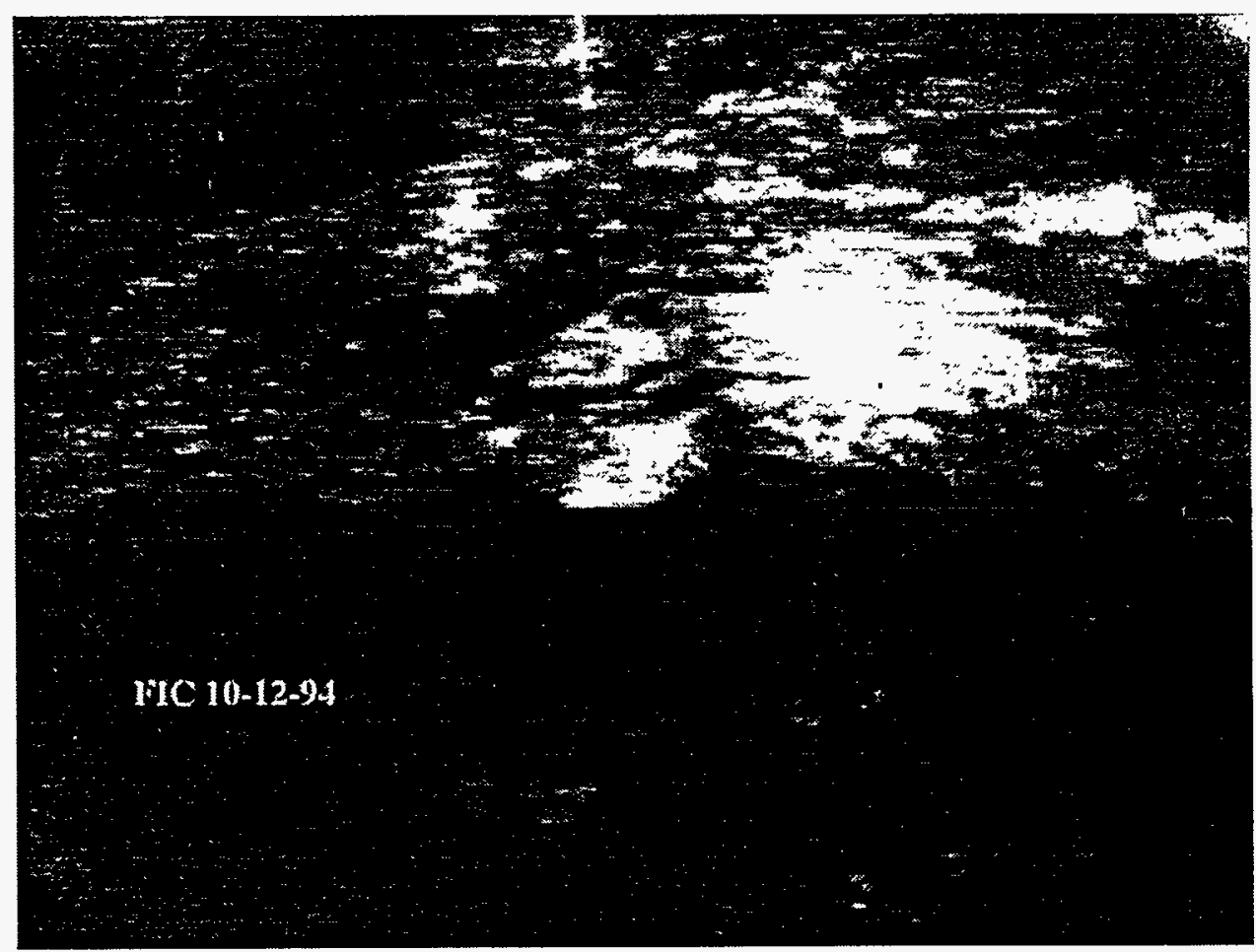

Figure 3.8. Area Around the FIC Probe on October 12, 1994 


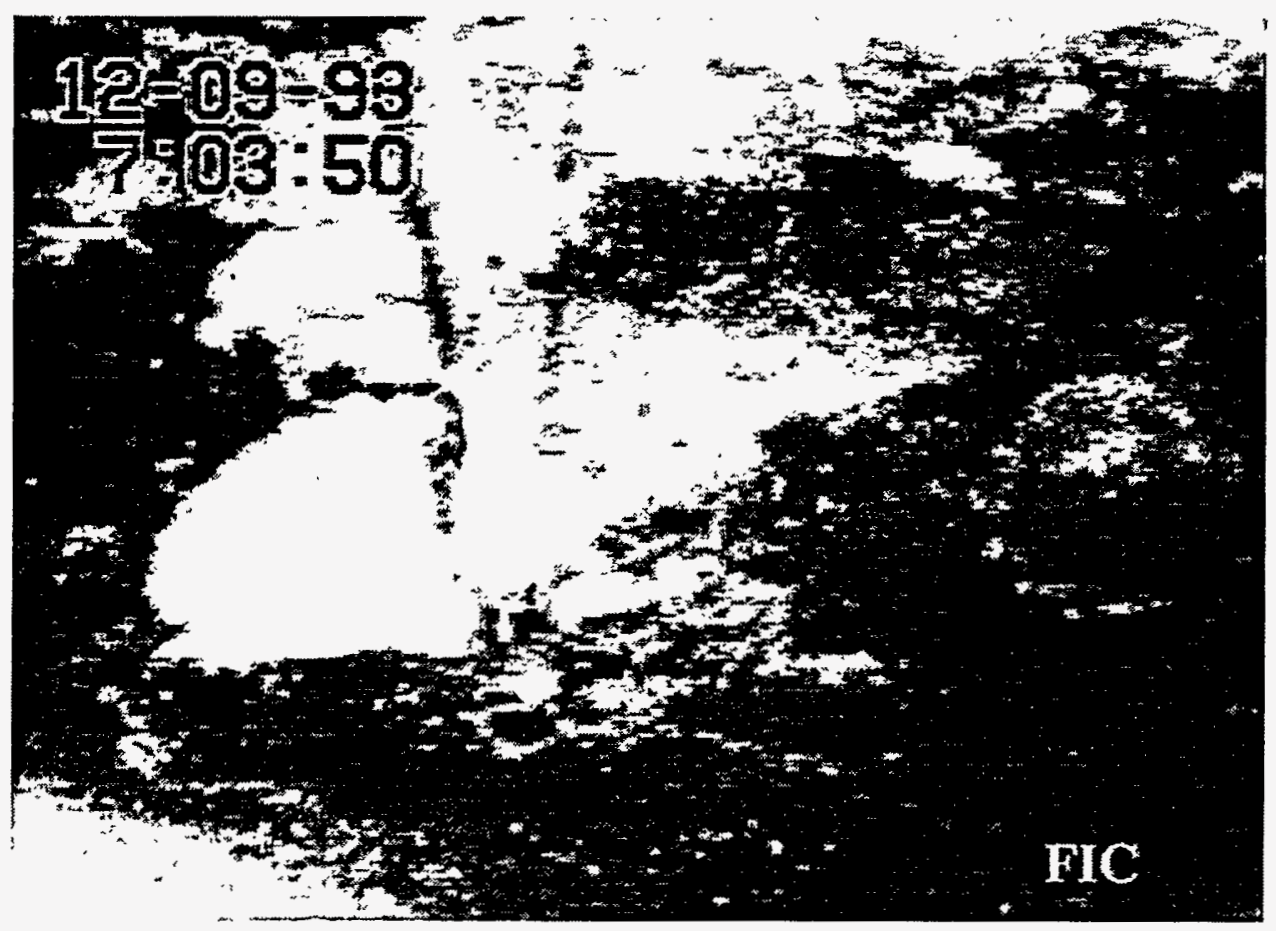

Figure 3.9. Closeup of FIC Probe on December 9, 1993

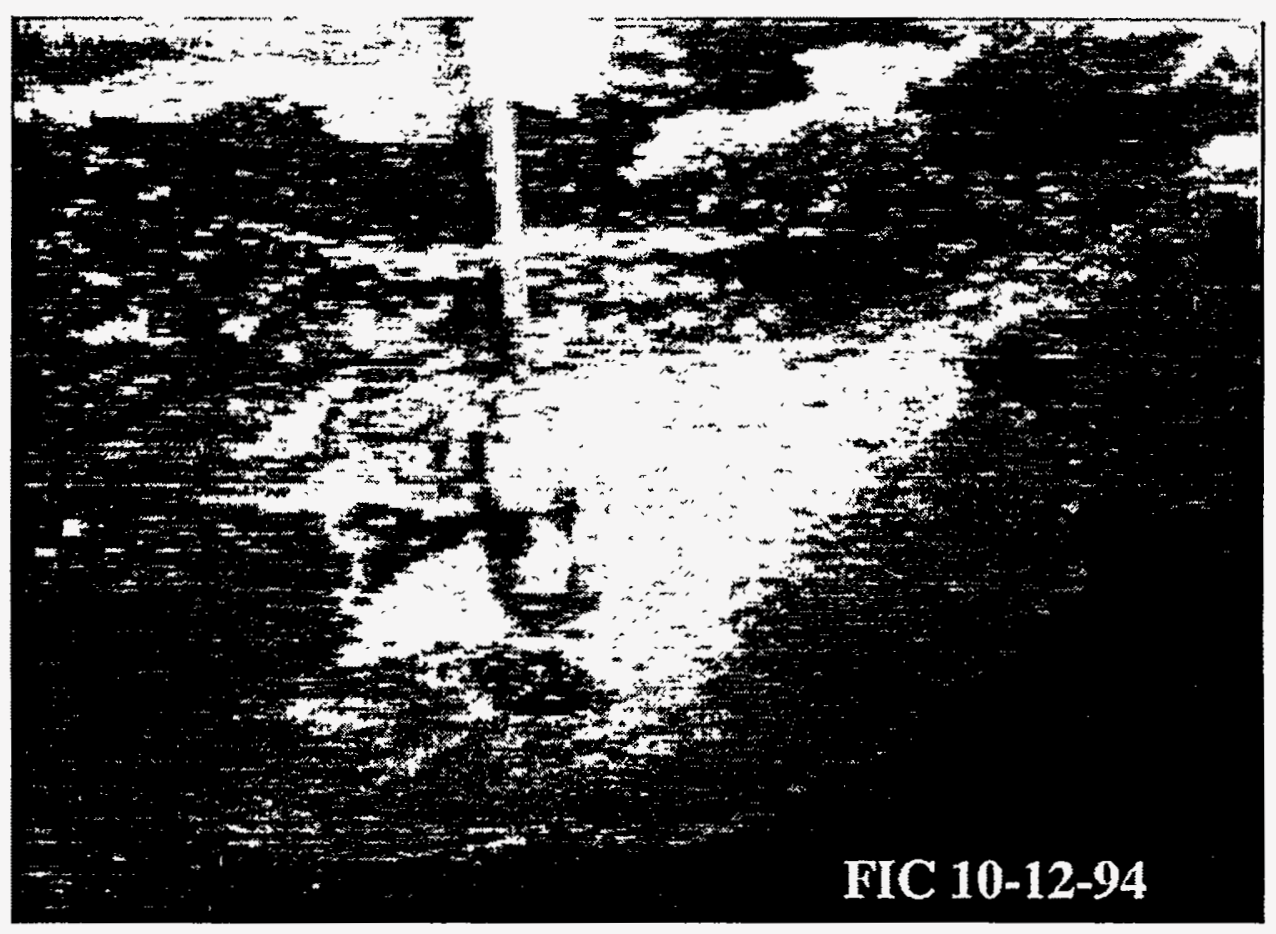

Figure 3.10. Closeup of FIC Probe on October 12, 1994 
While it is impossible to judge changes in surface height from these frames, it is clear that no major irregularities have appeared or disappeared directly under the probe to affect level measurements.

\subsection{Crust Buoyancy Effects}

Differences in the indications and trends of the four waste level-measuring instruments in Tank 241-SY-101 (radar gauge, FIC, Enraf, and manual tape) over the last year have prompted many questions about potential effects on indicated waste level. For example, how does the level of the top of the crust and free liquid level change if the crust dries out or if the liquid density changes? How much gas is stored in the crust, and how does it respond to atmospheric pressure variation? A model is derived in this section to investigate some of these effects.

Consider a relatively thin (with respect to width) crust with uniform thickness, $\mathrm{H}$, floating freely (not attached to tank walls) on a homogeneous liquid. The liquid volume is bounded by the tank walls so that any displacement by the crust raises its level. The solid material in the crust is more dense than the surrounding liquid and must be supported by trapped gas in order to float. This might require as much as $102 \mathrm{~m}^{3}(3,600 \mathrm{SCF})$ of gas (equivalent to a $25 \%$ void fraction), depending on the values of density and porosity that are used. For the purposes of calculation, the gas is assumed trapped in the pores in a layer of uniform thickness, $L$, on the bottom of the crust layer.

The crust is assumed homogeneous, and the solid crust material has a constant density, $\rho_{c}$, and porosity, $\phi$. The crust occupies not all, but a large fraction, $\theta$, of the total tank cross-section. Liquid waste occupies the pores in the submerged crust material not already taken up by gas and the non-crust fraction of the cross section $(1-\theta)$. Only pure supernatant liquid can reach the former, while the latter is available to a mixture of liquid with bubbles and particles stirred up by the pump. Thus we designate two separate liquid densities for pure liquid and the mixture as $\rho_{L}$ and $\rho_{M}$, respectively. The mixture density includes the void fraction and solids fraction by the expression

$$
\rho_{M}=(1-\alpha)\left[(1-\varepsilon) \rho_{L}+\varepsilon \rho_{S}\right]
$$

where $\alpha$ is the void fraction, $\varepsilon$ is the solids fraction, and $\rho_{s}$ is the suspended particle density. The gas density is negligible with respect to the liquid. In addition, we assume that capillary forces pull liquid up into the exposed crust such that all of the exposed height of crust is saturated with supernatant liquid except for a thin layer of thickness, $x$. The exposed liquid tends to increase the weight of the crust and reduce the liquid level via continuity. We do not attempt to account for capillary action directly. This model is sketched in Figure 3.11.

The crust floats submerged to a depth, $\mathrm{D}$, where the weight of the crust and contained gas and liquid is equal to the weight of liquid-solid-void mixture displaced. This is expressed by 


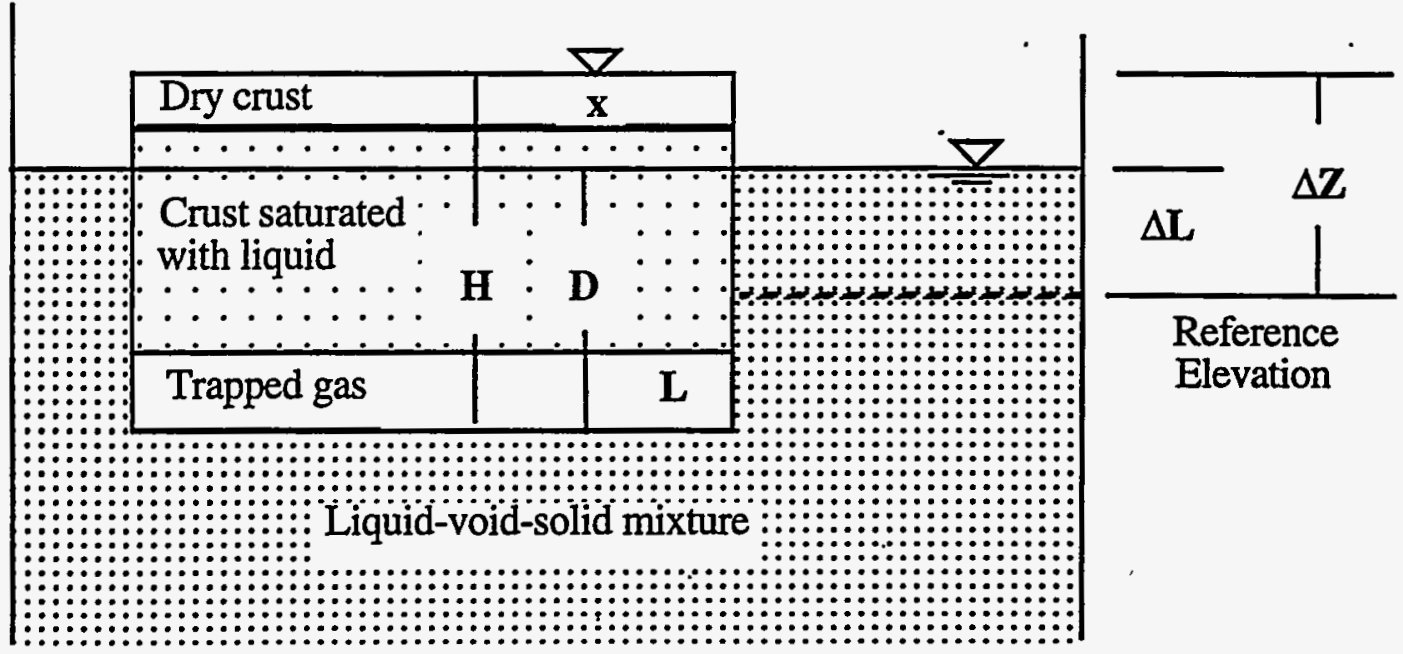

Figure 3.11. Floating Crust Model

$\left[\begin{array}{c}\text { weight of } \\ \text { mix. displaced }\end{array}\right]=\left[\begin{array}{c}\text { wt. of } \\ \text { crust mat'l. }\end{array}\right]+\left[\begin{array}{c}\text { wt. of liq. } \\ \text { submerged }\end{array}\right]+\left[\begin{array}{c}\text { wt. of liq. } \\ \text { exposed }\end{array}\right]$

$\rho_{M} D=\rho_{C} H(1-\phi)+\rho_{L}(D-L) \phi+\rho_{L}(H-D-x) f$

Solving Equation (3.6) for the submergence, D, gives

$$
\mathrm{D}=\mathrm{H} \frac{\rho_{\mathrm{C}}(1-\phi)+\rho_{\mathrm{L}} \phi}{\rho_{\mathrm{M}}}-(\mathrm{x}+\mathrm{L}) \phi \frac{\rho_{\mathrm{L}}}{\rho_{\mathrm{M}}}
$$

The submergence does not determine the waste level or the liquid level directly in a finite tank. The volume displaced by the submerged crust and trapped gas raises the liquid level. In an infinite ocean the liquid level rise would be negligible, and the crust would fall the entire submergence, D. If the crust occupied the entire tank cross-section, leaving negligible free area for liquid displacement, the liquid level would instantaneously rise a distance equal to $\mathrm{D}+\mathrm{L}$ and the crust would not fall at all. The tank will behave between these extremes in proportion to the amount of free area available.

Let the reference level be that of the liquid with the crust and trapped gas removed. Then, when the crust and trapped gas layer submerge, the liquid level will rise a distance, $\Delta \mathrm{L}$, such that the height of the top of the crust is equal to $\Delta \mathrm{L}+\mathrm{H}-\mathrm{D}$. The liquid level rise is given by

$$
\left[\begin{array}{c}
\text { Volume } \\
\text { added }
\end{array}\right]=\left[\begin{array}{c}
\text { Crust } \\
\text { submerged }
\end{array}\right]+\left[\begin{array}{c}
\text { Trapped gas } \\
\text { submerged }
\end{array}\right]-\left[\begin{array}{c}
\text { Exposed } \\
\text { liquid }
\end{array}\right]
$$


The total volume on the left references the entire tank cross-section, while the right side involves only the crust fraction. This is expressed mathematically by

$$
\Delta \mathrm{L}=\mathrm{D} \theta(1-\phi)+\mathrm{L} \theta \phi-(\mathrm{H}-\mathrm{D}-\mathrm{x}) \theta \phi
$$

With $\Delta \mathrm{L}$ known, the height of the top of the crust can be calculated as

$$
\begin{aligned}
& \Delta \mathrm{Z}=\Delta \mathrm{L}+\mathrm{H}-\mathrm{D} \\
& \Delta \mathrm{Z}=\mathrm{H}(1-\theta \phi)-\mathrm{D}(1-\theta)+(\mathrm{x}+\mathrm{L}) \theta \phi
\end{aligned}
$$

We will apply Equation (3.9) to investigate the following effects:

- $\quad$ Rising waste surface rise due to drying out of the exposed crust

- Changes in waste surface level due to growth of solid material, i.e., decreased porosity, decreased area fraction, increased crust height

- Changes in waste surface level due to changes in the density of the surrounding slurry

- Amplification of the contribution of the trapped gas layer to the change in waste level with changes in ambient pressure.

For comparison, a base case is defined in Table 3.3. The base case assumes the entire crust is saturated with liquid and is floating on pure supernatant liquid with no gas bubbles or suspended particles present. The combinations of density, porosity, and trapped gas volume yield a bulk crust specific gravity of 1.3 . The crust floats with $10.7 \mathrm{~cm}$ ( $4.2 \mathrm{in}$.) exposed above the liquid, and submerging the crust to this depth raises the liquid level by $56.6 \mathrm{~cm}$ ( $22.3 \mathrm{in}$.).

The waste surface level, the distance from the crust upper surface to the reference level, is sensitive to changes in weight of the crust. Drying out the top $5 \mathrm{~cm}$ ( 2 in.) of exposed crust, increasing the area fraction by $4 \%$, decreasing the porosity by $10 \%$, increasing the amount of trapped gas by $10 \%$, or increasing the crust height by $9 \%$ all increase the waste surface level by about $2.5 \mathrm{~cm}(1 \mathrm{in}$.). But the surface level is not very sensitive to the density of the surrounding liquid. Increasing the slurry void fraction to $5 \%$ or raising the suspended solids fraction to $15 \%$ changes the waste level by about $1 / 2 \mathrm{~cm}(1 / 4$ in.). Though the freeboard changes over $5 \mathrm{~cm}(2 \mathrm{in}$.) in each of these cases, the liquid level moves in the opposite direction to counteract it. Table 3.4 summarizes the changes in waste level caused by various effects.

It should be clear from the table that many factors other than changes in gas volume in the waste can potentially have significant effects on the readings of the waste level instruments. However, the direction of change over the last year has most probably been a drying out and adding to the mass of the crust. It is probable that the waste surface level is at least an inch higher now than the actual changes in gas inventory would indicate. 
Table 3.5. Base Case Parameters

\begin{tabular}{||l|c||}
\hline Parameter & Value \\
\hline \hline Crust height, $\mathrm{H}$ & $102 \mathrm{~cm} \mathrm{(40} \mathrm{in.)}$ \\
\hline Crust area fraction, $\theta$ & 0.9 \\
\hline Crust porosity, $\phi$ & 0.55 \\
\hline Dry crust, $\mathrm{x}$ & none \\
\hline Crust material S.G. & 2.0 \\
\hline Trapped gas layer, $\mathrm{L}$ & $51 \mathrm{~cm} \mathrm{(20} \mathrm{in.)}$ \\
\hline Liquid S.G. & 1.45 \\
\hline Bulk void fraction, $\alpha$ & 0.0 \\
\hline Bulk solids fraction, $\varepsilon$ & 0.0 \\
\hline Solids specific gravity & 2.0 \\
\hline
\end{tabular}

Table 3.6. Summary of Waste Level Changes

\begin{tabular}{|c|c|c|c|}
\hline Description of Effect & $\begin{array}{l}\text { Change in } \\
\text { Surface Level } \\
\text { cm (in.) }\end{array}$ & $\begin{array}{c}\text { Change in } \\
\text { Freeboard } \\
\mathrm{cm} \text { (in.) }\end{array}$ & $\begin{array}{l}\text { Change in } \\
\text { Liquid Level } \\
\text { cm (in.) }\end{array}$ \\
\hline Dry out $5 \mathrm{~cm} \mathrm{(2} \mathrm{in.)} \mathrm{of} \mathrm{exposed} \mathrm{crust}$ & $2.8(1.1)$ & $2.8(1.1)$ & 0.0 \\
\hline $\begin{array}{l}\text { Increase crust height } 6.3 \mathrm{~cm}(2.5 \mathrm{in} .) \\
\text { (slow accretion on bottom) }\end{array}$ & $2.5(1.0)$ & $-1.0(-0.4)$ & $-3.6(-1.4)$ \\
\hline Increase trapped gas in crust by $10 \%$ & $2.8(1.1)$ & $2.8(1.1)$ & 0.0 \\
\hline $\begin{array}{l}\text { Increase crust area fraction from } 0.9 \text { to } \\
0.94 \text { (crust growth fills open area) }\end{array}$ & $2.5(1.0)$ & 0.0 & $\cdot 2.5(1.0)$ \\
\hline $\begin{array}{l}\text { Decrease porosity from } 0.55 \text { to } 0.5 \\
\text { (crust growth fills pores) }\end{array}$ & $1.8(0.7)$ & $-4.6(-1.8)$ & $6.4(2.5)$ \\
\hline $\begin{array}{l}\text { Increase slurry void from zero to } 5 \% \\
\text { (mixture S.G. of } 1.38 \text { ) }\end{array}$ & $-0.5(-0.2)$ & $-4.8(-1.9)$ & $4.3(1.7)$ \\
\hline $\begin{array}{l}\text { Increase slurry solids fraction to } 15 \% \\
\text { (mixture S.G. of } 1.53 \text { ) }\end{array}$ & $0.5(0.2)$ & $4.8(1.9)$ & $-4.3(-1.7)$ \\
\hline
\end{tabular}


The additional effect of varying atmospheric pressure is easily evaluated by substituting Equation (3.7) for D in Equation (3.9) and taking the derivative with respect to pressure. The substitution yields

$$
\Delta \mathrm{Z}=\mathrm{H}\left[(1-\theta \phi)-\frac{\rho_{\mathrm{C}}(1-\phi)+\rho_{\mathrm{L}} \phi}{\rho_{\mathrm{M}}}(1-\theta)\right]+(\mathrm{x}+\mathrm{L}) \phi\left[\frac{\rho_{\mathrm{L}}}{\rho_{\mathrm{M}}}(1-\theta)+\theta\right]
$$

and the pressure derivative, assuming only the gas volume changes, is

$$
\frac{\mathrm{d} \Delta \mathrm{Z}}{\mathrm{dP}}=\phi\left[\frac{\rho_{\mathrm{L}}}{\rho_{\mathrm{M}}}(1-\theta)+\theta\right] \frac{\mathrm{dL}}{\mathrm{dP}}
$$

Substituting the gas volume, $\mathrm{V}=\mathrm{AL} \theta \phi$, and assuming an isothermal process (PV $=$ constant), we can rewrite Equation (3.11) as

$$
\frac{\mathrm{d} \Delta \mathrm{Z}}{\mathrm{dP}}=\frac{-\mathrm{V}}{\mathrm{AP}}\left[\frac{\rho_{\mathrm{L}}}{\rho_{\mathrm{M}}} \frac{(1-\theta)}{\theta}+1\right]
$$

Equation (3.12) reveals that the gas stored in the crust has a much larger contribution to the overall tank compressibility than gas retained in the lower layers. Not only is the term in brackets greater than 1.0 , but the pressure is very nearly equal to the ambient pressure. The pressure of gas stored near the tank bottom is over 2.5 times higher. The result is that $2.8 \mathrm{~m}^{3}\left(100 \mathrm{ft}^{3}\right)$ of gas in the crust has about the same response to a barometric pressure change as $8.5 \mathrm{~m}^{3}\left(300 \mathrm{ft}^{3}\right)$ in the bottom sludge layer. 


\subsection{Undissolved Gas Stored in the Waste}

Temperature profiles and the transient temperature response to pump runs measured at the two multifunction instrument trees (MITs), the results of the void fraction instrument (VFI) tests in December 1994 and January 1995, and the ball rheometer deployment in March and April 1995 were analyzed to determine the configuration of the waste and gas content in Tank 241-SY-101.

The condition of the waste in Tank 241-SY-101 can be inferred from temperature profiles and transient thermocouple response to pump operation indicated by the two MITs in risers 17B and 17C. Each MTT has 22 thermocouples, with the lowest four positioned 10.2, 40.6, 71.1, and $132.1 \mathrm{~cm}(4,16,28$, and 52 in.) above the tank bottom. A 'validation probe' is also run in each MIT occasionally, taking readings every $10 \mathrm{~cm}$ (4 in.), beginning $20 \mathrm{~cm}$ ( 8 in.) above the bottom. Recently, it has also become possible to measure properties in situ at specific points by using the ball rheometer and the VFI, or void meter. The VFI measured the vertical void fraction profile at riser 11B December 21, 1994, and at riser 4A January 17, 1995. The ball rheometer measured the viscosity, density, and yield strength profiles in riser 4A on March 28 and in $11 \mathrm{~B}$ on April 5, 1995. Figure 4.1 shows the approximate placement of these instruments in relation to the pump and its traditional nozzle orientations.

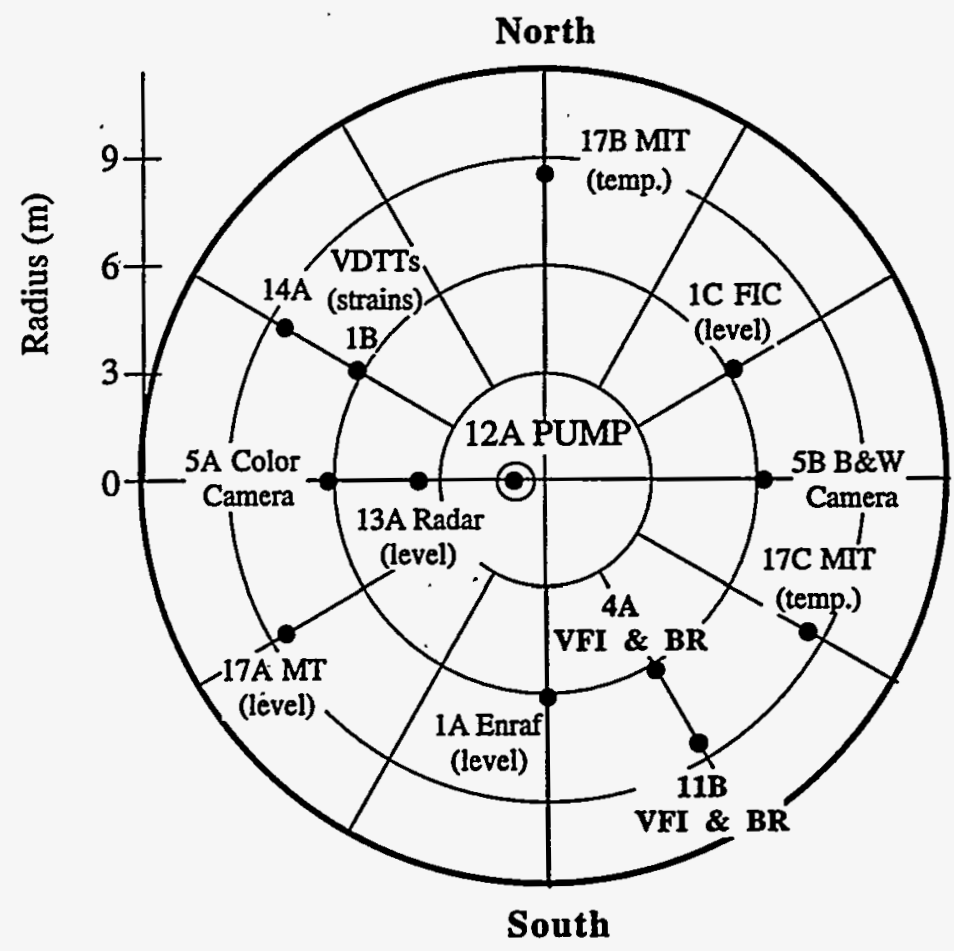

Figure 4.1. Location of Instruments in Tank 241-SY-101 
Both the $17 \mathrm{~B}$ and $17 \mathrm{C}$ MTTs and riser $11 \mathrm{~B}$ are at the $8.5-\mathrm{m}(28-\mathrm{ft})$ radius from the tank center. Riser $4 \mathrm{~A}$ is on the $6.1-\mathrm{m}(20-\mathrm{ft})$ radius. But the mixer pump is about one meter $(3 \mathrm{ft})$ west of the tank center, so the distance from the pump is $8.6 \mathrm{~m}(28.2 \mathrm{ft})$ to $17 \mathrm{~B}, 9.3 \mathrm{~m}(30.6 \mathrm{ft})$ to $17 \mathrm{C}$, $6.7 \mathrm{~m}(21.9 \mathrm{ft})$ to $4 \mathrm{~A}$, and $9.0 \mathrm{~m}(29.6 \mathrm{ft})$ to $11 \mathrm{~B}$. In addition, the VFI has a horizontal reach of $0.76 \mathrm{~m}(2.5 \mathrm{ft})$, so the minimum and maximum distances from the pump for a void measurement are 5.9 and $7.4 \mathrm{~m}(19.4$ and $24.4 \mathrm{ft})$ in $4 \mathrm{~A}$ and 8.3 and $9.8 \mathrm{~m}(27.1$ and $32.1 \mathrm{ft})$ in $11 \mathrm{~B}$.

\subsection{Temperature Profiles and Transient Temperature Response}

The vertical temperature profiles defined by several of the latest MIT validation probe readings at the MITs in risers 17B and 17C, shown in Figures 4.2 and 4.3, respectively, reveal four waste layers: a heat-generating nonconvective layer on the bottom, evidenced by a parabolic temperature profile; two distinct convective layers with a uniform temperature profile; and a solid crust on top with a linear temperature profile. Based on transient response of the temperature profile to the pump jet, the nonconvective layer actually consists of two separate layers of settled solids and sludge. Table 4.1 lists the five layers from top to bottom. Except for the crust at the top and a thin layer of sludge on the bottom, the waste is well-mixed as a result of more than one year of mixer pump operation, especially with the consistent thrice-weekly excavations performed since September 1994.

The crust layer has remained almost totally undisturbed and unchanged since early November 1993, when a gas release caused surface motion for the last time (see Section 3). Comparing MIT validation probe temperature profiles from July 1994 through July 1995, in Figure 4.2, with Figure 4.3 shows that the crust thickness of $102 \pm 10 \mathrm{~cm}(40 \pm 4 \mathrm{in}$.$) at 17 \mathrm{~B}$ and $76 \pm 10 \mathrm{~cm}$ (30 \pm 4 in.) at $17 \mathrm{C}$ has not changed measurably.

Below the crust, an upper convective layer forms as solids settle out during periods of reduced mixing. Aggressive pumping eliminates this layer by mixing it with the slurry below. This predominantly liquid layer is visible in the July 1994 validation probe profiles but not in the later ones after the regular high-speed excavation runs began. A similar upper convective layer was also evident following natural rollovers and the larger pump-induced gas releases prior to high-speed testing (Allemann et al. 1994) as well as during the 'regrowth' phase of Full-Scale testing (Stewart et al. 1994).

The most extensive layer is a mobile slurry that bears most of the solid material in a suspension that is maintained by mixing. The temperature profiles for July 1994 in Figures 4.2 and 4.3 show the top of the slurry layer contracted to about $760 \mathrm{~cm}$ (300 in.) at both $17 \mathrm{~B}$ and $17 \mathrm{C}$ after a relatively inactive period, while the later profiles show that regular excavation runs have expanded the slurry all the way to the crust.

The nonconvective, loosely settled layer evidently forms when the larger and/or heavier solid particles settle out of the slurry above within a few days of the last pump run. Its upper boundary can be estimated by the level where the transition from parabolic (nonconvective) to uniform (convective) temperature profile occurs a few days following a pump run. The July 1994 validation probe profile in Figure 4.2 indicates the boundary is between the 100 - and $150-\mathrm{cm}$ 


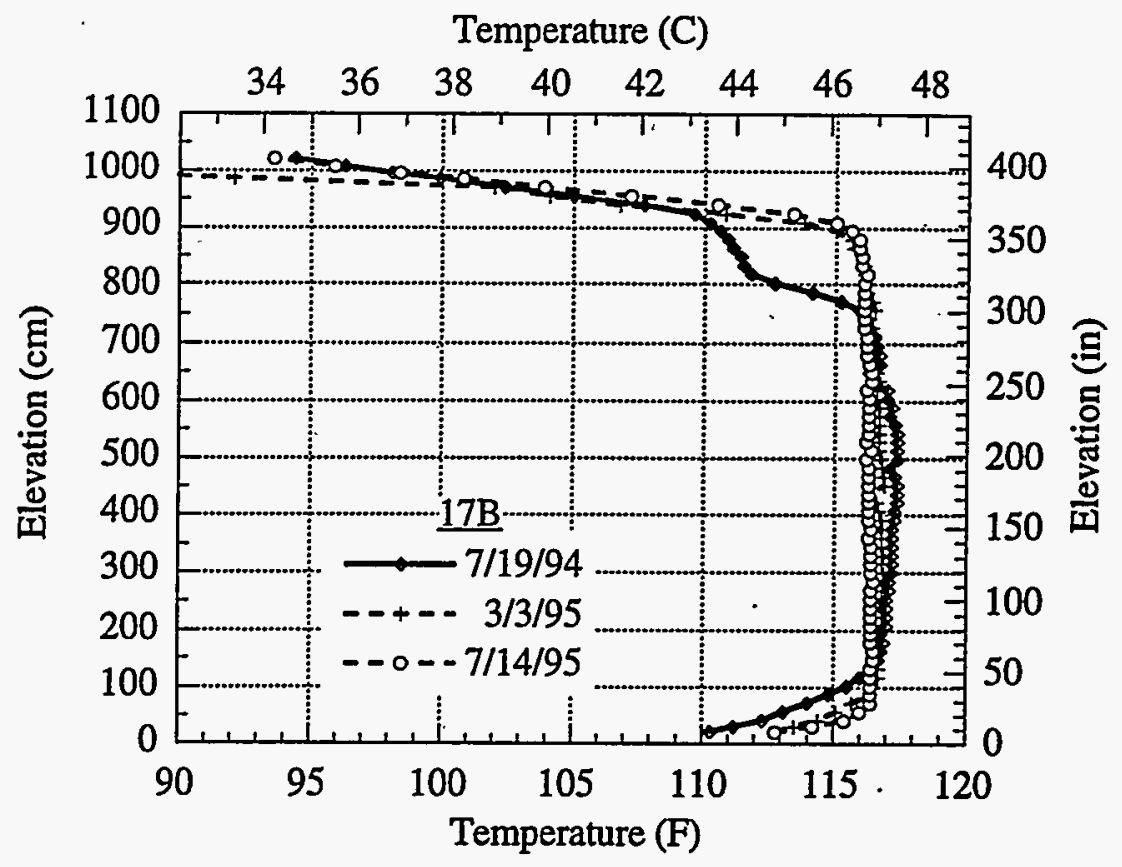

Figure 4.2. Temperature Profiles - 17B MIT Validation Probe

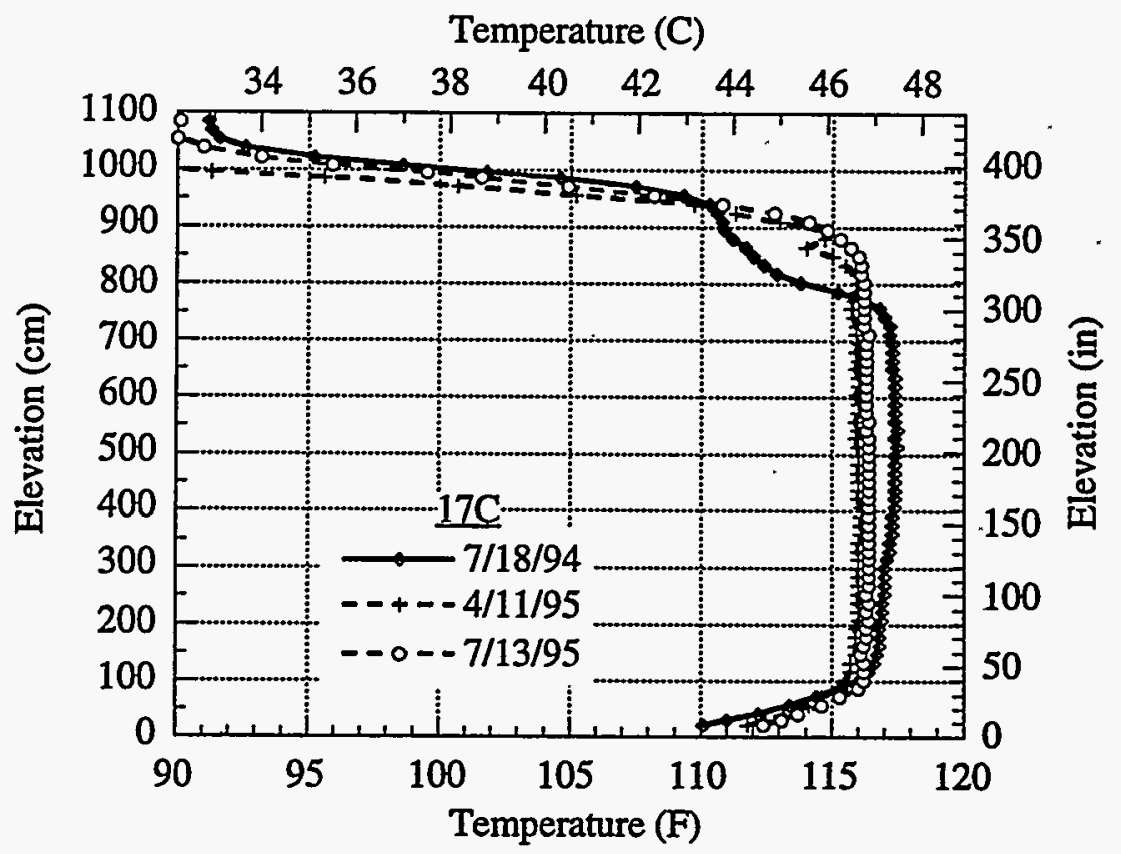

Figure 4.3. Temperature Profiles - 17C MIT Validation Probe 
Table 4.1. Waste Layering in Tank 241-SY-101

\begin{tabular}{||l|c|l||}
\hline \multicolumn{1}{|c|}{ Layer } & $\begin{array}{c}\text { Approx. Thickness } \\
\text { cm (in.) }\end{array}$ & \multicolumn{1}{|c|}{ Character } \\
\hline \hline Crust & $100(40)$ & $\begin{array}{l}\text { Porous solids floating on the liquid, essentially no } \\
\text { physical changes in over 12 months. }\end{array}$ \\
\hline Upper convective & $150(60)-0$ & $\begin{array}{l}\text { Mostly liquid, forms only during periods of } \\
\text { reduced mixing. }\end{array}$ \\
\hline Mobile slurry & $670(265)-$ & High fraction of suspended solids, well-mixed. \\
\hline Loosely settled solids & $75(30)-0$ & $\begin{array}{l}\text { Heavier, larger particles that settle out of slurry; } \\
\text { readily dispersed by jet, non-uniform depth. }\end{array}$ \\
\hline Undisturbed sludge & $\begin{array}{c}13(5)- \\
40(16)\end{array}$ & Eroding slowly, non-uniform depth. \\
\hline
\end{tabular}

(40- and 60-in.) levels. The July 1995 profile shows a 76-cm (30-in.) boundary. The boundary at $17 \mathrm{C}$, indicated by the July 1995 profile in Figure 4.3 , is $100 \mathrm{~cm}$ (40 in.). Although this material is sufficiently dense to suppress convection, a five-minute pump bump resuspends the entire layer, even after a month of settling. There is no evidence that the settled material gains any effective yield strength.

The elevation of the top of the undisturbed sludge layer is estimated by observing the sudden jump in thermocouple readings during a pump run, when a thermocouple is suddenly exposed to hotter fluid as the pump jet disturbs previously settled material. The thermocouple response at the 17B MIT on June 28,1995 , with the pump oriented at $97^{\circ}$, is shown in Figure 4.4. Thermocouple 1 jumped over $2^{\circ} \mathrm{C}\left(4^{\circ} \mathrm{F}\right)$ in the last half of the run. Since thermocouple 1 is located $10 \mathrm{~cm}$ ( 4 in.) above the tank bottom, we know that the top of the undisturbed sludge is below that level. Thermocouple 2 at $40 \mathrm{~cm}\left(16 \mathrm{in}\right.$.) rose over $1.5^{\circ} \mathrm{C}\left(2.7^{\circ} \mathrm{F}\right)$, and thermocouple 3 at $71 \mathrm{~cm}$ (28 in.) jumped about $1^{\circ} \mathrm{C}\left(2^{\circ} \mathrm{F}\right)$ during the run. The absence of a jump on thermocouple 4 at 132 $\mathrm{cm}$ (52 in.) indicates it is already within the mixed slurry layer.

The thermocouples on the 17C MIT provide similar information, as shown by the response June 23,1995 , with the pump aimed at $28^{\circ}$ in Figure 4.5 . But here the lowest elevation apparently mobilized is at thermocouple 2 at $40 \mathrm{~cm}\left(16 \mathrm{in}\right.$.), which jumps $1.5^{\circ} \mathrm{C}\left(2.7^{\circ} \mathrm{F}\right)$ very near the end of the run. Thermocouple 3 at $71 \mathrm{~cm}\left(28 \mathrm{in}\right.$.) rises about $1^{\circ} \mathrm{C}\left(2^{\circ} \mathrm{F}\right)$, and thermocouple 4 is constant, as above.

Although the sludge thickness should be least when it is directly in line with the jet, there is evidence that the sludge is not very much thicker between the angles away from its direct impact. The transient temperature response at 17B when the pump is aimed at different azimuths shows that the jet is able to move the waste below $70 \mathrm{~cm}\left(28\right.$ in.) over a $60^{\circ}$ sector following its passage. The jet clearly moves hotter fluid down to thermocouple 2 at $17 \mathrm{~B}$ when aimed at $125^{\circ}, 30^{\circ}$ away. 


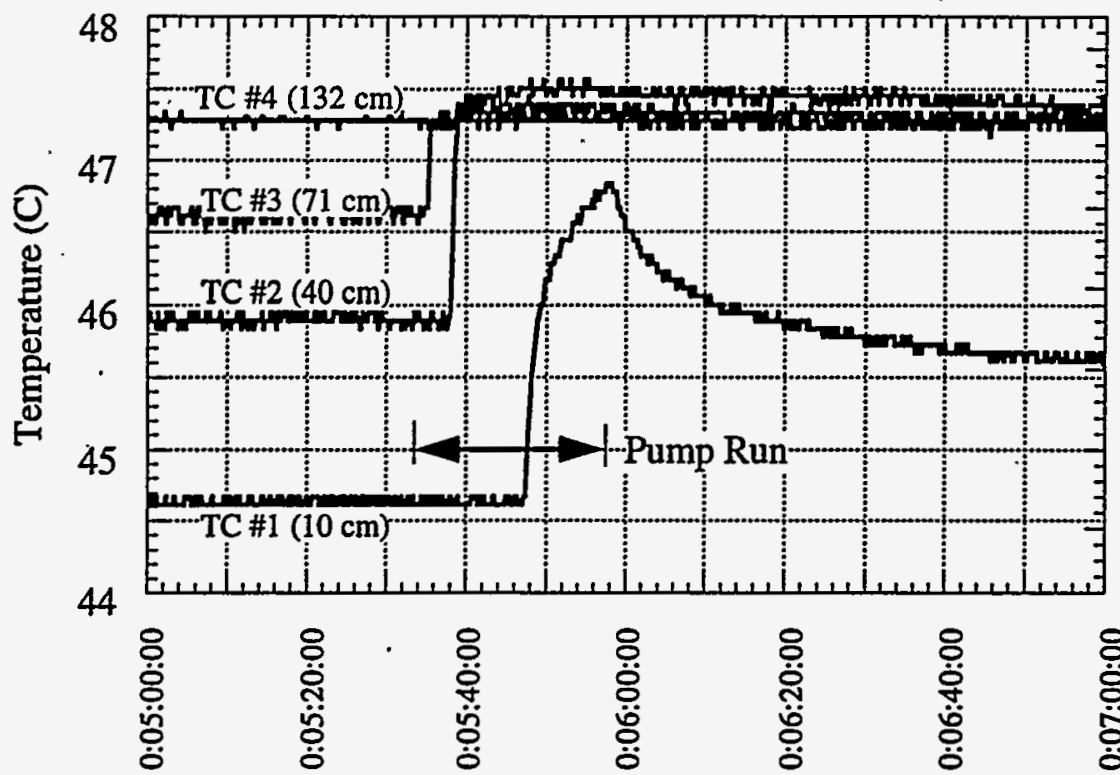

Figure 4.4. Transient Temperature Response at 17B June 28, 1995

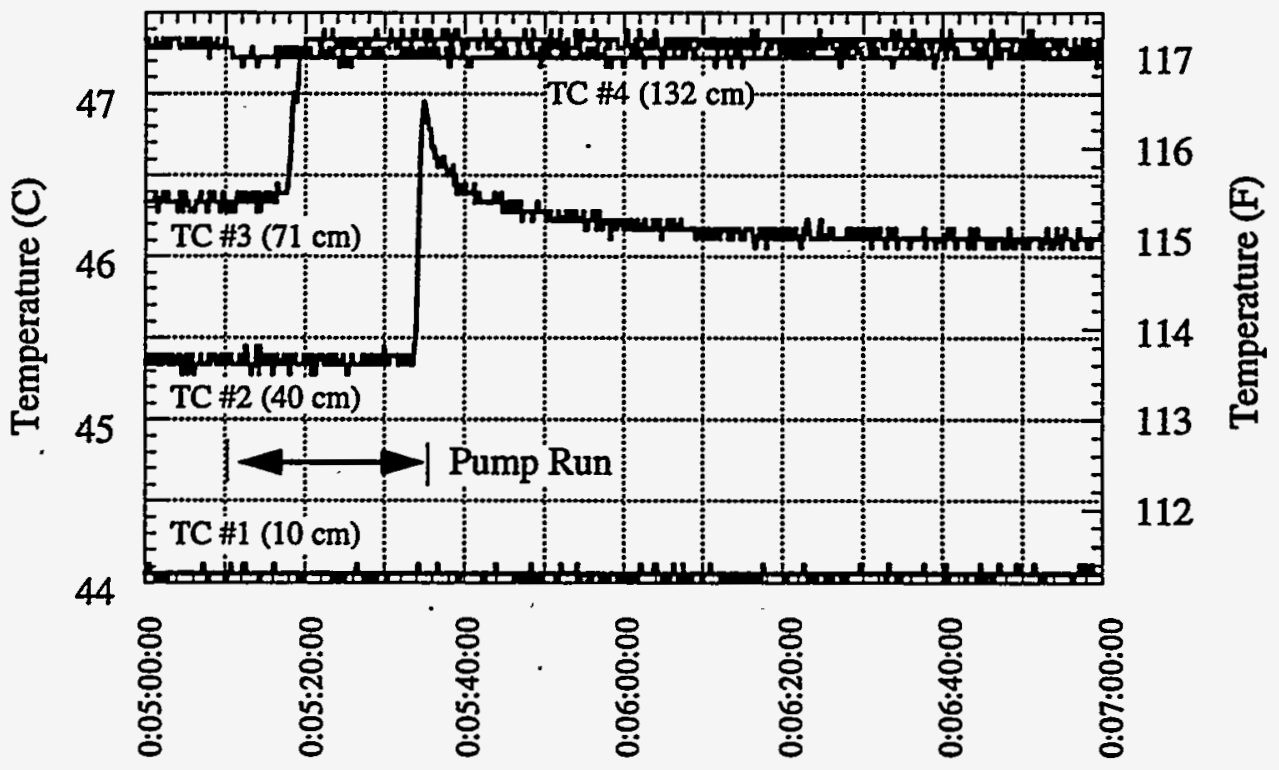

Figure 4.5. Transient Temperature Response at 17C June 23, 1995 
There is typically a response only down to thermocouple 3 with the jet at $155^{\circ}$ ( $60^{\circ}$ away), and no response at either thermocouple when the pump is run at $185^{\circ}$. No response is seen in advance of the jet's current position, as when the pump is aimed at $28^{\circ}$, apparently because solids settle sufficiently after a week's time to prevent motion at the lower levels. This effect was also confirmed by the PCA of temperature signatures discussed in Section 2.

\subsection{Void Fraction Instrument (VFI)}

The VFI estimates the local void fraction by compressing a waste sample captured in situ in a gas-tight test chamber. The ideal gas law is applied to calculate the void fraction based on the pressure change in a calibrated volume connected to the sample chamber. Deviations from ideal gas law behavior, the effects of soluble gases that are present, and surface tension effects are not accounted for in this analysis but have been shown to be small (Stewart et al. 1995).

The sample chamber is mounted on the end of a $76.2-\mathrm{cm}(2.5-\mathrm{ft})$ arm that can be rotated from vertical to horizontal when the instrument is deployed. The VFI is first lowered through the crust layer with the arm held vertical. Once through the crust the VFI is turned to the selected azimuth, and the arm is rotated horizontally. After a delay to reach thermal equilibrium, the VFI is lowered in steps, capturing, compressing, and releasing a sample, then moving to a lower elevation to repeat the cycle. More information on the deployment of this instrument is given in Stewart et al. (1995).

The VFI was first deployed in riser 11B in Tank 241-SY-101 on December 21, 1994, and a second time in riser $4 \mathrm{~A}$ on January 17,1995 . Two vertical traverses were accomplished in riser $11 B$ on December 21. On the first traverse, with the arm aimed inward toward the pump, the VFI measured zero void fraction from just below the crust to about $107 \mathrm{~cm}$ (42 in.) off the bottom. As the arm was lowered from the 43-cm (17-in.) level the sludge began to support the arm, and the supporting crane began to unload and reached zero support at $20 \mathrm{~cm}$ (8 in.). The arm was then raised slightly to reload the crane, and two measurements taken at $25 \mathrm{~cm}$ (10 in.) showed 10-12\% void fraction. After completing the first traverse, the VFI was raised back into the dome space, turned $180^{\circ}$ to orient the arm toward the tank wall, and lowered again for the second traverse. At about the $60-\mathrm{cm}$ (2-ft) level the crane began to unload rapidly again, indicating the presence of heavy sludge. A void measurement at this level failed due to leaking O-rings, and the test ended.

The second VFI deployment was performed in Tank 241-SY-101 through riser 4A on January 17. During the first traverse with the sample chamber oriented toward the pump, the VFI

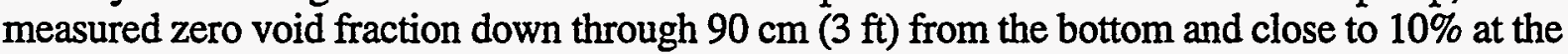
lowest elevations, as it did on the first deployment. There was no unloading of the crane on this or any of the succeeding traverses in this deployment.

All of the above void fraction measurements are plotted in Figure 4.6. Even though the data points are separated horizontally by up to $4 \mathrm{~m}$ (13 ft), the trend of increasing void fraction with depth is remarkably uniform. The curve fit represents all data except the two outliers from the second traverse in riser 4A. Though not shown on the figure, separate curve fits to the data from each deployment are essentially the same. The VFI data are basically consistent with the waste 
configuration inferred from temperature profiles. The highest void fractions below $40 \mathrm{~cm}(16 \mathrm{in}$.) represent the undisturbed sludge, while the $1-5 \%$ void fractions up to $120 \mathrm{~cm}(4 \mathrm{ft})$ are consistent with the loosely settled layer from the temperature profiles. The average void fraction of this layer, calculated by integrating the curve fit between $25 \mathrm{~cm}(10 \mathrm{in}$.) and $120 \mathrm{~cm}(4 \mathrm{ft})$, is just under $3 \%$.

There is evidence for the existence of azimuthal ridges, or 'scallops,' of material between the chosen pump outlet azimuths where the jet has not been directed. Risers 4A and 11B are located away from the direct impact of the jet between nominal pump azimuths (see Figure 4.1). Therefore, while the thermocouple responses at the 17B and 17C MITs indicate a sludge depth of $10-30 \mathrm{~cm}(4-12 \mathrm{in}$.) in line with the pump, the void profile in Figure 4.6 implies a depth of $25-40 \mathrm{~cm}(10-16 \mathrm{in}$.) or more at about the same radius. The crane unloading observations indicate strong sludge as high as $60 \mathrm{~cm}$ ( $24 \mathrm{in}$.).

On the other hand, the crane unloading might also indicate a local obstruction not representative of a typical 'scallop.' Since the crane unloaded at $60 \mathrm{~cm}$ (24 in.) with the arm directed away from the pump and at only $25 \mathrm{~cm}$ (10 in.) with the arm inward, the change in height of the highstrength material or obstruction must be quite abrupt.

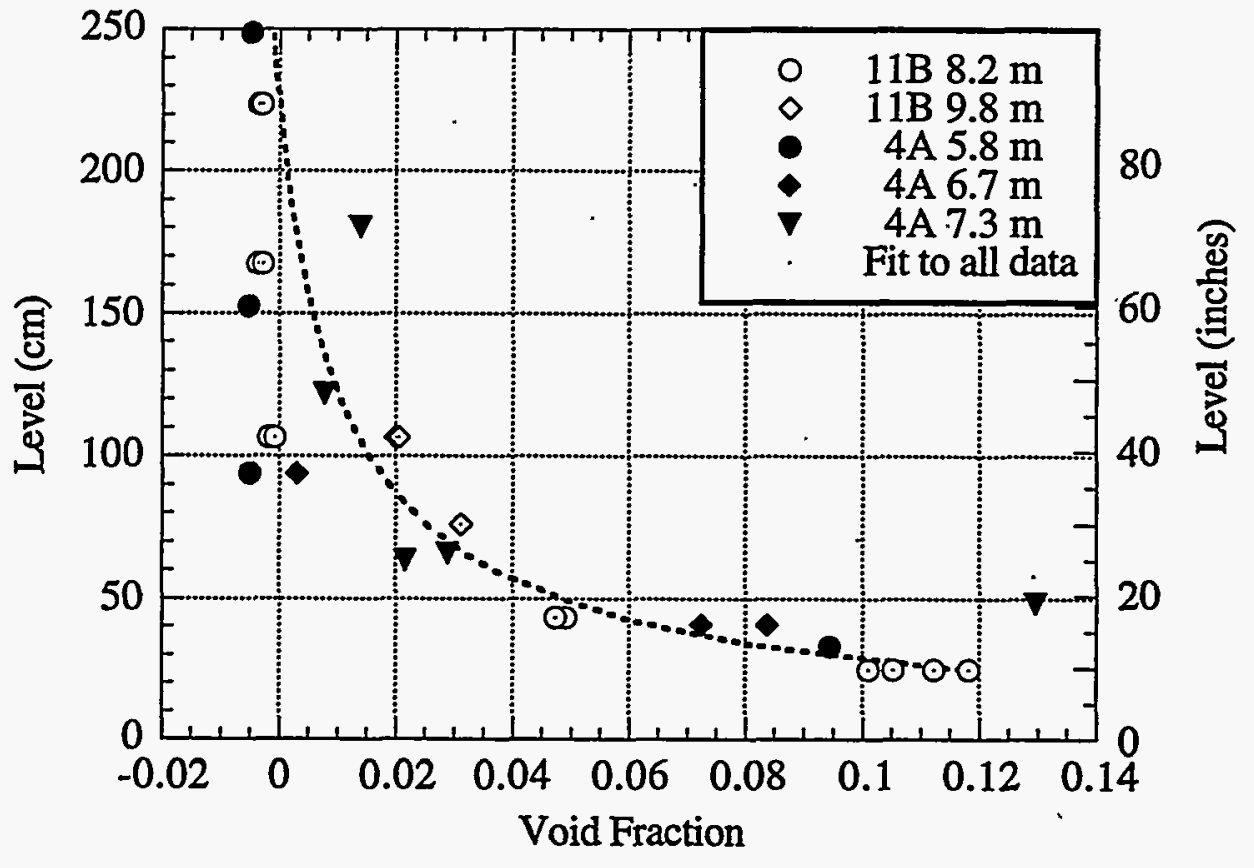

Figure 4.6. Void Fraction Measurements in Tank 241-SY-101 


\subsection{Results of the Ball Rheometer Tests}

The ball rheometer was deployed in the same two risers as the VFI in Tank 241-SY-101. The ball was lowered through riser 4A on March 28, 1995, and through riser 11B on April 5. The ball passed through the free liquid level at riser $4 \mathrm{~A}$ at a distance of $718 \mathrm{~cm}$ (283 in.) below the 'zero' reference point in the housing.(a) Operators saw the ball disappear from sight below the crust surface on the in-tank video before the load reduction indicated the liquid level. Since the ball diameter is $9.1 \mathrm{~cm}$ ( $4.6 \mathrm{in}$.), the liquid level is at least one radius or $4.6 \mathrm{~cm}$ (1.8 in.) below the crust surface.

Once below the crust, the ball was lowered at a constant $2 \mathrm{~cm} / \mathrm{s}$. The measured drag on the ball was minimal until it began increasing for about the last $40 \mathrm{~cm}$ (16 in.) of travel. The ball became fully supported at a distance of $1,727 \mathrm{~cm}$ (680 in.) below reference. This is $1,009 \mathrm{~cm}$ (397 in.) below the indicated liquid level. Adding one ball radius for the lower surface and one more for the crust surface makes the minimum distance between the crust surface and the point the ball came to rest $1018 \mathrm{~cm}$ (400.8 in.). The nearest waste surface level measurement from the Enraf gauge approximately 20 feet away typically reads $1024 \mathrm{~cm}$ (403 in.). Therefore, it is quite probable that the ball actually reached the tank bottom or to within one ball diameter $(9 \mathrm{~cm})$ of it.

In the next test a week later, the liquid level at riser $11 \mathrm{~B}$ registered $720 \mathrm{~cm}(283.5 \mathrm{in}$.) below the reference point. As before, the ball disappeared below the crust before the load decreased at the liquid level, and there was minimal drag on the ball until it reached about $30 \mathrm{~cm}$ (12 in.) from where it became supported at $1656 \mathrm{~cm}$ (652 in.). Adding one ball diameter to the difference (as above) yields a minimum distance from the crust surface to the stopping point of $945 \mathrm{~cm}$ ( 372 in.). If the crust surface elevation is $1024 \mathrm{~cm}$ (403 in.), as given by the Enraf gauge, the ball stopped $79 \mathrm{~cm}$ (31 in.) above the tank bottom. This is approximately the same level where the VFI began meeting resistance, although it was able to penetrate down to about $61 \mathrm{~cm} \mathrm{(24} \mathrm{in.)}$ by virtue of its greater weight.

The mixed slurry was found to be a non-Newtonian shear-thinning fluid with viscosity of just under 10 Poise but no measurable shear stress. The material near the bottom that the ball was able to pass through before stopping showed shear thickening behavior with a very small yield strength of about $20 \mathrm{~Pa}(0.004 \mathrm{psi})$ and an average viscosity of approximately 200 Poise. The yield stress (strength) profile from riser 4A (where the ball approached the tank bottom) is plotted in Figure 4.7. The elevation at which the yield stress increases corresponds approximately to the elevations where the highest void fractions were measured.

(a) Ball position is measured to the center of the ball; therefore, one radius ( $4.6 \mathrm{~cm}$ or $1.8 \mathrm{in}$.) must be added to calculate the elevation of a surface supporting the ball. 


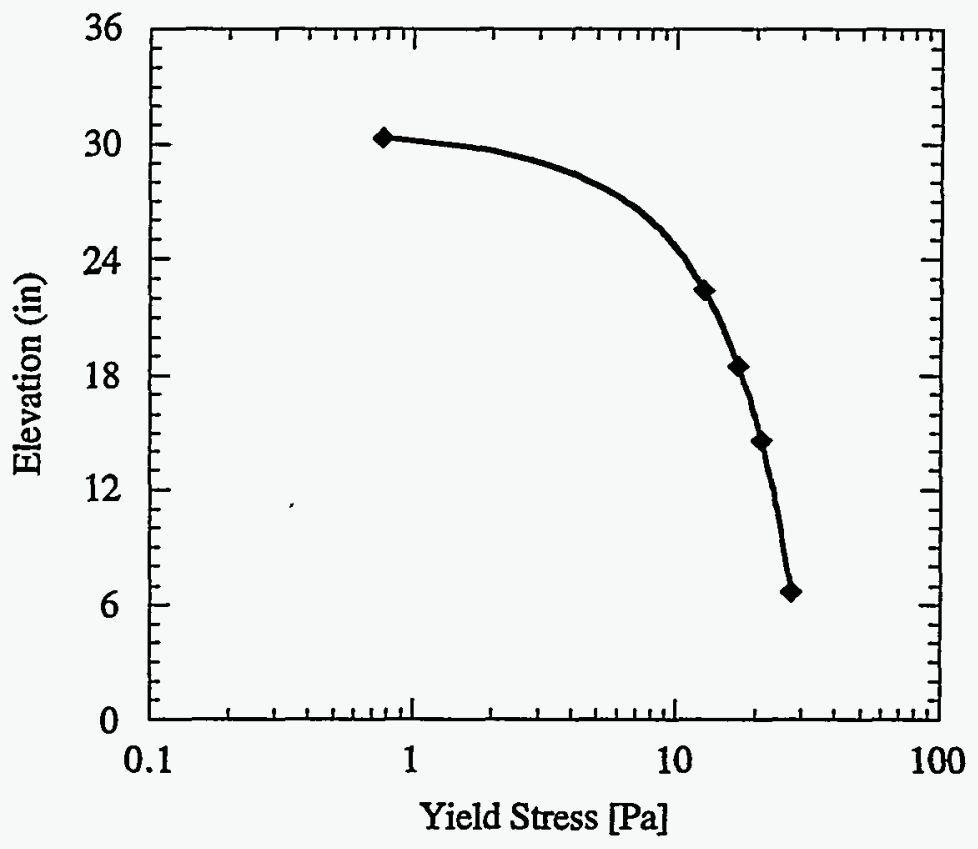

Figure 4.7. Yield Stress of the Loosely Settled Layer in Tank 241-SY-101

\subsection{Gas Volume Estimate}

The VFI, ball rheometer, and two MITs provide evidence of sludge depth at nine locations in four risers (two MITs, two rheometer tests, and five VFI traverses). The locations are generally in the northeast third of the tank spread over a sector of $138^{\circ}$ (about the pump column) and distances from about 6.7 to $9.7 \mathrm{~m}$ ( 22 to $32 \mathrm{ft}$ ) from the pump. The available data points are summarized in Table 4.2. The ball rheometer data also provide a measure of the height of the loosely settled layer above the sludge. Although considerable uncertainty remains, these data allow us to estimate the volume of nonconvecting material on the bottom and the total volume of gas contained therein. The rest of this section addresses these two issues.

\subsubsection{Dimensions Of The Nonconvecting Làyers}

With data at so few locations, constructing a plausible geometry for the sludge layer is a truly daunting task involving much uncertainty. The problem is estimating the three-dimensional geometry of sludge using the information at hand. In view of the uncertainty in any one model, we propose two to illustrate different ways to interpret the results. Model ' $A$ ' is intended to represent the effects of a buoyant jet, and Model ' $B$ ' represents a non-buoyant jet. These shapes only qualitatively reflect jet behavior. No formal analysis has been attempted to determine exact dimensions due to the paucity of required data. 
Table 4.2. Sludge Depth Data from MITs, VFI, and Ball Rheometer

\begin{tabular}{|c|c|c|c|}
\hline $\begin{array}{l}\text { Location } \\
\text { (riser/azimuth/radius)(a) }\end{array}$ & $\begin{array}{l}\text { Sludge Depth } \\
\text { (cm) }\end{array}$ & Date & Source of Estimate \\
\hline $4 A-233^{\circ}-19.4,7.4$ & $<33$ & $1 / 17 / 95$ & VFI - no crane unloading \\
\hline $4 A-233^{\circ}-6.7$ & 0 & $3 / 28 / 95$ & Ball penetration to tank bottom \\
\hline $17 \mathrm{~B}-97^{\circ}-8.6$ & $<41$ & $4 / 13 / 94$ & Temp. jump at TC \#2 \\
\hline $17 \mathrm{~B}-97^{\circ}-8.6$ & $<10$ & $6 / 28 / 95$ & Temp. jump at TC \#1 \\
\hline $17 C-208^{\circ}-9.3$ & $<41$ & $6 / 23 / 95$ & Temp. jump at TC \#2 \\
\hline $17 C-208^{\circ}-9.3$ & $>10$ & $6 / 23 / 95$ & No response at TC \#1 \\
\hline $11 \mathrm{~B}-235^{\circ}-8.3$ & $20-25$ & $12 / 21 / 94$ & VFI - crane unloading \\
\hline $11 \mathrm{~B}-235^{\circ}-9.8$ & $60-76$ & $12 / 21 / 94$ & VFI - crane unloading \\
\hline $11 B-235^{\circ}-9.0$ & 76 & $4 / 5 / 95$ & Ball supported \\
\hline
\end{tabular}

In both models the data from 17B and 17C MITs are used to represent the sludge thickness in line with the jet at 8.6 and $9.3 \mathrm{~m}(28.2$ and $30.5 \mathrm{ft}$ ) from the pump, respectively, and we assume that the thickness varies linearly with distance from the pump. The data in Table 4.2 show thicknesses just over $10 \mathrm{~cm}(4 \mathrm{in}$.) at the near radius and below $40 \mathrm{~cm}(16 \mathrm{in}$.) at the far one. This creates a planar surface that intersects the wall and tank bottom, leaving a large central region without any sludge. However, to be somewhat more conservative, we assume the sludge thickness slopes linearly down to the floor directly under the pump from the $8.6-\mathrm{m}(28.2-\mathrm{ft})$ radius. Actually, since the nozzles are about $60 \mathrm{~cm}(2 \mathrm{ft})$ off the bottom, a shallow cone of sludge a few meters in radius might be expected under the pump. However, the volume would be minimal compared with the uncertainty in the rest of the model, and we choose to ignore it.

Where the two models differ is in the treatment of the scallops between the chosen nozzle azimuths evidenced by the VFI and ball rheometer measurements. We assume in both models that the height of the scallop is nominally $76 \mathrm{~cm}$ (30 in.) at the radius of riser 11B. But Model A assumes the scallop slopes linearly from the pump to the wall and down to the jet centerline. The resulting geometry for a 1/12 (30-degree) sector is shown in Figure 4.8. This model is somewhat conservative in the central region, where the ball rheometer's passage all the way to the bottom would indicate less sludge than the model. 


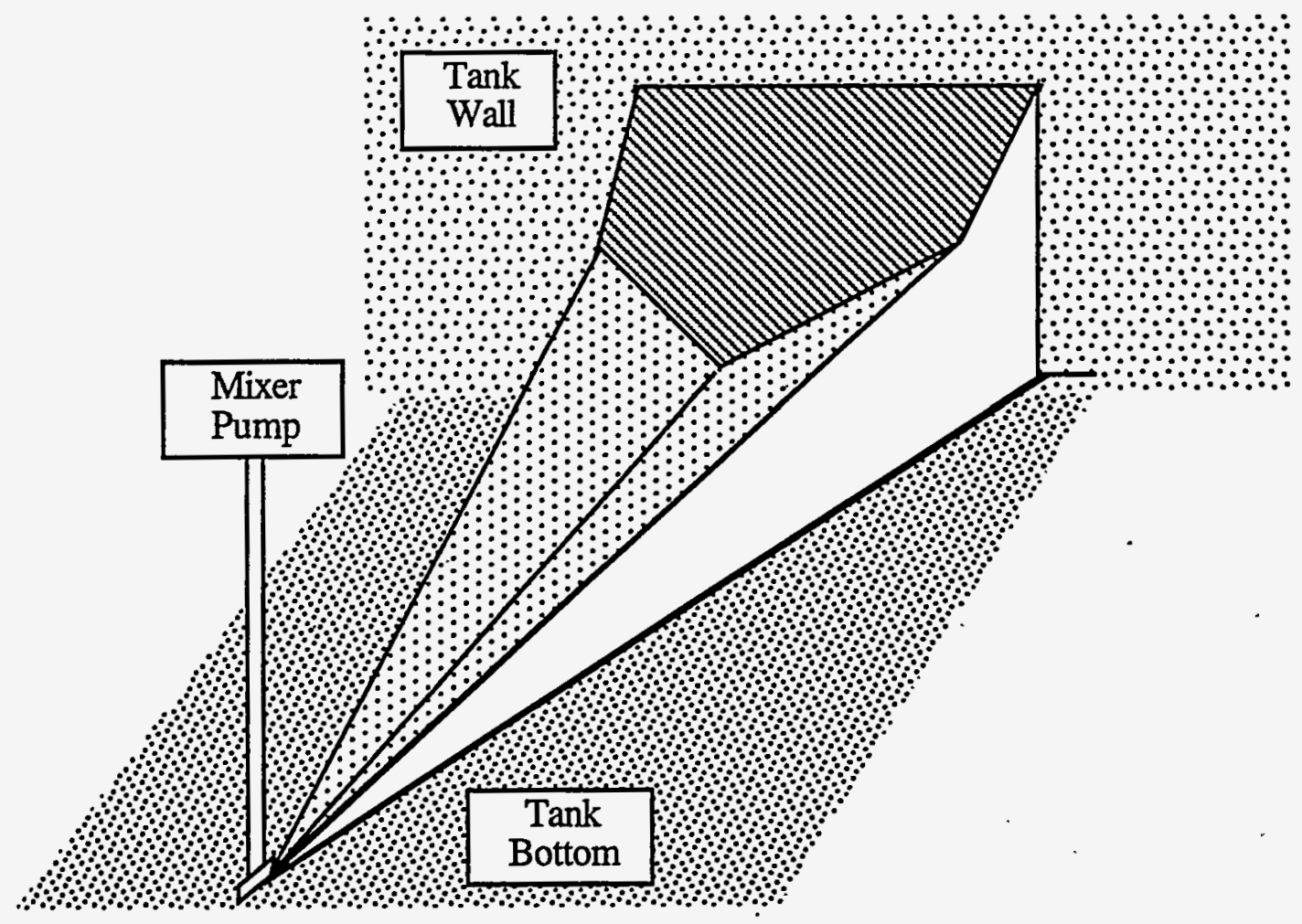

Figure 4.8. Sludge Geometry Model A

Model B divides each $1 / 12$ segment into two subsectors, one in line with the jet and one representing the scallops, without interpolating the sludge height between them. Thus one of the variables determining the sludge volume is the fraction of the segment comprising the jet angle. With the current pump and waste properties, a non-buoyant jet would occupy approximately twothirds of the sector at a 7.3-m (24-ft) radius.(a) The scallop in Model B does not vary linearly from pump to wall but assumes a 'stair step' geometry. The step begins at the $9.3-\mathrm{m}(30.5-\mathrm{ft})$ radius, and its top extends from there to the wall at constant height. The height of the lower part of the step decreases linearly from the wall to the pump centerline. The stair step is a picture of the difference in height where crane unloading occurred during the VFI test in riser 11B. A 1/12 sector of Model B is sketched in Figure 4.9.

In addition to the undisturbed sludge, the data also indicate a loosely settled nonconvective layer that forms from solids settling out of the slurry after a pump run. Both models assume this loose layer fills in the non-sludge volume below some uniform elevation. Considering the temperature, void fraction, and yield stress profiles in Figures 4.2, 4.3, 4.6, and 4.7, respectively, the top of the loose layer is from 60 to $150 \mathrm{~cm}$ ( 2 to $5 \mathrm{ft}$ ) above the tank bottom with a best estimate of $90 \mathrm{~cm}(3 \mathrm{ft})$.

(a) Discussions with D.S. Trent and Y. Onishi, Pacific Northwest Laboratory, Richland, Washington. 


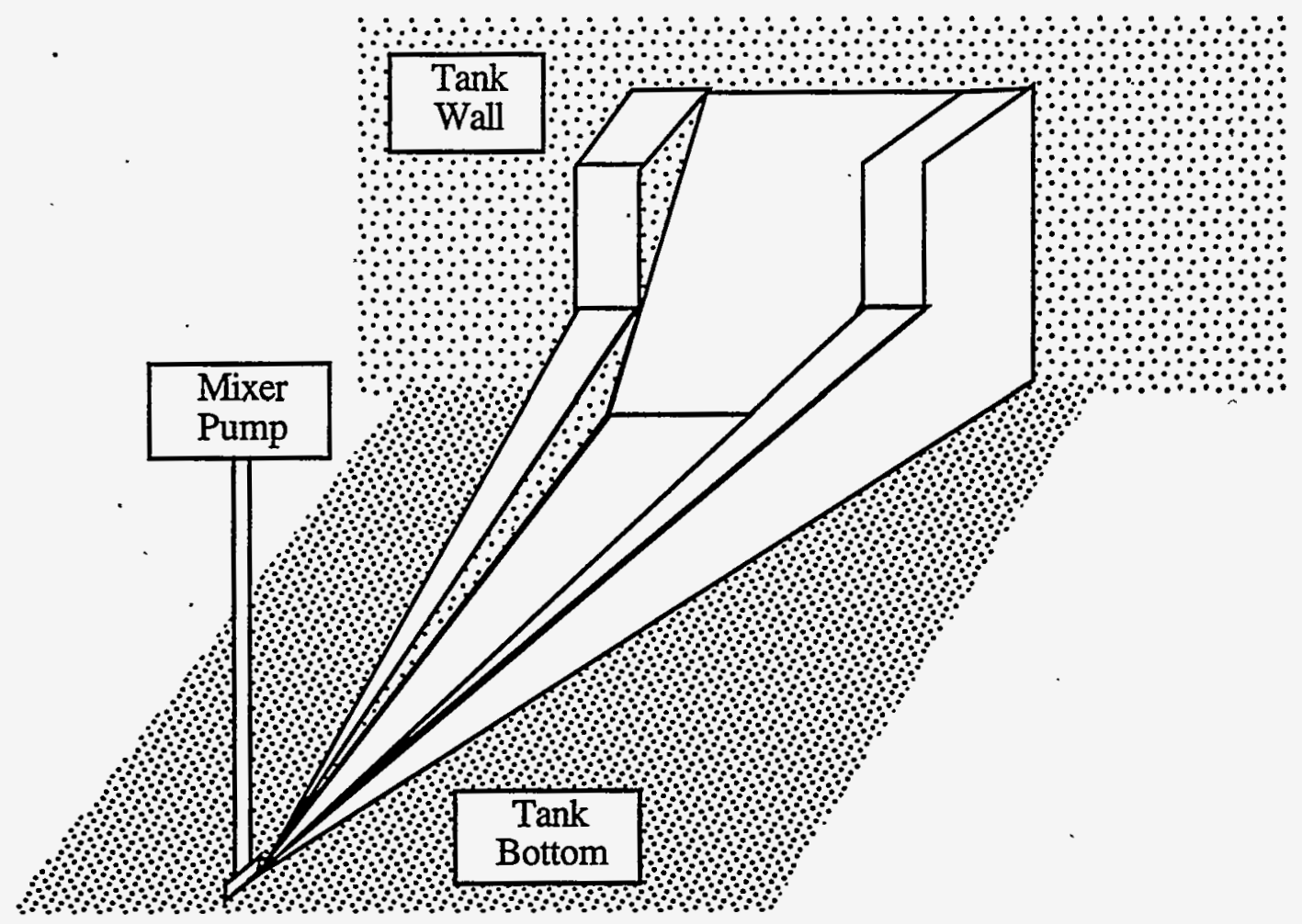

Figure 4.9. Sludge Geometry Model B

The most significant assumptions in these models are that the conditions at a few points represent the entire tank and that the sludge thickness at the wall can be extrapolated from conditions inboard. There is no direct information concerning the sludge depth near the wall, and we cannot eliminate the possibility of large volumes of sludge in quadrants where there are no direct measurements. However, we can add a few less quantitative bounds to the problem to show that the assumptions are reasonable even if they cannot be directly verified.

The sludge layer is almost certainly not exceedingly deep at the wall and may, in fact, be thinner there than just inboard. The uniform temperature measured by the infrared scan of the annulus performed during Full-Scale mixer pump testing would not be consistent with wall sludge above $250 \mathrm{~cm}$ (100 in.). Also, the jet should be deflected outward and downward by the wall, which would tend to prevent a deep sludge layer next to the wall. While there is evidence of somewhat thicker sludge in the scallops between normal pump operation angles, it is not high enough to form a major obstacle to azimuthal flow. Temperature response at the MITs gives a clear indication of pump-induced fluid motion below $70 \mathrm{~cm}$ over a sector at least $60^{\circ}$ from the jet centerline.

\subsubsection{Stored Gas Volume}

The volumes calculated for the sludge and loosely settled layers by the two models are given in Table 4.3. The three values given correspond to maximum, minimum, and best estimates of the various model dimensions.' In terms of a volume estimate with uncertainty, Model A gives a 
Table 4.3. Sludge Volume Calculation Summary

\begin{tabular}{|c|c|c|c|}
\hline Model A (buoyant jet) & Minimum & Best Est. & Maximum \\
\hline Depth at $8.6 \mathrm{~m}(28.2 \mathrm{ft})-\mathrm{cm}$ (in.) & $10(4)$ & $15(6)$ & $20(8)$ \\
\hline Depth at $9.3 \mathrm{~m}(30.5 \mathrm{ft})-\mathrm{cm}$ (in.) & $15(6)$ & $30(12)$ & $40(16)$ \\
\hline Scallop height at $9.3 \mathrm{~m}(30.5 \mathrm{ft})-\mathrm{cm}$ (in.) & $60(24)$ & $75(30)$ & $90(36)$ \\
\hline Loose layer height $-\mathrm{cm}$ (in.) & $60(24)$ & $90(36)$ & $120(48)$ \\
\hline Sludge volume - $\mathrm{m}^{3}\left(\mathrm{ft}^{3}\right)$ & $143(5,045)$ & $182(6,429)$ & $222(7,863)$ \\
\hline Loose layer volume $-\mathrm{m}^{3}\left(\mathrm{ft}^{3}\right)$ & $107(3,791)$ & $193(6,824)$ & $278(9,808)$ \\
\hline Model B (non-buoyant jet) & Minimum & Best Est. & Maximum \\
\hline Depth at $8.6 \mathrm{~m}(28.2 \mathrm{ft})-\mathrm{cm}$ (in.) & $10(4)$ & $15(6)$ & $20(8)$ \\
\hline Depth at $9.3 \mathrm{~m}(30.5 \mathrm{ft})-\mathrm{cm}$ (in.) & $15(6)$ & $30(12)$ & $40(16)$ \\
\hline Scallop height $R>9.3 \mathrm{~m}(30.5 \mathrm{ft})-\mathrm{cm}$ (in.) & $60(24)$ & $75(30)$ & $90(36)$ \\
\hline Scallop height $R<9.3 \mathrm{~m}(30.5 \mathrm{ft})-\mathrm{cm}$ (in.) & $30(12)$ & $40(16)$ & $60(24)$ \\
\hline Jet angle fraction & 0.75 & 0.6667 & 0.5 \\
\hline Loose layer height - cm (in.) & $60(24)$ & $90(36)$ & $120(48)$ \\
\hline Sludge volume $-\mathrm{m}^{3}\left(\mathrm{ft}^{3}\right)$ & $76(2,668)$ & $134(4,738)$ & $193(6,818)$ \\
\hline Loose layer volume $-\mathrm{m}^{3}\left(\mathrm{ft}^{3}\right)$ & $175(6,168)$ & $241(8,515)$ & $307(10,854)$ \\
\hline
\end{tabular}

sludge volume of $181 \pm 40 \mathrm{~m}^{3}\left(6,400 \pm 1,400 \mathrm{ft}^{3}\right)$ with a loosely settled layer of $192 \pm 85 \mathrm{~m}^{3}$ $\left(6,800 \pm 3,000 \mathrm{ft}^{3}\right)$. As expected, Model B yields a lower sludge volume of $133 \pm 59 \mathrm{~m}^{3}$ $\left(4,700 \pm 2,100 \mathrm{ft}^{3}\right)$ but a correspondingly larger loosely settled layer of $240 \pm 65 \mathrm{~m}^{3}$ $(8,500 \pm 2,300 \mathrm{ft} 3)$. Once we assign a void fraction, the volume of gas in the sludge layers, corrected to one atmosphere, is given by

$$
\mathrm{V}_{\text {GAS }}=\alpha \mathrm{V}_{\text {LAYER }}\left[\frac{\mathrm{P}_{\text {LAYER }}}{\mathrm{P}_{1 \text { am }}}\right]
$$

where $V_{L A Y E R}$ and $P_{L A Y E R}$ are the volume and local pressure of a waste layer, respectively, and $\alpha$ is its void fraction.

The uncertainty in the gas volume can be calculated as the root-mean-square of the individual uncertainties formed from the differential of Equation (4.1). Neglecting the relatively small uncertainty in hydrostatic pressure, this yields 


$$
\Delta V_{\mathrm{GAS}}=\frac{\mathrm{P}_{\text {LAYER }}}{\mathrm{P}_{\mathrm{I}_{\mathrm{amm}}}}\left[\left(\mathrm{V}_{\mathrm{LAYER}} \Delta \alpha\right)^{2}+\left(\alpha \Delta \mathrm{V}_{\mathrm{LAYER}}\right)^{2}\right]^{1 / 2}
$$

The next step is to assign a void fraction and uncertainty. The VFI measured from $8-12 \%$ at the lowest locations, so we can assign a value of $\pm 2 \%$ to the uncertainty in the void fraction due to location and interpretation of results in the sludge. The uncertainty in the void measurement itself is $\pm 2 \%$ by design, although tests and error analyses consistently indicated errors of less than $1 \%$ (Stewart et al. 1995). Assuming the former, the total void fraction and rms uncertainty in the sludge is $10 \pm 3 \%$. The loosely settled layer above the sludge measured $2-5 \%$ void. We shall assume a combined $2 \%$ uncertainty to give the void fraction of this layer as $3.5 \pm 2 \%$.

Given these void fractions and the volumes of the two lowest layers, Eq. (4.1) and (4.2) yield gas volumes of $62 \pm 21 \mathrm{~m}^{3}(2,200 \pm 700 \mathrm{SCF})$ at one atm for Model A and $53 \pm 22 \mathrm{~m}^{3}$ $(1,900 \pm 800 \mathrm{SCF})$ for Model B. One can also assume that the material that supported the VFI and ball under riser $11 \mathrm{~B}$ was only a local obstruction, and that the void fraction profile given in Figure 4.6 applies everywhere. Integrating this void profile assuming a uniform $11 \%$ void below $25 \mathrm{~cm}$ (10 in.) yields a gas volume of $59 \pm 22 \mathrm{~m}^{3}(2,100 \pm 800 \mathrm{SCF})$ at STP. It is clear that, within the uncertainty of the calculation, there is no significant difference in the gas volume estimated for these three models.

The void fraction typically measured zero in the convective slurry. Although this is consistent with the relatively fast rise times of even very small bubbles and bubble-particle systems, the uncertainty in the VFI zero measurement might allow up to $1 \pm 0.5 \%$ void fraction in the slurry. Subtracting the volume of the sludge and loosely settled layers from the total non-crust waste volume (allowing $\pm 10 \mathrm{~cm}$ uncertainty in crust thickness and computing the rms combination) yields a total slurry volume of $3,400 \pm 100 \mathrm{~m}^{3}\left(120,000 \pm 3,500 \mathrm{ft}^{3}\right)$ for both Model A and B geometries. At a $1 \pm 0.5 \%$ void, this volume would contain $58 \pm 29 \mathrm{~m}^{3}\left(2,040^{\circ} \pm 1,000 \mathrm{SCF}\right)$ of gas at STP assuming it is stored at $1.7 \mathrm{~atm}$.

Since all gas released from the waste must eventually pass through the crust, this layer must contain some gas. In fact, since the solid crust material is more dense than the surrounding liquid, it must have a significant gas content to float. This is estimated to be $102 \pm 34 \mathrm{~m}^{3}$ $(3,600 \pm 1,200 \mathrm{SCF})$ at STP, a $25 \%$ void fraction, using a reasonable estimate for crust properties(a) along with a reasonable range of property values and uncertainty in crust thickness. The pressure of this gas volume is considered to be one atmosphere.

Adding up the stored gas volumes of each of the four layers yields a total of $222 \pm 53 \mathrm{~m}^{3}$ $(7,800 \pm 1,700 \mathrm{SCF})$ of gas at $1 \mathrm{~atm}$. Individual contributions, with lower layers based on

(a) Herting et al. (1992) report that the solids in the (Window C) crust samples taken in May 1992 showed approximately the same chemical and radiochemical composition as that of the nonconvective layer samples. Because of this, in estimating the void fraction of the crust to be $\sim 25 \%$, we have assumed a crust solids density of $2.3 \mathrm{~g} / \mathrm{cm}^{3}$ and a liquid density of $1.46 \mathrm{~g} / \mathrm{cm}^{3}$. The bulk crust density is assumed to be $1.42 \mathrm{~g} / \mathrm{cm}^{3}$ (somewhat lower than the liquid density), and the crust liquid fraction is taken to be $35 \%$, within the crust water fraction range report by Herting et al. 
Model A, are summarized in Table 4.4.(a) The compressed volume in situ is obtained by dividing by the effective pressure to get $170 \pm 37 \mathrm{~m}^{3}\left(6,000 \pm 1,300 \mathrm{ft}^{3}\right)$. The equivalent waste level if all gas were removed ("degassed level") is computed from the compressed volume by

$$
\mathrm{L}_{\mathrm{NO}-\mathrm{GAS}}=\mathrm{L}_{\mathrm{M}}-\frac{\mathrm{V}_{\mathrm{In}-\mathrm{Situ}}}{\mathrm{A}} \text {. }
$$

where $L_{M}$ is the waste level corresponding to the time the gas volume was measured and $V_{\text {In-Situ }}$ is the compressed volume. Given the waste level of $1016 \pm 5 \mathrm{~cm}(400 \pm 2 \mathrm{in}$.) when the void measurements were made, the degassed waste level is $975 \pm 10 \mathrm{~cm}$ (384 \pm 4 in.) from Equation (4.3).

A release of $156 \mathrm{~m}^{3}(5,500 \mathrm{SCF})$ would be required to raise the hydrogen concentration to the lower flammability limit of $3 \%$, assuming a total dome volume of about $1,560 \mathrm{~m}^{3}\left(55,000 \mathrm{ft}^{3}\right)$ and that the gas is $30 \%$ hydrogen. This means that the estimated total retained gas volume would potentially exceed the flammability limit if it were all released simultaneously. But it is essentially impossible to release all the stored gas at once. The largest gas release event recorded in SY-101 (Event $\mathrm{G}$ in September 1992 released over $280 \mathrm{~m}^{3}$ ) released under $50 \%$ of the gas estimated to be stored at that time. Using this fraction, the maximum release of the gas currently stored would be only $102 \mathrm{~m}^{3}(3,600 \mathrm{SCF})$.

Table 4.4. Volume of Gas Stored in Waste Layers

\begin{tabular}{||l|c|c|c|c||}
\hline Waste Layer & $\begin{array}{c}\text { Layer Volume } \\
\left(\mathrm{m}^{3}\right) /\left(\mathrm{ft}^{3}\right)\end{array}$ & Void (\%) & $\begin{array}{c}\text { Pressure } \\
(\mathrm{atm})\end{array}$ & $\begin{array}{c}\text { Gas Volume } \\
\left(\mathrm{m}^{3} \text { at STP)/(SCF) }\right.\end{array}$ \\
\hline \hline Crust & $\begin{array}{c}416 \pm 42 \\
(14,700 \pm 1,470)\end{array}$ & $25 \pm 8$ & 1.0 & $\begin{array}{c}102 \pm 34 \\
(3,600 \pm 1,200)\end{array}$ \\
\hline Mixed Slurry & $\begin{array}{c}3,400 \pm 100 \\
(120,000 \pm 3,500)\end{array}$ & $1 \pm 0.5$ & 1.7 & $\begin{array}{c}58 \pm 29 \\
(2,000 \pm 1,000)\end{array}$ \\
\hline Loosely Settled & $\begin{array}{c}192 \pm 85 \\
(6,800 \pm 3,000)\end{array}$ & $3.5 \pm 2$ & 2.4 & $\begin{array}{c}16 \pm 12 \\
(600 \pm 400)\end{array}$ \\
\hline Sludge & $\begin{array}{c}181 \pm 40 \\
(6,400 \pm 1,400)\end{array}$ & $10 \pm 3$ & 2.5 & $\begin{array}{c}46 \pm 17 \\
(1,600 \pm 600)\end{array}$ \\
\hline Total (or Avg.) & $\begin{array}{c}4,188 \\
(147,900)\end{array}$ & $3.8 \pm 1.2$ & $1.3(\mathrm{a})$ & $\begin{array}{c}222 \pm 49(\mathrm{~b}) \\
(7,800 \pm 1,700)\end{array}$ \\
\hline \hline $\begin{array}{l}\text { (a) Pressure calculated to give equivalent compressibility. } \\
\text { (b) Uncertainties combined as rms. }\end{array}$
\end{tabular}

(a) The gas volumes and uncertainties given in the last column of Table 4.4 are slightly different from the values reported in Table 2.3 of Stewart et al. (1995). The earlier table contained several errors in gas volume calculation and uncertainty propagation that have since been corrected. 
- Even this event is extremely unlikely. No rollovers have been observed since Phase B testing, and there is no indication from tank data that any significant gas release is imminent. The slurry, the loosely settled layer, and the top of the sludge layer are violently disturbed every few days by the pump jets with the express purpose of releasing the maximum amount of gas possible. All gas releases during pump runs since Phase B testing have been under $500 \mathrm{SCF} /$ day. There is no reason to expect any larger spontaneous release from these layers. Finally, the gas in the crust is held in a stable condition that is not subject to sudden releases.

\subsection{Estimated Gas Release Fraction}

It is impossible for the entire free gas content of the waste to be released in a gas release event (GRE). Even if the entire volume of gas-bearing sludge participates, gas is released only until the sludge that has come to the surface returns below neutral buoyancy. Then the sludge and the gas still retained within it sinks back to the bottom of the tank. Also, bubbles smaller than approximately 100 microns in diameter attached to particles probably do not escape. Historically this "unreleasable" gas fraction has been estimated at 6-8\% void.

The actual fraction of the total retained gas volume released in each event represents the product of the fraction of sludge participating and the fraction of gas that is released from that sludge volume. This product is equal to the ratio of pre-GRE gas volume to the volume released. Since we have reasonably good estimates of the current total gas content in SY-101 from the void fraction instrument, the amount of gas stored in the waste prior to each historical GRE can be calculated from the waste level. No estimate of the effective pressure of the stored gas is necessary since the ratio of gas release to initial inventory is independent of pressure. The release fraction is calculated by

$$
F_{\text {rel }}=\frac{\Delta L_{\mathrm{GRE}}}{\left(\mathrm{L}_{\mathrm{GRE}}-\mathrm{L}_{\mathrm{NO}-\mathrm{GAS}}\right)}
$$

where $\Delta \mathrm{L}_{\mathrm{GRE}}$ is the level drop, $\mathrm{L}_{\mathrm{GRE}}$ is the pre-burp waste level, and $\mathrm{L}_{\mathrm{NO}-\mathrm{GAS}}$ is the degassed waste level from Equation (4.3).

A summary of the historical data from GREs that have been observed in SY-101 since March 25, 1989, is given in Table 4.5. Based on the estimated no-gas level of $975 \pm 10 \mathrm{~cm}$ (384 \pm 4 in.), the average release fraction from this data is $0.26 \pm 0.08$.(a) The largest release,

(a) Pasamehmetoglu has calculated an no-gas level of $963 \mathrm{~cm}$ (379 in.), which gives higher estimates of the pre-burp gas volume and therefore much lower release fractions. See Bubble Inventory in Tank 241-SY-101, by K. O. Pasamehmetoglu,, 1994. LANL Calc-Note TSA6-CN-WT-SA-GR-034, Los Alamos National Laboratory, Los Alamos, New Mexico. 
Event $G$ (September 3, 1992), had the highest release fraction of 0.413 . The observed waste level drop and the reported gas releases are taken from Reynolds(a) and from Wilkins.(b)

The \pm 0.08 uncertainty in the average release fraction is the standard deviation of the values in Table 4.5 about the average. Assuming an uncertainty of $\pm 5 \mathrm{~cm}(2 \mathrm{in}$.) in absolute level and $\pm 3 \mathrm{~cm}$ (1 in.) in level drop, the uncertainty in an individual release fraction calculation using Equation (4.4) is on the order of \pm 0.03 . Since the random effect of this error is effectively already included in the data scatter we do not attempt to combine it with the overall uncertainty a second time. The rms contribution is small in any event.

Table 4.5. A Summary of GREs in Tank 241-SY-101

\begin{tabular}{||c|c|c|c|c|c|c||}
\hline \hline Event & Date & $\begin{array}{c}\text { Level drop } \\
(\mathrm{cm})\end{array}$ & $\begin{array}{c}\text { In-Situ Gas } \\
\text { release }\left(\mathrm{m}^{3}\right)\end{array}$ & $\begin{array}{c}\text { Pre-GRE } \\
\text { Level }(\mathrm{cm})\end{array}$ & $\begin{array}{c}\text { Pre-GRE Gas } \\
\text { Volume }\left(\mathrm{m}^{3}\right)\end{array}$ & $\begin{array}{c}\text { Fraction of Gas } \\
\text { Released }\end{array}$ \\
\hline \hline & $3 / 25 / 89$ & 25 & 101 & 1075 & 408 & $0.247 \pm 0.026$ \\
\hline & $6 / 10 / 89$ & 17 & 69 & 1063 & 358 & $0.192 \pm 0.029$ \\
\hline & $9 / 12 / 89$ & 21 & 88 & 1063 & 362 & $0.242 \pm 0.029$ \\
\hline & $12 / 30 / 89$ & 20 & 80 & 1058 & 339 & $0.237 \pm 0.031$ \\
\hline & $4 / 19 / 90$ & 23 & 93 & 1058 & 339 & $0.274 \pm 0.031$ \\
\hline A & $10 / 24 / 90$ & 28 & 116 & 1050 & 307 & $0.376 \pm 0.034$ \\
\hline B & $2 / 16 / 91$ & 13 & 52 & 1039 & 262 & $0.199 \pm 0.040$ \\
\hline C & $5 / 16 / 91$ & 18 & 75 & 1046 & .292 & $0.257 \pm 0.036$ \\
\hline D & $8 / 27 / 91$ & 14 & 57 & 1049 & 302 & $0.190 \pm 0.035$ \\
\hline E & $12 / 4 / 91$ & 33 & 135 & 1057 & 337 & $0.402 \pm 0.031$ \\
\hline F & $4 / 20 / 92$ & 18 & 75 & 1052 & 313 & $0.240 \pm 0.033$ \\
\hline G & $9 / 3 / 92$ & 34 & 138 & 1057 & 333 & $0.413 \pm 0.032$ \\
\hline H & $2 / 2 / 93$ & 21 & 84 & 1044 & 283 & $0.298 \pm 0.037$ \\
\hline I & $6 / 26 / 93$ & 16 & 67 & 1049 & 300 & $0.222 \pm 0.035$ \\
\hline \hline
\end{tabular}

(a) Reynolds, D. A. 1992. Technical Basis for Selection of Tank 101-SY Intrusion Window. WHCSD-WM-TI458 Rev. 3, Westinghouse Hanford Company, Richland, Washington.

(b) Wilkins, N. E. 1993. Evaluation of September 1992 Tank 241-SY-101 Gas Release Event. WHC-SD-WM-PE-047 Rev. 0, Westinghouse Hanford Company, Richland, Washington. 



\subsection{Other Stored Gas Estimates}

In Section 4, a "best" estimate of retained gas volume was derived from the direct measurements by the void fraction instrument (VFI) and the ball rheometer, temperature profiles, and transient temperature responses to mixer pump operation. This information was integrated into a. coherent picture of the current volume and distribution of free gas in the tank. This section contains a discussion of two more retained gas estimate methods. With the proper assumptions, both of these methods yield gas volumes consistent with the "best" estimate.

The first method uses a correlation of atmospheric pressure and waste surface level to determine the compressibility of the waste. The compressibility, along with an estimated effective hydrostatic pressure, provides another estimate of the retained gas volume. The second method, developed in support of the current mixer pump safety assessment, uses an extrapolation from historical tank data prior to pump installation to determine a gas-free waste level. The current gas inventory is then determined from the difference between the current waste level and the gas-free level.

\subsection{Computing Retained Gas Volume from Barometric Pressure-Induced Level Changes}

Barometric pressure and level data from Tank 241-SY-101 have been examined to compute the amount of retained gas in the tank. The average response of the surface level to barometric pressure changes was estimated as $-0.35 \pm 0.08 \mathrm{~cm} / \mathrm{kPa}(-0.95 \pm 0.23 \mathrm{in} . / \mathrm{psi})$ during the time from March 16 to June 15,1995 . The corresponding estimate of standard gas volume is $238 \pm 68 \mathrm{~m}^{3}$ $(8,400 \pm 2400 \mathrm{SCF})$ at $1 \mathrm{~atm}$ assuming the gas is held at an effective pressure of $1.29 \pm 0.1 \mathrm{~atm}$. This choice of effective pressure is based on the distribution of gas described in Section 4.

\subsubsection{Technical Basis}

Let us first review the technical basis of the calculation. We assume that the gas in the waste is ideal and isothermal. We also assume that a change in absolute tank dome pressure is instantaneously translated to an equal change in pressure of the gas in situ. Using the property that the standard volume of the gas is independent of the pressure at which the gas is held, the waste level, $L$, can be expressed as

$$
L=L_{0}+\frac{V_{s t} P_{0}}{A P}
$$

where $L_{0}$ is the level that would be observed if all gas were removed, $P_{0}$ is standard atmospheric pressure, $P$ is the effective hydrostatic pressure of the gas, and $A$ is the tank cross-sectional area. Differentiating Equation (5.1) with respect to $P$ gives

$$
\frac{\partial L}{\partial P}=-\frac{V_{s t} P_{0}}{A P^{2}}
$$


The slope $\partial \mathrm{L} / \partial \mathrm{P}$ is a measure of the total compressibility of the tank and is proportional to the amount of gas present. Solving Equation (5.2) for $\mathrm{V}_{\mathrm{st}}$ gives

$$
V_{s t}=-\frac{P^{2} A}{P_{0}} \frac{\partial L}{\partial P}
$$

Note that the standard volume estimate depends on the square of the pressure at which the gas is held.

An alternative derivation was described in Allemann et al. (1994). This derivation relies on the in situ volume of the gas, $\mathrm{V}$, which is not independent of pressure. We have

$$
\mathrm{PV}=\text { constant }
$$

Differentiating Equation (5.4) with respect to $P$ gives

$$
\mathrm{V}+\mathrm{P} \frac{\partial \mathrm{V}}{\partial \mathrm{P}}=0
$$

The level of the tank is given by

$$
\mathrm{L}=\mathrm{L}_{0}+\frac{\mathrm{V}}{\mathrm{A}}
$$

Differentiation with respect to $P$ and substitution from Equation (5.5) gives

$$
\frac{\partial L}{\partial P}=-\frac{V}{A P}
$$

which is equivalent to (5.2). Solving Equation (5.7) for the volume, we obtain

$$
V=-P A \frac{\partial L}{\partial P}
$$

To obtain the average void fraction, we divide Equation (5.8) by the volume of waste, $L$, to obtain

$$
\text { void fraction }=-\frac{P}{L} \frac{\partial L}{\partial P}
$$

The standard volume of gas in the tank is obtained from the in-situ volume by

$$
\mathrm{V}_{\mathrm{st}}=\frac{\mathrm{PV}}{\mathrm{P}_{0}}
$$


We take the value of $\mathrm{L}$ to be $10.16 \mathrm{~m}$ ( $400 \mathrm{in}$.) based on current FIC measurements. The area, obtained from the tank diameter of $22.86 \mathrm{~m}$ ( $75 \mathrm{ft})$, is $410.4 \mathrm{~m}^{2}\left(4418 \mathrm{ft}^{2}\right)$. The slope, $\partial \mathrm{L} / \partial \mathrm{P}$, is calculated in units of $\mathrm{cm} / \mathrm{kPa}$ (in./psi).

We can calculate the void fraction and standard volume of gas in the waste from Equation (5.9) and (5.3) provided we make an assumption for the pressure $P$ of the gas in situ. An assumption of $2.5 \mathrm{~atm}$ places most of the gas near the bottom of the tank and can be considered a conservative estimate. An estimate of $1 \mathrm{~atm}$ places most of the gas volume in the crust and is probably more accurate based on the distribution of gas developed in Section 4. These two extremes of pressure give very different estimates of the retained gas volume, since the standard volume depends on the square of the pressure at which the gas is held, as shown in Equation (5.3). The difference between an assumption of $2 \mathrm{~atm}$ and $1 \mathrm{~atm}$ changes the estimate of the standard volume by a factor of 4 .

The formula relating the barometric pressure difference to the level change assumes that the average depth at which the gas is held will not change. This hypothesis is unlikely to be accurate, however. Only gas that is physically trapped in the sludge or the crust will not change depth in response to barometric pressure changes. In the current state of the waste, some of the gas is in the form of free bubbles that are rising due to buoyancy in addition to being transported convectively. A decrease in barometric pressure causes the bubbles to expand, increasing the buoyant force and thus increasing the rate of rise. When bubbles are attached to a solid particle to form a neutrally buoyant complex, a decrease in barometric pressure would also raise the level at which the complex is neutrally buoyant. Both effects would cause an increase in the response $\partial \mathrm{L} / \partial \mathrm{P}$, leading to an overprediction of the amount of retained gas. The quantitative effect of these factors has been modeled (see Sections 6.1 and 6.2 ).

There is an additional effect due to surface tension that would apply to small bubbles-that effect is not considered here. The volume-average bubble diameter is estimated (Section 6) to be over $0.1 \mathrm{~mm}$, for which the added internal pressure due to surface tension is less than $0.004 \mathrm{~atm}$.

In principle, the waste level is a nonlinear function of the barometric pressure. Thus a measurement of the second derivative of level with respect to pressure would determine the effective hydrostatic pressure directly. In practice, the presence of other factors affecting the level (intermittent gas retention and release by pumping) obscure the nonlinear response to barometric pressure. However, if sufficient high-quality data become available in unmixed tanks, the nonlinearity of the response might make it possible to estimate the gas volume and its pressure simultaneously.

\subsubsection{Prediction of Level Response from Stored Gas Estimates}

Based on the VFI, the best estimate of retained gas volume is $222 \mathrm{~m}^{3}(7,800 \mathrm{SCF})$ at one atmosphere. From the average depth of each layer and the estimated volumes given in Table 4.4, we can estimate the contribution to the response of the surface level to changes in the barometric pressure using Equation (5.2). This yields a predicted compressibility of $-0.317 \pm 0.12 \mathrm{~cm} / \mathrm{kPa}$ $(-0.86 \pm 0.32$ in./psi). 
The uncertainty in the expected response of level to barometric pressure is driven by the uncertainty in the volume of gas in the crust, whose primary components are uncertainty in the thickness of the crust, the porosity of the solid matrix of the crust, and the density of the crust solids. No direct measurement of retained gas in the crust is available. Other contributions to the uncertainty come from movement of free bubbles or bubble/particle complexes (Section 6) and changes in buoyancy of the crust, both effects leading to amplification of the response to barometric pressure. These effects were taken into account in setting the uncertainty intervals in the pressure for the convective layer and the crust:

We can solve Equation (5.7) for an effective pressure that produces a volume estimate of $222 \mathrm{~m}^{3}(7,800 \mathrm{SCF})$ given a level response of $-0.317 \pm 0.12 \mathrm{~cm} / \mathrm{kPa}(-0.86 \pm 0.32 \mathrm{in} . / \mathrm{psi})$. The equation is

$$
P_{\text {eff }}=\sqrt{\frac{V_{s t} P_{0}}{A \frac{\partial L}{\partial P}}}
$$

The result of this calculation is $P_{e f f}=1.29 \mathrm{~atm}$. A precise propagation of errors has not been performed on this estimate; based on engineering judgement, we will use an uncertainty interval of $\pm 0.1 \mathrm{~atm}$. Using this value for the effective pressure, the measured response of $-0.35 \pm 0.08 \mathrm{~cm} / \mathrm{kPa}(-0.95 \pm 0.23 \mathrm{in} . / \mathrm{psi})$ corresponds to $238 \pm 68 \mathrm{~m}^{3}(8,400 \pm 2,400 \mathrm{SCF})$ at $1 \mathrm{~atm}$. This matches the best estimate closely within the overlapping uncertainties.

\subsubsection{Estimates of Response from Enraf Level Measurements}

Data from the Enraf level instrument was available beginning December 15,1994 . The Enraf gauge appears to be highly accurate (Peters and Park 1992). The uncertainty in the absence of significant horizontal movement is $\pm 0.076 \mathrm{~cm}$ ( $\pm 0.03 \mathrm{in}$.), which is less than $10 \%$ of the maximum level difference. Data from manual readings of the Enraf gauge, once per shift, and barometric pressure readings, at the beginning of each shift, were examined. Outliers were identified graphically and from the correlation between level instruments and removed. A quadratic fit was subtracted from the level time series to remove long-term trends from the level data. Points at extreme values of the pressure were removed to avoid biasing the slope estimate and, finally, a linear regression was performed that provided an estimate of the slope and a "goodness of fit" estimate.

This analysis was performed on three-month intervals of data corresponding to the first and second quarters of 1995 . The results from the two periods are similar and agree to well within the $95 \%$ confidence limit. For the first quarter of 1995 a value of $-0.38 \pm 0.08 \mathrm{~cm} / \mathrm{kPa}$ $(-1.03 \pm 0.22 \mathrm{in} . / \mathrm{psi})$ was obtained. For the second quarter of 1995 the value was $-0.35 \pm 0.08 \mathrm{~cm} / \mathrm{kPa}(-0.95 \pm 0.23 \mathrm{in} . / \mathrm{psi})$.

To determine the accuracy of the barometric pressure measurement, barometric pressure readings collected hourly over a six-month period were obtained from the PNL weather station, whose barometer is calibrated by the National Weather Service. The readings were corrected by 
the weather station staff to a point midway between the $200 \mathrm{~W}$ and $200 \mathrm{E}$ areas. A comparison of barometric pressure and DACS weather station readings at selected times was performed; differences were less than $0.1 \%$ of the readings; this corresponds to an error of $\pm 0.1 \mathrm{kPa}(0.03 \mathrm{in} . \mathrm{Hg})$. Pressure differences used in the barometric pressure to level correlation were about $1.0 \mathrm{kPa}$ $(0.3$ in. $\mathrm{Hg})$. Thus the error in a given pressure difference measurement is no more than $10 \%$.

A certain amount of the error in the slope estimate may be due to uncertainties in the time at which the level measurement was taken. We have assumed the measurement is taken at the beginning of each shift, but it may actually be taken at any time during the shift. A linear correlation between level and pressure measurements is not an ideal statistical technique in this case because of the uncertainty in the pressure caused by the lack of precise times for level measurements. When there is a significant amount of noise in the $x$-axis data as well as the $y$-axis data, a linear correlation typically underpredicts the slope. To obtain an accurate prediction of the slope, a different regression technique should be used that accounts for both types of errors. When the Enraf level data are available on-line, the barometric pressure will also be available at the corresponding times.

\subsubsection{Estimates of Response from Radar Measurements}

In this section the estimation of the response $\partial \mathrm{L} / \partial \mathrm{P}$ from DACS radar gauge measurements is described. This estimate was used prior to December 15, 1994, when the Enraf level data first became available. The radar gauge apparently succumbed to radiation during the spring of 1995 and is no longer giving useful data.

All measurements are taken at 12-second intervals, and there is no need to interpolate between them. To remove noise, the data were averaged over five-minute intervals. The absolute tank dome pressure was obtained by adding the DACS barometric pressure to the tank dome gauge pressure. The level was measured with the radar gauge. Level and pressure differences were calculated on all intervals from November 3 to 12,1994. Where measurements of all quantities were available, the response was calculated as the ratio of these differences. Intervals with a pressure difference of less than $0.01 \mathrm{~atm}(0: 15 \mathrm{psi})$, which is about half the maximum pressure difference observed, were discarded since the effects of noise are amplified when the denominator is small. The remaining data were averaged with equal weight, and the resulting mean value is $-0.51 \pm 0.074 \mathrm{~cm} / \mathrm{kPa}(-1.38 \pm 0.2 \mathrm{in} . / \mathrm{psi})$.

The $95 \%$ confidence interval was obtained according to a formula derived for this procedure from numerical experiments applied to artificial data produced by a random number generator. The results of this experiment are that the standard deviation of the average response is equal to the standard deviation of the sample multiplied by 0.14 . If the samples were truly independent the multiplying factor would be the $(-1 / 2)$ power of the number of samples, but because the responses come from overlapping intervals in a time series, they are not completely independent. The resulting $95 \%$ confidence interval for the gas volume estimate is $\pm 13 \%$.

These estimates of response are much larger than are being obtained currently with the Enraf and FIC gauges. While the radar gauge data have the advantage of frequent measurements at precise times, they are corrupted by very large noise and unknown effects that may correlate with pressure changes. The gas volume estimates based on the radar gauge should be viewed with suspicion. 


\subsubsection{Historical Estimates of Response}

Historically, correlations between barometric pressure and Tank 241-SY-101 surface level have yielded predictions of large amounts of gas, with a large range of uncertainty due to the lack of information about model assumptions. This subsection revisits these estimates of the pressure response in light of the distribution of gas determined in Table 4.4 to calculate the stored gas volumes and equivalent degassed waste levels.

The barometric pressure/level correlation was extensively studied in Allemann et al. (1994) for the period around May 1992 , when a response of $-0.317 \pm 0.052 \mathrm{~cm} / \mathrm{kPa}(-0.86 \pm 0.14 \mathrm{in} . / \mathrm{psi})$ was calculated. This period followed GREs in late 1991 and on April 20, 1992, that had completely submerged the crust. Thus we may assume that the gas in May 1992 is primarily held in sludge $5.1 \mathrm{~m}$ (200 in.) deep at an average pressure of $2.2 \mathrm{~atm}$, with a smaller amount in submerged crust at one atm and with a combined effective pressure of roughly $1.9 \mathrm{~atm}$. This yields a standard volume of $478 \pm 170 \mathrm{~m}^{3}(16,800 \pm 6,000 \mathrm{SCF})$. Starting from an FIC reading of $1029 \pm$ $3 \mathrm{~cm}(405 \pm 1 \mathrm{in}$.), this corresponds to a degassed level of $968 \pm 15 \mathrm{~cm}$ (381 $\pm 6 \mathrm{in}$.).

An estimate of $-0.43 \pm 0.09 \mathrm{~cm} / \mathrm{kPa}(-1.17 \pm 0.24 \mathrm{in} . / \mathrm{psi})$ made using data from December 1993 is reported in Stewart et al. (1994). The temperature profiles in that report on Full-Scale testing show that the crust depth is about $100 \mathrm{~cm}$ (40 in.). If we assume that the crust, convective, and loosely settled layers have similar gas contents, as presented in Table 4.4 , then $-0.26 \mathrm{~cm} / \mathrm{kPa}$ $(-0.7 \mathrm{in./psi)}$ of the response is due to the crust, and the effective pressure of the non-crust gas is roughly $2.2 \mathrm{~atm}$. This estimate matches the earlier one closely at standard volume of $458 \pm 230 \mathrm{~m}^{3}$ $(16,000 \pm 8,200 \mathrm{SCF})$. With an FIC level of $1016 \pm 5 \mathrm{~cm}$ (400 $\pm 2 \mathrm{in}$.), the degassed level is 952 $\pm 23 \mathrm{~cm}(375 \pm 9$ in.).

The more recent calculation above based on the radar gauge for November 1994 gave a response of $-0.51 \pm .07 \mathrm{~cm} / \mathrm{kPa}(-1.38 \pm 0.2 \mathrm{in} . / \mathrm{psi})$. This yields quite a large gas estimate of $570 \pm 220 \mathrm{~m}^{3}(20,000 \pm 7,600 \mathrm{SCF})$ and a degassed level of $935 \pm 20 \mathrm{~cm}$ (368 $\pm 8 \mathrm{in}$.), starting from an FIC level of $1013 \pm 5 \mathrm{~cm}(399 \pm 2$ in.).

These estimates are summarized in Table 5.1. It is clear that gas volume estimates for SY101 are typically high and suffer from a large uncertainty. Scatter in the linear fit between barometric pressure and level is aggravated by the movement and release of gas caused by pumping and the subsequent settling and/or rising of bubbles and bubble/particle complexes. This also can contribute a significant amplification of the response as gas changes elevation due to pressure changes, tending to cause an overprediction in gas content. The influence of this activity on the level response is investigated in Section 6.

\subsubsection{Soluble Gas Effects}

One of the gases generated in Tank 241-SY-101 is ammonia. Because it is soluble in the waste, a significant concentration of dissolved ammonia exists in the liquid phase. Bubbles that form due to the generation of the relatively insoluble gases also contain ammonia in the gas phase in an appropriate amount to maintain phase equilibrium. Changes in bubble pressure affect the concentration of ammonia within the bubble; the ammonia concentration will increase or decrease to maintain the partial pressure defined by Henry's Law. 
Table 5.1. Stored Gas Parameters Calculated from Level Response to Barometric Pressure

\begin{tabular}{||c|c|c|c|c|c||}
\hline \hline Date & Best estimate & May 1992 & December 1993 & November 1994 & June 1995 \\
\hline \hline $\begin{array}{c}\text { Response } \\
(\mathrm{cm} / \mathrm{kPa})\end{array}$ & $-0.317 \pm 0.12$ & $-0.43 \pm 0.09$ & $-0.51 \pm 0.07$ & $-0.61 \pm 0.06$ & $-0.35 \pm 0.08$ \\
\hline $\begin{array}{c}\text { Crust response } \\
(\mathrm{cm} / \mathrm{kPa})\end{array}$ &. & 0 & $-0.26 \pm 0.07$ & $-0.26 \pm 0.07$ & \\
\hline $\begin{array}{c}\text { Non-crust } \mathrm{P}_{\text {eff }} \\
(\mathrm{atm})\end{array}$ & & $1.9 \pm 0.3$ & $2.2 \pm 0.3$ & $2.1 \pm 0.3$ & \\
\hline $\begin{array}{c}\text { Std. gas volume } \\
\left(\mathrm{m}^{3}\right)\end{array}$ & $222 \pm 34$ & $478 \pm 170$ & $458 \pm 230$ & $570 \pm 220$ & $238 \pm 68$ \\
\hline $\begin{array}{c}\text { Gas volume in } \\
\left.\text { situ (m }{ }^{3}\right)\end{array}$ & $163 \pm 39$ & $250 \pm 57$ & $267 \pm 91$ & $327 \pm 80$ & $184 \pm 53$ \\
\hline Waste level (cm) & $1016 \pm 5$ & $1029 \pm 3$ & $1016 \pm 5$ & $1013 \pm 5$ & $1016 \pm 5$ \\
\hline $\begin{array}{c}\text { Degassed level } \\
(\mathrm{cm})\end{array}$ & $976 \pm 10$ & $968 \pm 15$ & $952 \pm 23$ & $935 \pm 20$ & $971 \pm 10$ \\
\hline
\end{tabular}

This phenomenon has implications on the retained gas inventory estimates, which are based on correlations between atmospheric pressure and waste surface level. As atmospheric pressure increases, bubble pressure increases. In this case, the ammonia is driven back into solution to restore the ammonia partial pressure defined by Henry's Law. As the mass of gas contained in the bubble decreases, so does its volume (similar arguments can be made for decreases in atmospheric pressure). Because of this, ammonia phase equilibrium contributes to the pressure-level correlation as an amplification of the correlation and, as a result, estimates of the retained, insoluble gas inventory are higher than they would be if this phenomenon were considered. However, this error is negligible.

To determine the impact of this phenomenon on the pressure-level correlations, a spread sheet was developed to estimate the change in bubble volume that results from ammonia phase equilibrium effects and compared with the bubble volume changes that result from pressure variations (i.e., what is intended in the correlation). An example of the results is given as Table 5.3. The ammonia concentration, Henry's Law constant, and surface tension values are intended to be representative quantities and are based on those reported by Norton and Pederson (1994).

In the example, a $150-\mu \mathrm{m}$ bubble is considered that is located at a depth of five meters (approximately half of the tank depth). A change in ambient pressure occurs so that the pressure increases by $0.7 \mathrm{kPa}(0.007 \mathrm{~atm})$. The volume decrease of approximately $0.38 \%$ occurs as a result of the pressure increase. The volume decrease associated with ammonia solubility is a factor of 107 smaller. The largest effect occurs when the bubble size is large (i.e., minimal surface tension effects) and the bubble depth is small. For example, if the bubble is $1 \mathrm{~mm}$ in diameter and at a depth of only $1 \mathrm{~m}$, the solubility effect is $2 \times 10^{4}$ smaller than the pressure-related volume change, still much smaller than other errors associated with the pressure-level gas inventory estimates. 


\subsection{Extrapolation from Past GRE Behavior}

Pasamehmetoglu provides an additional method for estimating the inventory of retained gas in Tank 241-SY-101 as a function of observed waste surface level.(a) The approach is to quantify the gas inventory at a presumed state that occurred just before a large GRE prior to mixer pump installation in July 1993. A neutral buoyancy model is used to estimate the gas inventory at this state. The gas inventory at a lower waste level can be computed by assuming a hypothetical GRE with the appropriate level drop. This method also yields a hypothetical "gas-free" level by removing the entire initial gas inventory.

This method and the resulting estimates were developed in support of safety assessments for tank waste retrieval. It is quite indirect and depends heavily on data obtained or estimated before pump installation. It is likely that the physics of gas retention in the waste have changed significantly, making this type of extrapolation tenuous for the purposes of accurately estimating the current tank conditions. Nevertheless, with appropriate property values and assumptions, this model provides estimates of gas inventory that are quite consistent with the "best" estimate from Section 4.

The calculation is based on conditions prior to Event $G$. Then the waste level was $1058 \mathrm{~cm}$ (416.5 in.), of which $559 \mathrm{~cm}$ (220 in.) was assumed to be gas-retaining nonconvective material based on waste temperature profiles, $423 \mathrm{~cm}$ (167 in.) was convective liquid, and the floating crust layer was assumed to be $76 \mathrm{~cm}$ ( 30 in.) thick. Given the averaged degassed densities of the three layers, one computes the void fraction required for neutral buoyancy in the nonconvective layer. The gas required for neutral buoyancy of the convective layer is also included. These are computed as

$$
\begin{aligned}
& \alpha_{\mathrm{NCL}}=1-\frac{\rho_{\mathrm{L}}}{\rho_{\mathrm{NCL}}} \\
& \alpha_{\mathrm{CL}}=1-\frac{\rho_{\mathrm{L}}}{\rho_{\mathrm{Cl}}}
\end{aligned}
$$

where $\rho_{L}$ is the liquid density, $\rho_{C L}$ is the convective layer density, and $\rho_{N C L}$ is the density of the nonconvective sludge. The gas volume in each layer is the product of the void fraction and the volume of the layer. The total initial in situ gas inventory is given by the sum of layer volumes

$$
\mathrm{V}_{\mathrm{T}}=\mathrm{A}\left(\alpha_{\mathrm{CL}} \mathrm{L}_{\mathrm{CL}}+\alpha_{\mathrm{NCL}} \mathrm{L}_{\mathrm{NCL}}\right)
$$

This volume represents the total amount of gas in the waste when its level is $1058 \mathrm{~cm}$ (416.5 in.).

(a) Pasamehmetoglu, K. O. 1995. Calc-Note: TSA6-CN-WT-SA-GR-034. Los Alamos National Laboratory, Los Alamos, New Mexico. 
Then the in situ gas volume at any lower level can be computed by subtracting the volume representing the difference in level from the total gas volume. This is given by

$$
V(L)=V_{T}-A\left(L_{T}-L\right)
$$

With liquid, convective, and nonconvective layer densities of 1460,1520 , and $1700 \mathrm{~kg} / \mathrm{m}^{3}$, respectively, Equations (5.11 and 5.12) predict a neutral buoyancy void fraction in the convective layer of $3.9 \%$ and $14.1 \%$ in the nonconvective layer. Equation (5.13) then gives an initial inventory of $393 \mathrm{~m}^{3}\left(14,000 \mathrm{ft}^{3}\right)$ in situ or $778 \mathrm{~m}^{3}(27,470 \mathrm{SCF})$ at $1 \mathrm{~atm}$. At the current waste level of $1016 \mathrm{~cm}$ (400 in.), Equation (5.14) gives $220.3 \mathrm{~m}^{3}\left(7,780 \mathrm{ft}^{3}\right)$ in situ or $397 \mathrm{~m}^{3}$ $(14,030 \mathrm{SCF})$ at $1 \mathrm{~atm}$. If the entire initial inventory were removed, the degassed level would be $963 \mathrm{~cm}$ (379 in.). This is about twice the $222 \mathrm{~m}^{3}$ (7,800 SCF) at 1 atm estimated from direct VFI measurement.

The main reason for this discrepancy is that gas is assumed to be stored in the convective layer by the same kind of Rayleigh-Taylor neutral buoyancy model as in the non-convective layer. The density of the convective layer from earlier core sample data was higher than that of pure liquid due to suspended particles, so it was assumed that the layer could retain sufficient gas until its density was reduced to the pure liquid density. The reduced convective layer density also increases the void fraction required for the neutral buoyancy in the nonconvective layer.

There is no realistic mechanism for gas retention in the convective layer. A Raleigh-Taylor instability is not observed because thermal convection keeps this layer well-mixed. Gas is transported through the convective layer by bubble rise, bulk convection, and diffusion. Any gas bubbles in this layer are in motion, and calculations show that even the smallest bubbles rise quickly enough so that the equilibrium void fraction is effectively zero. Even bubbles attached to particles at a hypothetical neutral buoyancy condition would quickly move either up or down since neutral buoyancy is unconditionally unstable to small changes in pressure. Direct VFI measurements confirm that there is essentially no gas in this region, though a small void fraction was assumed to allow for measurement uncertainty.

On the other hand, gas retention in the crust is explicitly omitted in this model. Estimates presented in Section 4.4 indicate the crust contains approximately $102 \mathrm{~m}^{3}\left(3600 \mathrm{ft}^{3}\right)$ of gas. Though there might have been somewhat less gas in the crust during the time large GREs were occurring every few months, it is reasonable to scale the volume on the estimated crust thickness. If the crust were $75 \%$ of its present thickness, the gas volume would be $76 \mathrm{~m}^{3}\left(2,700 \mathrm{ft}^{3}\right)$.

For accurate calculation of the retained gas inventory in the nonconvective layer, the neutral buoyancy model should use the measured convective layer density, and the neutral buoyancy model should not be applied to compute gas retention in the convective layer. This is important because the quantity of retained gas is extremely sensitive to changes in the convective layer density value. The correct equation set would be

$$
\alpha_{\mathrm{NCL}}=1-\frac{\rho_{\mathrm{CL}}}{\rho_{\mathrm{NCL}}}, \quad \alpha_{\mathrm{Cl}}=0
$$




$$
\mathrm{V}_{\mathrm{T}}=\mathrm{A} \alpha_{\mathrm{NCL}} \mathrm{L}_{\mathrm{NCL}}+\mathrm{V}_{\mathrm{C}}
$$

where $V_{C}$ is the gas estimated to be held in the crust. Equation (5.14) is not changed.

Using the same densities as before, Equation (5.15) gives a neutral buoyancy void fraction of $10.6 \%$. Setting the crust gas volume to $76 \mathrm{~m}^{3}\left(2,700 \mathrm{ft}^{3}\right)$, Equation (5.16) predicts the initial in situ inventory of $319 \mathrm{~m}^{3}\left(11,300 \mathrm{ft}^{3}\right)$ or $598 \mathrm{~m}^{3}(21 ; 100 \mathrm{SCF})$ at $1 \mathrm{~atm}$. Now Equation (5.14) estimates the gas in the mitigated tank at a level of $1016 \mathrm{~cm}\left(400 \mathrm{in}\right.$.) to be $148 \mathrm{~m}^{3}(5,230 \mathrm{ft})$ in situ or $210 \mathrm{~m}^{3}$ at $1 \mathrm{~atm}(7,400 \mathrm{SCF})$ assuming the volume in the crust is $102 \mathrm{~m}^{3}\left(3,600 \mathrm{ft}^{3}\right)$. Note that this agrees closely with the best estimate of Table 4.4. These results are summarized in Table 5.2.

Table 5.2. Estimates of Gas Volume from Past Pre-GRE State

Quantity

Density $\left(\mathrm{kg} / \mathrm{m}^{3}\right)$

Fluid

Convective layer

Nonconvective layer

Neutral buoyancy void

Convective layer

Nonconvective layer

Initial in-situ inventory

at $1060 \mathrm{~cm}$ level $\left(\mathrm{m}^{3}\right)$

Crust

Convective layer

Nonconvective layer

Total

Mitigated in-situ inventory

at $1016 \mathrm{~cm}$ level $\left(\mathrm{m}^{3}\right)$

Crust

Convective layer

Nonconvective layer

Total in-situ

Mitigated inventory

at $1 \mathrm{~atm}\left(\mathrm{~m}^{3}\right)$

Crust

Convective layer

Nonconvective layer

Total at $1 \mathrm{~atm}$

Degassed waste level (cm)

\section{Best Est. Original $\quad$ Corrected}

$\begin{array}{ll}1,460 & 1,520 \\ 1,520 & 1,520 \\ 1,700 & 1,700\end{array}$

$3.9 \%$

$14.1 \%$

$0 \%$

$10.6 \%$

0

76

69

324

0

393

243

319

102

34

25

161

0

102

0

45

220

173

102

0

108

62

222

397

210

963

974 


\subsection{Bubble Dynamics Analysis}

Undissolved gas exists in the waste as bubbles, and the motion of individual bubbles is a necessary part of mitigation process. The mixer pump induces gas releases, apparently by a combination of freeing bubbles from the loosely settled layer and detaching them from attached particles to allow them to rise. The larger the bubble, the faster it rises. However, after almost two years of mixing, most bubbles in the waste are quite small, requiring many hours to rise to the surface after being liberated by a pump run. While rising, their motion, and hence the behavior of the entire tank, is affected by pressure changes.

This section describes two major accomplishments in understanding bubble behavior in SY-101. Section 6.1 describes a rather sophisticated model for the dynamics of a bubble population responding both to periodic mixer pump runs and to changes in barometric pressure. Section 6.2 presents some of the results and implications of the model. Section 6.3 describes a method of calculating the bubble size distribution from the hydrogen concentration history following a pump run and compares the resulting distribution to those known to arise from specific bubble behavior models.

\subsection{Bubble Dynamics Model}

Estimating the amount of undissolved retained gas and its location in Tank SY-101 is an important issue in the safety assessment of the tank. Direct measurements, such as those obtained with the VFI, are difficult, expensive, and possible only at a few locations in the tank. Indirect measurements, such as the response of the tank waste level to barometric pressure changes, provide little information as to the distribution of the gas and, in fact, require some knowledge of the distribution of the gas in order to provide an estimate of retained gas quantity.

To help address this problem, a set of dynamic bubble/particle models are developed here which provide insight into the state, amount, and distribution of retained gas in this tank as it responds to the mixing pump and to barometric pressure variations. The models predict average amounts of retained gas in various layers of the tank-crust, convective layer, and loosely settled layer-which are compared with the results of the void fraction instrument to calibrate the model. Parameters may be adjusted so that the model results agree with observations. Caution should be exercised in interpreting these parameters quantitatively because of the many simplifying assumptions that enter into the models. A true test of the models is not possible at this time because of the dearth of reliable, continuous level measurements. However, the model output provides valuable insight into possible explanations for observed tank behavior and measured distributions of retained gas.

\subsubsection{Model Assumptions}

A variety of complex physical processes occur simultaneously in the tank. Some are poorly understood and are modeled simplistically from lack of information. Other processes are simplified to make the problem tractable. For example, a full 3-D simulation might be more

\section{1}


realistic but would require massive computational resources and would probably not change the qualitative results. The components of the model are gas generation, the motion of bubble/particle complexes in the convective layer, the loosely settled layer at the bottom of the tank, the floating. crust, the actions of the mixer pump, and the barometric pressure profile. We do not include the unexcavated sludge in our model.

We assume that the gas generation rate is constant, consistent with current understanding of the mechanisms for gas generation in the waste. Gas, including hydrogen, nitrous oxide, nitrogen, ammonia, and small amounts of other species, is generated by a combination of radiolytic and chemical reactions occurring in the liquid waste (Bryan and Pederson 1994). Initially, generated gas is dissolved in the liquid. Since the solubilities of hydrogen, nitrous oxide, and nitrogen are very small (Allemann 1995), the dissolved fraction of these species will be neglected. On the other hand, ammonia is highly soluble and is released from the waste by diffusion at a nearly steady rate affected little by mixer pump operation (Stewart et al. 1994). Therefore this model does not include the full generation rate of ammonia, only that fraction which is free gas retained and released as bubbles. This represents approximately $6 \%$ of the total generation rate for undissolved gases.

The amount of solid surface present appears to affect both the rate of reaction and the rate of nucleation of bubbles. Except for a relatively thin layer on the bottom, the mixer pump has resuspended most of the solids in the tank-only about $20 \%$ of these suspended solids settle out between pump runs. It is not known if this loosely settled layer has a greater or smaller generation rate than the bulk liquid, since there is a greater amount of solid surface but a lesser amount of liquid. Therefore it is reasonable to assume that the gas generation rate is essentially uniform throughout the slurry and loosely settled layers.

We assume that all bubbles contain the same mass of gas and each is attached to a particle of a specified size. In the absence of nonlinear effects such as coalescence or growth of bubbles, the model is linear with respect to a distribution of bubble or particle sizes. This means that the solution of a model having a prescribed distribution of particle sizes can be obtained as a superposition, or weighted average, of solutions of the model with a single particle size. The weights in this case would be given by the particle size distribution itself. Therefore, no additional information is obtained by working with a model having distributions of bubble or particle sizes unless there is interaction among the populations, such as coalescence or growth. These effects are not included in the current model.

The vertical motion of gas in the convective layer is assumed to be given by the instantaneous terminal velocity of the bubble particle complex. This is determined by equating the buoyancy and drag of the complex. This means we are assuming that the response of the velocity to change in depth, with a corresponding change in bubble size affect both buoyancy and drag forces, happens so quickly that the transient acceleration is negligible for our purposes.

The buoyancy force is computed by

$$
F_{B}=-\rho_{1} g \frac{\pi^{3}}{6}\left(d_{b}\right)+\left(\rho_{p}-\rho_{1}\right) g \frac{\pi^{3}}{6}\left(d_{p}\right)
$$


The drag force is assumed to be the sum of the drag for bubble and particle separately. This approximation is correct in the limits of bubble diameter much smaller or much larger than particle diameter, but in the intermediate region where we are working, it is somewhat suspect.

$$
F_{D}=-3 \pi d_{p} \mu_{1} U-\frac{k}{8} \pi d_{b} \mu_{1} U
$$

We then equate the buoyancy and drag forces and solve for $U$ to obtain

$$
U=\left[\frac{g}{18 \mu_{1}}\right] \frac{\left[\rho_{1}\left(d_{b}\right)^{3}-\left(\rho_{p}-\rho_{1}\right)\left(d_{p}\right)^{3}\right]}{\left[d_{p}+\frac{k}{24} d_{b}\right]}
$$

Since the terminal velocities predicted by Equation (6.3) are so small, we will use units of inches/day. Hereafter, the variable $U$ denotes the velocity of the bubble/particle complex in inches/day.

Bubble/particle complexes that rise to the surface of the convective layer enter the foam layer in the crust and are assumed to be released at some finite rate to the tank dome space. This release is modeled by local linearization; that is, the release rate has a constant term, $\mathrm{r}_{0}$, and a term that is proportional, with constant $r_{1}$, to the amount of retained gas in the foam layer. These constants have no particular physical basis but are adjusted within the model to provide reasonable quantities of retained gas in the foam layer.

The loosely settled layer accumulates on the bottom of the tank as particles settle and is easily disturbed by the mixing pump. We model this layer as a lumped parameter whose gas content is governed by the flux of gas into the loosely settled layer through its boundaries and by the generation of gas inside the layer. The gas is assumed to be held motionless at the average depth of the layer. We assume the loosely settled layer grows at a constant rate.

The action of the mixer pump is modeled as an instantaneous change occurring at a specified interval in the state of the gas and the solid particles. The pump is typically run for 25 minutes, and forced convection dominates in this period. Rather than try to model details of this period, we model only the net effect of the entire pump run.

A working hypothesis for the release of gas by the pump is that bubbles are detached from the particles and then rise to the surface. We assume the detachments take place during the actual pump run and these bubbles are removed from our model because they are no longer attached to particles, even though they may not actually be released from the waste into the dome space for many hours. Since these bubbles do not have attached solids, we also assume that they do not contribute to retention of gas in the foam layer.

The pump jets act directionally to disturb the loosely settled layer. Rather than keep track of what has been disturbed and what has not (as was attempted in the state-space models described in Section 8.1), we model this effect by allowing a fraction of layer to be resuspended and a frac- 
tion of the gas to be released. Since the current pump operating procedure is very regular in the choice of orientations (the 1800 opposing pump nozzles are shifted by +300 before each pump run), this is a reasonable assumption for the net effect on the loosely settled layer.

We assume that the bubble/particle complexes remaining in the convective layer are uniformly distributed because 1) we know that the mixing action is sufficient to maintain a uniform distribution of temperature in the waste; 2) we have no knowledge to the contrary; and 3) it drastically simplifies the calculations to obtain the steady state of the system at constant pressure.

In summary, the effect of the pump is to remove a specified fraction, $\theta_{2}$, of the gas and particles from the loosely settled layer and release a specified fraction, $\theta_{1}$, of the gas from the loosely settled layer into the dome space. Therefore, the post-pump-run gas in the convective layer consists of all the gas that was in the convective layer before pumping plus a fraction, $\theta_{2}-\theta_{1}$, of the gas from the loosely settled layer, distributed uniformly throughout the layer.

To observe the effect of bubble distribution on the correlation of barometric pressure to level, we impose an instantaneous change of pressure immediately following a pump run. Otherwise the pressure is held constant. This choice of ambient pressure profile will maximize the effect of bubble dynamics on the correlation.

\subsubsection{Governing Equations}

The equation governing the evolution of the distribution of bubbles within the convective layer is the conservation law

$$
\frac{\partial x}{\partial t}+\frac{\partial(\mathrm{ux})}{\partial z}=q
$$

This law states that bubbles are transported at the variable velocity, $u$, and are generated at the rate q. The initial conditions for $\mathrm{z}$ in $\left[0, \mathrm{z}_{\mathrm{t}}\right]$ are

$$
\mathrm{x}(0, \mathrm{z})=\mathrm{x}_{0}(\mathrm{z})
$$

The value of $\mathrm{x}_{0}(\mathrm{z})$ describes the distribution of bubbles at the time the model is "turned on," which is set at $t=0$ for convenience. In addition, if the value of $u$ at the surface is negative, we must impose a boundary condition $x(t, 0)=0$, which expresses the assumption that no gas flows from the foam layer or dome space into the waste. The equation governing the gas in the foam layer is

$$
\frac{\mathrm{dm}_{0}}{\mathrm{dt}}=\mathrm{ux}+\mathrm{r}_{0}-\mathrm{f}_{0} \mathrm{~m}_{0}
$$


Table 6.1. Definitions of Model Parameters and Variables, Their Assigned Symbols, Selected Values or Ranges, and Units

PARAMEIER

\begin{tabular}{|c|c|c|}
\hline VARIABLE & VALUE & UNTS \\
\hline$t$ & $t \geq 0$ & day \\
\hline$z$ & {$\left[0, z_{t}\right]$} & $\mathrm{m}$ \\
\hline$z_{i}$ & 8.7 & $\mathrm{~m}$ \\
\hline $\mathrm{x}$ & {$[0,1)$} & 1 \\
\hline $\mathbf{u}$ & - & $\mathrm{m} / \mathrm{day}$ \\
\hline$q$ & $100 / V_{t}$ & $1 /$ day \\
\hline$\rho_{1}$ & 1.4 & $\mathrm{~g} / \mathrm{cc}$ \\
\hline$\rho_{p}$ & 2.0 & g/cc \\
\hline$d_{b}$ & {$[.001,01]$} & $\mathrm{cm}$ \\
\hline$d_{p}$ & & $\mathrm{~cm}$ \\
\hline $\mathrm{g}$ & 1000 & $\mathrm{~cm} / \mathrm{s}^{2}$ \\
\hline$\mu_{1}$ & 0.40 & Poise \\
\hline $\mathrm{m}_{2}$ & & $\mathbf{m}$ \\
\hline$A_{t}$ & $\pi / 4 * 232$ & $\mathrm{~m}^{2}$ \\
\hline$V_{t}$ & $A_{t}^{*} z_{t}$ & $\mathrm{~m}^{3}$ \\
\hline $\mathrm{m}_{0}$ & & $\mathrm{~m}$ \\
\hline $\mathrm{T}$ & 2 or 3 & days \\
\hline
\end{tabular}

Reference pressure, assumed to hold at the base of the crust, which is the top of the convective layer. Computed from ambient pressure plus the estimated additional weight of crust

Effective bubble diameter at reference pressure

Additional loading due to crust

Ambient pressure in the tank dome space

Height of loosely settled layer

Depth of top of loosely settled layer

Constant and linear terms of the release rate from the foam layer

Pump effect parameter, fraction of gas in loosely settled layer released by the pump

Pump effect parameter, fraction of gas in loosely settled layer resuspended in the convective layer or released.by the pump

Relative height of the neutral buoyancy point as compared to $z_{t}$

$\begin{array}{lcl}\mathrm{p}_{0} & {[.001,01]} & \begin{array}{l}\text { atm } \\ \mathrm{d}_{\mathrm{b} 0}\end{array} \\ \mathrm{p}_{\mathrm{c}} & 36 / 343 * 1.4 & \mathrm{~cm} \\ \mathrm{p}_{\mathrm{a}}=\mathrm{p}_{0}-\mathrm{p}_{\mathrm{c}} & 0.986 \text { initially, then } 0.966 & \mathrm{~atm} \\ \mathrm{z}_{2}(\mathrm{t}) & {[0,1]} & \mathrm{atm} \\ \mathrm{z}_{\mathrm{b}}(\mathrm{t}) & \mathrm{z}_{\mathrm{t}}-\mathrm{z}_{2} & \mathrm{~m} \\ \mathrm{r}_{0}, \mathrm{r}_{1} & & \mathrm{~m} \\ \theta_{1} & \mathrm{~m}, 1 / \text { day } \\ \theta_{2} \geq \theta_{3} & & 1 \\ \theta_{3} & & 1 \\ & & 1\end{array}$

The initial conditions $m_{0}(0)=m_{00}$ describe the amount of gas in the foam at $t=0$. The equation governing the gas in the loosely settled layer is

$$
\frac{d m_{2}}{d t}=\left(u_{s}+u\right) x+z_{2} q
$$

The initial conditions $m_{2}(0)=m_{20}$ describe the amount of gas in the loosely settled layer at $t=0$. 
The action of the mixer pump is assumed to occur instantaneously. We denote the state before the pump run by a (-) superscript and the state after the pump run by a $(+)$ superscript. The fraction of gas in the loosely settled layer that is released or redistributed by pump action is $\theta_{2}$. The remainder stays in the layer, and the mean height of the layer decreases correspondingly.

$$
\begin{aligned}
& \mathrm{m}_{2}^{+}=\left(1-\theta_{2}\right) \mathrm{m}_{2}^{-} \\
& \mathrm{z}_{2}^{+}=\left(1-\theta_{2}\right) \mathrm{z}_{2}^{-}
\end{aligned}
$$

The fraction of gas in the loosely settled layer that is release by pump action is $\theta_{1}$. If $\theta_{2}>\theta_{1}$, there is a net increase in the amount of gas in the convective layer that is redistributed uniformly by the pump action.

$$
\begin{aligned}
& \mathrm{m}_{1}^{+}=\mathrm{m}_{1}^{-}+\left(\theta_{2}-\theta_{1}\right) \mathrm{m}_{2}^{-} \\
& \mathrm{x}^{+}(\mathrm{z})=\frac{\mathrm{m}_{1}^{+}}{\mathrm{z}_{\mathrm{t}}-\left(1-\theta_{2}\right) \mathrm{z}_{2}^{-}}
\end{aligned}
$$

Gas in the foam layer is not affected by pump action.

\subsubsection{Calculations}

The hyperbolic equation (6.4) can be converted into a set of coupled ordinary differential equations by the method of characteristics (Whitham 1974).

$$
\begin{aligned}
& \frac{d z}{d t}=u \\
& \frac{d x}{d t}=-x \frac{\partial u}{\partial z}+q
\end{aligned}
$$

The initial conditions for the characteristic equations are

$$
\begin{aligned}
& \mathrm{z}(0)=\mathrm{z}_{0} \\
& \mathrm{x}(0)=\mathrm{x}_{0}\left(\mathrm{z}_{0}\right)
\end{aligned}
$$

In theory, the characteristics equations must be solved for every value $z_{0}$ in order to fully determine the solution of the original equation. In practice, we solve the equations for a set of initial values, $z_{0, i}, i=1, \ldots, n_{z}$, with a uniform spacing, $k$, which is sufficiently finely spaced to allow accurate interpolation between values. The solution of the characteristic equations is performed numerically by the MATLAB, which uses a variable-step, variable-order Runge-Kutta method, to a tolerance 10-6. The amounts of gas in the lumped parameters are updated at a fixed time step, $\mathrm{h}$. 
The variable $m_{1}$ represents the amount of gas in the convective layer expressed in terms of height in inches, if the gas is held in a cylinder of base area $A_{t}$ at a pressure of $1 \mathrm{~atm}$, and is calculated from

$$
m_{1}(t)=\int_{0}^{z_{b}(t)} x(t, z) d z
$$

where $\mathrm{z}_{b}(t)$ is the depth of top of loosely settled layer below the bottom of the crust.

To determine the retained gas, $\mathrm{m}_{1}$, in the convective layer, we integrate with the trapezoidal rule for a fixed $t_{j}$ on the grid $z_{i}\left(t_{j}\right)$ with function values $x_{i}\left(t_{j}\right), i=1, \ldots, n z$. For accuracy we include the endpoints of the convective layer in the integration grid and interpolate to obtain the concentration $\mathrm{x}$ at these points. The tank level associated with the distribution of gas in the convective layer is calculated similarly, except that the integration argument is divided by the hydrostatic pressure of the gas in atmospheres as a function of depth, $\mathrm{z}$.

The numerical method is first-order accurate with respect to space and time steps. Therefore, a fine grid is needed for an accurate solution by the conventional approach. To gain accuracy without using a fine grid, a higher-order method is obtained from Richardson extrapolation, which uses the asymptotic form of the error for small step size and combines two evaluations, one at half the step size of the other, to produce a second order scheme. Let $x_{0}$ be the numerical solution at step size $h$ and $x_{1}$ be the numerical solution at step size $h / 2$. The Richardson extrapolation for a first-order method yields

$$
x_{r}=2 x_{1}-x_{0}
$$

The estimated relative error in our solution for a time step of $1 / 64$ days and a space step of $\mathrm{z}_{\mathrm{t}} / 6.5 \mathrm{~m}$ is less than 0.0001 .

Certain characteristics of the steady-state solution (that is, constant ambient pressure and periodic solution) are matched by adjusting model parameters to experimental or physically justified values in order to produce results relevant to the actual state of the tank waste. From physical considerations, the crust is estimated to contain $102 \mathrm{~m}^{3}$ (3,600 SCF) of gas. From VFI measurements, the combined loosely settled and convective layers are estimated to contain $56 \mathrm{~m}^{3}(1,990$ SCF) of gas. From long-term tank data, the background gas released is $50 \%$ of the generation rate. Therefore, at steady state, the gas released by the pump action must be $50 \%$ of the gas generated between pump runs.

With fixed values of the bubble diameter (at $1 \mathrm{~atm}$ ) $\mathrm{d}_{0}$ and neutral buoyancy parameter $\theta_{3}$, the pump effect parameters $\theta_{1}$ and $\theta_{2}$ are adjusted to produce at steady state (constant ambient pressure) a correct volume of gas in the combined loosely settled and convective layers and the required amount of gas released by pump action. The gas release parameter $r_{0}$ is then adjusted to give the correct gas volume in the foam layer. This does not change the behavior of the gas below the crust. The numerical results are presented and discussed in the next section. 


\subsection{Results from Bubble Dynamics Model}

Although this model is preliminary and needs further refinements, we expect it to provide valuable insight into the dynamics of bubble/particle systems in the convective layer as a function of bubble and particle size. The model shows that the quantity of gas retained from the gas generated in the convective layer is highly sensitive to the size of the bubble. All other parameters being the same, small bubbles lead to larger estimates of retained gas in the convective layer. In addition, the amount of retained gas is dependent on the amount of solids attached to the bubble and, in the steady state, to the details of the mixer pump effect. The distribution of the retained gas is strongly influenced by the mixing action of the pump and is highly variable in time.

The observed change in level in response to barometric pressure is affected by the motion of bubbles. In the current model, the effect on the total response is relatively small $(<25 \%)$ due to the largest fraction of the gas being held in the crust and thus restrained from moving. The effect is highly variable with time and is dependent on the time since the last pump run and the rate of change of barometric pressure. This effect probably accounts for most of the 'noise' in the correlation of barometric pressure and Enraf level data.

\subsubsection{Representative Model Solution}

Figure 6.1 shows a representative model solution. In this example, the barometric pressure is $0.986 \mathrm{~atm}$ for the first two days and $0.966 \mathrm{~atm}$ thereafter. The pump is run every two days, and the pressure change follows immediately after a pump run. The initial conditions are chosen so that the system is in 'steady state' at the initial barometric pressure. In the initial state, the greatest level is observed immediately after a pump run, when the gas is distributed uniformly in the convective layer. It is clear from the graph that the system is not in steady state after the barometric pressure change. If the model is run long enough, a steady state will be achieved. The amplification of the level response to the barometric pressure change is caused by the additional increase in the level with time as the system undergoes a change in the distribution of gas. The amount of gas in the system is affected only slightly by the change in barometric pressure and is not sufficient in itself to account for the level change.

\subsubsection{Parameter Study for a Fixed Bubble Size}

In this study, the bubble size was held constant at 60 microns, and the relative height of the neutral buoyancy point $\left(\theta_{3}\right)$ was varied systematically between 0.205 and 0.38 . The parameter estimation that accompanied each change in $\theta_{3}$ produced a change in the values of the pump effect parameters $\theta_{1}$ and $\theta_{2}$. The study is summarized in Table 6.2. The amplification of the level response is observed to attain a minimum value at around $\theta_{3}=0.209$. The minimum effective pressure in the convective layer for this bubble size is observed to be about $1.2 \mathrm{~atm}$.

To test the effect of variable bubble size, a few computations were performed to demonstrate that the effective pressure is strongly dependent on bubble size (see Table 6.3). A thorough study of this effect was not carried out; however, it is clear that a very small change in bubble size affects the effective gas pressure and level response significantly. 


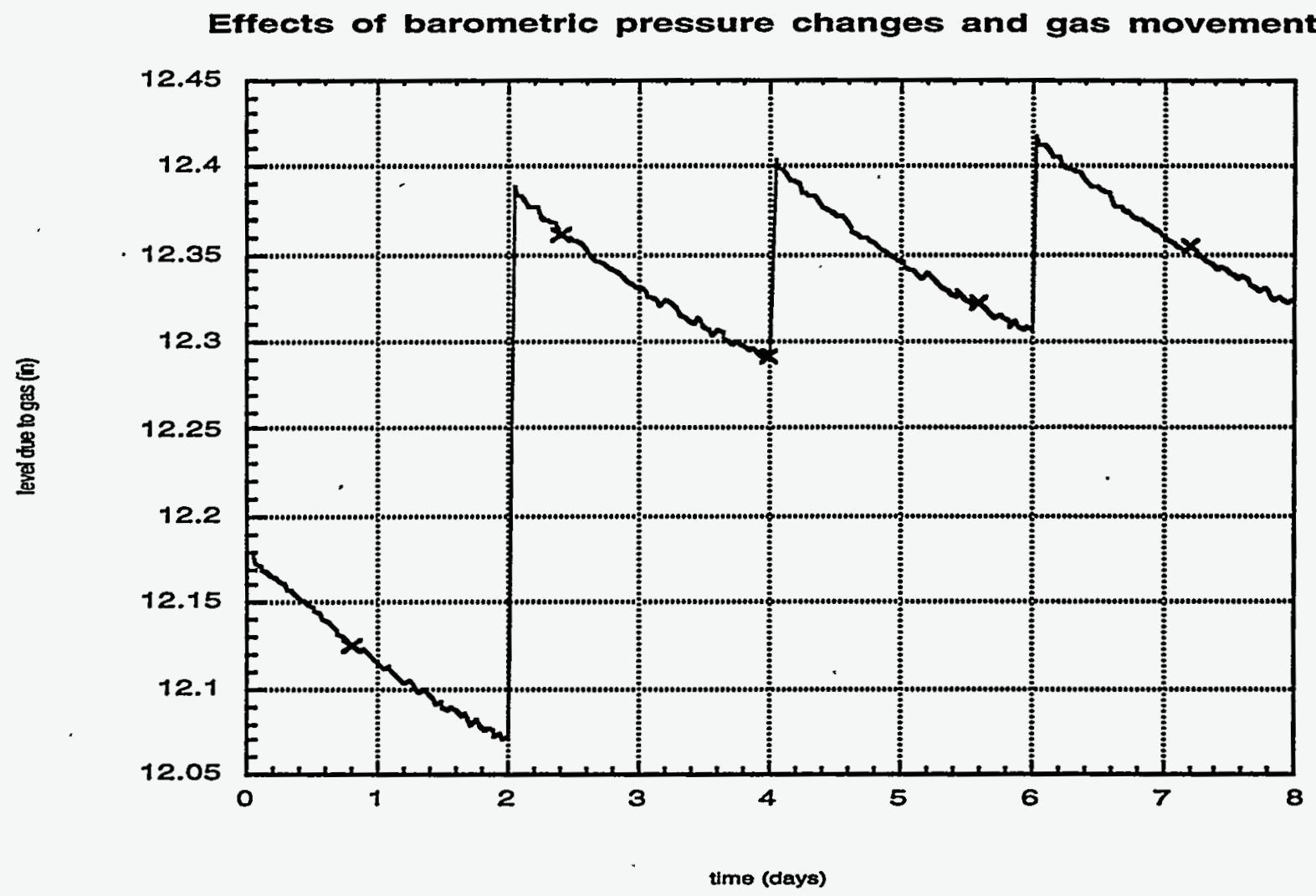

Figure 6.1. Total Level Due to Gas as a Function of Time

Table 6.2. Parameter Study Results

\begin{tabular}{|l|l|l|l|l|l||}
\hline$\theta_{1}$ & $\theta_{2}$ & $\theta_{3}$ & $P_{\text {eff }}(\mathrm{atm})$ & $\mathrm{P}_{\mathrm{av}}(\mathrm{atm})$ & $\begin{array}{l}\text { Level response } \\
\mathrm{cm} / \mathrm{kPa} \text { (in.psi) }\end{array}$ \\
\hline \hline 0.1325 & 0.9421 & 0.205 & 1.3105 & 1.6920 & $0.2040(0.7874)$ \\
\hline 0.1261 & 0.8345 & 0.209 & 1.1575 & 1.7044 & $0.3179(0.8514)$ \\
\hline 0.1247 & 0.8111 & 0.21 & 1.1597 & 1.7075 & $0.3174(0.8502)$ \\
\hline 0.1129 & 0.6321 & 0.22 & 1.1847 & 1.7355 & $0.3130(0.8383)$ \\
\hline 0.0932 & 0.3752 & 0.25 & 1.2610 & 1.8014 & $0.3012(0.8068)$ \\
\hline 0.0790 & 0.2171 & 0.30 & 1.5167 & 1.8788 & $0.2794(0.7484)$ \\
\hline 0.0723 & 0.1486 & 0.35 & 1.6017 & 1.9202 & $0.2675(0.7164)$ \\
\hline 0.0698 & 0.1234 & 0.38 & 1.6445 & 1.9419 & $0.2647(0.7090)$ \\
\hline
\end{tabular}


Table 6.3. Parameters for Variable Bubble Size

\begin{tabular}{||c|c|c|c|c|c|c||}
\hline$\theta_{1}$ & $\theta_{2}$ & $\theta_{3}$ & $\begin{array}{c}\text { Bubble diameter } \\
\text { (microns at 1 atm) }\end{array}$ & $p_{\text {eff }}(\mathrm{atm})$ & $\mathrm{pav}_{\text {atm }}(\mathrm{atm})$ & $\begin{array}{c}\text { Level response } \\
\mathrm{cm} / \mathrm{kPa} \text { (in./psi) }\end{array}$ \\
\hline \hline 0.1247 & 0.8111 & 0.21 & 60 & 1.1597 & 1.7075 & $0.3174(0.8502)$ \\
\hline 0.1329 & 0.8956 & 0.21 & 59 & 1.1653 & 1.6939 & $0.3150(0.8436)$ \\
\hline
\end{tabular}

\subsection{Bubble Size Distribution from Gas Release Signatures}

One of the most important parameters in understanding tank behavior is the size distribution of gas bubbles liberated by periodic mixing. Changes in bubble size distributions are important indicators of changes in waste behavior and help set the mixer pump operation strategy.

No method is available to directly measure bubbles sizes in the waste, but we found that the bubble size distribution could be estimated using average hydrogen gas release signatures over the 24-hour period following a 25-minute mixer pump run. The same method might be useful in more general chemical processing applications. This section describes the method and some of the results obtained from Hanford Tank 241-SY-101.

\subsubsection{Model Derivation}

Gas bubbles in the waste contain approximately $30 \%$ is hydrogen, $24 \%$ nitrous oxide, $33 \%$ nitrogen, and $11 \%$ ammonia by volume (Sullivan 1995). Some of these bubbles can be trapped near the bottom of the tank in the settled solids and sludge. Other bubbles escape and rise to the waste surface as a steady background release independent of the mixer pump. Mixer pump agitation liberates some of the trapped bubbles, allowing them to rise freely to the waste surface. This causes a characteristic rise and fall in hydrogen concentration measured in the exhaust flow during the day after the pump run.

Because smaller bubbles take longer to rise to the surface, the time since pump shutoff becomes an approximate measure of size. The measured hydrogen concentration and ventilation flow rate can then be used to calculate the number rate of bubbles breaking the surface. The combination of bubble size and number rate at that size yields the bubble size distribution directly.

In estimating bubble size distributions we assume that all bubbles are liberated simultaneously from a similar vertical position in the tank. Also, pump operation ( $\approx 24$ minutes) is short compared with gas release times ( $>1350$ minutes), so convective transport is not important after the pump is shut down. After the pump is shut off, we assume the liberated bubbles rise freely to the surface in Stoke's flow and release directly to the dome space above the waste upon reaching the surface. Since the time constant for flow in the dome space is less than one hour, we assume the gas to be well-mixed. The ventilation flow is constant. We ignore changes in the bubble size due to decreasing hydrostatic pressure as it rises to the surface (the diameter of a spherical bubble increases by $25 \%$ going from $2 \mathrm{~atm}$ to $1 \mathrm{~atm})$. The bubbles are sufficiently large $\left(D_{b}>10\right.$ microns) that surface tension effects are negligible. 
Stoke's flow is valid for computing the rise velocity of hard spheres with Reynold's numbers less than 1 . Using reasonable estimates of waste properties (liquid density $1650 \mathrm{~kg} / \mathrm{m}^{3}$ and viscosity $600 \mathrm{cP}$ ) the Reynold's number in Stokes flow is less than 1 for bubbles smaller than $6.2 \mathrm{~mm}$ in diameter. Therefore, assuming that the bubble density is small compared with the liquid density, $\rho_{f}$, and that the bubble diameter, $D_{b}$, does not change appreciably as it rises, Stoke's Law for bubble rise velocity, $\mathrm{u}_{\infty}$, is expressed as

$$
u_{\infty}=\frac{\rho_{1} g_{a} D_{b}^{2}}{k \mu_{1}}
$$

The gravitational constant is $g_{c}, \mu_{f}$ is the liquid.viscosity, and $k=18$ for Stoke's flow with solid spheres. Given a rise distance, $h$, a bubble rise time, $\tau_{b}$, is given by

$$
\tau_{b}=\frac{h}{u_{\infty}}=\frac{h k \mu_{1}}{\rho_{1} g_{a} D_{b}^{2}}
$$

When bubbles reach the surface they enter the dome space and increase the hydrogen concentration measured in the ventilation flow. The bubble volume $d V_{b}(t)$ released to the dome space between time $t$ and $t+d t$ is given by

$$
\mathrm{dV}_{\mathrm{b}}=\mathrm{N}(\mathrm{t}) \frac{\pi}{6} D_{\mathrm{b}}^{3}(t) d t
$$

where $N(t)$ is the number of bubbles released between time $t$ and $t+d t$. The rate of bubble release can be related to the measured hydrogen concentration, $y$, by a mass balance for hydrogen in the dome space. This is given by

$$
V_{d} \frac{d y}{d t}=x \frac{d V_{b}}{d t}+J_{s s} A-y v_{h}
$$

where $V_{d}$ is the dome space volume, $x$ is the volume fraction of hydrogen in a bubble, $\mathrm{J}_{s s}$ is the steady state flux of hydrogen from the waste to the tank dome space, $A$ is the surface area of the dome space, and $v_{h}$ is the volumetric flow rate of gas leaving the dome space.

Since there is no true steady state and we are more concerned with the effect of the disturbance from mixing than the absolute gas concentration, the steady state flux, $\mathrm{J}_{\mathrm{ss}}$, is taken as the flux immediately prior to a pump run. This invalidates the estimate in cases where one pump run follows another by significantly less than 24 hours. Defining $y_{s s}$ as the steady-state volume concentration of hydrogen such that $J_{s s}=y_{s s} v_{h}$ and using Equation (6.14), Equation (6.16) can be rewritten as 


$$
V_{d} \frac{d y}{d t}=N(t) x \frac{\pi}{6} D_{b}^{3}(t)-\left(y-y_{s s}\right) v_{h}
$$

Solving Equation (6.17) for $N(t)$ and substituting Equation 2 for $D_{b}$ yields an estimate of the bubble size distribution $\mathrm{N}(\mathrm{t})$ :

$$
N(t)=\frac{V_{d} \frac{d y}{d t}+\left(\dot{y}-y_{s s}\right) v_{h}}{x \frac{\pi}{6} D_{b}^{3}(t)}=\frac{6}{\pi x}\left[V_{d} \frac{d y}{d t}+\left(y-y_{s s}\right) v_{h}\right]\left[\frac{\rho_{1} g_{a}}{h k m_{1}}\right]^{3 / 2} t^{3 / 2}
$$

Typically what is of interest is not $N(t)$ but $N_{d}\left(D_{b}\right)$, which is the size probability density distribution. Substituting Equation (6.14) for $t$ and noting that

$$
\frac{d t}{d D_{b}} d_{b}=-2 \frac{h k \mu_{1}}{\rho_{1} g_{a} D_{b}^{3}} d D_{b}
$$

gives an equation for $N_{d}\left(D_{b}\right)$ :

$$
N_{d}\left(D_{b}\right)=\frac{12}{\pi x}\left[V_{d} \frac{d y}{d t}+\left(y-y_{s s}\right) v_{b}\right]\left[\frac{h k \mu_{1}}{\rho_{1} g_{a}}\right] \frac{1}{D_{b}^{6}}
$$

Also of interest is a volume probability density distribution given by

$$
N_{m}(m)=\left[\frac{\pi^{3}}{54}\right]^{1 / 2} \frac{1}{x}\left[v_{d} \frac{d y}{d t}+\left(y-y_{s s}\right) v_{h}\right]\left[\frac{h k \mu_{1}}{\rho_{1} g_{a}}\right] \frac{1}{m^{8 / 3}}
$$

where $m$ is the bubble volume. This distribution was used to calculate an average bubble volume, $\mu$, using

$$
\mu=\frac{\int_{0}^{\infty} N_{m}(m) m d m}{\int_{0}^{\infty} N_{m}(m) d m}
$$

It is apparent from Equations (6.20) and (6.21) that relatively small changes in the bubble size translates into relatively large changes in the hydrogen gas release signature. 


\subsubsection{Application To Tank SY-101}

Hydrogen signatures changed between September 8, 1994, and March 13, 1995. Average signatures were calculated for two periods: from September 13 to October 5, 1994, and from January 30 to February 27, 1995. Changes in hydrogen signatures and appropriate averaging periods were identified using a multivariate statistical procedure (Gallagher et al. 1995). These average signatures were used to estimate $y_{s s}$, give an estimate of $y(t)$, and calculate an estimate of $\mathrm{dy} / \mathrm{dt}$.

Table 6.4 gives the parameters used to calculate bubble size distributions in 241-SY-101. Appropriate average hydrogen concentration signatures were used as estimates of the concentration $y(t)$. The time derivative dy/dt was calculated from $y(t)$ using local five-point fits to a second-order polynomial. Using the parameters given in Table 6.4 , the calculated average diameter was about 340 microns for both distributions.

The pump is operated for only 25 minutes. Mostly large bubbles (>1.5 mm) are calculated to be released to the dome space during this period. Most of the bubbles are smaller than this, suggesting that convective transport of gas bubbles is not important for the majority of the release. However, pump operation may affect the initial location of the bubbles, which changes the rise distance, $h$. If the average height of the bubbles increased $1 \mathrm{~m}$ (39.3 in.) (i.e., $h$ decreases by $1 \mathrm{~m}$ ) the calculated distribution would shift to smaller sizes by about 30 microns, yielding an average size, $\mu$, of about 310 microns. An additional effect of pumping may be to broaden the initial bubble height distribution (at $t=0$ ) such that the bubble location cannot be adequately represented by an average $h$. No attempt was made to use a height distribution in this analysis.

Table 6.4. Model Parameters

\begin{tabular}{||c|c|c|c||}
\hline Input Parameter & $\begin{array}{c}\text { Low } \\
\text { Estimate }\end{array}$ & $\begin{array}{c}\text { High } \\
\text { Estimate }\end{array}$ & $\begin{array}{c}\text { Value Used } \\
\text { In Model }\end{array}$ \\
\hline \hline $\mathrm{v}_{\mathrm{h}}\left(\mathrm{m}^{3} / \mathrm{hr}\right)[\mathrm{ft} 3 / \mathrm{min}]$ & & & $934[550]$ \\
\hline $\mathrm{x}$ & & & 0.29 \\
\hline$\rho_{\mathrm{f}}\left(\mathrm{kg} / \mathrm{m}^{3}\right)$ & 1450 & 1750 & 1650 \\
\hline$\mu_{\mathrm{f}}(\mathrm{cP})$ & 300 & 1000 & 600 \\
\hline $\mathrm{h}(\mathrm{m})[\mathrm{in}]$ & $1.3[50]$ & $9.6[376]$ & $5.1[200]$ \\
\hline $\mathrm{k}$ & & & 18 \\
\hline $\mathrm{y}_{\mathrm{ss}}(\mathrm{ppm})$ & & & $27.8,20$ \\
\hline $\mathrm{V}_{\mathrm{d}}\left(\mathrm{m}^{3}\right)\left[\mathrm{ft}^{3}\right]$ & & & $1,360[48,000]$ \\
\hline
\end{tabular}


Figure 6.2 shows plots of $\mathrm{N}_{\mathrm{d}}$ calculated using Equation 6.8 and the two average gas release signatures. The calculated volume average bubble diameters are not significantly different, but the calculated distributions are. The calculated distribution for February 1995 has more gas bubbles in the range from about 200 to 240 microns and less from about 250 to 350 microns than the September 1994 distribution. The later distribution has shifted to smaller sizes.

The estimated distributions shown in Figure 6.2 provide the mean bubble size, which is important in understanding waste behavior. However, it is possible to infer further information by comparing the estimated distributions with the Pareto distribution, which is typical of a freely rising swarm influenced by coalescence, and the exponential distribution, which is a characteristic of bubble breakup (Stewart et al. 1993).

Figure 6.3 shoiws distributions of $\mathrm{N}_{\mathrm{m}}(\mathrm{m})$ as a function of $m$ normalized by the mean volume for each time period. For this figure, the pump operation time corresponds to scaled sizes $\mathrm{m} / \mu$ greater than 80 . Also plotted in Figure 6.3 are the Pareto and exponential distributions. Equations (6.23) and (6.24) give expressions for the Pareto and Exponential probability density functions, respectively.

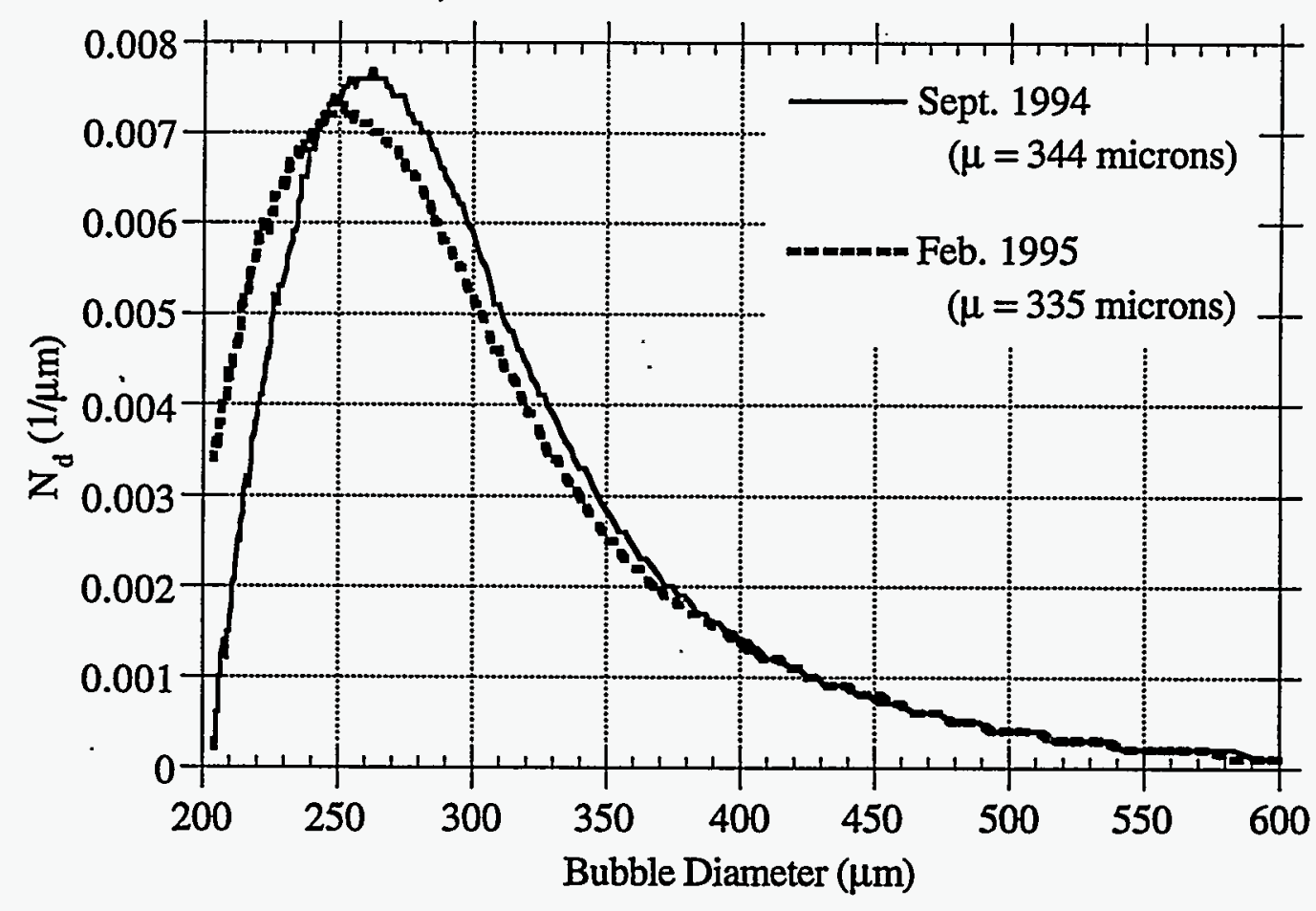

Figure 6.2. Normalized $N_{d}\left(D_{b}\right)$ as a Function of $D_{b}$ 


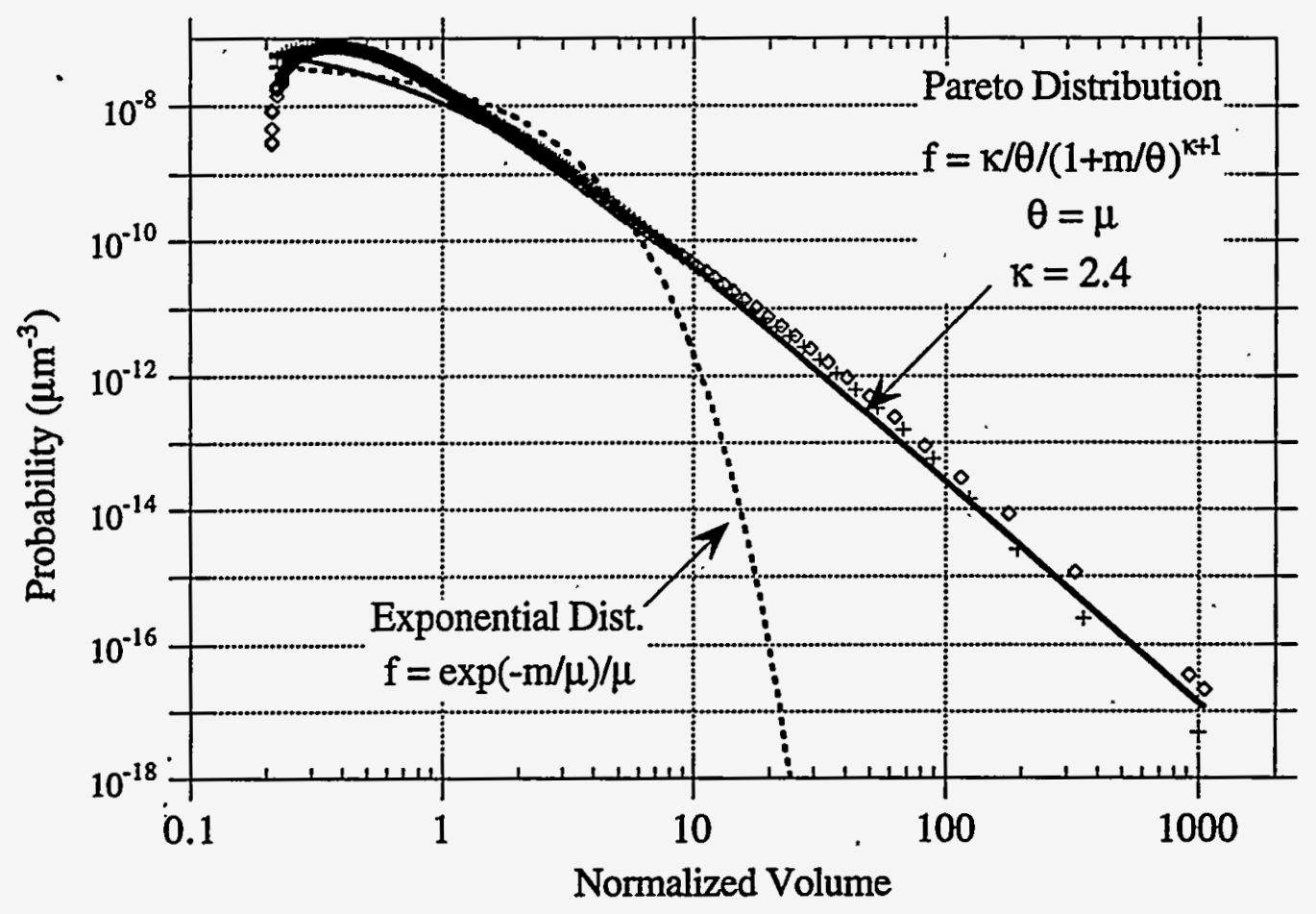

Figure 6.3. Probability Density Versus $N_{m}(m / \mu)$

Pareto: $\quad f(m)=\frac{\kappa}{\theta}\left[1+\frac{m}{\theta}\right]^{-\kappa-1}$

Exponential: $\quad \mathrm{f}(\mathrm{m})=\frac{1}{\mu} \exp \left[-\frac{\mathrm{m}}{\mu}\right]$

The estimated probability density for the bubble volume is in good agreement with the Pareto distribution for $\mathrm{m} / \mu>1$ using parameters $\kappa=2.4$ and $\theta=\mu$. The exponential distribution misses the tail completely and generally fails to follow the trend of the distribution. This indicates that bubbles in the waste likely experienced some coalescence as they grew while trapped in the sludge but are too small to experience breakup during the pump run. But bubbles smaller than about half the mean volume are influenced by processes other than coalescence or breakup.

Although it is difficult to determine initial bubble height accurately, reasonable estimates can usually be made. The above procedure is appropriate for bounding estimates of bubble sizes in any case. The relatively good match to the Pareto distribution also implies that the technique for calculating the distributions from gas release signatures is reasonable. 



\subsection{Unusual Gas Release Observations}

This section describes unusual behavior involved with gas releases in response to mixer pump operation that does not bear directly on safety issues. These issues have not yet been fully explained but remain interesting, because they may eventually provide evidence that help explain the physical phenomena driving overall waste behavior. Hydrogen suppression following pump bumps and variations in the ratio of nitrous oxide to hydrogen are discussed.

\subsection{Hydrogen Suppression}

Since the beginning of detailed monitoring of hydrogen gas in the tank dome space, it has been observed that about $80 \%$ of all pump bumps (runs of five minutes, typically at $1000 \mathrm{rpm}$ ) create a characteristic pattern of hydrogen concentrations involving levels much lower than the baseline. The last observed hydrogen suppression occurred on July 22, 1994. There have been six pump bumps since that time (August 19, 1994, August 20, October 31, November 16, and December 13, 1994, and January 23, 1995), but none have exhibited hydrogen suppression. Instead, there has been an increase in hydrogen concentration to 40-70 ppm after each bump that decays in a pattern similar to the releases induced by excavations. An explanation for this change necessitates a hypothesis for the mechanism of the earlier hydrogen suppressions.

The typical hydrogen suppression signature is shown in Figure 7.1. From a baseline level of $\sim 20 \mathrm{ppm}$, the pump bump causes an initial rise of 5-10 ppm that lasts 1-2 hours. This is followed by a rapid decrease to a level of 5-10 ppm lasting up to 12 hours. After this low-level period there is an increase above baseline levels that may last 12 hours or more. The net effect of a hydrogen suppression on the total gas release is zero to within measurement uncertainty (10\% or more). There is considerable variability in the actual concentrations observed in a suppression, but the pattern is highly repeatable.

The most significant feature of the hydrogen suppression is the rapid rate at which the low concentrations (5-10 ppm) are achieved. This happens so rapidly that, according to a well-mixed model of the tank dome space, the actual release of hydrogen gas from the waste surface is reduced to essentially zero (see Figure 7.2). It is surprising that a pump bump could have such a profound effect.

Historically, pump bumps released gas only from the sludge near the pump, because the five-minute run time is not long enough for the jet to penetrate far into the sludge. When hydrogen. suppressions were observed, the pattern of pump runs was a sequence of bumps only, without intervening longer runs. This pattern tends to introduce a larger void fraction in the slurry around the pump column. Since this region would be less dense than the rest of the tank, hydrostatic forces would cause this column to rise, creating an "updraft" around the pump. When this convective pattern is present, bubbles of gas released from the sludge tend to be swept along with the fluid updraft because of the high viscosity of the liquid waste. As a result of the convective transport of bubbles, most of the gas reaches the surface around the middle of the tank. But this effect would have to apply to all gas released from the tank, including the background release, for this mechanism to explain hydrogen suppression. 


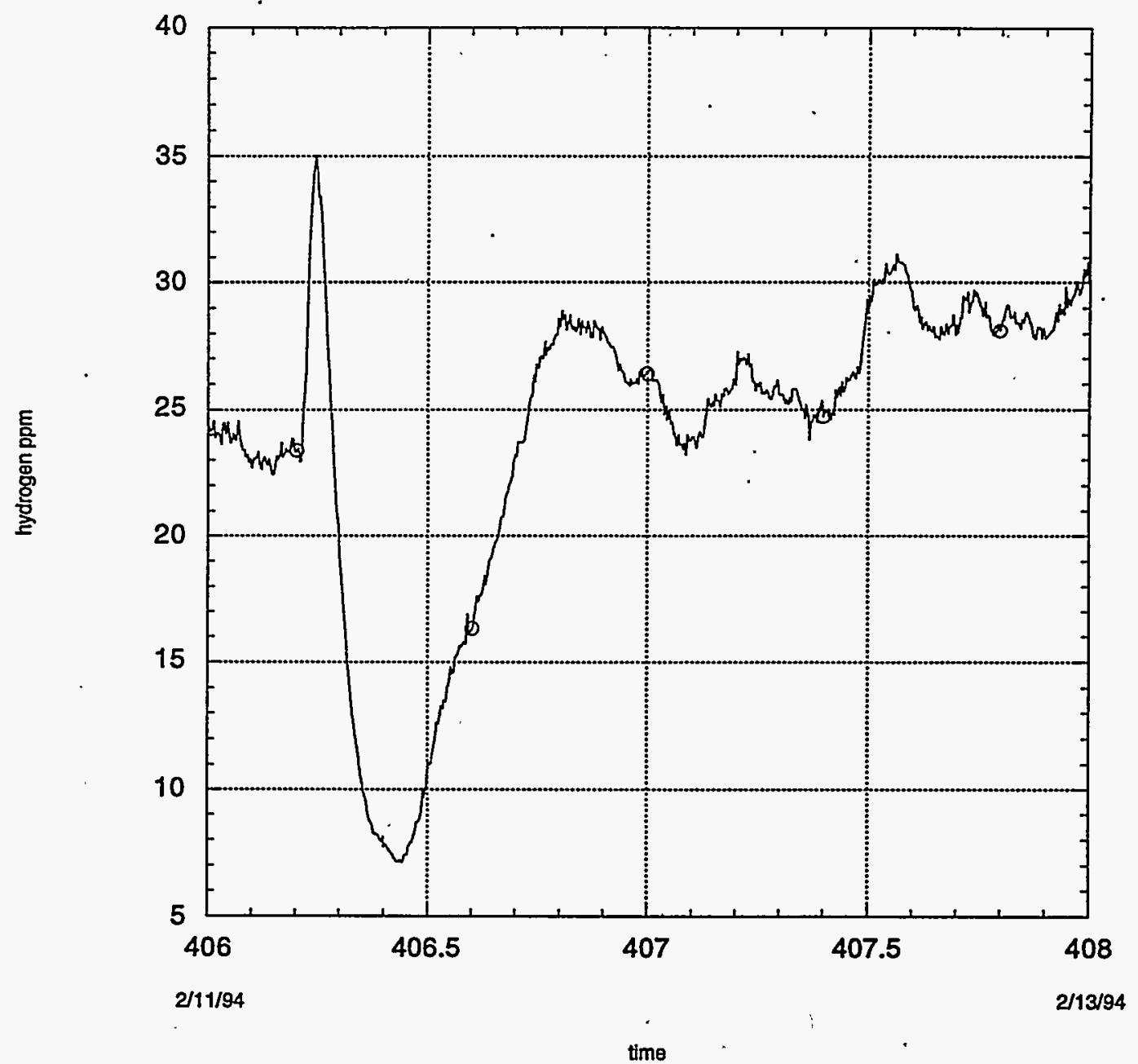

Figure 7.1. Hydrogen Suppression Event Induced by the Pump Bump (2/11/94 at 5:06)

The pump inlet is about $6 \mathrm{~m}$ ( $20 \mathrm{ft}$ ) from the tank bottom and draws fluid in from all directions. When the pump is running, gas bubbles rising near the pump column are swept into the pump and released through the pump nozzles at a lower level, about $71 \mathrm{~cm}(28$ in.) from the tank bottom. A bump draws about $8.5 \mathrm{~m}^{3}\left(300 \mathrm{ft}^{3}\right)$ through the pump. At a void fraction of, say, 


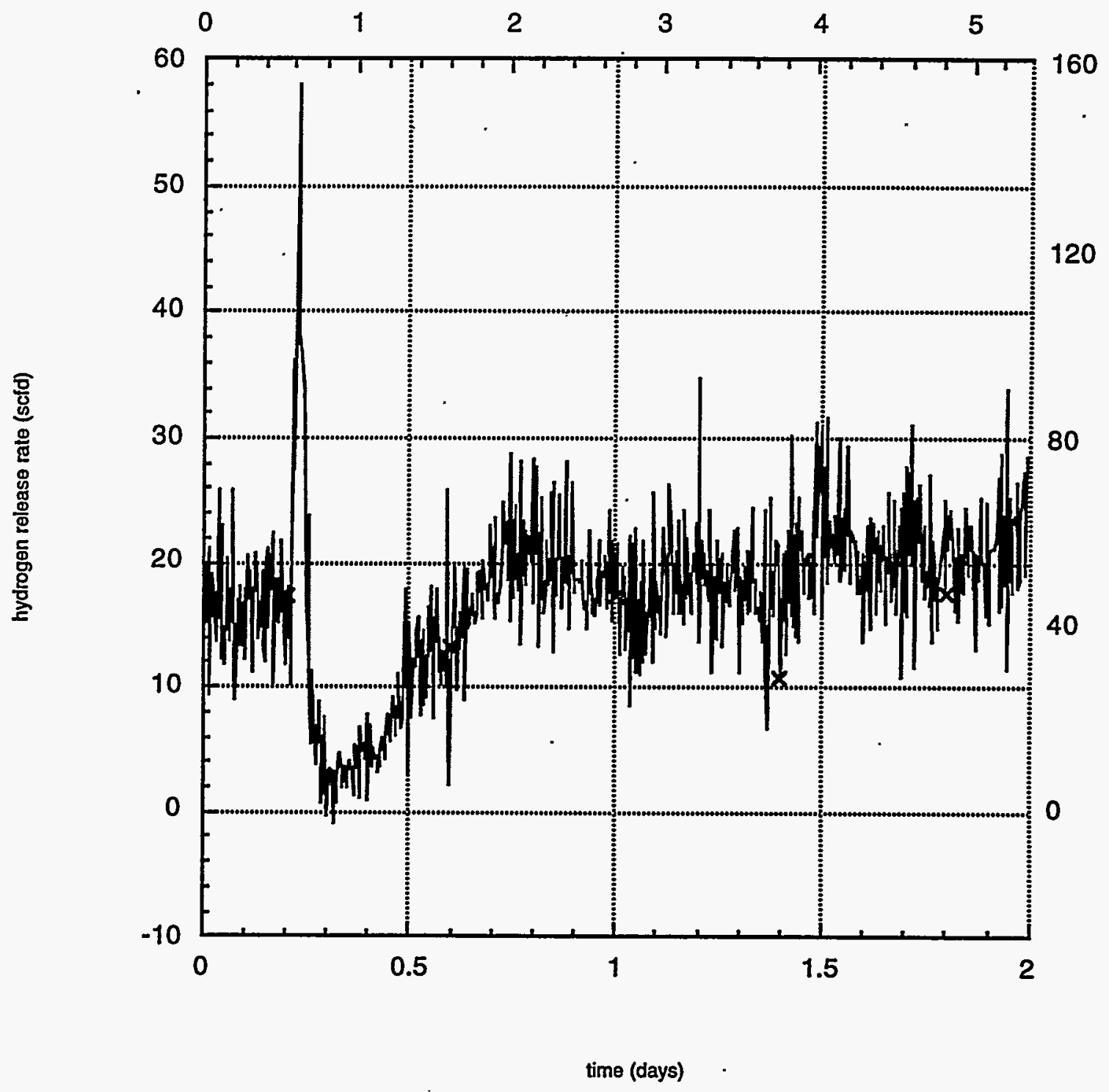

Figure 7.2. Well-Mixed Model for Hydrogen Suppression (2/11/94 at 5:06)

$4 \%$, this corresponds to $0.34 \mathrm{~m}^{3}\left(12 \mathrm{ft}^{3}\right)$ of gas, $0.5 \mathrm{~m}^{3} 1(8 \mathrm{SCF})$ if held at 1.5 atmospheres. The background release of gas is about $1.4 \mathrm{~m}^{3}(50 \mathrm{SCF}) /$ day. Thus a substantial fraction of the background release could be inhibited by a pump bump resulting in the observed hydrogen 
concentration suppression. However, the overall convection pattern of the liquid would be preserved, even enhanced, by the bump. Thus the volume of gas that is pulled into the pump is merely delayed in reaching the surface, resulting in an increase in concentration above background following the suppression. This mechanism agrees with the pattern of hydrogen suppression.

Since July 26, 1994, however, pump excavations (25 minutes, $1000 \mathrm{rpm}$ ) or tank sweeps (180 minutes, $750 \mathrm{rpm}$ ) have occurred every $2-3$ days. Pump bumps have only occurred when a regularly scheduled excavation or sweep could not be run. This large and regular energy input has suspended most of the sludge, especially near the pump, and the pump nozzles are no longer under the sludge. For either pump bumps or excavations, the jet will extend much greater distances from the pump, releasing gas throughout the tank. It is likely that this has disturbed the "updraft" convection pattern. There may now be no set pattern at all, or it is possible that a different convective pattern has been established that is consistent with the pump action. Instead of interrupting the flow of gas to the surface, the effect of a pump bump under these conditions could be to provide a small amount of agitation or a small enhancement of the present convection pattern that leads to a slightly enhanced gas release into the dome space.

\subsection{Variation in Ratio of $\mathrm{N}_{2} \mathrm{O}$ to $\mathrm{H}_{2}$}

In current calculations of the total gas volume, the gas released from the tank is assumed to have a constant fraction of hydrogen equal to the fraction in the released gas obtained in the grab samples during large gas releases that occurred prior to mixer pump installation. There are a number of phenomena and observations that suggest that this assumption might not be valid.

Measurements of release gas composition were made from gas samples obtained from the exhaust header during GREs. Since the release gas is diluted by air, it was necessary to correct for this dilution by measuring the amount of a "tie gas," which originally was argon but was switched to oxygen for reasons of accuracy. The mass spectrometer measurements of these sam- . ples give only the noncondensable fraction of the release gas, namely hydrogen, nitrous oxide, and nitrogen. Condensable and soluble components such as water vapor and ammonia are removed during sample preparation. The compositions reported by LANL (1994) are presented in Table 7.1. The term "total released gas" applies only to gas that was retained in the tank as bubbles. Since $75 \%$ of the ammonia release now comes from previously dissolved gas, current FTIR measurements of ammonia flow through the vent header do not reflect the contribution of ammonia to the total released gas.

Table 7.1. Released Gas Compositions (LANL 1994)

\begin{tabular}{||c|c|}
\hline Gas Component & Reported Composition \\
\hline \hline Hydrogen & $33.2 \% \pm 4.8 \%$ \\
\hline Nitrous Oxide & $28.2 \% \pm 5.2 \%$ \\
\hline Nitrogen & $37.7 \% \pm 8.7 \%$ \\
\hline
\end{tabular}


The gas released during the historical GREs was "fossil gas," that is, gas that had formed long before it was released. This gas could undergo further chemical reactions during its residence in the sludge, which would alter the hydrogen fraction. Currently, most gas is probably released soon after it is formed. During the summer of 1994, a fair amount of fossil gas was released as previously undisturbed sludge was excavated. Preliminary studies of gas release and level measurements over these periods suggest that the fossil gas has a higher concentration of hydrogen than fresh gas.

According to FTIR measurements, the current average nitrous oxide-to-hydrogen ratio of 1.5 is different than that used in the Safety Assessment (LANL 1994), which is 0.85. Figure 7.3 shows the gas concentration ratios computed by integrating the gas release signatures during the 22 hours following pump runs (see Section 2). It was suggested by Allemann (1994) that systematic uncertainties occurred due to interference of a nearby large carbon dioxide peak and that "the mass spectrometer was not operating smoothly due to temperature control problems." Assuming the hydrogen-to-nitrogen and hydrogen-to-ammonia ratios have not changed (there is no evidence for or against this assumption), the current hydrogen fraction of released gas appears to be about $24 \%$ instead of $29 \%$.(a)

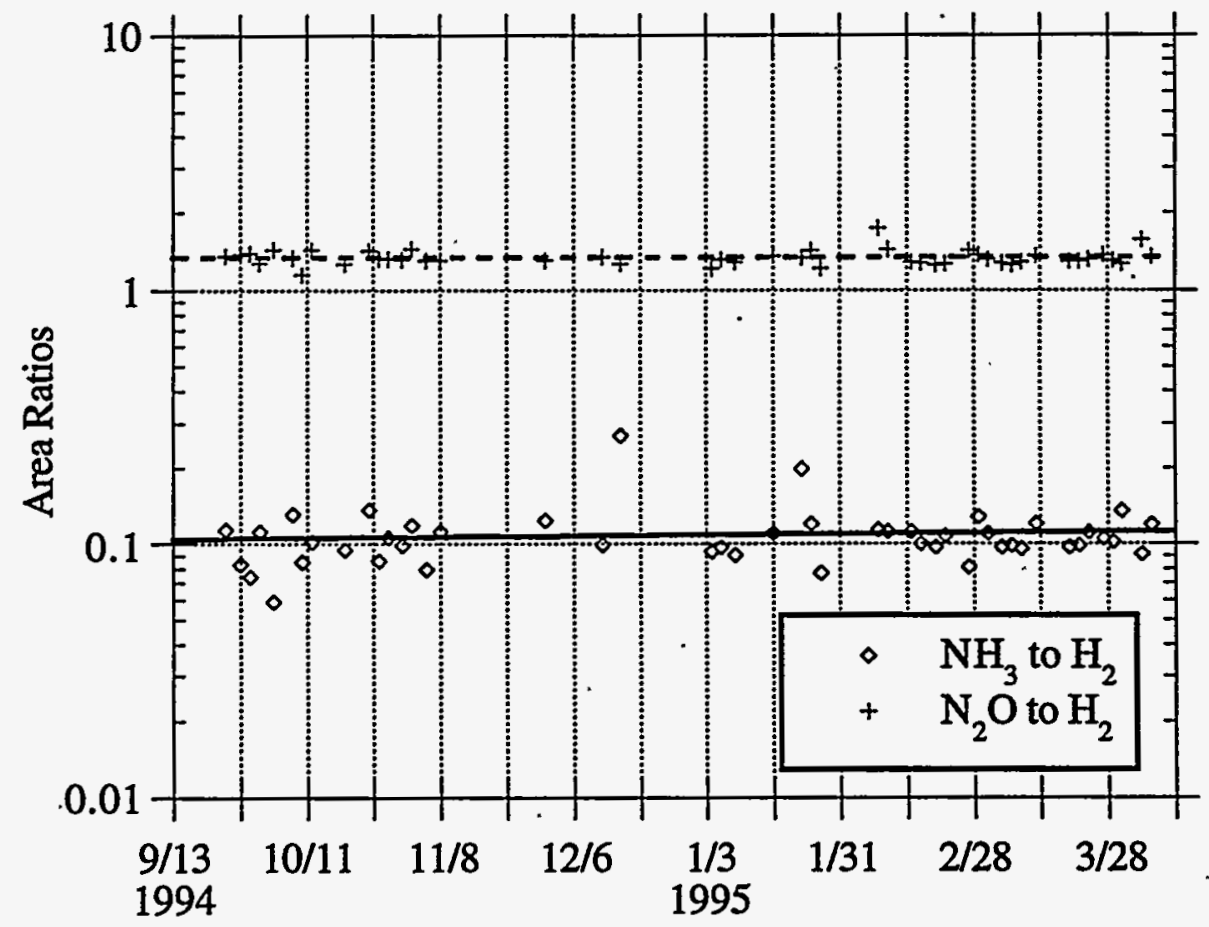

Figure 7.3. Integrated Ratios of Gas:Concentrations in Pump-Induced Gas Releases

(a) Brewster, M. E., E. J. Eschbach, and Z. I. Antoniak. January 1995. Uncertainty Status of Selected Instruments in Tank 241-SY-101. Letter report PNL-MIT:013095, Pacific Northwest Laboratory, Richland, Washington. 
The ammonia fraction is highly variable on a short-term basis because significant amounts of ammonia are released from solution while the other gases are released primarily as bubbles. The consequence is that, following a pump run, the ratio of ammonia to hydrogen in the vent stream gas is lower than during background release. There are also seasonal and barometric pressure variations in the ratio of ammonia to hydrogen, possibly due to variations in the permeability of crust or foam (Allemann 1994). 


\subsection{Unsuccessful Attempts at Correlating Gas Releases}

We describe in this section certain analyses that were attempted but did not provide positive results. The purpose of including these negative results here is two-fold: first, to avoid duplication of failed efforts; second, to document certain attempts that might have been successful if additional information had been available, so that the methods can be more easily revisited without duplicating preliminary work.

The methods that are discussed are state-space models and various empirical modeling approaches including correlations to pump operational properties and Fast Fourier Transform analysis (FFT). The state-space model was unsuccessful primarily because we lacked information about the physical mechanisms of gas retention and release due to pump action. The empirical models were also insufficient to explain the variability in gas release and might benefit from input on physical mechanisms. The FFT analysis showed primarily the period of pump operation and the harmonics of that period. This effect was so large that any other effects could not be discerned.

\subsection{State-Space Models}

Lumped-parameter or state-space models can be used to describe the overall behavior of complex systems when detailed information is not desired or the mechanisms that determine the details are not sufficiently understood. For these methods to be effective, the model must capture the most significant processes that govern the overall or lumped behavior of the system.

We considered a lumped-parameter model to described the generation and release of gas from the tank in response to pumping. The simplest model would contain a single lumped parameter representing the total retained gas in the tank. However, the pump nozzles are oriented in different directions for different pump runs, and the sectors into which the pump jet moves appear to respond differently than the sectors that are not directly affected by the pump jet. It has been observed that repeated pumping with the same nozzle orientation produces diminishing gas releases, while moving the jet to an orientation that has not been pumped for a long time produces larger gas releases. Therefore, to account for the effect of pump orientation, it is necessary to consider several lumped parameters representing the gas retained in prescribed sectors of the tank.

Several attempts were made to construct evolution equations for the lumped parameters representing retained gas in the sectors. Gas was assumed generated at a constant rate in all sectors. In general, the gas release was assumed to be proportional to the retained gas; the gas release depended on functions of the pump operating parameters or integrals of these quantities. While it was possible to reproduce the approximate typical or average profile of gas release, with these models it was not possible to account for the variations observed from this average behavior. The release is observed to vary greatly even when the pump operating procedure remains constant, and the model does not have sufficient flexibility to accommodate this behavior.

The quantity that is ultimately of interest is the total gas retained in the tank, which is the difference between the gas generated and the gas released. We may artificially separate the gas released into that released by pumping and the background release. The division is artificial 
because there is not a sharp cutoff at the end of a pump-induced gas release. There are many factors that may be affecting the profile and amount of gas released in response to pumping, the background gas release and the gas generation rate, including the state of the sludge, the size of the bubbles, atmospheric parameters, and the amount of suspended solids.

The nature of the waste being pumped appears to have a strong effect on the amount of gas released as well as on its composition. Early in the mixer pump operation, fresh sludge was excavated when the frequency, speed, and duration of pumping was increased, and larger releases with lower nitrous oxide content were observed. Currently, the pump has been operating at an essentially constant frequency, speed, and duration, and new sludge is not being excavated. Gas releases are lower and have a higher nitrous oxide content. The depth of the sludge at the thermocouple trees can be inferred from the temperature profiles, and the VFI and viscometer measurements have provided additional information. However, this information is valid only at the location and time of the measurement and does not provide sufficient detail to accurately determine the depth of the sludge in a sector at a given time.

The signature analysis described in Section 2 shows that there has been a significant change in the gas release profile that coincides with this change in operational pattern. The bubble size analysis in Section 3.3 suggests that the size of retained gas bubbles is a dominant factor in determining the gas release profile in response to pumping because of variations in rise time and bubble diameter. There is no direct evidence available on the size of retained gas bubbles in the tank.

Atmospheric parameters-barometric pressure, humidity and temperature-might play a role in gas release due to pumping and might also affect background release. The models described in Section 3.1.2 for bubble dynamics suggest that barometric pressure might have a significant effect on the fraction of bubbles that are positively buoyant and hence rise to the surface, contributing to the background release. It is difficult to separate these effects from the stronger effects described above. Also, information on particle sizes and the configuration of bubble/particle complexes is lacking.

Factors affecting the generation rate are still not well-known. In our modeling efforts we generally assume that the generation rate is a constant that is determined from an average of the gas release over long time periods. However, there is some evidence that increased surface area enhances generation rates. Therefore, there is some question about the effect resuspending the solids by pumping them from the sludge into the liquid has on the generation rate. It is also reasonable to expect that chemical reaction rates involved in the generation mechanism will be affected by the temperature of the waste, which varies seasonally.

For a lumped-parameter model to be successful, it is necessary to determine which of these factors are most significant and to incorporate these effects in a meaningful way into the governing equations for the evolution of the lumped parameters. Our early attempts at formulating a lumpedparameter model were unsuccessful because of a lack of understanding of the significance of the various effects. While we have made significant progress in understanding these effects, as described in the sections above, the picture is still not sufficiently clear to make it worthwhile to revisit the lumped-parameter model at this time. 


\subsection{Correlation Calculations}

In modeling the effect of pump operation on gas release, it is of interest to determine whether the data indicate an effect of past pump operations and/or gas releases on more recent gas releases. Correlation functions for variables of interest can provide clues in looking for these effects. For the period from February 4 to September 30, 1994, the cross-correlation function was calculated between pump rpm and GC3 hydrogen measurements. The auto-correlation functions were also calculated. In addition, an FFT was also calculated for the hydrogen data to examine periodic effects. These calculations provide evidence that prior pump operations and gas releases had little or no effect on current gas releases and that the major correlation and periodicity is primarily due to pump operation procedures.

Figure 8.1 shows the results of the cross-correlation function calculated for time increments up to seven days in approximately five-minute intervals. The greatest correlation between GC3 hydrogen $(\mathrm{C})$ and pump rpm $(\mathrm{P})$ occurs at a time increment of 1.5 hours. This is interpreted as the time required for the concentration to peak after a pump run is initiated. Surprisingly, the correlation between $C$ and $P$ starts to go up before time $=0$. This implies that there is some "anticipation" of a pump run.

Correlation between pump rpm and measured hydrogen concentration is also noted at times of about $2,3,4,5,6$, and 7 days. This is what would be expected if pump operations were performed every other day. That is, you would expect high cross correlation at regular intervals.

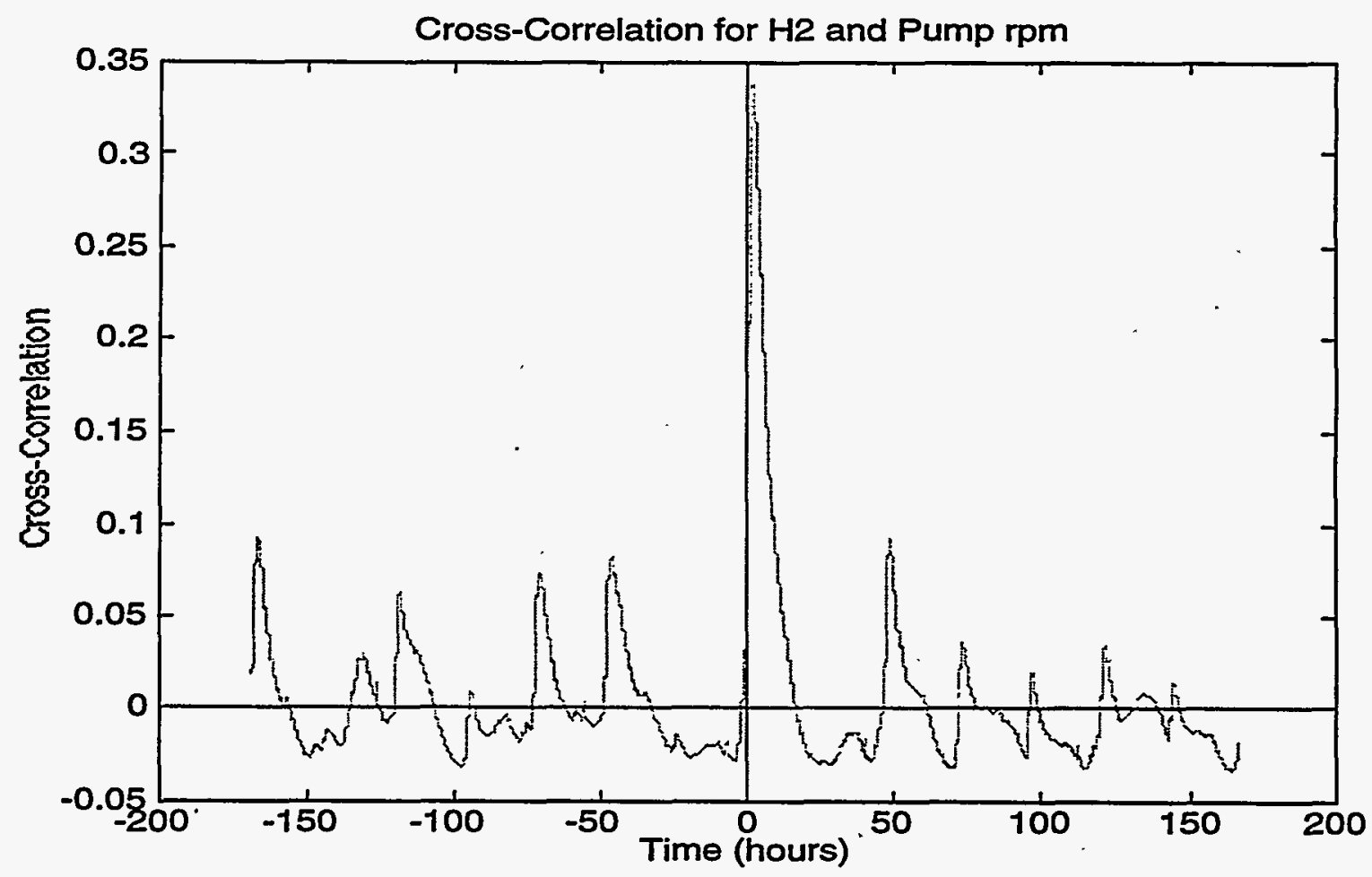

Figure 8.1. Cross-Correlation Function for Pump rpm and Hydrogen Concentration 
In particular, you would expect correlation at two and four days for the weekly pump operation, and three, five, and seven days apart for operations in adjoining weeks. Some correlation is also noted for 3.5 and 5.5 days, probably corresponding to a few pump operations performed in the afternoon rather than morning. Some correlation is also noted at six days and is also likely due to periodic pump operations.

The auto-correlation function is a measure of the 'self' correlation for a variable over a period of time. The relative correlation of variable $\mathrm{P}$ with itself, separated by a measured time increment, can be compared at different time increments. Figure 8.2 shows the auto-correlation function for $\mathrm{P}$ (pump rpm) and shows that there is distinct correlation at $2,3,4,5$, and 7 days. This is indicative of periodic (non-random) pump operation procedures that would be expected if operations occurred regularly on a Monday, Wednesday, and Friday.

The auto-correlation function for hydrogen measurements is given in Figure 8.3. This figure gives information on the effect of prior pump operations on gas release. Again, the periodic correlation attributed to non-random pump operation is apparent. Other possible correlation exists but is masked by the large correlation peaks attributed to pump operation. Note that the correlation peaks for hydrogen shown in Figure 8.3 are broader than the pump rpm correlation peaks shown in Figure 8.2. This is a result of the hydrogen release occurring over about a day compared with the pump operation, which is either about 5 or 24 minutes.

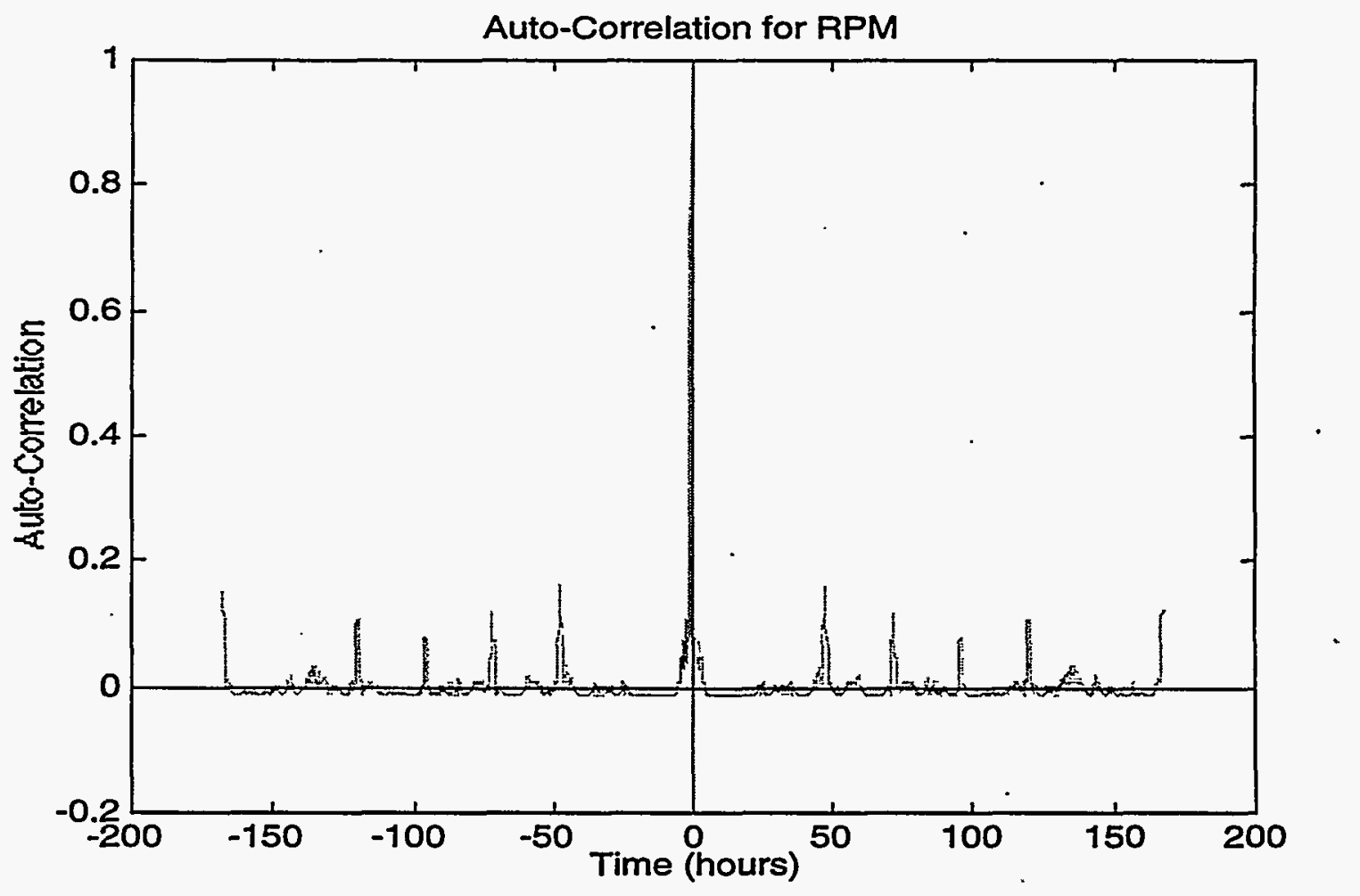

Figure 8.2. Auto-Correlation Function for Pump rpm 


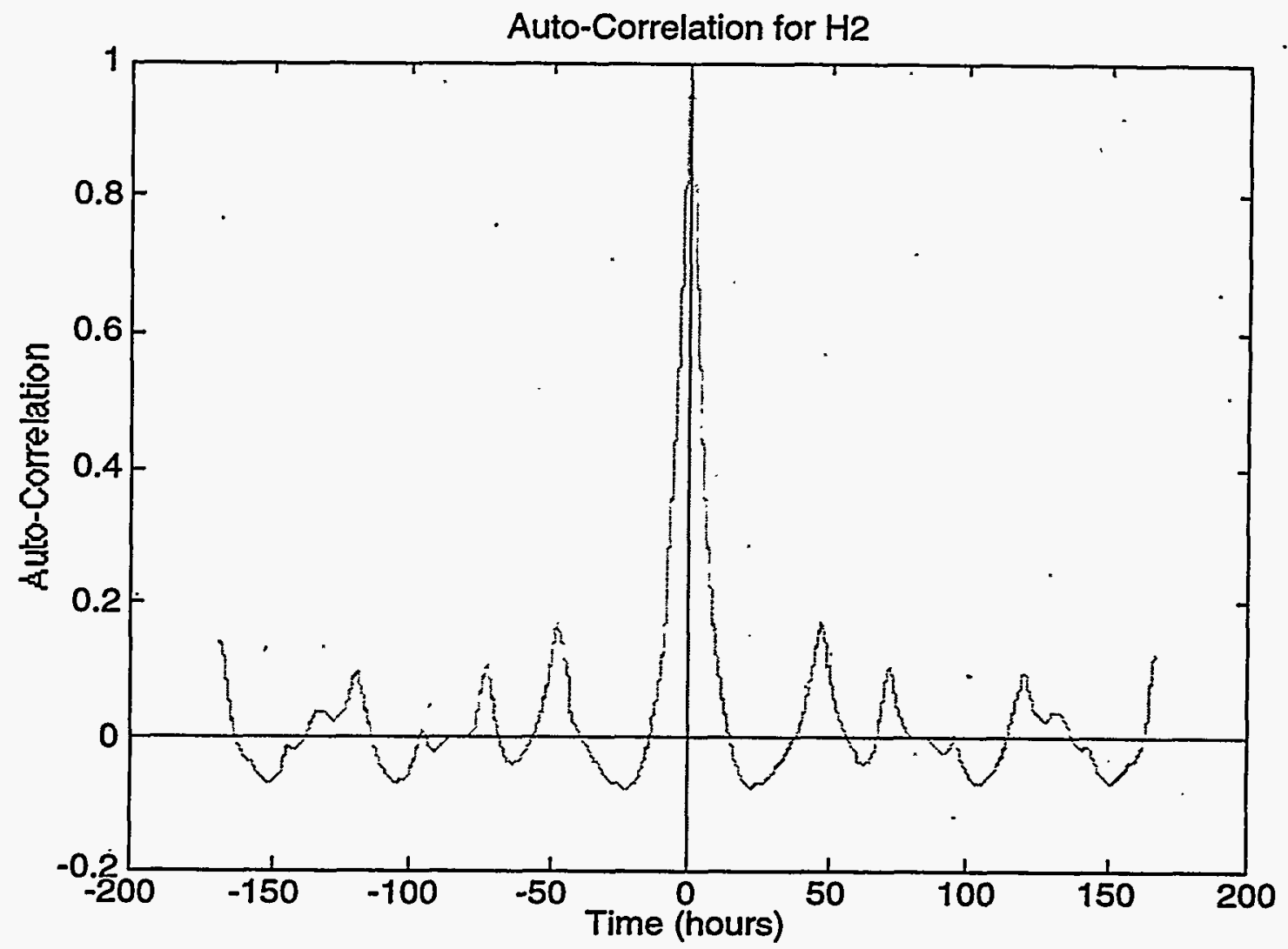

Figure 8.3. Auto-Correlation Function for Hydrogen Concentration

Figure 8.4 shows the results of an FFT calculation for GC3 hydrogen measurements. The calculation was performed over the entire time domain from February 4 to September 30, 1994. Thus this calculation gives a power spectrum for periods of over 100 days down to as small as 0.0035 days (approximately five minutes). Again, the periodic pump operation is apparent. A frequency of $0.5 /$ day is observed to have a relatively high power. This is expected for pump operations that occur every two days at about the same time of day. Several peaks can be interpreted as harmonics of this primary frequency; other peaks are difficult to interpret, primarily because the pump operations occur on a regular (periodic) basis.

Correlation calculations suggest that, under present periodic and non-random pump operation procedures, there is no evidence that previous pump activity and/or prior gas releases have an effect on more recent gas releases. However, non-random pump operation resulting in periodic ' gas release may be masking an underlying phenomenon that cannot be directly observed in the data. Therefore, although other periodic behavior not related to pump activity may exist, it is difficult to detect using this analysis. 


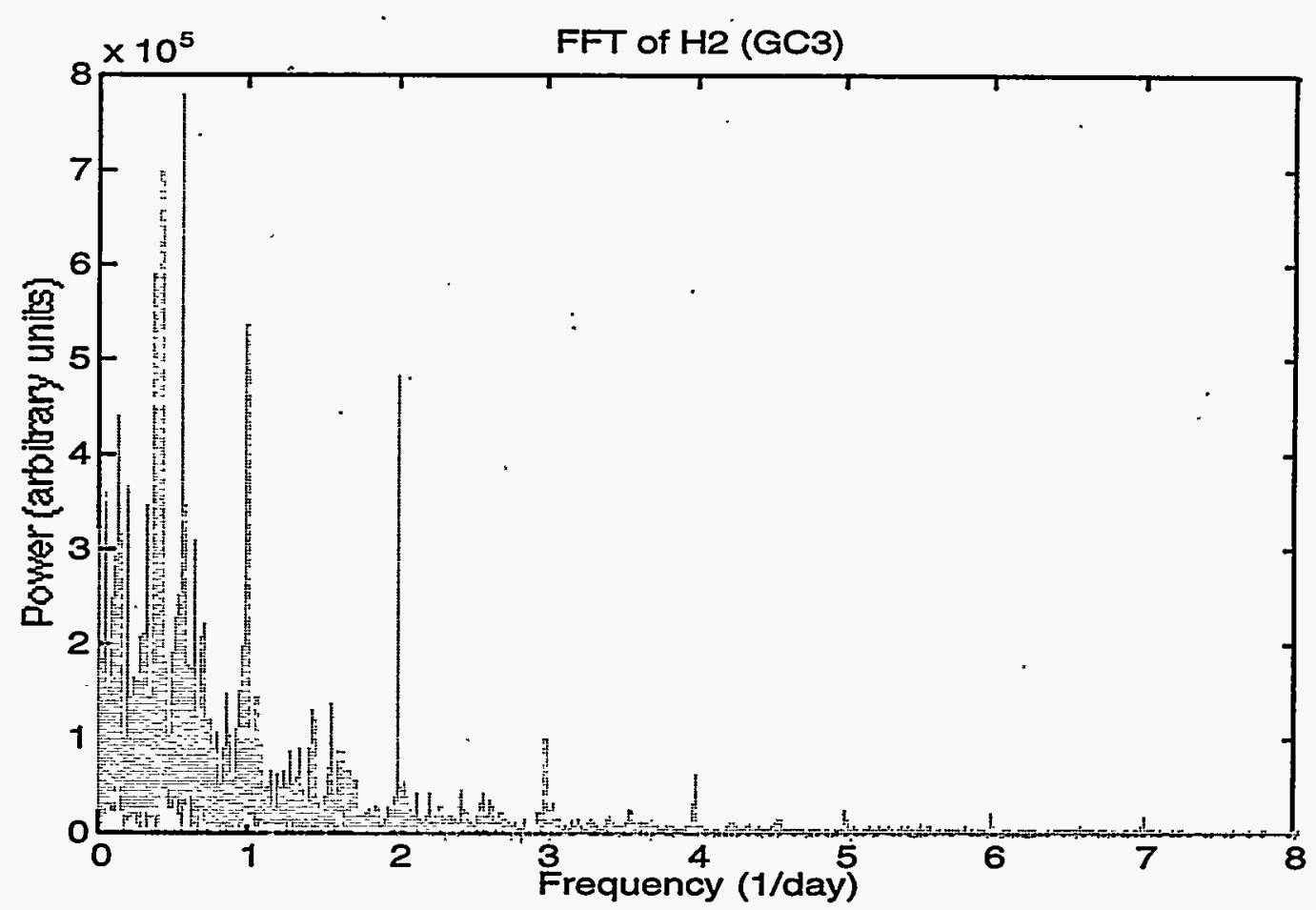

Figure 8.4a. FFT of Hydrogen Concentration: Power Versus Frequency

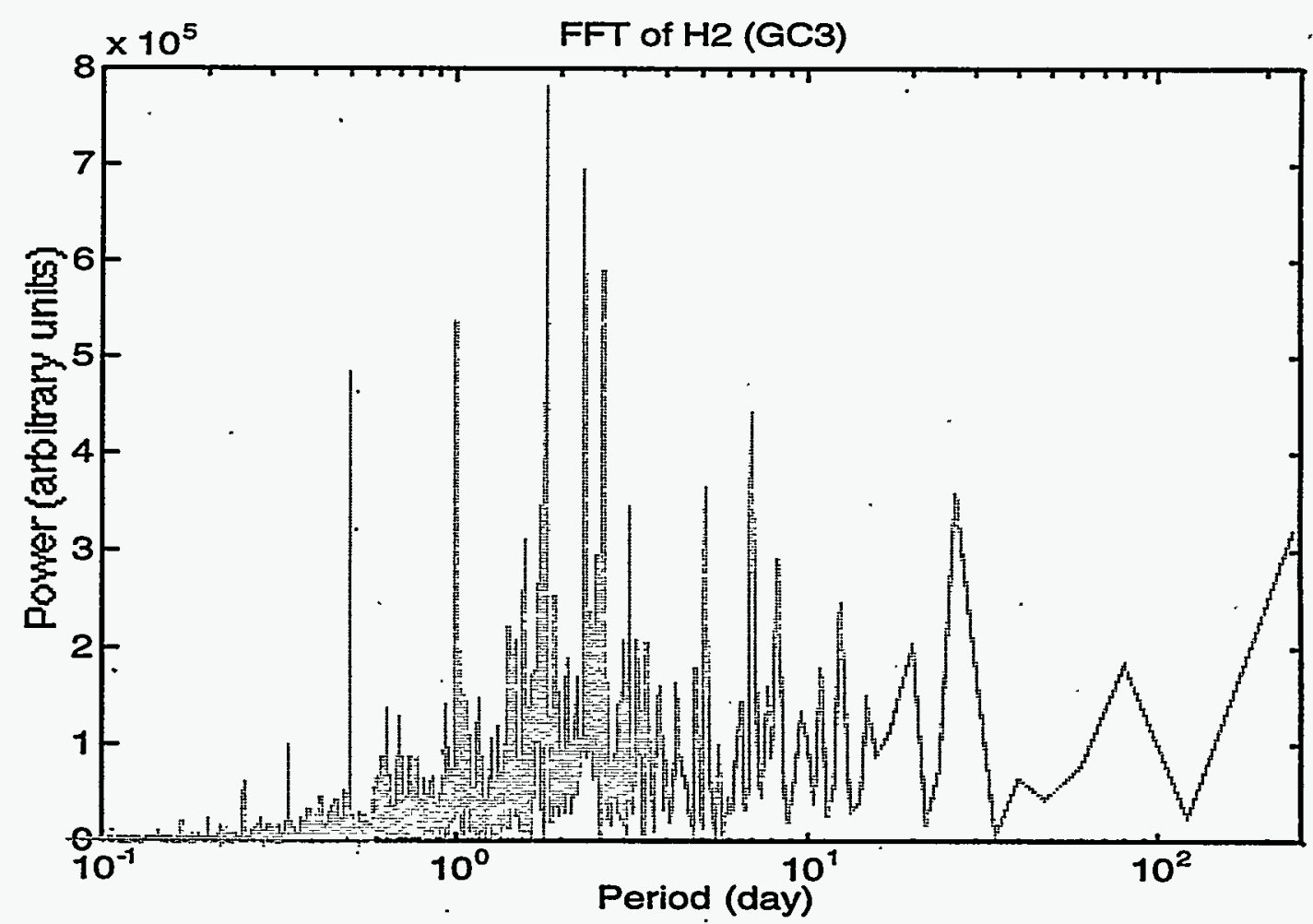

Figure 8.4b. FFT of Hydrogen Concentration: Power Versus Period 


\subsection{Empirical Model of Gas Release}

A model has been developed to describe gas release from Tank 241-SY-101 as a function of mixer pump operation. This model captures gross features in the data but is insufficient for confident prediction. In this model, pump operation parameters are the inputs, and a measure of the total off-gas attributed to pumping is the output. The model was fit over the period from February 5 through May 18, 1994, and contained 53 pump events. The model calibration was obtained with a partial least-squares technique using mean-centered and variance-normalized data. The model was cross-validated using the venetian blinds method. The minimum predicted residual error sum of squares was obtained using three latent variables.

The definition of a pump cycle and a pump event determine the magnitude of the model input parameters. A pump cycle is simply defined as the time from turning the pump on to when it is turned off. A pump event may contain one or more pump cycles and is initiated when the pump is turned on at time $=t_{i}$ (i.e., when the first cycle in a pump event is started). A pump event is defined as completed when the change in off-gas concentrations induced by the entire pump event decays to its baseline level. In general, the time for the concentration to decay to its baseline level is less than one day. The minimum observed decay time was slightly larger than 0.55 days for the modeling period.

For each pump event the model uses four input parameters, S, S*T, A, and dT, which are defined as follows: $S$ is a measure of pump speed; it is a time average pump speed (rpm) determined over each pump cycle within a pump event. $T$ is the pump operation duration; it is the sum of pump cycle times within a pump event. Therefore, $S * T$ is an indication of total pump flow during a pump event. The parameter $A$ is an indication of 1) how much the orientation of the pump has changed in the tank from the previous pump event to the present pump event and 2) how much the orientation changes within a pump event. It is normalized to 30 degrees. For example, if the pump orientation was measured at 35 degrees for pump event $i$, and 95 degrees for pump event $i+1$, A for pump event $i+1$ would be 2 . Now consider if pump event $i+1$ contains two pump cycles where the pump orientation changes from 95 degrees for the first cycle to 125 degrees in the second pump cycle. Parameter A for pump event $i+1$ would be 3 , the sum due to changes from the previous direction of 35 degrees (2), and due to changes within the pump event (1). The fourth input parameter, $\mathrm{dT}$, is the time between pump events in the same orientation. The time between pump events at nearby angles is not included as an input parameter in this model.

Model outputs for a pump event are a measure of the total amount of off-gas attributable to the pump event. For each pump event the model uses four output parameters obtained by calculating the integral of the concentration of four gas species from the start of a pump event (time $=t_{i}$ ) to time $=t_{i}+t_{d}$. For this model, $t_{d}$ was 0.55 days, which was chosen so that gas releases from different pump events did not overlap. The four gas species are hydrogen (ppm) measured by gas chromatograph (GC) 2, hydrogen (ppm) measured by GC3, nitrous oxide (ppm) measured by FTIR, and ammonia (ppm) measured by FTIR.

Figure 8.5 shows results of the model for hydrogen measured by GC3. For clarity only a portion of the modeling period is shown. These results are representative of the entire model period. The solid line in Figure 8.5 is hydrogen(ppm) from GC3, and the open circles are the 


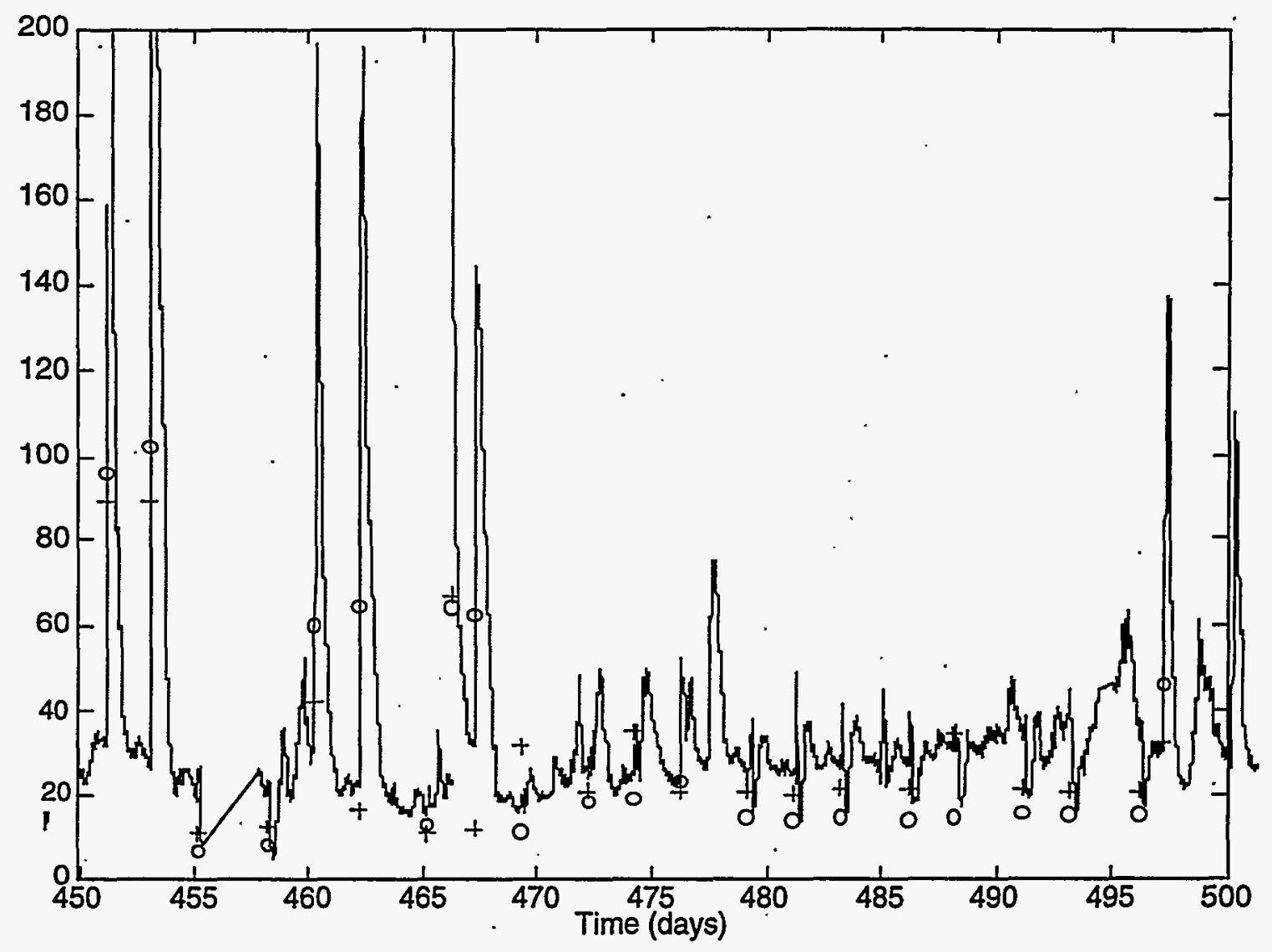

Figure 8.5. Hydrogen Concentration History Compared with Empirical Model

integrals of the solid line from the initiation of a pump event (time $=t_{i}$ ) to time $=t_{i}+0.55$ days. The open circles are plotted at times $=t_{i}$. The model fits (fit to the open circles) are shown as crosses ( + ). The figure shows a total of 22 pump events.

Figure 8.5 shows that the fit captures the gross behavior of the gas releases due to pumping and, for a few pump events, the fit could be considered good. However, the fit is not good over the bulk of the pump events and indicates that the model is insufficient for confident prediction.

\subsection{Correlation of Hydraulic Energy Input to Gas Release}

Gas release from.Tank 241-SY-101 is obviously related to pump activity. But efforts to quantify the relationship have been largely unsuccessful. One factor is the large scatter in gas release volumes, even for identical pump run durations and speeds. Another is that, in the long term, gas cannot be released on average any faster than it is generated, estimated to be $2.9 \mathrm{~m}^{3 / \mathrm{d}}$ (102 SCF/d) (Stewart et al. 1994). Figure 8.6 shows that increasing pump activity (rate of 


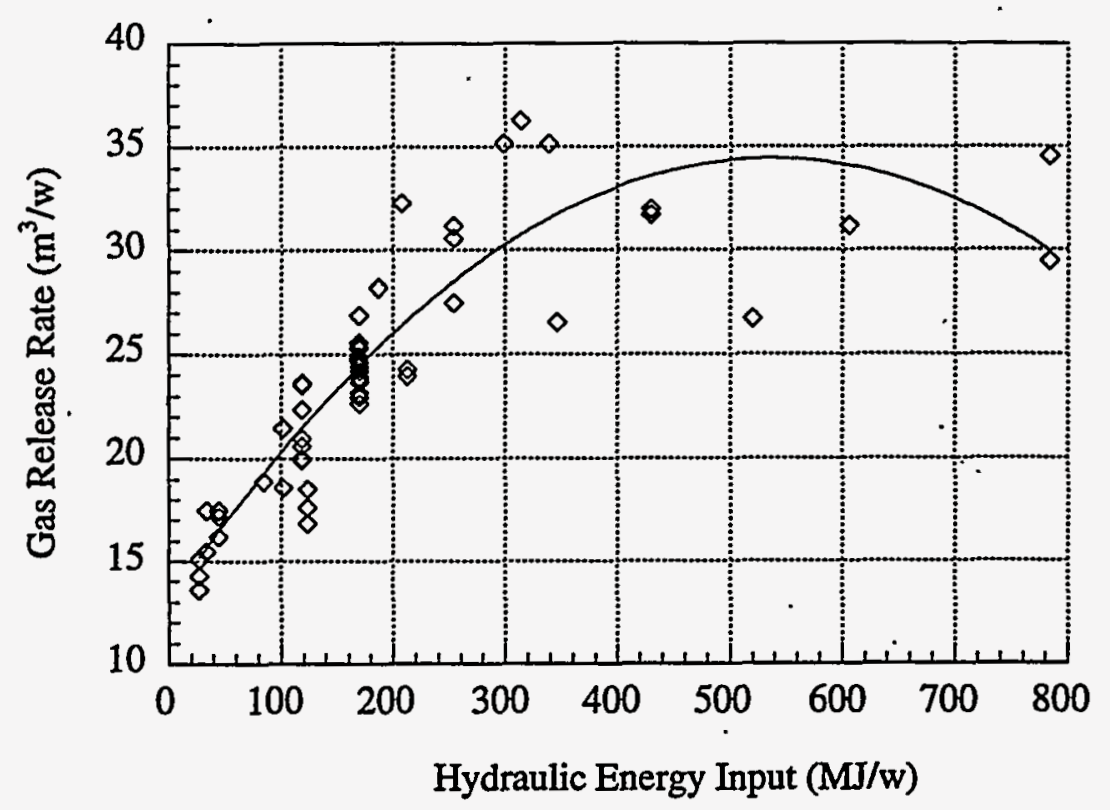

Figure 8.6. Weekly Gas Release Versus Hydraulic Energy Input

hydraulic energy input) beyond $268 \mathrm{MJ} / \mathrm{w}$ [100 horsepower-hours/week (hph/w)] does not lead, on the average, to increased gas release. (The hydraulic energy input was computed assuming a 95\% power factor for the pump instead of the $86 \%$ obtained in tests of the spare mixer pump.)(a)

The dependence of the gas release/pump activity relationship on the state of the tank waste is strongly influenced by the overall level of pump activity. This is illustrated in Figure 8.7, where the rate of hydraulic energy input predicted to produce an average of $2.8 \mathrm{~m} 3 / \mathrm{d}(100 \mathrm{SCF} / \mathrm{d})$ and the actual pump activity during the same period are plotted over time. The predicted energy input is . estimated according to a linear correlation of data taken from a 60-day period.

There are several periods during which the pump activity is much greater than the "predicted-optimal" level, notably during the previous quarter (June 15-September 14, 1994). Predictions based on these periods are not reliable, because a significant change in the actual pump activity will lead to a change in the correlation and hence in the prediction. The most reliable estimates occur when the predicted-optimal and actual levels of pump activity are similar. One such period occurred from April 26 to June 25, 1994, at a level of 88-120 MJ/w (40-50 hph/w). Another appears to occur from September 19,1994, to November 18, 1994, although at a much higher level of pump activity $(268 \mathrm{MJ} / \mathrm{w}[100 \mathrm{hph} / \mathrm{w}])$. The difference between these two quasisteady states may be the quantity of retained gas, which can be inferred roughly from the waste

(a) Antoniak, Z. I., et al. 1995. Quarterly Review of 241-SY-101 Mixer Pump Data. PNL-MIT:952644, Pacific Northwest Laboratory, Richland, Washington. 


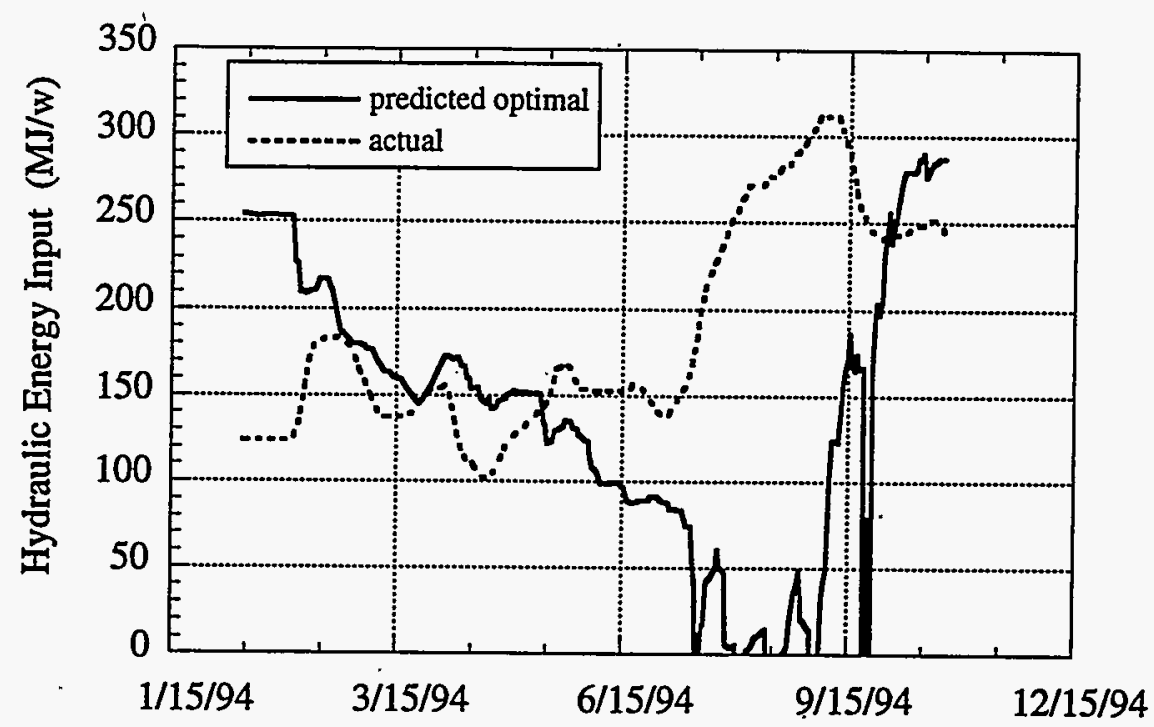

Figure 8.7. Actual and Predicted Energy Input

level. Between April 26 and June 25, 1994, the waste level averaged $1018 \mathrm{~cm}$ (400.7 in.) (FIC) or $1021 \mathrm{~cm}$ (402.2 in.) (radar), while between September 19 and November 18, 1994, the average waste level was $1013 \mathrm{~cm}$ (398.9 in.) (FIC) or $1020 \mathrm{~cm}$ (401.9 in.).(radar). 


\subsection{References}

Allemann, R. T. 1994. Some Theories of Dissolved Gas Release from Tank 241-SY-101. PNL10091, Pacific Northwest Laboratory, Richland, Washington.

Allemann, R. T., Z. I. Antoniak, W. D. Chvala, L. E. Efferding, J. G. Fadeff, J. R. Friley, W. B. Gregory, J. D. Hudson, J. J. Irwin, N. W. Kirch, T. E. Michener, F. E. Panisko, C. W. Stewart, and B. M. Wise. 1994. Mitigation of Tank 241-SY-101 by Pump Mixing: Results of Testing Phases $A$ and B. PNL-9423, Pacific Northwest Laboratory, Richland, Washington.

Antoniak, Z. I. 1993. Historical Trends in Tank 241-SY-101 Waste Temperatures and Levels. PNL-8880, Pacific Northwest Laboratory, Richland, Washington.

Babad, H., G. D. Johnson, and D. A. Reynolds. 1992. Understanding of Cyclic Venting Phenomena in Hanford Site High-Level Waste Tanks: The Evaluation of Tank 241-SY-101. WHC-SA-1364-FP, Westinghouse Hanford Company, Richland, Washington.

Bryan, S. A., and L. R. Pederson. 1994. Composition, Preparation, and Gas Generation Results from Simulated Wastes of Tank 241-SY-101. PNL-10075, Pacific Northwest Laboratory, Richland, Washington.

Bussell, J. H. 1992. Condition Report on Selected Thermocouples in Tank 241-SY-101. WHC-SD-ER-152 Rev. 0, Westinghouse Hanford Company, Richland, Washington.

Gallagher, N. B., B. M. Wise, and C. W. Stewart. 1995. "Application of Multi-Way Principal Components Analysis to Nuclear Waste Storage Tank Monitoring." Submitted for publication in Computers and Chemical Engineering.

Herting, D. L., D. B. Bechtold, B. A. Crawford, T. L. Welsh, and L. Jensen. 1992. Laboratory Characterization of Samples Taken in May 1991 from Hanford Waste Tank 241-SY-101. WHC-SD-WM-DTR-024, Westinghouse Hanford Company, Richland, Washington.

Jackson, J. E., 1991. A User's Guide to Principal Components. John Wiley \& Sons, New York.

Jackson, J. E., and G. S. Mudholkar. 1979. "Control Procedures for Residuals Associated with Principal Component Analysis.” Technometrics, 21(3):341-349.

Kreith, F., and M. S. Bohn. 1986. Principles Of Heat Transfer, 4th ed. Harper \& Row, Cambridge, Massachusetts, p. 109.

LANL. 1994. A Safety Assessment Of Proposed Pump Mixing Operations To Mitigate Episodic Gas Releases In Tank 241-SY-101: Hanford Site, Richland, Washington. LA-UR-92-3196 Rev. 13, Los Alamos National Laboratory, Los Alamos, New Mexico.

Nomikos, P., and J. F. MacGregor. 1994. "Monitoring Batch Processes Using Multiway Principal Component Analysis." AIChE Journal, 40(8):1361-1375.

Nomikos, P., and J. F. MacGregor. 1995. "Multivariate SPC Charts for Monitoring Batch Processes." Technometrics, 37(1):41-59. 
Norton, J. D., and L. R. Pederson. 1994. Ammonia in Simulated Hanford Double-Shell Tank Wastes: Solubility and Effects on Surface Tension. PNL-10173, Pacific Northwest Laboratory, Richland, Washington.

Peters, T. J., and W. R. Park. 1992. Performance Evaluation of the Enraf-Nonius Model 872 Radar Gauge. PNL-8464, Pacific Northwest Laboratory, Richland, Washington.

Stewart, C. W., C. T. Crowe, and S. C. Saunders. 1993. "A Model for Simultaneous Coalescence of Bubble Clusters." Chemical Engineering Science, 48(19):3347-3354.

Stewart, C. W., J. D. Hudson, J. R. Friley, F. E. Panisko, Z. I. Antoniak, J. J. Irwin, F. G. Fadeff, L. E. Efferding, T. E. Michener, N. W. Kirch, and D. A. Reynolds. 1994. Mitigation of Tank 241-SY-101 by Pump Mixing: Results of Full-Scale Testing. PNL-9959, Pacific Northwest Laboratory, Richland, Washington.

Stewart, C. W., C. L. Shepard, J. M. Alzheimer, T. I. Stokes, and G. Terrones. 1995. In Situ Determination of Rheological Properties and Void Fraction in Hanford Waste Tank 241-SY-101. PNL-10682, Pacific Northwest Laboratory, Richland, Washington.

Sullivan, H. A. 1995. A Safety Assessment of Proposed Pump Mixing Operations to Mitigate Episodic Gas Releases in Tank 241-SY-101: Hanford Site, Richland, Washington.

LA-UR-92-3196 Rev. 14, Los Alamos National Laboratory, Los Alamos, New Mexico.

Whitham, G. B. 1974. Linear and Nonlinear Waves. John Wiley and Sons, New York.

Wold, S., P. Geladi, K. Esbensen, and J. Ohman. 1987. "Multi-Way Principal Components and PLS-Analysis." J. Chemometrics , 1:41-56.

Wold, S. 1987. "Principal Component Analysis." Chemometrics and Intelligent Lab. Sys., 2:37-52. 


\section{Distribution}

No. of

Copies

Offsite

12 DOE Office of Scientific and

Technical Information

C. S. Abrams

1987 Virginia

Idaho Falls, ID 83404

E. C. Ashby

225 North Avenue

Boggs Chemistry Building

Georgia Institute of Technology

Atlanta, GA 30332

K. Bandyopadhyay

Building 129

Brookhaven National Laboratory

Upton, NY 11973

N. W. Bibler

Westinghouse Savannah River Co.

Building 773A, Room B132

Box 616

Aiken, SC 29802

D. Campbell

102 Windham Road

Oak Ridge, TN 37830

F. N. Carlson

6965 North, 5th West

Idaho Falls, ID 83401

E. D. Collins

Oak Ridge National Laboratory

P.O. Box 2008

7930, MS-6385

Oak Ridge, TN 37831-6385
No. of

Copies

Morton Corn

School of Hygiene and Public Health

John Hopkins University,

615 N. Wolf Street, Room 6010

Baltimore, MD 21205

M. First

Harvard School of Public Health

665. Huntington Avenue

Boston, MA 02115

Charles W. Forsberg

Oak Ridge National Laboratory

P.O. Box 2008, MS-6495

Oak Ridge, TN 37831-6495

E. P. Horwitz

Chemistry Department

Argonne National Laboratory

9700 Cass Avenue

Argonne, II 60439-4831

Billy C. Hudson

202 Northridge $C t$.

Lindsborg, KS 67456

M. S. Kazimi

Massachusetts Institute of Technology

Department of Nuclear Engineering

77 Massachusetts Avenue

Cambridge, MA 02139

J. L. Kovach

Nuclear Consulting Services, Inc.

P.O. Box 29151

Columbus, OH 43229-0151

B. R. Kowalski

Chemistry Department, BG-10

University of Washington

Seattle, WA 98195

Dist. 1 
No of

Copies

Thomas S. Kress

102-B Newridge Road

Oak Ridge, TN 37830

4 Los Alamos National Laboratory

P.O. Box 1663

Los Alamos, NM 87545

Attn: J. R. White, K555

W. L. Kubic, K557

K. Pasamehmetoglu, K555

T. E. Larson, MS-P915, DX-DO

D. Meisel

Chemistry Department

Argonne National Laboratory

9700 Cass Avenue

Argonne, II 60439-4831

D. T. Oakley

Waste Policy Institute

Suite 600

555 Quince Orchard Road

Gaithersburg, MD 20878

Don Orth

124 Vivion Drive

Aiken, South Carolina 29803

F. L: Parker

Vanderbilt University

P.O. Box 1596, Station B

Nashville, TN 37235

D. Pepson

U.S. Department of Energy

Trevion II Building, EM-35

Washington, D.C. 20585-0002

G. E. Schmauch

Air Products and Chemicals, Inc.

7201 Hamilton Boulevard

Allentown, PA 18195-1501
No of

Copies

Scott E. Slezak

Sandia National Laboratory

Org. 6471/MS 0741

P.O. Box 5800

Albuquerque, NM 87185-0744

Dana Powers

Sandia National Laboratory

Dept. 6404/MS-0744

P.O. Box 5800

Albuquerque, NM 87815-0744

W. J.'Thomson

Dept. of Chemical Engineering

Washington State University

Pullman, WA 99164

J. Tseng

U.S. Department of Energy

Trevion II Building, EM-35

Washington, D.C. 20585-0002

A. S. Veletsos

5211 Paisley

Houston, TX 77096

\section{Onsite}

9 DOE Richland Operations Office

M. F. Campbell

S7-73

R. E. Gerton

S7-54

J. M. Gray (3)

S7-54

C.A. Groendyke

S7-54

D. H. Irby

S7-54

M. F. Jarvis

S7-54

G. W. Rosenwald

Dist. 2 
No of

Copies

29 Westinghouse Hanford Company

H. Babad

W. B. Barton

T. R. Benegas

D. L. Herting

J. D. Hopkins

G. D. Johnson (5)

N. W. Kirch

J. R. Kristofzki

D. C. Larsen

J. A. Lechelt

J. W. Lentsch (5)

R. M. Marusich

N. G. McDuffie

J. E. Meacham

R. E. Mendoza

D. A. Reynolds

C. A. Rieck

C. P. Shaw

J. E. Van Beek

R. J. Van Vleet

N. E. Wilkins
S7-30

R2-11

N1-27

T6-09

R2-11

S7-15

R2-11

T6-06

R1-51'

R2-11

S7-15

H4-65

S7-15

S7-15

R1-51

R2-11

R3-27

L5-07

R3-27

H4-63

R2-11
No of

Copies

33 Pacific Northwest Laboratory

J. M. Alzheimer

K5-22

Z. I. Antoniak K7-15

J. M. Bates

K7-15

S. Q. Bennett

P. R. Bredt

M. E. Brewster (5)

K7-90

P7-25

K7-15

J. W. Brothers

P. A. Gauglitz

W. B. Gregory

J. D. Hudson

T. E. Michener

F. E. Panisko

K. P. Recknagle

H. C. Reid

A. Shekarriz

C. L. Shepard

N. J. Stajduhar

C. W. Stewart (5)

G. Terrones

J. M. Tingey

Information Release (5)
K5-22

P7-41

K7-22

K7-15

K7-15

P8-34

K7-15

K7-15

K7-15

K5-25

K9-89

K7-15

K7-15

P7-25

Dist. 3 
